\title{
Pacific Northwest Laboratory Annual Report for 1989 to the DOE Office of Energy Research
}

Part 1: Biomedical Sciences

May 1990

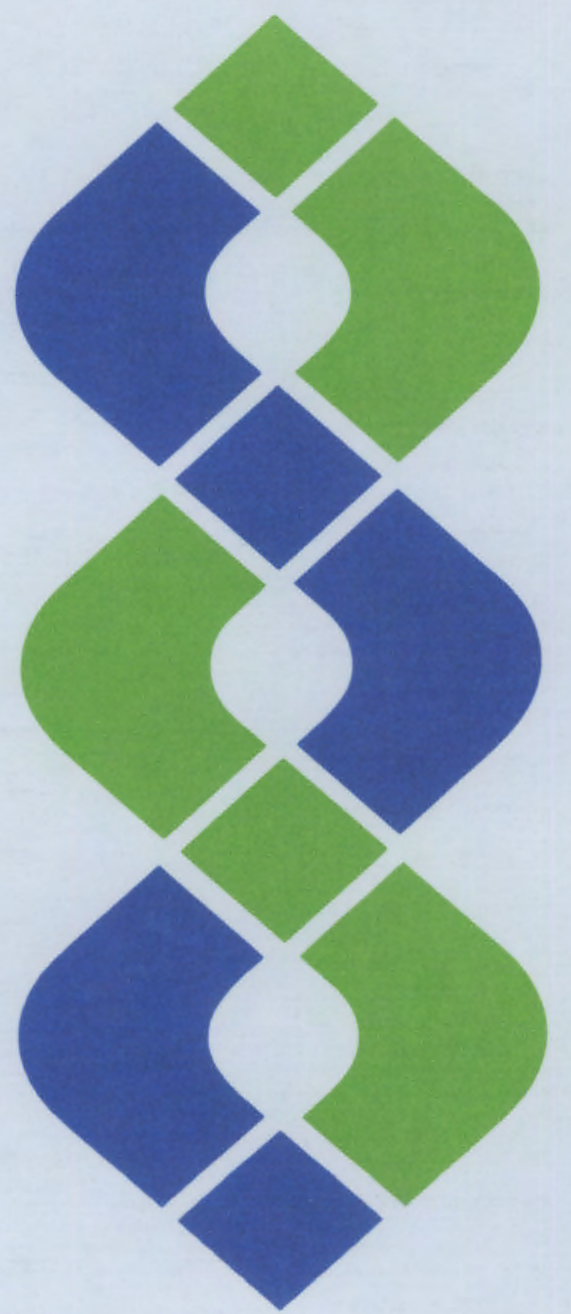

Prepared for the U.S. Department of Energy under Contract DE-AC06-76RLO 1830

Pacific Northwest Laboratory Operated for the U.S. Department of Energy by Battelle Memorial Institute

\section{*. Battelle}




\section{DISCLAIMER}

This report was prepared as an account of work sponsored by an agency of the United States Government. Neither the United States Government nor any agency thereof, nor Battelle Memorial Institute, nor any of their employees, makes any warranty, expressed or implied, or assumes any legal liability or responsibility for the accuracy, completeness, or usefulness of any information, apparatus, product, or process disclosed, or represents that its use would not infringe privately owned rights. Reference herein to any specific commercial product, process, or service by trade name, trademark, manufacturer, or otherwise, does not necessarily constitute or imply its endorsement, recommendation, or favoring by the United States Government of any agency thereof, or Battelle Memorial Institute. The views and opinions of authors expressed herein do not necessarily state or reflect those of the United States Government or any agency thereof.

\section{PACIFIC NORTHWEST LABORATORY operated by \\ BATTELLE MEMORIAL INSTITUTE for the \\ UNITED STATES DEPARTMENT OF ENERGY under Contract DE-AC06-76RLO 1830}

Printed in the United States of America

Available to DOE and DOE contractors from the

Office of Scientific and Technical Information, P.O. Box 62, Oak Ridge, TN 37831; prices available from (615) 576-8401. FTS 626-8401.

Available to the public from the National Technical Information Service, U.S. Department of Commerce, 5285 Port Royal Rd., Springfield, VA 22161.

NTIS Price Codes, Microfiche A01

Printed Copy

\begin{tabular}{cr}
\hline Price Code & Page Range \\
\hline A02 & $1-10$ \\
A03 & $11-50$ \\
A04 & $51-75$ \\
A05 & $76-100$ \\
A06 & $101-125$ \\
A07 & $126-150$ \\
A08 & $151-175$ \\
A09 & $176-200$ \\
A10 & $201-225$ \\
A11 & $226-250$ \\
A12 & $251-275$ \\
A13 & $276-300$ \\
A14 & $301-325$
\end{tabular}

\begin{tabular}{cc}
\hline Price Code & Page Range \\
\hline A15 & $326-350$ \\
A16 & $351-375$ \\
A17 & $376-400$ \\
A18 & $401-425$ \\
A19 & $426-450$ \\
A20 & $451-475$ \\
A21 & $476-500$ \\
A22 & $501-525$ \\
A23 & $526-550$ \\
A24 & $551-575$ \\
A25 & $576-600$ \\
A99 & $601-U p$
\end{tabular}




\title{
Pacific Northwest Laboratory Annual Report for 1989 to the DOE Office of Energy Research
}

\author{
Part 1: Biomedical Sciences \\ J. F. Park and Staff
}

May 1990

Prepared for

the U.S. Department of Energy

under Contract DE-AC06-76RLO 1830

Pacific Northwest Laboratory

Pichland, Washington 99352 


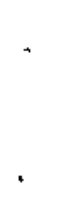




\section{Preface}

This 1989 Annual Report from Pacific Northwest Laboratory (PNL) to the U.S. Department of Energy (DOE) describes research in environment, safety, and health conducted during fiscal year 1989 . The report again consists of five parts, each in a separate volume.

The five parts of the report are oriented to particular segments of the PNL program. Parts 1 to 4 report on research performed for the DOE Office of Health and Environmental Research in the Office of Energy Research. Part 5 reports progress on all research performed for the Assistant Secretary for Environment, Safety, and Health. In some instances, the volumes report on research funded by other DOE components or by other governmental entities under interagency agreements. Each part consists of project reports authored by scientists from several PNL research departments, reflecting the multidisciplinary nature of the research effort.

The parts of the 1989 Annual Report are:

Part 1: Biomedical Sciences

Program Manager: J. F. Park J. F. Park, Report Coordinator

S. A. Kreml, Editor

Part 2: Environmental Sciences

Program Manager: R. E. Wildung $\quad$ M. G. Hefty, Report Coordinator and Editor

Part 3: Atmospheric Sciences

Program Manager: C. E. Elderkin $\quad$ C. E. Elderkin, Report Coordinator

E. L. Owczarski, Editor

Part 4: Physical Sciences

Program Manager: $\quad$ L. H. Toburen $\quad$ L. H. Toburen, Report Coordinator

K. A. Parnell, Editor

Part 5: Environment, Safety, Health, and Quality Assurance

Program Managers: L. G. Faust

P. G. Doctor

S. K. Ennor, Report Coordinator and Editor

J. M. Selby

Activities of the scientists whose work is described in this annual report are broader in scope than the articles indicate. PNL staff have responded to numerous requests from DOE during the year for planning, for service on various task groups, and for special assistance.

Credit for this annual report goes to the many scientists who performed the research and wrote the individual project reports, to the program managers who directed the research and coordinated the technical progress reports, to the editors who edited the individual project reports and assembled the five parts, and to Ray Baalman, editor in chief, who directed the total effort.

W. J. Bair and T. S. Tenforde

Environment, Health, and Safety

Research Program 
Previous reports in this series:

Annual Report for:

\begin{tabular}{|c|c|}
\hline 1951 & HW-25021, HW-25709 \\
\hline 1952 & HW-27814, HW-28636 \\
\hline 1953 & HW-30437, HW-30464 \\
\hline 1954 & HW-30306, HW-33128, HW-35905, HW-35917 \\
\hline 1955 & HW-39558, HW-41315, HW-41500 \\
\hline 1956 & HW-47500 \\
\hline 1957 & HW-53500 \\
\hline 1958 & HW-59500 \\
\hline 1959 & HW-63824, HW-65500 \\
\hline 1960 & HW-69500, HW-70050 \\
\hline 1961 & HW-72500, HW-73337 \\
\hline 1962 & HW-76000, HW-77609 \\
\hline 1963 & HW-80500, HW-81746 \\
\hline 1964 & BNWL-122 \\
\hline 1965 & BNWL-280, BNWL 235, Vol. 1-4; BNWL-361 \\
\hline 1966 & BNWL-480, Vol. 1; BNWL-481, Vol. 2, Pt. 1-4 \\
\hline 1967 & BNWL-714, Vol. 1; BNWL-715, Vol. 2, Pt. 1-4 \\
\hline 1968 & BNWL-1050, Vol. 1;, Pt. 1-2; BNWL-1051, Vol. 2, Pt. 1.3 \\
\hline 1969 & BNWL-1306, Vol. 1; Pt. 1-2; BNWL-1307, Vol. 2, Pt. 1-3 \\
\hline 1970 & BNWL-1550, Vol, 1;, Pt. 1-2; BNWL-1551, Vol. 2, Pt. 1-2 \\
\hline 1971 & BNWL-1650, Vol. 1;, Pt. 1-2; BNWL-1651, Vol. 2, Pt. 1-2 \\
\hline 1972 & BNWL-1750, Vol. 1;, Pt. 1-2; BNWL-1751, Vol. 2, Pt. 1-2 \\
\hline 1973 & BNWL-1850, Pt. $1-4$ \\
\hline 1974 & BNWL-1950, Pt. $1-4$ \\
\hline 1975 & BNWL-2000, Pt. 1-4 \\
\hline 1976 & BNWL-2100, Pt. 1-5 \\
\hline 1977 & PNL-2500, Pt. 1-5 \\
\hline 1978 & PNL-2850, Pt. 1-5 \\
\hline 1979 & PNL-3300, Pt. 1-5 \\
\hline 1980 & PNL-3700, Pt. $1-5$ \\
\hline 1981 & PNL-4100, Pt. 1-5 \\
\hline 1982 & PNL-4600, Pt. 1-5 \\
\hline 1983 & PNL-5000, Pt. 1-5 \\
\hline 1984 & PNL-5500, Pt. $1-5$ \\
\hline 1985 & PNL-5750, Pt. $1-5$ \\
\hline 1986 & PNL-6100, Pt. $1-5$ \\
\hline 1987 & PNL-6500, Pt. $1-5$ \\
\hline 1988 & PNL-6800, Pt. 1-5 \\
\hline
\end{tabular}




\section{Foreword}

This report summarizes progress on OHER human health, biological, general life sciences, and medical applications research programs conducted at PNL in FY 1989. The research develops the knowledge and scientific principles necessary to identity, understand, and anticipate the long-term health consequences of energy-related radiation and chemicals. Our continuing emphasis is to decrease the uncertainty of health risk estimates from existing and developing energy-related technologies through an increased understanding of how radiation and chemicals cause biological damage.

The sequence of this report of PNL research reflects the OHER programmatic structure. The first section, on human health research, concerns statistical and epidemiological studies for assessing health risks. The next section contains reports of biological research in laboratory animals and in vitro cell systems, including research with radionuclides and chemicals. The general life sciences research section reports research conducted for the OHER human genome research program, and the medical applications section summarizes commercial radioisotope production and distribution activities at DOE facilities.

\section{Human Health Research}

The section on human health research reports the status of epidemiological studies, including occupational studies of radiation workers and a study of body iron stores as biological markers related to cancer in Japanese atomic bornb survivors.

Cancer risk analyses of combined data from mortality studies of workers at the Hanford Site, Oak Ridge National Laboratory, and Rocky Flats Nuclear Weapons Plant were published in Radiation Research. These analyses focused on the effects of occupational exposure to external radiation, and were the first of several planned efforts to combine data on workers at DOE facilities and to pool analyses of data from nuclear workers in the United States, the United Kingdom, and Canada. All confidence limits from individual sites and combined data included zero and were much wider than those based on atornic bomb survivors, but upper limits based on the combined data were comparable to those based on atomic bomb survivors. These results strengthen the hypothesis that estimates obtained through extrapolation from high-dose data do not seriously underestimate risk estimates for low-dose exposure, but leave open the possibility that extrapolation may overestimate the risks.

A comparison of five epidemiological studies of body iron stores and cancer risk was completed. In studies of overall cancer risk, high body iron stores were associated with increased risk. When stomach cancer cases were examined individually, low body iron stores were associated with increased risk of stomach cancer. Studies suggest that high body iron may play an etiological role in most types of cancer; however, precursors of stomach cancer may lead to poor iron absorption and loss of iron from bieeding. Studies are continuing on the possible interaction of iron stores and radiation.

\section{Biological Research}

The section on biological research reports results from experimental animal inhalation dose-effect relationship studies with inhaled radionuclides. Lifespan studies in beagles that inhaled ${ }^{239} \mathrm{PuO}_{2}$, ${ }^{238} \mathrm{PuO}_{2}$, or ${ }^{239} \mathrm{PuO}\left(\mathrm{NO}_{3}\right)_{4}$ are summarized to 16,15 , and 12 years after exposure, respectively. The primary plutonium-exposure-related causes of death were lung cancer for inhaled ${ }^{239} \mathrm{PuO}_{2}$, and lung and bone cancer for inhaled ${ }^{238} \mathrm{PuO}_{2}$ and ${ }^{239} \mathrm{PuO}\left(\mathrm{NO}_{3}\right)_{4}$. Other plutonium-exposure-related effects include sclerosis of the tracheobronchial lymph nodes, lymphopenia, focal radiation pneumonitis, focal dystrophic osteolytic lesions in bone, adenomatous hyperplasia of the liver, serum chemistry indicative of liver damage, and intrahepatic bile duct tumors. In a new project, "National Radiobiology Archives," information from these lifespan studies in beagles and from beagle radiation studies from other DOE laboratories will 
be stored in a computerized database with selected research dosuments and tissues for future research and analyses.

Dose-effect relationship studies on inhaled ${ }^{239} \mathrm{PuO}_{2}$ in rats are in progress to obtain lung-tumor-incidence data at lifetime lung doses of 0.07 to $20 \mathrm{~Gy}$. Thus far, the lung cancer dose-response curve is best fitted by a quadratic function and a "practical" threshold of $>1$ Gy; maximum lung cancer incidence was at 8 Gy. Quantitative scanning electron microscopy and autoradiography indicate lung carcinoma formation was preceded by proliferative dysplastic lesions associated with peribronchiolar plutonium aggregates. A much higher cell turnover rate was seen in puimonary celis associated with large plutonium aggregates than in other areas of the lung. Proliferative rates of hyperplastic, metaplastic, and neoplastic lesions, often associated with regions of $\mathrm{Pu}$ aggregation, were similar to those seen in cells encompassing $\mathrm{Pu}$ aggregates.

Rats exposed by inhalation to radon daughters are under study to determine the influence of dose, dose rate, and cigarette smoke on lung cancer incidence. Analyses of histopathological data for 100-WL (working-level) exposure rates showed that lung tumor incidence was elevated compared to that of controls at cumulative exposures comparable to those found in houses, that is, 40 WLM (working-level months). Histopathological examination of sacrificed rats at 25 and 52 weeks from start of exposure to 100 WL and 320 WLM on an initiation-promotion-initiation study showed no lung tumors at 25 weeks. At 52 weeks, those with a 320 WLM continuous exposure had increased lung tumor incidence compared to those with split exposure with or without cigarette smoke. A search for nonrespiratory tract neoplasms in 1000 rats exposed to various levels of radon daughters and uanium ore dust revealed a trend toward excess kidney tumor neoplasms versus cumulative radon-daughter exposure. Carcinogenesis modeling of PNL radon-induced lung tumor data in rats within the framework of the two-mutation recessive oncogenesis model revealed that fractionation of exposure increased the lifetime probability of tumors; the first but not the second mutation rate was strongly deperident on the rate of exposure to radon daughters.

A DOE interlaboratory comparison of survival-response data on Chinese hamster ovary cells exposed to radon and radon daughters revealed $a D_{37}$ value of about a 75-cGy dose to the cell nucleus. Southern blot analysis of radon-induced mutations at the CHO-HGPAT Joius showed predominantly deletion-type events. Chromosome aberrations in human peripheral blood lymphocytes increased as metaphases were collected at later time intervals after radon-daughter exposures of 6 to $17 \mathrm{cGy}$. Methods for calculating the radiation dose to cell nuclei from radon and daughter products have been developed for our in vitro cell exposures. These methods allow comparison of dose distribution and hit probability calculations for cells of the human respiratory tract with cells grown and irradiated under laboratory conditions.

Studies to examine the role of oncogenes, growth factors, and their receptors in radiation-induced lung cancer use tumor tissue from the animal studies previously described. Using immunocytochemical assays in formalin-fixed, paraffin-embedded lung tissue, we have demonstrated abnormally high expression of epidermal growth factor receptor, epidermal growth factor, transforming growth factor- $\alpha$, and bombesin in radon-induced rat lung tumors and plutonium-induced dog lung tumors, mainly associated with epidermoid carcinomas.

The dog $\mathrm{N}$-ras DNA sequence shares homology with the human genes, $100 \%$ with the first exon and $94 \%$ for the second exon. The comparisons of the predicted amino acid sequences show homology of $100 \%$ and $96 \%$ for the first and second exons, respectively. Our studies indicate that radiation and chemicals activate the ras genes by different mechanisms. Chemical agents usually activate ras genes by causing specific and reproducible single-point mutations in the 12th, 13th, 59th, or 61st codons. in plutoniuminduced dog lung tumors examined thus far, the $\mathrm{N}$-ras second exon sequences are identical with the normal canine sequence. In the first exon, only one tumor had altered sequences. Radiation does not usually cause point mutations in the ras genes. Aather, radiation appears to activate the ras genes by causing gene rearrangements that result in overexpression of the affected genes. 
In our chernical-related biological research, we began studies to identify structural and functional changes in chromatin associated with formation of bulky adducts during tumor initiation. Incubation of benzo[a]pyrene (BaP), freshly isolated rat hepatocytes, and a 3200-bp plasmid (pXP-14) fragment resulted in DNA adduct profiles that were essentially identical to those found in mouse skin where BaP-induced tumors are initiated. These results suggest that bulky DNA adducts can be prepared in vitro in quantities sufficient that the influence of carcinogenic adducts on chromatin structure and gene expression can be evaluated in simple in vitro systems as surrogates for in vivo systems. A new genetic system is being used to study chemical exposure-induced mutations in synthetic DNA targets in Ames tester strain bacteria. Targets consisting of GCGCGC (guanine, cytosine) had a low rate of mutation when exposed to 6-aminochrysene. However, a target that was a direct repeat of this target and its flanking regions had a high rate. Subsequent analysis of the DNA sequences of these mutants showed that the entire repeated insert was deleted. Targets consisting of GGGGGG were also highly mutable; mutations were either 1-bp deletions or 14-bp insertions (a repeat of target flanking sequences).

In our fetal and juvenile radiation research, we continued to examine correlates between the physicochemical and biological factors that may be involved in fetopiacental radionuclide disposition. We found that fetoplacental radionuclide disposition displays a general relationship to values of fractional absorption from the gastrointestinal tract. Studies to apply newer methodological approaches to the problem of the mechanisms by which prenatal isradiation produces teratogenesis showed that in vitro radiation exposures below 1 Gy produced cell death, altered histology, and caused histochemical changes in embryonic limbs.

In our inhalation technology studies, aerosol chambers for whole-body exposure of rodents have been modified with a recirculation system that increases the uniformity of concentration of reactive aerosols in the chamber without substantially increasing the volume requirements for conditioned air or the mass of aerosolized material. Theoretical studies to evaluate the size of aerosol particles that have equivalent mobility in gases determined that the mean velocity is defined by weighting the average molecular speeds of the component gases in the mixture by their mote fraction rather than their average molecular weight. We have assembled equipment and developed techniques to perform a wide variety of pulmonary function measurements on experimental animals during exposure to estimate inhaled dose and, following exposure, to measure acute and chronic effects.

\section{General Life Sciences Research}

J. E. Schmaltz, a detailee to OHER's Human Genome Research program, provides computer science expertise to the computational analysis and database components of the Human Genome Task Group. He participates in review, coordination, and liaison of the informatics components of this multidisciplinary program.

PNL is developing a computer information system to graphically display and manipulate the vast amounts of information on the human genome. The user interface, named GnomeView, provides researchers with graphical representations of chromosomes, genetic and physical maps, and DNA sequences on a SUN workstation. It accesses database centers such as GENBANK as primary information sources. Unique features include the ability to provide genetic information in easily understandable color graphics, allowing the user to create hybrid or new maps.

PNL biomedical research is an interdisciplinary effort requiring scientific contributions from many research departments at PNL. Personnel in the Life Sciences Center are the principal contributors to this report.

Requests for reprints from the list of publications for 1989 will be honored while supplies are available. 


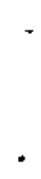




\section{Contents}

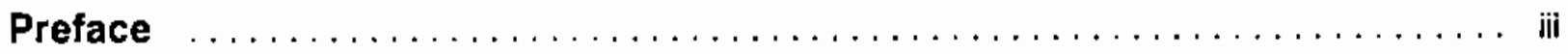

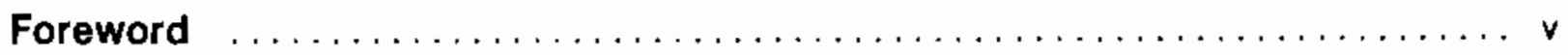

\section{Human Health Research}

Statistical Health Effects Studies, E. S. Gilbert $\ldots \ldots \ldots \ldots \ldots \ldots \ldots \ldots \ldots \ldots$

Iron Stores and Risk of Cancer, $R$. G. Stevens $\ldots \ldots \ldots \ldots \ldots \ldots \ldots \ldots \ldots \ldots$

\section{Biological Research}

Inhaled Plutonium Oxide in Dogs, J. F. Park $\ldots \ldots \ldots \ldots \ldots \ldots \ldots \ldots \ldots \ldots \ldots$

Inhaled Plutonium Nitrate in Dogs, G. E. Dagle $\ldots \ldots \ldots \ldots \ldots \ldots \ldots \ldots \ldots \ldots \ldots$

National Radiobiology Archives, $C . R$. Watson $\ldots \ldots \ldots \ldots \ldots \ldots \ldots \ldots \ldots \ldots \ldots$

Low-Level ${ }^{239} \mathrm{PuO}_{2}$ Lifespan Studies, C. L. Sanders $\ldots \ldots \ldots \ldots \ldots \ldots \ldots \ldots \ldots \ldots$

Inhalation Hazards to Uranium Miners, $F$. $T$. Cross $\ldots \ldots \ldots \ldots \ldots \ldots \ldots \ldots \ldots$

Mechanisms of Radon Injury, F. T. Cross $\ldots \ldots \ldots \ldots \ldots \ldots \ldots \ldots \ldots \ldots \ldots \ldots$

Microdosimetry of Radon Daughters, $D$. R. Fisher $\ldots \ldots \ldots \ldots \ldots \ldots \ldots \ldots \ldots \ldots$

Growth Factors in Radiation Carcinogenesis, F. C. Leung $\ldots \ldots \ldots \ldots \ldots \ldots \ldots$

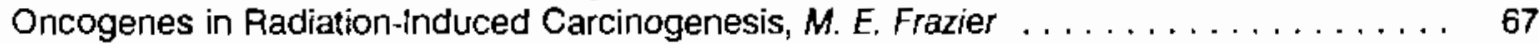

Molecular Events During Tumor Initiation, D. L. Springer $\ldots \ldots \ldots \ldots \ldots \ldots \ldots \ldots \ldots$. 73

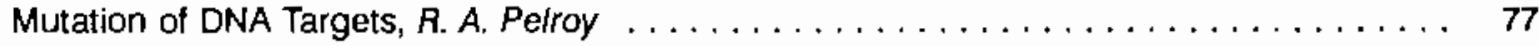

Fetal and Juvenile Radiotoxicity, $M$. $R$. Sikov $\ldots \ldots \ldots \ldots \ldots \ldots \ldots \ldots \ldots \ldots \ldots \ldots$

Aerosol Technology Development, A. C. James $\ldots \ldots \ldots \ldots \ldots \ldots \ldots \ldots \ldots \ldots$

\section{General Life Sciences Research}

Synthesis of Human Genome Information, J. E. Schmaltz $\ldots \ldots \ldots \ldots \ldots \ldots \ldots \ldots$. 91

GnomeView: A Graphical Interface to the Human Genome, A. J. Douthart . . . . . . . . 95

\section{Medical Applications}

Radioisotope Customer List, $R$. A. Peloquin $\ldots \ldots \ldots \ldots \ldots \ldots \ldots \ldots \ldots \ldots$

Appendix - Dose-Effect Studies with Inhaled Plutonium in Beagles . . . . . . 101

\section{Publications and Presentations}

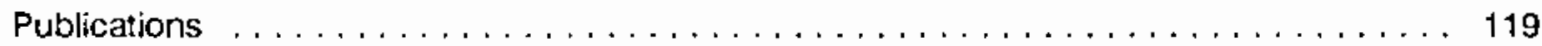

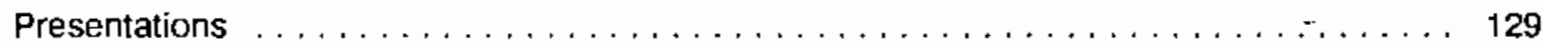

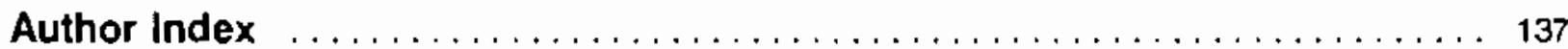

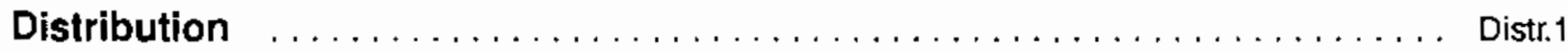




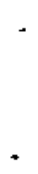


Human

Health

Research 


\title{
Statistical Health Effects Studies
}

\author{
Principal Investigator: E. S. Gilbert
}

\author{
Other Investigators: J. A. Buchanan, J. J. Fix, and N. A. Holter
}

The overall objective of this project is to increase understanding of health risks resulting from low-level chronic exposure by providing methodology and analyses for a direct assessment of these risks. Analyses of data on workers exposed occupationally to low levels of radiation are a major component of this project. Efforts in the past year have included contributing to national and international pooling of data, improving understanding of historical external dosimetry data, participating in plans for DOE's Comprehensive Epidemiologic Data Resource (CEDR), and developing updated and more detailed data on Hanford workers to meet the needs of both pooled analyses and CEDR. Analyses of combined data from U.S. studies have been published, and reports documenting historical dosimetry practices and describing a dosimetry validation study are near completion.

\section{Pooling of Data from U.S. Department of Energy (DOE) Facilities}

Analyses of combined data from the Hanford Site, Oak Ridge National Laboratory (ORNL), and Rocky Flats Nuclear Weapons Plant have been conducted, with the results published in Radiation Research. These analyses focus on the effects of occupational exposure to external radiation, and are the first of several planned efforts to combine data on workers at DOE facilities. Analyses based on combined data provide greater power for detecting departures from risk estimates obtained through extrapolation from data on populations exposed at high doses, and provide tighter confidence limits on risk estimates than those based on data from any single study population. Also, application of similar methodology to data from all populations, and presentation of results in a comparable format, facilitate the comparison of results from different studies.

Table 1 shows excess relative risk estimates with confidence limits for all cancer and for leukemia, based on each of the individual studies and based on the combined data. The comparable estimates, based on recent atomic bomb survivor data and recently revised (DS86) dosimetry, are also given. Because Hanford is the largest population, the upper confidence limits based on the Hanford data were considerably lower than those based on ORNL or Rocky Flats data. The upper confidence limits based on the combined data were lower, however, than those obtained from the Hanford data alone.

\begin{tabular}{|c|c|c|}
\hline & All Cancer & Leukernia ${ }^{(b)}$ \\
\hline Hantord & $-0.9 \% \quad(<0,0.9 \%)$ & $<0^{(c)}(<0,4.8 \%)$ \\
\hline ORNL & $-0.7 \% \quad(<0,3.2 \%)$ & $<0^{(c)}(<0,13 x)$ \\
\hline Rocky Elats & $<0^{(c)} \quad(<0,2.8 \%)$ & $4.3 \%(<0,52 \%)$ \\
\hline Combined & $-1.0 \% \quad(<0,0.4 \%)$ & $<0^{(c)}(<0,3.4 \%)$ \\
\hline $\begin{array}{l}\text { Atomic bomb } \\
\text { survivors (d) }\end{array}$ & $0.41 \%(0.32 \%, 0.52 \%)$ & $5.2 \%(3.8 \%, 7.1 \%)$ \\
\hline
\end{tabular}

(a) Based on monitored white males employed at least 6 months at the Manford Site (WA), Oak Ridge National Laboratory (TN), or the Rocky Flats Nuclear Weapons Plant (CO).

(b) Excluding chronic lymphatic leukemia.

(c) Likelihood maximized at a value that would have led to negative relative risks.

(d) As presented in Shimizu et al. (Y. Shimizu, H. Kato, W. J. Schull, D. L. Preston, S. Fujita, and D. A. Pierce. 1987. Life Span Study Repon II, Part I. Comparison of Risk Coetficients for Site-Specific Cancer Mortality Based on the DS86 and T65D Shielded Kermas and Organ Doses. TR87-12, Padiation Effects Research Foundation, Hiroshima 730, Japan) for all cancer (column 1) except loukemia, and for leukemia only (column 2). 
All confidence fimits based on the worker studies included zero and were much wider than those based on the atomic bomb survivors, but upper limits based on the combined data were roughly comparable to those based on the atomic bomb survivors. A number of difficulties (such as possible lack of dosimetry comparability and bias resulting from unidentified confounding factors) make this comparison imprecise. Nevertheless, these results strengthen support for the conclusion that estimates obtained through extrapolation from high-dose data do not seriously underestimate risks of low-dose exposure, but leave open the possibility that extrapolation may overestimate risks.

A second paper, based on the combined U.S. data, emphasizes statistical methodology for analyzing combined data, and is intended to provide a model that will be useful in planning future pooled analyses. The paper also uses data from the three studies noted previously to evaluate and compare results based on various levels of aggregation of exposure data. The use of grouped exposure data has been common practice in most epidemiologic studies of nuclear workers, and thus the possible loss of statistical power or precision of estimates from this practice is of concern. On this issue, the paper concludes that using just three dose categories (as has been done in some studies) is not to be recommended; the loss of power resulting from this practice rather than using ungrouped data is roughly equivalent to the loss that would result from halving the sample size. However, the use of 11 categories (rather than using ungrouped data) leads to much less loss of power, roughly equivalent to a $3 \%$ reduction in sample size.

\section{Pooling of Data from the United States, the United Kingdom, and Canada}

Plans for international combined analyses of nuclear worker studies in the United States, the United Kingdom, and Canada are proceeding with the International Agency for Research on Cancer (IARC) serving as the coordinating agency. A subcommittee of the working group (consisting of representatives from all studies) has met twice, with PNL providing representation for the U.S. studies. As a result of these meetings, a protocol for analyses of the combined international data has been developed that sets out criteria for selection of cohorts to be included and describes the variables that must be provided by participants. The subcommittee also identified two topics needing special attention in pooled analyses; these topics are 1) the use of job category data in determining socioeconomic status, and 2) dosimetry.

For Hanford workers, PNL and the Hanford Environmental Health Foundation (HEHF) are explor. ing the use of job category data as an indicator of socioeconomic status or social class. Difficulties in using this information are inconsistencies in titles for similar jobs in different time periods or for different contractors, errors in coding job titles, and difficulties in handling workers with several different titles during their employment. A system to provide a measure of socioeconomic status based on Hanford job titles has been developed. The system is reasonably comparable to that used in the United Kingdom for defining social class from job titles.

Comparability of dosimetry in various studies was a major forsus of a second subcommittee meeting held at IARC in April, which included dosimetry experts with PNL representing the United States. A questicnnaire on dosimetry practices was requested from each of the contributing studies (including Hanford, ORNL, and Rocky Flats in the United States), and this information was used for preliminary evaluation of dosimetry comparability. An objective of the dosimetry evaluation is to determine possible bias in recorded measurements of external dose, at different facilities and in different time periods, relative to the $1-\mathrm{cm}$-depth dose in tisisue. A second objective is to provide the best feasible assessment of organ dose. In the United States, the need for this information led to the formation of a dosimetry committee for further evaluation of dosimetry for the three U.S. studies. The data on external doses, supplied to IARC, will consist of the doses as reported by individual facilities, tut the outcome of the dosimetry evaluation may suggest the need for adjustment factors to be applied in some analyses.

\section{External Dosimetry for Hanford Site Workers}

A technical report documenting historical dosimetry practices at the Hanford Site is near completion. The preparation of this report has included a review of dosimetry documents and of quality assurance studies. Overall, it has been found that 
the Hanford Site dosimetry system is well documented and that good professional practices were followed. An intercomparison study of the response of all past Hanford beta/gamma and neutron personnel dosimeters to several sources of radiation has atso been conducted. Based on this study, the comparability of recorded doses over time, and the relationship of recorded dose to the 1-cm-depth dose, are being evaluated.

A study of detailed dosimetry source records for 139 workers is also near completion. The objectives of this investigation are 1) to assess the extent to which dose estimates used in mortality analyses agree with information in source records and 2) to gain a better understanding of dosimetry practices. The workers selected for this study were chosen to provide validation of doses of leukemia deaths, muttiple myeloma deaths, and other cancer deaths with cumulative doses exceeding 20 rem. They were also chosen to provide information on special groups such as workers in occupations of special interest, workers known to have a high potential for neutron exposure, and workers in jobs with little or no potential for exposure.

Dose estimates obtained from information on microfiche or microfilm source records have been compared with dose estimates on computerized files used in mortality analyses. Because of difficulties in reading some early source records " and because of variation in the format of records and in algorithms for calculating whole-body dose, this validation has been difficult. In many instances, dose estimates used in monality analyses could not be verified exactly, but most apparent discrepancies led to only minor modifications in cumulative dose. Discrepancies in cumulative dose were less than 0.1 rem for $88 \%$ of the workers in this study, never exceeded 1.5 rem, and would be unlikely to distor conclusions of dose-response analyses. Also, most discrepancies occurred in early years of the study, especially 1944-1946, with very few problems with dose estimates from the 1960 s and 1970s.

This study also provides data on dosimetry practices, including frequency of monitoring, the number and proportion of dosimeters yielding positive results, and the magnitude of doses recorded for individual dosimeters. Information on these variables has been tabulated by calendar year and for various subgroups of workers.

\section{Comprehensive Epidemiologic Data Resource (CEDR)}

PNL has participated in the DOE's Comprehensive Epidemiologic Data Resource (CEDR) Working Group. The CEDR program was established to develop a public use data set containing worker demographics, work histories, radiation and chemical exposures, medical information, vital statistics, and other health-related data on workers at DOE facilities. The program is a coordinated effort between DOE's Otfice of Health and Environmental Research, Oak Ridge Associated Universities, Los Alamos National Laboratory, PNL, and HEHF, the major groups currently involved in epidemiologic studies of DOE workers. Argonne National Laboratory is serving as coordinator for CEDR, and a National Academy of Sciences Advisory Committee has been established to provide guidance on the establishment and control of data included in CEDR.

The CEDR working group has met three times to address questions such as what data should be included, how to facilitate collection of data from DOE facilities for which data are not yet available, documentation of data, database management, and the provision of basic information on the nature of operations at included facilities. Particular attention has been given to what variables should be included in the database, and lists of variables that are currently available for each facility have been assembled. The initial CEDR will include variables specified by the IARC protocol for the three study populations contributing to the international combined analyses (Hanford, ORNL, and Rocky Flats). Additional variables and data from other facilities will be added later.

\section{Update of the Hanford Site Database}

The database for the Hanford worker study is being updated to include workers employed between 1979 and 1983 and more recent dosimetry. This updating process involves linkage of occupational histories (maintained by HEHF) and dosimetry files (maintained by PNL's Health Physics Department), extensive edits of the two files against one another and against our previous analysis file, and resolution of identified discrepancies. Additional detail on both job histories and dosimetry is being extracted to meet the requirements of the IARC protocol. 


\title{
Iron Stores and Risk of Cancer
}

\author{
Principal Investigator: R. G. Stevens
}

\author{
Other Investigators: S. Akiba, M. Kabuto, K. Neriishi, and D. Stram, Radiation \\ Effects Research Foundation, Hiroshima, Japan; W. Blot and \\ C. Land, National Cancer Institute, Bethesda, Maryland
}

This research program is studying the effect of body iron stores on the long-term risk of cancer and on the prognosis after cancer diagnosis, and the possible modifying effect of iron stores on risk of radiationinduced tumor formation. During this year, biological mechanisms whereby iron might influence risk of radiation injury have been examined in detail. Results of our stomach cancer case-control study in a Japanese population have been compared to previous studies of iron and cancer, and this comparison has been presented at an international symposium.

\section{Mechanisms}

Biological mechanisms whereby iron might influence risk of radiation injury were reviewed [see Stevens and Kalkwarf, Environ. Health Perspect. 87 (in press)]. The two general mechanisms by which iron may increase risk of cancer or affect radiationinduced transformation are depicted in Figure 1. First, excess intracellular iron may increase the ambient concentration of oxygen radicals, leading to depletion of cellular reserves of reducing agents. Increased oxidative stress may thus render the cell more sensitive to the radicals produced by ionizing radiation (left side of Figure 1). Excess intracellular iron may also increase the effective range of radicals produced by radiation. Second, iron may be a limiting nutrient to the growth and replication of a transformed cell in the human body, and high iron stores thus may increase the likelihood that a transformed cell will survive to become a clinically apparent neoplasm (right side of Figure 1).

If body iron stores affect sensitivity to radiation injury, this effect has important implications for 1) second malignant neoplasms arising from radiation therapy, 2) diagnostic radiation exposure, 3) occupational radiation and residential radon exposures, and 4) exposure of astronauts and airline crews to cosmic radiation. In these instances, relative capacity of the host to scavenge oxygen radicals may influence cancer risk associated with radiation exposure, and this capacity may be closely related to iron metabolism. Nutritional antioxidants have received much attention in this regard, but the "oxidant" iron has received very little.

\section{Epidemiological Study Populations}

A comparison of the available epidemiological studies of iron and cancer risk was presented at the Fourth International Symposium in Hematology and Oncology at the Karolinska Hospital in Stockholm [Stevens, Medical Oncology \& Tumor Pharmacotherapy (in press)]. This comparison, designed to provide perspective on our work on the Japanese atomic bomb survivors, is summarized here. Five epidemiological study populations were compared:

- Akiba et al, (in review; Journal of the National Cancer institute) have completed a study of serum ferritin and transferin and risk of stomach cancer in Japanese atomic bomb survivors (subsequently referred to as Japan). From 1970 to 1972 , blood samples were drawn from participants in the Adult Health Study of atomic bomb survivors at biennial clinical examinations at the Radiation Effects Research Foundation in Hiroshima and Nagasaki. In this group, 233 cases of stomach cancer were diagnosed from 1973 to 1983. Serum ferritin and transferrin levels in stored serum from 1970 to 1972 for the stomach cancer cases were compared to levels in controls matched for age, sex, city, and radiation exposure. Adjustment was made for smoking. 


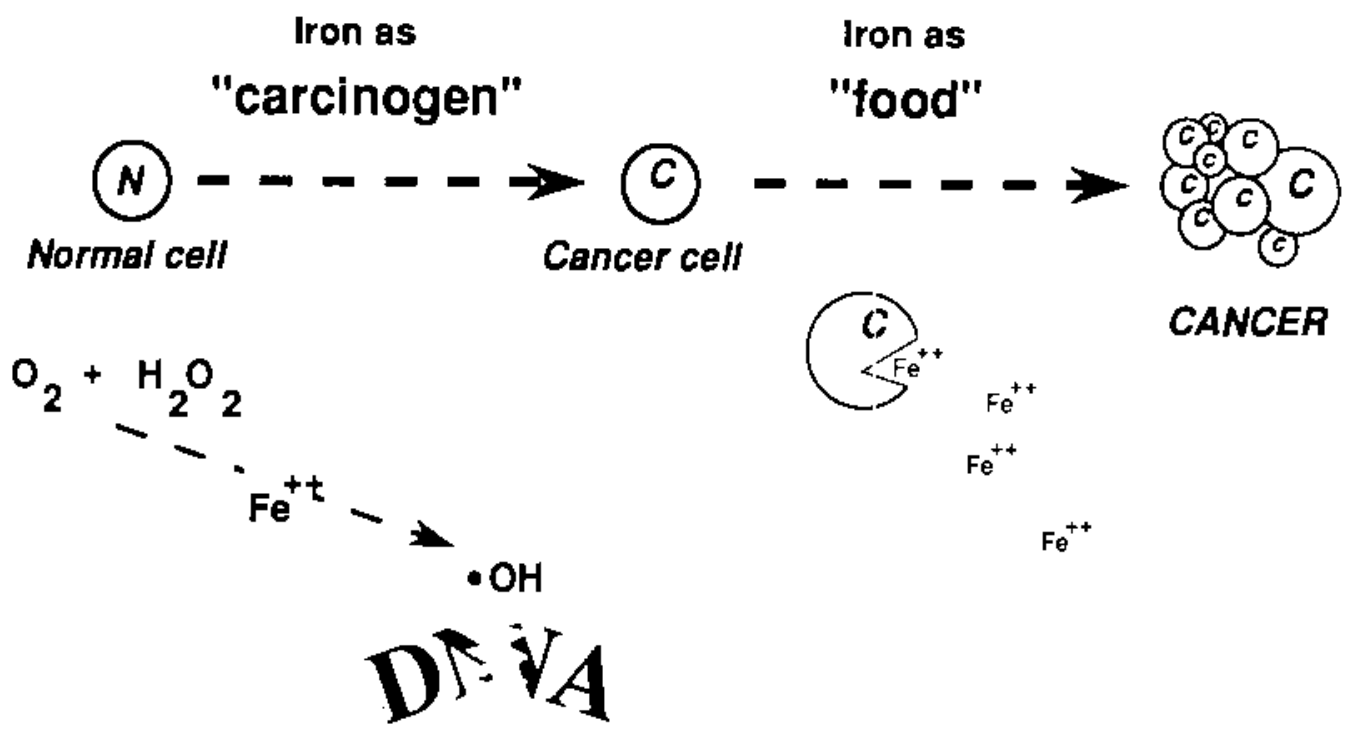

FIGURE 1. Hustration of Two Possible Mechanisms by Which Iron Might Increase Cancer Pisk. Firt (left), iron can catalyze the production of oxygen radicale, which may be directly carcinogenic or may increase oxidative stress to a cell and thereby increese senstlvity to ionizing radiation demage. Second (right), cencer cells need iron to grow. Iron may be a limting nutrient to growth and development of cancer cell into a clinically apparent neoplasm.

- Stevens et al. (Am. J. Epidemiol. 118:550, 1983) studied the relationship of serum ferritin and transferrin to subsequent risk of death for a 10-year period in the Solomon Islands (referred to hereafter as Solomons).

- Stevens et al. (J. Natt. Cancer Inst. 76:605, 1986) reported the results of a study of serum ferritin and transferrin level in serum stored since 1975-1978 in 192 male Chinese government workers who developed primary hepatocellular carcinoma (PHC) or died of any cancer by 1983 , and in 358 age-matched control men who had not died or developed cancer (referred to as Taiwan).

- Selby and Friedman (int. J. Cancer 41:677, 1988) reported more than 175,000 members of a health maintenance plan in northern California followed from 1964 to 1973 (referred to as Kaiser). Each subject had a baseline medical examination and a measurement of total ironbinding capacity (TBC) during this period. The population was followed through 1980, and incident cases of cancer recorded; TIBC was compared between cases and those who did not develop cancer over the study period.
- Using the existing database on the National Health and Nutrition Examination Survey $\mathrm{I}^{*}$ in the United States, Stevens et al. ( $N$. Engl. J. Med. 119:1047, 1988) compared transferrin saturation and $T B C$ in 14,707 subjects who developed cancer as of 1984 to those who did not (referred to as NHANES).

\section{Comparison of Iron Stores}

Populatioris differed for each of the iron stores studies; measurement methods for iron status and outcomes also differed. However, comparison of results provided further insight into the possible effect of iron status on cancer risk. Serum ferritin and serum transferrin were used in the Solomons study of general mortality, in the Taiwan study of incidence of PHC and cancer deaths excluding $\mathrm{PHC}$, and in the Japan study of stomach cancer incidence. The NHANES study used transferrin saturation and TIBC, whereas the Kaiser study used only $T B C$. In general, there is a direct correlation of serum ferritin and transterrin saturation with available body iron stores, and an inverse correlation of senum transterrin and $\pi B C$ with iron stores; that is, high iron stores result in 
high ferritin and transferrin saturation and low serum transferrin and TIBC.

Figure 2 qualitatively summarizes the data presented in Tables 1, 2, and 3. Table 1 shows a comparisori of the studies that used ferritin or transferrin saturation. Serum ferritin was significantly higher in men in the Solomons study who died than in those who did not die over a 10-year period; the difference in women was not significart. In Taiwan, men who died of cancer had higher ferritin although not significantly so. Men who died of or developed PHC had significantly higher ferritin than their controls. In the NHANES study, men who developed cancer (all types combined) had significantly higher transferrin saturation than controls, whereas women did not. Persons with stomach cancer in the Japan study had significantly lower ferritin than controls.
Table 2 shows results for serum transterrin and TIBC. Transferrin was significantly lower in those who died than in those who did not in the Solomons. Men who died of cancer had significantly lower transferrin than those who did not in Taiwan. Women with cancer in the Kaiser study, and men with cancer in the NHANES study, had lower TIBC than controls. In the Japan study, stomach cancer cases had significantly higher transferrin than controls.

The Solomons, Taiwan, and NHANES studies gave results consistent with the hypothesis that higher iron stores increase risk of death or of cancer in men. The Kaiser study gave evidence for an association in women but not in men. The NHANES study suggested that women with very high transferrin saturation might also be at moderately elevated risk of cancer.

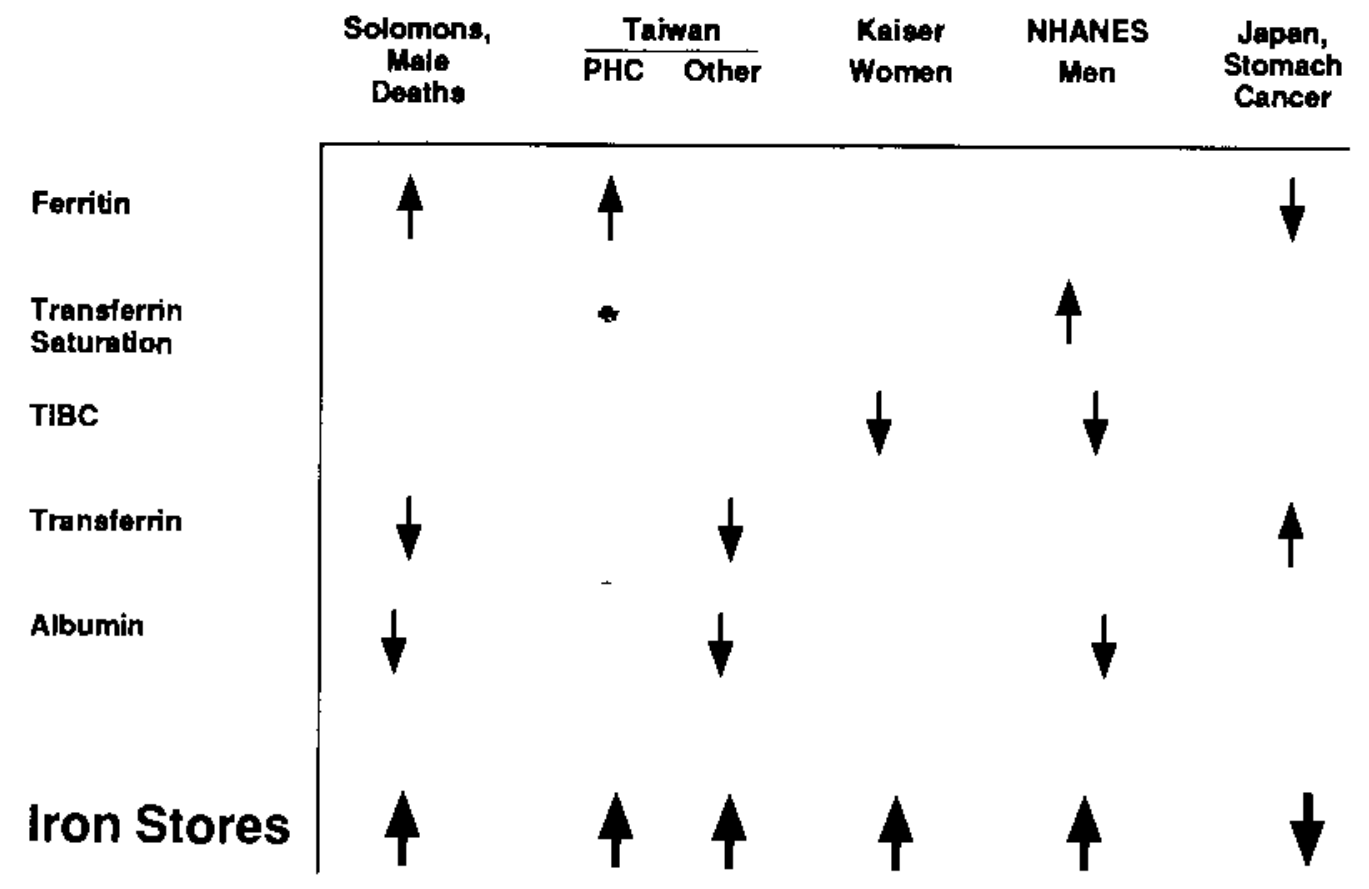

FIGURE 2. Cualitative Description of Resulto Presented in Tables 1, 2, and 3. Case value an compared to control is given for serum ferritin, trangferrin saturation, TIBC, serum transferrin, and serum albumin. Iron status in cases compared to controls is then inferred. Upward-pointing arrow indicates cases had higher value than controls. 
TABLE 1. Mean Serum Level of Ferrltin ( $\mathrm{ng} / \mathrm{m}$ ) or Traneferrin Saturation (\%) in Cancer Cases and Controls. A higher level in cancer patients is consistent with the hypothes/s thet cases had higher iron stozes than controls before death or diegnosis.

$\frac{\text { Ferritin }}{\text { Cases Controls }} \frac{\begin{array}{l}\text { Traneferrin } \\ \text { Sahuration }\end{array}}{\text { Ceses Controls }}$

Solomons

Males, death

Femeles, death

$71^{(a)} \quad 51.8$

$52 \quad 51$

Taiwan

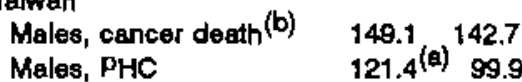

NHANES

Males, cancer incidence

Males, stomech cencer

Females, cancer incidence

$33.1^{(a)} \quad 30.7$

$26.4 \quad 30.7$

$28.2 \quad 27.4$

Japan

Stomach cancer

$49^{(e)} \quad 69.2$

(a) Significantly different from control. Solomons, Solomon Islands study; Talwan, study of Chinese government workers; NHANES, National Health and Nutrition Examination Survey l; Japan, Japanese atomic bomb survivors.

(b) Excluding PHC, primery hepatocellular carcinoma.

In the Japan study, the association of serum ferritin and transferrin is in the opposite direction: lower iron stores are associated with increased stomach cancer incidence. There were only 8 cases of stomach cancer in the NHANES study and 24 in the Taiwan study. However, the male cases in NHANES had a transferrin saturation of $26.4 \%$, lower than controls, and TIBC of $67.0 \mu \mathrm{mol} / \mathrm{liter}$, higher than controls. In the Taiwan study, persons with stomach cancer also had lower ferritin than controls. Thus, thie results of these three studies are consistent.

In the Taiwan study, persons with liver cancer had greatly elevated ferritin before diagnosis. The highest ferritin values were found in those diagnosed less than 1 year atter blood samples were drawn, suggesting that elevated ferritin may be a marker of early PHC.

Table 3 shows mean levels of serum albumin before diagnosis of disease in cases and controls. A consistent, and highly statistically significant, negative association of serum albumin level in men and risk of death and/or cancer was seen in these studies. Albumin is lower in smokers than nonsmokers, and decreases with age. However, the negative association persisted after controlling for these factors.

TABLE 2. Serum Levele of Transferrin ( $\mathrm{mg} / \mathrm{dl}$ ) or Total Iron Binding Capacity (TBC, $\mu$ molliter) in Cases and Controls. A lower level in cases ls consistent with the hypothesis thet cases had higher iron stores than controls betore death or diagnosis.

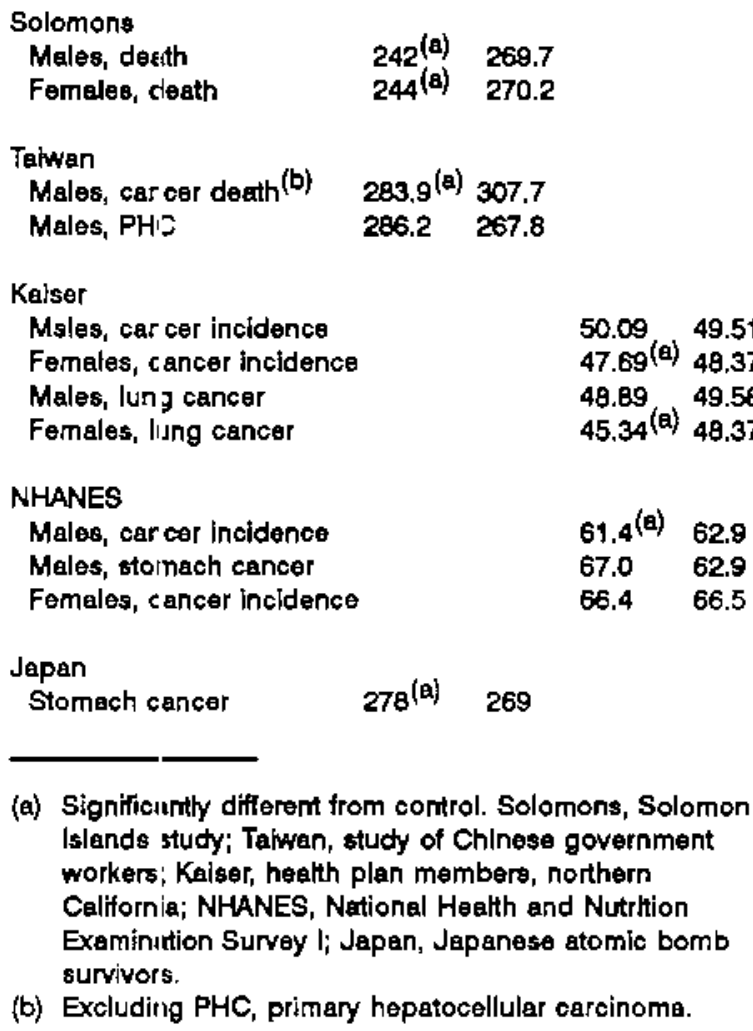

(a) Significuntly different from control. Solomons, Solomon Islends study; Tawan, study of Chlnese government workers; Kaiser, health plan members, northern California; NHANES, National Health and Nutrltion Exeminution Survey l; Japen, Japanese atomic bomb survivors.

(b) Excluding PHC, primary hepatocellular carcinome.

\section{Discussion}

Stomach cancer risk appears to be associated with lowel' iron stores. A mechanism whereby precursors of stomach cancer lead to lower iron stores is a possible explanation discussed in the paper reforting the Japan study.

Blumberg et al. (Proc. Natl. Acad. Sci. 78:3222, 1981) stated the hypothesis that the risk of $\mathrm{PHC}$ in 
chronic carriers of hepatitis B virus (HBV) is increased in those with high liver iron stores. Lustbader et al. (Science 220:423, 1983) studied hemodialysis patients challenged with HBV, and found that those patients who became chronic carriers had higher serum ferritin before challenge than those who developed antibody. Evidence from the Taiwan study further implicates iron level in the etiology of HBV-induced PHC.

TABLE 3. Serum Albumin In Cases and Controls in Three Epidemiologlcal Studieo

\begin{tabular}{|c|c|c|}
\hline & Serum A & in (q/liter) \\
\hline & Cases & Controis \\
\hline Solomons & & \\
\hline Males, death & 39.1 & $41.5^{(\mathrm{e})}$ \\
\hline Females, death & 40.1 & 40.6 \\
\hline Talwan & & \\
\hline Males, cancer death ${ }^{(b)}$ & 42.0 & $44.0^{(\theta)}$ \\
\hline NHANES & & \\
\hline Males, cancer incidence & 43.7 & $44,3^{(\mathrm{a})}$ \\
\hline Females, cancer incidence & 43.3 & 43.4 \\
\hline
\end{tabular}

(a) Statistically significant difference.

(b) Excluding PHC, primary hepatoceliular carcinoma.

The negative association of serum albumin level and subsequent cancer risk in men seen in these epidemiological studies is an intriguing finding. It may result simply from confounding effects of age and cigarette smoking, although adjustment was made for these factors in analyses. Albumin level is used clinically to assess protein-calorie status, and low albumin suggests low protein intake. Protein intake, however, has been found to increase cancer risk in experimental animals; low albumin in cancer victims appears inconsistent with results from animal studjes. Albumin is the most abundant serum protein and is important in maintaining osmotic pressure of blood, and in transporting many substances. In particular, albumin may bind iron to inhibit the growth of bacteria, and, by extension, the growth of cancer cells.
The iron-cancer hypotheses have many potential applications. Blood donors might be at reduced risk of cancer because of their chronically lowered iron levels. Atthough asbestos is believed to be carcinogenic in humans, particularly in conjunction with cigarette smoking, the difference in carcinogenicity between amphibole asbestos (high cancer risk and high iron content) and serpentine asbestos (low cancer risk and low iron content) may be explained by the iron content of these respective silicates. Iron may influence cancer at some sites and not at others. Data presented from the studies reviewed here show evidence of increased overalf cancer risk, atthough of lower stomach cancer risk, in those with high iron stores. It has been argued that iron binding by phytase may account for a reduced colon cancer risk for those consuming a high-fiber diet.

The prominence of iron in human physiology, and the high iron content of the western diet, emphasize the importance of pursuing further research on the possible role of iron in risk of cancer and in risk of radiation-induced transformation.

\section{Future Plans}

Studies of smoking and serum proteins in Japanese atomic bomb survivors and of iron stores and the risk of stomach cancer in Japanese populations, described in the Pacific Northwest Laboratory Annual Report for 1988 to the DOE Office of Energy Research, are in journal review (American Journal of Epidemiology).

Analyses of serum albumin and cancer risk in Japanese bomb survivors are continuing as is the development of a research protocol for a study of serum ferritin and transferrin and subsequent risk of colon and bladder cancers. A new study of hepatitis B virus and risk of liver cancer is also planned. Possible roles of iron stores (Stevens et al., J. Natt. Cancer Inst. 76:605, 1986) and radiation in this relationship (Asano et al., J. Natl. Cancer-Inst. 69:1221, 1982) will also be investigated. 


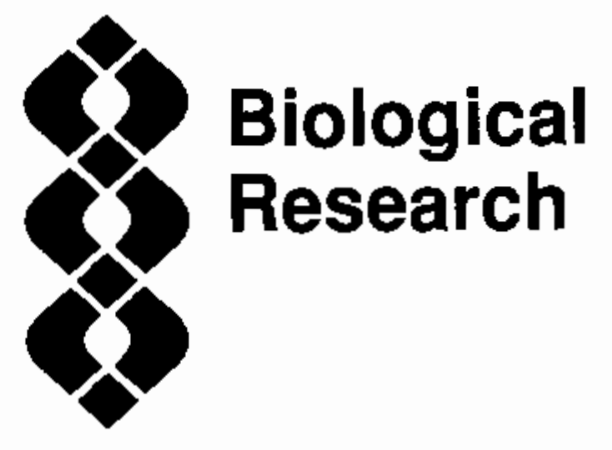




\title{
Inhaled Plutonlum Oxide In Dogs
}

\section{Principal Investigator: J. F. Park}

\author{
Other investigators: R. L. Buschbom, G. E. Dagle, K. M. Gideon, E. S. Gilbert, \\ G. J. Powers, H. A. Ragan, C. O. Romsos, C. R. Watson, \\ R. E. Weller, E. L. Wierman, and J. R. Williams
}

\section{Technical Assistance: K. H. Debban, R. F. Flores, B. B. Kimsey, B. G. Moore, R. P. Schumacher, M. J. Steele, and N. B. Valentine}

This project is concerned with long-term experiments to determine the lifespan dose-effect relationships of inhaled ${ }^{239} \mathrm{PuO}_{2}$ or ${ }^{238} \mathrm{PuO}_{2}$ in beagles. The data will be used to estimate the health effects of inhated transuranics. Beagle dogs given a single exposure to ${ }^{239} \mathrm{PuO}_{2}$ or ${ }^{238} \mathrm{PuO}_{2}$ aerosols to obtain dose-level groups with initial lung burdens (ILB) approximately 1, 8, 40,50, 700, and 2800 times the maximum permissible lung dose for a plutonium worker are being observed for lifespan dose-effect relationships. Increased incidence of lung tumors was observed in the four highest dose-level groups exposed to ${ }^{239} \mathrm{PuO}_{2}$ during the 16-year postexposure period. All the dogs exposed to ${ }^{239} \mathrm{PuO}_{2}$ are dead. During the 15 years after exposure to ${ }^{238} \mathrm{PuO}_{2}$, increased incidence of lung and/or bone tumors was observed in the five highest dose-level groups. Chronic lymphopenia, occurring 0.5 to 2 years after exposure, was the earliest observed effect after inhalation of either ${ }^{239} \mathrm{PuO}_{2}$ or ${ }^{238} \mathrm{PuO}_{2}$ in the four highest dose-level groups that had ILB $\geq 80 \mathrm{nCi}$. Other plutonium-exposure-related effects include sclerosis of the tracheobronchial lymph nodes, focal radiation pneumonitis, adenomatous hyperplasia of the liver, and dystrophic osteolytic lesions in the skeleton.

To determine the lifespan dose-effect relationships of inhaled plutonium, 18-month-old beagle dogs were exposed to aerosols of ${ }^{239} \mathrm{PuO}_{2}$ (mean AMAD, $2.3 \mu \mathrm{m}$; mean GSD, 1.9), prepared by calcining the oxalate at $750^{\circ} \mathrm{C}$ for 2 hours; or to ${ }^{238} \mathrm{PuO}_{2}$ (mean AMAD, $1.8 \mu \mathrm{m}$; mean GSD, 1.9), prepared by calcining the oxalate at $700^{\circ} \mathrm{C}$ and subjecting the product to $\mathrm{H}_{2}{ }^{16} \mathrm{O}$ steam in argon exchange at $800^{\circ} \mathrm{C}$ for 96 hours. This material, referred to as pure plutonium oxide, is used as fuel in space-nuclear-power systems.

One hundred thirty dogs exposed to ${ }^{239} \mathrm{PuO}_{2}$ in 1970 and 1971 were selected for long-term studies; 14 were sacrificed to obtain plutonium distribution and pathology data; 116 were assigned to lifespan dose-effect studies (Table 1). The 116 dogs exposed to ${ }^{239} \mathrm{PuO}_{2}$ in 1973 and 1974 were selected for lifespan dose-effect studies (Table 2), and 21 additional dogs were exposed for periodic sacrifice. The Appendix (which follows Part 1 of this Annual Report) shows the status of the dogs in these experiments.
TABLE 1. Lifespan Dose-Effect Studies with Inhaled

${ }^{239} \mathrm{PuO}_{2}$ in Boagles

\begin{tabular}{|c|c|c|c|c|}
\hline \multirow{2}{*}{$\begin{array}{l}\text { Dose- } \\
\text { Level } \\
\text { Group }\end{array}$} & \multicolumn{2}{|c|}{$\begin{array}{c}\text { Number of } \\
\text { Dogs }\end{array}$} & \multicolumn{2}{|c|}{ Initial Lung Deposition (b) } \\
\hline & Male & Female & $\mathrm{nCl}^{(\mathrm{c})}$ & $\mathrm{nCl} / \mathrm{g}$ Lung $(\mathrm{c})$ \\
\hline Control & 10 & 10 & 0 & 0 \\
\hline 1 & 12 & 12 & $3.5 \pm 1.3$ & $0.029 \pm 0.011$ \\
\hline 2 & 10 & 11 & $22 \pm 4$ & $0.18 \pm 0.04$ \\
\hline 3 & 10 & 10 & $79 \pm 14$ & $0.66 \pm 0.13$ \\
\hline 4 & 11 & 11 & $300 \pm 62$ & $2.4 \pm 0.4$ \\
\hline 5 & 10 & 11 & $1100 \pm 170$ & $9.3 \pm 1.4$ \\
\hline 6 & $\frac{3}{66}$ & $\frac{5}{70}$ & $5800 \pm 3300$ & $50 \pm 22$ \\
\hline
\end{tabular}

(a) Exposed in 1970 and 1971.

(b) Estimeted from extemal thorex counts at 14 and 30 days atter exposure and estimated lung weights $(0.011 \mathrm{x}$ body weight).

(c) Mean $\pm 95 \%$ confidence intervals around means.

Table 3 summarizes, by dose-level group, the mortality and lesions associated with deaths through 16 years atter exposure to ${ }^{239} \mathrm{PuO}_{2}$. All the dogs exposed to ${ }^{239} \mathrm{PuO}_{2}$ are dead. Mean survival time 
was decreased in the three highest dose-level groups compared to that in the other groups. Fourteen dogs were sacriticed for comparison of plutonium tissue distribution. Table 4 shows the primary cause of death and the distribution of ${ }^{239} \mathrm{Pu}$ in the tissues as percent of final bocty burden. Figure 1 shows the plutonium tissue distribution as percent of initial lung burden (ILB). TABLE 2. Lifespan Dose-Effect Studiee wth inheled ${ }^{238} \mathrm{PuO}_{2}$
in Beagles

\begin{tabular}{|c|c|c|c|c|}
\hline \multirow{2}{*}{$\begin{array}{l}\text { Dose. } \\
\text { Level } \\
\text { Grous }\end{array}$} & \multicolumn{2}{|c|}{$\begin{array}{c}\text { Number of } \\
\text { Dogs }\end{array}$} & \multicolumn{2}{|c|}{ Initial Lung Deposition ${ }^{(b)}$} \\
\hline & Male & Female & $n \mathrm{Cl}^{(\mathrm{C})}$ & nCl/g Lung ${ }^{(c)}$ \\
\hline Control & 10 & 10 & 0 & 0 \\
\hline 1 & 10 & 10 & $2.3 \pm 0.8$ & $0.016 \pm 0.007$ \\
\hline 2 & 41 & 10 & $18 \pm 3$ & $0.15 \pm 0.03$ \\
\hline 3 & 12 & 10 & $7 \pm 11$ & $0.56 \pm 0.07$ \\
\hline 4 & 10 & 10 & $350 \pm 81$ & $2.6 \pm 0.5$ \\
\hline 5 & 10 & 10 & $1300 \pm 270$ & $10 \pm 1.9$ \\
\hline 6 & $\frac{7}{70}$ & $\frac{6}{66}$ & $5200 \pm 1400$ & $43 \pm 12$ \\
\hline
\end{tabular}

(a) Exposed in 1973 and 1974.

(b) Estimeted from external thorax counts at 14 and 30 days after exposure and estimated lung weights $(0.011 \times$ body woight).

(c) Mean $\pm 95 \%$ corfidence intervals around means.

Table 4 indicates that, as survival time increased, the fraction of plutonium in the lung decreased to $16 \%$ of the final body burden by 15 to 16 years after exposure. During the first year after exposure, plutonium was translocated primarily to the thoracic lymph nodes; little plutonium was translocated to other tissues. Plutonium content of the thoracic lymph nodes increased to $71 \%$ of the final body burden at 15 to 16 years after exposure; the abdominal lymph nodes, principally the hepatic nodes, contained $\sim 3 \%$. The fraction of plutonium in liver increased, accounting for $25 \%$ of the final body burden in the higher $\geq 75 \mathrm{nCi}$ final body burden) dose-level groups. The organ distribution of plutonium in the periodically sacrificed dogs was generally similar to that of the higher dose-level dogs euthanized when death was imminent during the first 2 years after exposure. The lower dose level ( $\leq 75 \mathrm{nCi}$ final body burden) dogs sacrificed or euthanized during the 4th to 16th postexposure years generally had a much smaller fraction of the final body burder in the liver, with a larger fraction retained in the lungs and/or thoracic lymph nodes.
The fraction of plutonium in the livers of these dogs was $\sim 7 \%$ of the final body burden 15 to 16 years after exposure; about $1 \%$ was in the skeleton.

Figure 1 shows the ${ }^{239} \mathrm{Pu}$ tissue distribution as percent of the ILB for all dogs for which tissue radiochemical analyses are complete. The ILB for those dogs for which radiochemical analysis of excreta were not complete were estimated from external thorax counts at 14 and 30 days after exposure. For dogs whose analyses were complete, ILB were estimated from the summation of the tissue burdens of plutonium, plus the plutonium excreted, minus plutonium excreted in the feces during the first 3 days after exposure. The latter was assumed to be deposited in the upper respiratory tract. Uptake and retention functions were fitted to the organ burden data. Based on the premise that the organ burdens were interrelated, the uptake and retention function for all organs was fittec simultaneously instead of fitting isolated functions for each organ.

The organs were treated as compartments of a single system, with transfer rates specifying the total amount, leaving a compartment per unit time and the fractional distribution of that amount among the other compartments. The transfer rates assumed that plutonium moved through the body in a single pass. The material initially deposited in the lung was either excreted or moved to some other organ, from which it was excreted. It was assumed that there were no feedback loops in the system. Organ systems included lung, thoracic lymph notes, liver, skeleton, and all other tissues. The functions were estimated using weighted, nonlinear least squares. The weights were estimated by biweighting procedures that give the more extreme data values very little weight. The curves for liver were based on all dogs; dogs with $\leq 75 \mathrm{nCi}$ had less plutonium translocated to the liver.

The nine dogs euthanized because of radiation pneumonitis during the 3-year postexposure period had increased respiration rates, and hypercapnia and hypoxemia associated with lesions in the lungs. Intermittent anorexia and bocty weight loss accompanied the respiratory insufficiency. Histopathological examination of the lungs showed radiation pneumonitis characterized by focal 
TABLE 3. Summary of Leslons in Doge Euthanked During the $16-$ Year Period Atter Inhalation of ${ }^{239} \mathrm{PuO}_{2}$

Number of Doge/Oroup

Number of Dead Dogs/Group

Mean Survival Poet Expoeure, yeare

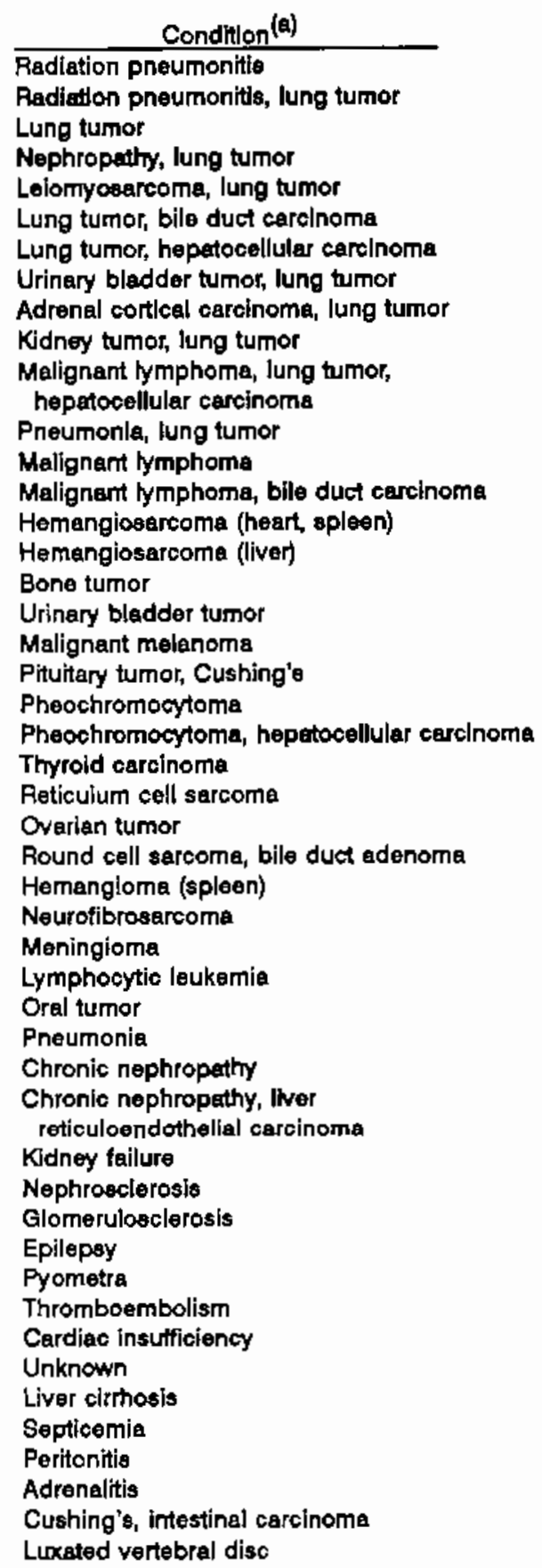

Dose Group

\begin{tabular}{rrrrrrr}
\hline$\underline{6}$ & $\underline{5}$ & $\underline{4}$ & $\underline{3}$ & $\underline{2}$ & $\underline{1}$ & Control \\
6 & 21 & 22 & 20 & 21 & 24 & 20 \\
8 & 21 & 22 & 20 & 21 & 24 & 20 \\
2 & 6 & 10 & 13 & 13 & 12 & 13
\end{tabular}

19

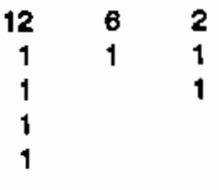

1

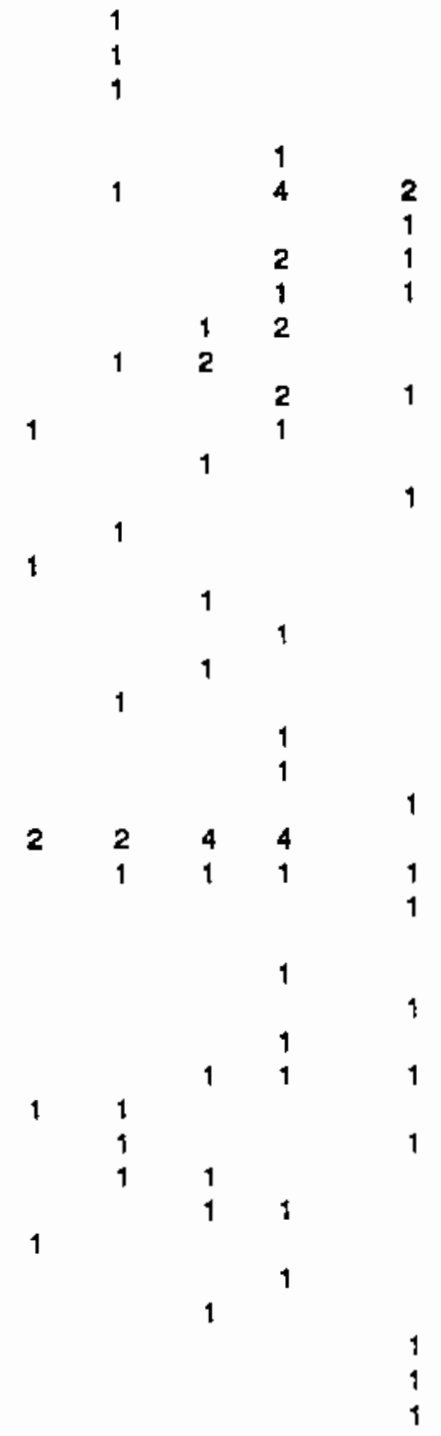

(a) Number of dogs with lesions associated with death. 
TABLE 4. Theoue Distrlbution of Plutonium In Beaglee After Inhalation of ${ }^{239} \mathrm{PuO}_{2}$

\begin{tabular}{|c|c|c|c|c|c|c|c|c|}
\hline \multirow[b]{2}{*}{$\begin{array}{l}\text { Dog } \\
\text { Number }\end{array}$} & \multirow[b]{2}{*}{$\begin{array}{l}\text { Time After } \\
\text { Exposure, } \\
\text { monthis }\end{array}$} & \multirow[b]{2}{*}{$\begin{array}{c}\text { Final Body } \\
\text { Burden, } \\
\ldots \mathrm{Ci} \\
\end{array}$} & \multicolumn{5}{|c|}{ Percent of Final Body Burden } & \multirow[b]{2}{*}{ Caupe of Death } \\
\hline & & & Lungs & $\begin{array}{l}\text { Thoracle } \\
\text { Lymph } \\
\text { Nodes (a) } \\
\end{array}$ & $\begin{array}{l}\text { Abdominal } \\
\text { Lymph } \\
\text { Nodes (b) } \\
\end{array}$ & Liver & Skeleloton & \\
\hline $478 M$ & 0.25 & 0.293 & 98 & 0.15 & 0.02 & 0.24 & 0.18 & Sacrlfice \\
\hline $435 F$ & 0.25 & 3.841 & 99 & 0.11 & 0.01 & 0.00 & 0.03 & Sacrifice \\
\hline $816 M$ & 0.50 & 0.399 & 99 & 0.52 & 0.01 & 0,00 & 0.03 & Sacrhice \\
\hline $918 M$ & 1 & 0.074 & 99 & 0.82 & 0.02 & 0.11 & 0.08 & Sacrifice \\
\hline $920 \mathrm{~F}$ & 1 & 0.011 & 94 & 0.47 & 0.03 & 0.08 & 0.61 & Sacrifice \\
\hline $913 \mathrm{M}$ & 1 & 4.849 & 98 & 1.1 & 0.00 & 0.00 & 0.05 & Sacrifice \\
\hline $702 \mathrm{~F}$ & 5 & 1.682 & 84 & 5,7 & 0.00 & 0.01 & 0.09 & Secrifice \\
\hline $709 \mathrm{M}$ & 5 & 1.726 & 97 & 2.2 & 0.00 & 01.00 & 0.05 & Sacrifice \\
\hline $734 \mathrm{M}$ & 5 & 0.914 & 96 & 3.4 & 0.00 & 0.01 & 0.05 & Sacriflce \\
\hline $739 F$ & 5 & 1.511 & 95 & 4.7 & 0.03 & $(1, \infty 0$ & 0.00 & Sacrifice \\
\hline $910 \mathrm{M}$ & 11 & 12.220 & 84 & 15 & 0.01 & 0.06 & 0.05 & Redletion pneumonitis \\
\hline $747 \mathrm{~F}$ & 12 & 5.434 & 71 & 29 & 0.03 & 0.07 & 0.07 & Radiation pneumonitis \\
\hline $906 \mathrm{~F}$ & 12 & 6.154 & 80 & 12 & 0.00 & $(1.03$ & 0.05 & Radiation pneumonltis \\
\hline $849 \mathrm{~F}$ & 13 & 0.0007 & 20 & 15 & 0.20 & 0.04 & 1.6 & Sacrifice \\
\hline $896 F$ & 15 & 4.115 & 81 & 15 & 0.92 & 0.23 & 0.12 & Radiatlon pneumonitls \\
\hline $817 \mathrm{M}$ & 21 & 3.794 & 64 & 34 & 0.13 & 1.4 & 0.19 & Radiation pneumonitis \\
\hline $815 \mathrm{M}$ & 25 & 0.074 & 64 & 32 & $\cdots$ & $(1,08$ & 0.10 & Secrifice \\
\hline $\mathrm{B} 29 \mathrm{M}$ & 26 & 3.198 & 75 & 19 & 0.79 & 4.2 & 0.45 & Radiation pneumonitis \\
\hline $760 \mathrm{M}$ & 31 & 0.978 & 71 & 23 & 0.57 & 5.7 & 0.28 & Radiation pneumonitis \\
\hline $890 F$ & 31 & 2.012 & 55 & 28 & 2.2 & 13 & 0.26 & Rediation pneumonitis \\
\hline $\mathrm{BOAM}$ & 37 & 1.101 & 62 & 29 & 0.19 & 7.9 & 0.36 & $\begin{array}{l}\text { Rediation pneumonitis, } \\
\text { lung tumor }\end{array}$ \\
\hline $798 F$ & 43 & 0.0056 & 55 & 44 & 0.02 & 61.17 & 0.43 & Sacrifice \\
\hline $772 M$ & 53 & 1.821 & 42 & 22 & 0.88 & $\mathbf{x}_{1}$ & 0.69 & Lung tumor \\
\hline $759 \mathrm{M}$ & 53 & 0.707 & 43 & 27 & 12 & $1 E$ & 0.65 & Lung tumor \\
\hline $796 F$ & 55 & 0.671 & 40 & 31 & 4.1 & 21 & 1.0 & Lung tumor \\
\hline $783 \mathrm{M}$ & 59 & 1.377 & 59 & 11 & 1.8 & 2 & 0.67 & Lung tumor \\
\hline $873 \mathrm{M}$ & 62 & 1.746 & 45 & 27 & 6.4 & 16 & 0.76 & Lung tumor \\
\hline $753 \mathrm{~F}$ & 69 & 1.171 & 35 & 31 & 0.09 & 24 & 0.84 & Lung tumor \\
\hline $761 \mathrm{M}$ & 69 & 1.064 & 36 & 37 & 6.3 & $1 \mathrm{~s}$ & 0.53 & Lung tumor \\
\hline $727 \mathrm{M}$ & 72 & 0.585 & 39 & 24 & 12 & 22 & 0.78 & Lung tumor \\
\hline $762 \mathrm{M}$ & 72 & $0.00 \div 7$ & 51 & 42 & 0.34 & C.71 & 0.66 & Sacrilice \\
\hline $837 \mathrm{M}$ & 72 & 1.034 & 42 & 38 & 0.70 & 14 & 0.46 & Lung tumor \\
\hline $863 F$ & 76 & 0.817 & 33 & 12 & 1.3 & 47 & 1.4 & Lung tumor \\
\hline $852 F$ & $n$ & 1.067 & 33 & 35 & 0.88 & $\mathbf{2 6}$ & 0.94 & Lung tumor \\
\hline $803 \mathrm{M}$ & 79 & 0.415 & 20 & 46 & 11 & $x$ & 1.4 & Interstitlel pneumonitis \\
\hline $875 M$ & 83 & 0.0026 & 24 & 66 & 0.34 & C.84 & 6.3 & Malignant kymphoma, kidnøy \\
\hline $754 M$ & 84 & 0.0046 & 29 & 66 & 0.23 & C.39 & 1.2 & Status epllepticus \\
\hline $835 F$ & 66 & 0.099 & 27 & 65 & 0.95 & 3.1 & 1.7 & Retculum cell sarcome \\
\hline $880 F$ & 66 & 0.468 & 19 & 31 & 13 & 34 & 0.37 & Lung tumor \\
\hline $769 F$ & 90 & 0.019 & 36 & 57 & 0.32 & 1.7 & 1.8 & Ovarian tumor \\
\hline $888 \mathrm{M}$ & 93 & 0.179 & 32 & 40 & 10 & 12 & 2.1 & Lung tumor \\
\hline $256 \mathrm{~F}$ & 94 & 0.308 & 40 & 45 & 0.78 & 9.0 & 3.9 & Lung tumor \\
\hline $889 F$ & 94 & 0.613 & 14 & 27 & 6.9 & 41 & 8.1 & Lung tumor \\
\hline $787 \mathrm{M}$ & 95 & 0.473 & 24 & 19 & 12 & 39 & 2.7 & Lung tumor \\
\hline $820 \mathrm{~F}$ & 96 & 0.387 & 14 & 40 & 7.6 & 29 & 1.4 & Lung turmor \\
\hline $834 F$ & 97 & 0.025 & 30 & 46 & 17 & 3.5 & 0.91 & Pyometre \\
\hline $752 \mathrm{M}$ & 88 & 0.055 & 24 & 62 & 1.2 & 7.7 & 0.98 & Lung tumor \\
\hline $864 \mathrm{~F}$ & 100 & 0.616 & 18 & 22 & 2.9 & 50 & 2.9 & Lung tumor \\
\hline $908 \mathrm{~F}$ & 101 & 0.0073 & 14 & $\overline{72}$ & 0.049 & 0.56 & 0.33 & Unknown \\
\hline $778 \mathrm{M}$ & 102 & 0.065 & 11 & 85 & 1.3 & 1.0 & 0.52 & Pulmonay thromboembolism \\
\hline $812 \mathrm{M}$ & 100 & 0.288 & 15 & 36 & 29 & 16 & 2.2 & Lung tumor \\
\hline
\end{tabular}

(a) Includes tracheobronchial, mediastinal, and sternal lymph noder.

(b) Includee hepatic, splenic, and mesenterlc lymph nodes. 
TABLE 4. Conthued

\begin{tabular}{|c|c|c|c|c|c|c|c|c|}
\hline \multirow[b]{2}{*}{$\begin{array}{l}\text { Dog } \\
\text { Number }\end{array}$} & \multirow[b]{2}{*}{$\begin{array}{l}\text { Time After } \\
\text { Exposure, } \\
\text { months. }\end{array}$} & \multirow[b]{2}{*}{$\begin{array}{c}\text { Final Body } \\
\text { Burden, } \\
\begin{array}{r}\mathrm{HCl} \\
\end{array}\end{array}$} & \multicolumn{5}{|c|}{ Percent of Finel Body Burden } & \multirow[b]{2}{*}{ Cause of Death } \\
\hline & & & Lungs & $\begin{array}{l}\text { Thoracic } \\
\text { Lymph } \\
\text { Nodes }(a)\end{array}$ & $\begin{array}{l}\text { Abdominal } \\
\text { Lymph } \\
\text { Nodeg (b) } \\
\end{array}$ & L Lver & Skgleton & \\
\hline $814 \mathrm{~F}$ & 104 & 0.054 & 49 & 33 & 4.1 & 10 & 1.6 & Lung tumor \\
\hline $840 F$ & 107 & 0.389 & 17 & 35 & 5.8 & 37 & 2.0 & Lung tumor \\
\hline $77 \mathrm{M}$ & 109 & 0.392 & 11 & 52 & 7.8 & 24 & 1.7 & Lung tumor \\
\hline $857 \mathrm{M}$ & 100 & 0.333 & 20 & 39 & 9.4 & 27 & 2.4 & Lung tumor \\
\hline $898 \mathrm{~F}$ & 111 & 0.333 & 10 & 34 & 28 & 21 & 3.4 & $\begin{array}{l}\text { Urinary bladder tumor, } \\
\text { lung tumor }\end{array}$ \\
\hline $899 \mathrm{~F}$ & 113 & 0.0066 & 7.5 & 87 & 0.14 & 0.27 & 1.6 & Hemanglosarcoma (heart) \\
\hline $697 \mathrm{M}$ & 114 & 0.141 & 15 & 64 & 8.1 & 9.9 & 1.4 & Cardiec Inoufitciency \\
\hline $809 \mathrm{M}$ & 115 & 0.444 & 16 & 46 & 11 & 25 & 1.2 & Lung tumor \\
\hline $824 \mathrm{~F}$ & 116 & 0.178 & 21 & 75 & 0.50 & 2.3 & 0.70 & Pneumorila \\
\hline $691 \mathrm{M}$ & 116 & 0.0023 & 11 & 64 & 0.064 & 0.48 & 1.5 & Septlcemia \\
\hline ESOM & 117 & 0.333 & 12 & 63 & 15 & 7.4 & 0.97 & Lung tumor \\
\hline $692 \mathrm{M}$ & 120 & 0.348 & 10 & 47 & 18 & $\infty$ & 3.7 & Lung tumor \\
\hline $784 M$ & 120 & 0.397 & 13 & 33 & 14 & 31 & 3.5 & Pitultary tumor, Cushing's \\
\hline $781 \mathrm{~F}$ & 122 & 0.034 & 37 & 59 & 0.25 & 1.1 & 0.72 & Kidney tumor, lung tumor \\
\hline $809 F$ & 120 & 0.120 & 12 & 36 & 18 & 28 & 3.3 & $\begin{array}{l}\text { Llver cirhosis, } \\
\text { thyroid tumor, Addleon's }\end{array}$ \\
\hline B54M & 124 & 0.435 & 12 & 66 & 15 & 3.8 & 1.3 & Lung tumor \\
\hline $807 \mathrm{~F}$ & 125 & 0.0021 & 10 & 71 & 0.55 & 1.2 & 1.3 & Pltuitary tumor, Cushing's \\
\hline $810 F$ & 126 & 0.219 & 5.9 & 43 & 20 & 22 & 1.8 & Lung tumor \\
\hline $900 \mathrm{M}$ & 126 & 0.0016 & 13 & 60 & 2.3 & 9.0 & 2.9 & $\begin{array}{l}\text { Round cell sarcoms, } \\
\text { bile duct adenoma }\end{array}$ \\
\hline $748 F$ & 127 & 0.0015 & 10 & 50 & 0.87 & 0.33 & 1.2 & Unknown \\
\hline $860 \mathrm{M}$ & 133 & 0.335 & 8,2 & 68 & B. 0 & 11 & 2.5 & Lung tumor \\
\hline $805 F$ & 134 & 0.169 & 5.6 & 55 & 8.9 & 21 & 2.8 & $\begin{array}{l}\text { Esophageal leiomyoma, } \\
\text { lung twmor }\end{array}$ \\
\hline $780 \mathrm{~F}$ & 135 & 0.0074 & 28 & 69 & 0.37 & 0.02 & 0.78 & Pheochromocytoma \\
\hline $905 \mathrm{~F}$ & 135 & 0.080 & 13 & 50 & 10 & 19 & 1.7 & Malignant lymphoma \\
\hline B25F & 137 & 0.0020 & 9.5 & 85 & 0.74 & 0,54 & 2.7 & Hemangiosarcoma, spleen \\
\hline $764 \mathrm{~F}$ & 139 & 0.081 & 15 & 75 & 3.9 & 4.9 & 0.73 & Lung tumor \\
\hline BOBF & 139 & 0.206 & 41 & 30 & 1.8 & 53 & 3.0 & Lung tumor \\
\hline $806 \mathrm{~F}$ & 140 & 0.010 & 11 & 78 & 1.8 & 5.1 & 2.3 & Melignent melanoma, pelate \\
\hline $850 \mathrm{~F}$ & 140 & 0.00062 & 12 & $\mathrm{B2}$ & 0.61 & 0.11 & 2.0 & Bone tumor \\
\hline $233 F$ & 143 & 0.157 & 3.1 & 40 & 22 & 31 & 1.1 & $\begin{array}{l}\text { Metritis, adrenal and } \\
\text { thyroid carcinoma }\end{array}$ \\
\hline $862 M$ & 145 & 0.0026 & 21 & 56 & 0.85 & 4.4 & 6.9 & Peritonitio \\
\hline $904 \mathrm{~F}$ & 145 & 0.0013 & B.9 & 87 & 0.30 & 0.88 & 1.0 & Chondrosercome \\
\hline $756 \mathrm{M}$ & 147 & 0.0016 & 15 & 75 & 1.0 & 1.6 & 4.1 & Epilepsy \\
\hline $782 \mathrm{M}$ & 148 & 0.049 & 12 & 72 & 4.9 & 9.0 & 0.86 & Neurofibrosarcoma \\
\hline $886 F$ & 149 & 0,00085 & 13 & 51 & 15 & 3.6 & 13 & Meningiome \\
\hline $795 \mathrm{~F}$ & 152 & 0.030 & 24 & 26 & 8.3 & 38 & 1.5 & Lung tumor \\
\hline $771 F$ & 153 & 0.019 & 20 & 71 & 1.0 & 5.8 & 1.1 & Lung tumor \\
\hline $813 F$ & 153 & 0.036 & 22 & 44 & 4.7 & 27 & 1.1 & Multilobar sarcorna, skull \\
\hline $\mathrm{B} 26 \mathrm{~F}$ & 153 & 0.0034 & 8.0 & 88 & 0,39 & 0.02 & 1.2 & Hemengiome, spleen \\
\hline B59M & 154 & 0.048 & 19 & 31 & 29 & 7.3 & 0.79 & Urinary bladder tumor \\
\hline $870 \mathrm{~F}$ & 154 & 0.00062 & B.2 & 70 & 4.9 & 9.6 & 4.8 & Pneumonis \\
\hline B79M & 154 & 0.00093 & 19 & 75 & 0.52 & 0.81 & 1,6 & Hemenglosercoma \\
\hline $884 M$ & 155 & 0.077 & 13 & 45 & 9.4 & 30 & 1.6 & Lung tumor \\
\hline $831 F$ & 155 & 0.0087 & 24 & 71 & 0.65 & 3.3 & 1.0 & Pneumonia \\
\hline $866 \mathrm{M}$ & 156 & 0.145 & 15 & 41 & 9.3 & 34 & 0.20 & $\begin{array}{l}\text { Lung tumor, } \\
\text { hepatocelluler carcinome }\end{array}$ \\
\hline $823 \mathrm{M}$ & 157 & 0.072 & 7.3 & 89 & 1.8 & 6.0 & 1.5 & Urinery biadder tumor \\
\hline
\end{tabular}

(a) Includea tracheobronchial, mediastinal, and sternel lymph nodee.

(b) Includes hapatic, aplenic, and mesarteric lymph nodes. 
TABLE 4. Continued

\begin{tabular}{|c|c|c|c|c|c|c|c|c|}
\hline \multirow[b]{2}{*}{$\begin{array}{l}\text { Dog } \\
\text { Number }\end{array}$} & \multirow[b]{2}{*}{$\begin{array}{l}\text { Time After } \\
\text { Exposure, } \\
\text { months } \\
\end{array}$} & \multirow[b]{2}{*}{$\begin{array}{c}\text { Final Body } \\
\text { Burden, } \\
. \quad \mathrm{Cl} \\
\end{array}$} & \multicolumn{5}{|c|}{ Percent of Final Body Burden } & \multirow[b]{2}{*}{ Cause of Death } \\
\hline & & & Lunge & $\begin{array}{l}\text { Thoracic } \\
\text { Lymph } \\
\text { Nodes }(\theta) \\
\end{array}$ & $\begin{array}{l}\text { Abdominal } \\
\text { Lymph } \\
\text { Noded (b) } \\
\end{array}$ & Llver & Skeleton & \\
\hline $838 M$ & 157 & 0.044 & $\$ 8.0$ & 73 & 0.77 & 5.4 & 1.4 & $\begin{array}{l}\text { Melignant hymphoma, } \\
\text { lung tumor, } \\
\text { hepatocellular carelnoma }\end{array}$ \\
\hline $783 \mathrm{M}$ & 158 & 0.0022 & $\not 2$ & 70 & 2.0 & 1.8 & 0.11 & Chronic nephropathy \\
\hline $845 \mathrm{~F}$ & 158 & 0.012 & 28 & 69 & 0.25 & 1,5 & 0.63 & Urinary bladder tumor \\
\hline 853M & 158 & 0.0081 & 13 & $\pi$ & 2.2 & 5.4 & 0.54 & Bronchopneumonia \\
\hline $750 \mathrm{M}$ & 161 & 0.071 & 20 & 51 & 13.0 & 9.5 & 2.4 & $\begin{array}{l}\text { Lung tumor, } \\
\text { malignant lymphoma }\end{array}$ \\
\hline $847 \mathrm{M}$ & 160 & 0.00061 & 22 & 75 & 0.15 & 0.60 & 1.2 & Kdney fallure \\
\hline $776 \mathrm{M}$ & 163 & 0.0020 & $\mathbf{2 9}$ & 67 & 0.11 & 1.2 & 1.1 & Bronchopneumonia \\
\hline $802 \mathrm{M}$ & 164 & 0.019 & 13 & 45 & 33 & 6.7 & 1.3 & Pneumonla \\
\hline $827 F$ & 164 & 0.075 & 4.5 & 49 & 17 & $: 17$ & 1.5 & Acute preumonia \\
\hline$B 74 M$ & 165 & 0.0048 & 5.6 & 90 & 0.54 & 1.4 & 0.58 & Chronic nephropethy \\
\hline $842 \mathrm{M}$ & 166 & 0.0054 & 4.7 & 90 & 0.76 & 3.2 & 0.75 & $\begin{array}{l}\text { Lung tumor, } \\
\text { chronic nephropathy }\end{array}$ \\
\hline $770 F$ & 166 & 0.0023 & 17 & 80 & 0.15 & 0.69 & 0.52 & Glomerulosclerosis \\
\hline $844 F$ & 170 & 0.097 & 19 & 50 & 8.9 & 19 & $\$ .3$ & Nephropathy, lung tumor \\
\hline $819 F$ & 170 & 0.085 & 18 & 42 & 4.2 & so & 3.0 & Nephropathy, lung tumor \\
\hline SO7F & 174 & 0.00097 & 7.4 & 69 & 1.2 & 0.78 & 0.61 & Pneumonia \\
\hline B76F & 175 & 0.0080 & 10 & 80 & $1, \bar{B}$ & 6.1 & 0.88 & Nephropethy, lung tumor \\
\hline $877 \mathrm{~F}$ & 175 & 0.011 & 13 & 79 & 2.2 & 3.8 & 0.70 & Lung tumor \\
\hline $857 M$ & 175 & 0.0027 & 23 & 52 & 5.8 & 16 & 1.6 & Malignamt tymphoma \\
\hline $893 \mathrm{M}$ & 17 & 0.0021 & 10 & 87 & 0.19 & 0.63 & 1.0 & Preumonla \\
\hline $839 F$ & 177 & 0.105 & 6.4 & 53 & 11 & 27 & 2.0 & $\begin{array}{l}\text { Lung tumor, } \\
\text { billa duet carcinoma }\end{array}$ \\
\hline $841 \mathrm{~F}$ & 178 & 0.0028 & 6.8 & 89 & 0.13 & 2.1 & 0.84 & Malignant lymphoma \\
\hline $832 F$ & 178 & 0.0020 & 8.3 & 87 & 0.17 & 1.5 & 0.88 & Malignant lymphoma \\
\hline $767 \mathrm{M}$ & 180 & 0.0088 & 33 & 64 & 0.22 & 1.1 & 0.96 & Valuler endocardiopethy \\
\hline $848 \mathrm{~F}$ & 180 & 0.047 & 9.8 & 80 & 4.9 & 3.7 & 0.80 & Acute pneumonia \\
\hline $871 M$ & 181 & 0.0028 & 10 & 86 & 0.59 & 1.6 & 1.0 & Malignent melanoma (orel) \\
\hline B51F & 182 & 0.025 & 15 & 77 & 1.7 & 1.8 & 1.2 & $\begin{array}{l}\text { Thyroid carcinoma, } \\
\text { hypothyroidism }\end{array}$ \\
\hline B65F & 182 & 0.00062 & 7.0 & 89 & 0.23 & i).92 & 1.5 & Acute pneumonia, lung tumor \\
\hline $797 f$ & 162 & 0.056 & 11 & 43 & 11 & 31 & 1.7 & Lung tumor \\
\hline $881 \mathrm{~F}$ & 182 & 0.0066 & 13 & 85 & 0.27 & 13.33 & 0.75 & Acute pneumonia \\
\hline $786 \mathrm{M}$ & 183 & 0.047 & 11 & 60 & 6.5 & 1i) & 1.4 & $\begin{array}{l}\text { Adrenocortical carcinoma, } \\
\text { lung tumor }\end{array}$ \\
\hline $858 \mathrm{M}$ & 183 & 0.00042 & 5.4 & 88 & 2.2 & $\cdot .6$ & 0.80 & Lymphocytic leukemia \\
\hline $757 \mathrm{M}$ & 191 & 0.018 & 58 & 30 & 2.8 & 6.4 & 1.6 & $\begin{array}{l}\text { Lejomyosercoma, kidney } \\
\text { and lung turnor }\end{array}$ \\
\hline B83M & 196 & 0.036 & 11 & 76 & 3.2 & 6.0 & 2.0 & Chronic nephropathy \\
\hline
\end{tabular}

(a) Includes trecheobronehial, mediastinal, and eternal lymph nodes.

(b) Includee hepatlc, eplenic, and meserteric lymph nodes.

interstitial and subpleural fibrosis, increased numbers of alveolar macrophages, alveolar epithelial hyperplasia, and foci of squamous metaplasia. Autoradiographs showed activity primarily composed of large stars, more numerous in areas of interstitial and subpleural fibrosis. One dog euthanized because of radiation pneumonitis also had a pulmonary tumor. of 116 exposed dogs euthanized 3 to 16 years after exposure, 52 had lung tumors. Four control dogs were euthanized because of lung tumors. Radiographic evidence of pulmonary neoplasia trequently preceded development of respiratory insufficiency. In dogs with neoplasia in the lung, respiratory insufficiency, when it was observed, was usually a late clinical finding that occurred 


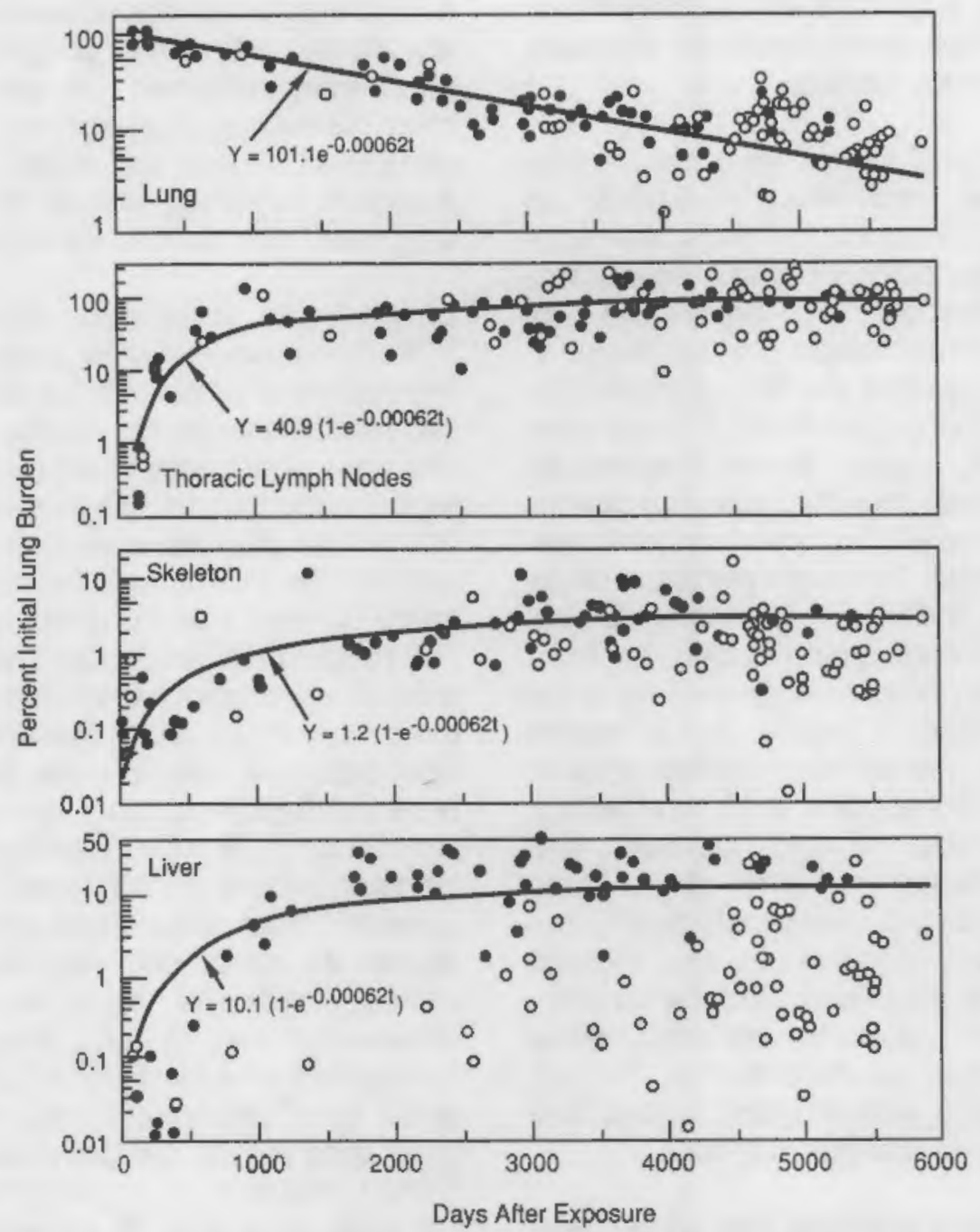

FIGURE 1. Plutonium in Tissues of Doge After inhalation of ${ }^{239} \mathrm{PuO}_{2}$. Points represent data from individual dogs (* $=\geq 75 \mathrm{nCl}$, $0=\leq 75 \mathrm{nCi}$ final body burden). Uptake and retention curves and function were based on dogs in which initial lung burdens were estimated from external thorex counts at 14 and 30 days after exposure. Curve for liver was based on all dogs.

shortly before euthanasia. Eleven of the dogs with lung tumors were euthanized for other causes.

Two dogs in dose-level 1 were euthanized 11.7 and 12.1 years, respectively, after exposure: one had an osteosarcoma involving the nasal cavity and maxilla; the other had a chondrosarcoma involving the nasal cavity. One dog in doselevel 2, euthanized 12.8 years atter exposure, had a multilobular sarcoma of the skull. No bone tumors were observed in the controls.

Two dose-level 4 dogs, one dose-level 3 dog, one dose-level $1 \mathrm{dog}$, and three control dogs had liver tumors (bile duct adenomas, bile duct carcinomas, hepatocellular carcinomas, or reticuloendothelial sarcomas) as incidental observations at necropsy not related to the cause of death. Three exposed dogs with incidental liver tumors also had lung tumors, and one was euthanized for other causes. The three control dogs also were euthanized for other causes. One dose-level 1 dog and one control dog died of liver hemangiosarcomas.

During the 7- to 16-year postexposure period, 51 exposed dogs died or were euthanized with causes presently thought to be unrelated to plutonium exposure; 22 died of various neoplastic diseases and 29 of various other causes. Of the control dogs, 4 were euthanized because of lung 
cancer, 1 of liver tumors, 3 with incidental liver tumors, 5 of various other neoplastic diseases, and 7 of various other causes.

In 23 dogs, the lung tumors were classified as bronchioloalveolar carcinoma; in 6 dogs, as adenosquamous carcinoma; in 9 dogs, adenocarcinoma; in 4 dogs, epidermoid and adenocarcinoma; in 4 dogs, epidermoid carcinoma; in 1 dog, epidermoid and bronchioloalveolar carcinoma; in 3 dogs, adenocarcinoma and bronchioloalveolar carcinoma; in 1 dog, epidermoid carcinoma, adenocarcinoma, and bronchioloalveolar carcinoma; and in another dog, adenocarcinoma, adenosquamous carcinoma, and bronchioloalveolar adenocarcinoma. The epidermoid carcinomas metastasized to the lungs, skeletons, brains, intestines, and thoracic lymph nodes; the bronchioloalveolar carcinomas metastasized only to the thoracic lymph nodes in $\mathbf{8}$ dogs, and to several organs (including mediastinum; kidney; thyroid; skeleton; heart; adrenal gland; aorta; and axillary, prescapular, cervical, splenic, thoracic, and hepatic lymph nodes) in 4 other dogs. Three adenosquamous carcinomas metastasized to thoracic lymph nodes, mediastinum, and thoracic pleura, and one to the hepatic and tracheobronchial lymph nodes. The adenocarcinomas metastasized to the lungs; tracheobronchial, hepatic, splenic, sternal and axillary lymph nodes; and heart, kidney, and esophagus in 5 dogs.

The lung tumors in the control dogs were classified as bronchioloalveolar adenocarcinomas in two dogs with metastase to thoracic and abdominal lymph nodes, trachea, esophagus, and mediastinum; adenocarcinoma with metastases to the diaphragm and abdominal lymph nodes in one dog; and combined epidermoid and adenocarcinoma with metastases to the thoracic lymph nodes, diaphragm, liver, and kidney in another.

Three of the exposed dogs had lesions of secondary hypertrophic osteoarthropathy. Sclerosing lymphadenopathy was associated with the high concentration of plutonium in the thoracic and hepatic lymph nodes of dogs in dose-level Groups 2, 3, 4, 5, and 6 . There was also a generalized lymphoid atrophy that may be related, in the dogs with respiratory insufficiency, to debilitation or to lymphopenia. Livers of the dogs in dose-level Groups 4 and 5, which were euthanized during the
4- to 13-year postexposure period, showed moderate, diffuse, centrilobular congestion. Liver cells in these areas contained fine, granular, yellow pigment resembling lipofuscin and were frequently vacuolated. Focal aggregation of vacuolated, lipofuscin-containing cells in the sinusoids was associated with alpha stars on autoradiographs.

Lymphopenia developed after inhalation of ${ }^{239} \mathrm{PuO}_{2}$ in dose-level groups with mean initial lung depositions of $79 \mathrm{nCi}$ or more (Figure 2). Through 123 months after exposure, mean lymphocyte values were significantly lower $(p<0.05)$ for doselevel Groups 3 and 4 than for the control group. At 127 months after exposure, mean lymphocyte values for dose-level Groups 3 and 4 were not significantly different from those of the control groups. The reduction in lymphocytes was dose related, both in time of appearance and magnitude. Over the course of this study, there has been a slight age-related decrease in mean lymphocyte values of control dogs. In addition, mean lymphocyte concentrations in Groups 3 and 4 have tended to increase, making the differences between control dogs and these groups less significant than previously. At mean lung depositions of 3.5 and $22 \mathrm{nCi}$, lymphocyte values were within ranges observed in control dogs. A reduction in total leukocytes was evident in the higher dose groups, which were also lymphopenic. No effects have been observed on red cell parameters following ${ }^{239} \mathrm{PuO}_{2}$ inhalation. By 14 years after exposure, too few dogs were alive for meaningful dose-group comparison.

Serum chemistry assays have been performed to detect organ-specific damage from plutonium that translocated from lung to extrapulmonary sites. No consistent dose-related alterations have occurred in serum constituents (glutamic pyruvic transaminase [GPT], glutamic oxaloacetic transaminase, alkaline phosphatase [ALP], urea nitrogen, and serum protein fractions) of dogs exposed to ${ }^{239} \mathrm{PuO}_{2}$.

Table 5 summarizes, by dose-level group, mortality and lesions associated with death through 15 years after exposure to ${ }^{238} \mathrm{PuO}_{2}$. During this period, all the dogs in the highest level dose group and in dose-level Groups 4 and 5, 21 dogs in Group 3, 19 dogs in Group 2, and 18 dogs in dose-level Group 1 were euthanized when death 

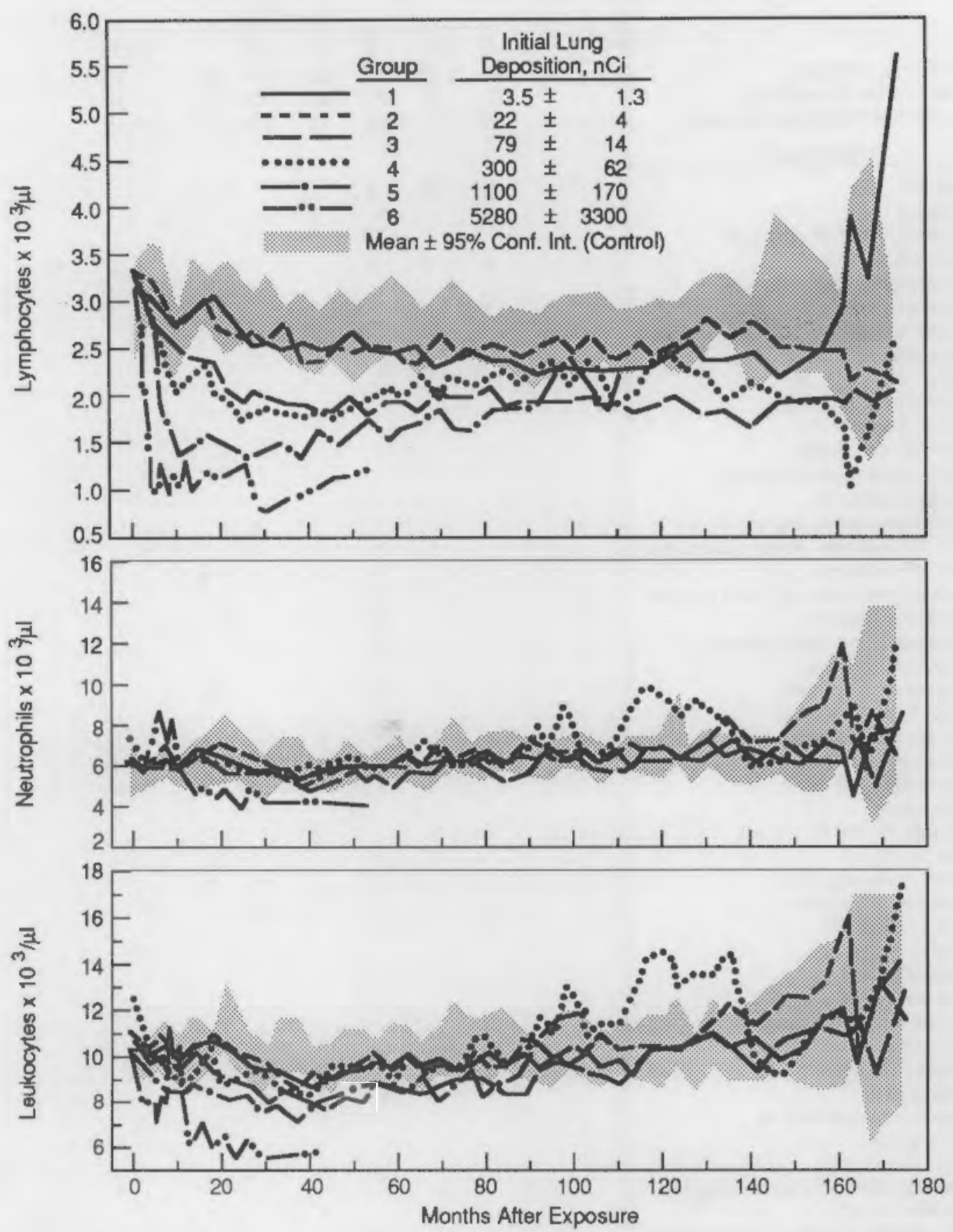

FIGURE 2. Mean Leukocyte, Neutrophil, and Lymphocyte Values in Dogs After Inhaletion of ${ }^{239} \mathrm{PuO}_{2}$

was imminent; 14 control dogs were also euthanized during the 15-year postexposure period. Mean survival time was decreased in the two highest dose-level groups compared to the other groups. Twenty-one dogs were sacrificed for comparison of plutonium tissue distribution. Table 6 shows the primary causes of death and the distribution of ${ }^{238} \mathrm{Pu}$ in the tissues of these animals as percent of final body burden. Figure 3 shows the plutonium tissue distribution as percent ILB. 
TABLE 5. Summary of Lesions in Dogs Euthanized During the 15 -Year Period After Inhalation of ${ }^{238} \mathrm{PuO}_{2}$

Number of Dogs/Group

Number of Dead Dogs/Group

Mean Survival Post Exposure, years

Condition (e)

Bone tumor

Lung tumor

Lung tumor, bile duct adenoma

Bone and lung tumor

Bone tumor, bile duct carcinoma

Bone tumor, Addison's disease

Bone and lung tumor, Addison's disease

Salivary squamous carcinoma,

lung tumor

Nasal sarcoma, lung tumor

Nasal carcinoma

Pneumonia, lung tumor

Malignant lymphoma, lung tumor,

cholangiocarcinoma

Malignant lymphoma, lung tumor

Malignant lymphoma, cholangiosarcoma

Malignant lymphoms

Malignant lymphoma, Addison's disease

Hemangioma (spleen)

Hemangiosarcoma (heart, spleen)

Fibrosarcoma (spleen)

Hemangiosarcoma (liver)

Hepatocellular carcinoma

Urinary bladder/urethra tumor

Urethra tumor, bile duct adenoma

Pituitary tumor, Cushing's

Pituitary tumor

Pneumonia, thyroid carcinoma

Thyroid carcinoma

Malignant melanoma (oral)

Malignant mesotheliome

Brain and heart tumor

Brain tumor

Perathyroid adenoma

Adrenal carcinome

Round cell sarcoma (kidney)

Adrenal and pitultary tumors

Lung tumor, metastatic

Pneumonia

Pulmonary interstitial fibrosis

Allergic bronchitis

Radiation pneumonitis

Renal emyloidosis, splenic hemangioma

Chronic nephropathy

Chronic nephropathy, bile duet adenoma

Addison's disease

Posterior paralysis

\begin{tabular}{|c|c|c|c|c|c|c|}
\hline \multicolumn{7}{|c|}{ Doas Croup } \\
\hline 6 & $\underline{5}$ & 4 & 3 & 2 & 1 & Control \\
\hline 13 & 20 & 20 & 22 & 21 & 20 & 20 \\
\hline 13 & 20 & 20 & 21 & 19 & 18 & 14 \\
\hline & 7 & 12 & 12 & 12 & 12 & 12 \\
\hline
\end{tabular}

Herniated vertebral disk

Spinal cord degenaration

Liver abscess

Hepatic dysplasia

Heart fallure

Immune hemolytic anemia

Pyometra

$\begin{array}{ll}2 & 11 \\ 3 & \\ 6 & 4 \\ 1 & \\ & 1\end{array}$

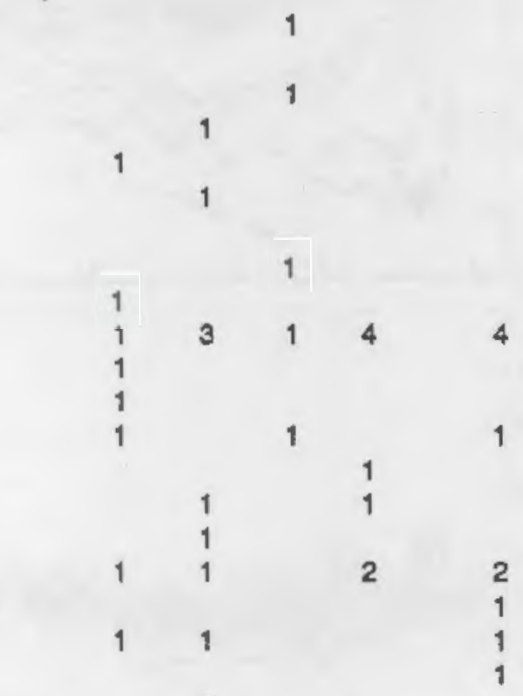

Aneethesie

(a) Number of dogs with lesion associated with death. 
TABLE 6. Thsoue Dietribution of Plutonium in Beaglee After Inhalation of ${ }^{238} \mathrm{PuO}_{2}$

\begin{tabular}{|c|c|c|c|c|c|c|c|c|}
\hline \multirow[b]{2}{*}{$\begin{array}{l}\text { Dog } \\
\text { Number }\end{array}$} & \multirow[b]{2}{*}{$\begin{array}{l}\text { Time After } \\
\text { Exposure, } \\
\text { months } \\
\end{array}$} & \multirow[b]{2}{*}{$\begin{array}{c}\text { Final Body } \\
\text { Burden, } \\
\text { } \mathrm{CI} \\
\end{array}$} & \multicolumn{5}{|c|}{ Percent of Final Body Burden } & \multirow[b]{2}{*}{ Cause of Death } \\
\hline & & & Lungs & $\begin{array}{l}\text { Thoracic } \\
\text { Lymph } \\
\text { Nodes }(a) \\
\end{array}$ & $\begin{array}{l}\text { Abdominal } \\
\text { Lymph } \\
\text { Nodes (b) } \\
\end{array}$ & Llver & Skeleton & \\
\hline $1032 \mathrm{M}$ & 0.25 & 0.150 & 97 & 0.34 & 0.20 & 1.7 & 0.16 & Sacrifice \\
\hline $921 \mathrm{~F}$ & 1 & 0.0044 & 93 & 0.65 & 0.04 & 0.38 & 2.1 & Sacrifice \\
\hline 930F & 1 & 0.052 & 99 & 0.63 & 0.01 & 0.07 & 0.35 & Secrifice \\
\hline $931 \mathrm{~F}$ & 1 & 0.347 & 96 & 1.9 & 0.01 & 0.05 & 0.36 & Sacrifice \\
\hline $929 \mathrm{~F}$ & 2 & 0.017 & 91 & 7.5 & 0.002 & 0.26 & 0.58 & Sacrifice \\
\hline $932 F$ & 2 & 0.382 & 96 & 2.5 & 0.01 & 0.18 & 0.39 & Sacrifice \\
\hline $923 F$ & 2 & 0.0023 & 88 & 9.4 & 0.03 & 0.09 & 0.44 & Sacrifice \\
\hline $925 \mathrm{M}$ & 3 & 0.0064 & 91 & 4.1 & 0.04 & 0.04 & 1.2 & Sacrifice \\
\hline $926 \mathrm{M}$ & 3 & 0.078 & 87 & 11 & 0.23 & 0.65 & 1.1 & Sacrifice \\
\hline $934 \mathrm{M}$ & 3 & 0.902 & 92 & 4.8 & 1.7 & 0.45 & 0.95 & Secrifice \\
\hline $1318 \mathrm{M}$ & 12 & 0.030 & 45 & 27 & 0.08 & 10 & 15 & Secrifice \\
\hline $1319 \mathrm{M}$ & 12 & 0.077 & 41 & 26 & 0.03 & 11 & 20 & Sacrifice \\
\hline $1214 \mathrm{M}$ & 13 & 0.014 & 52 & 9.2 & 0.32 & 6.2 & 16 & Sacrifice \\
\hline $1310 \mathrm{M}$ & 25 & 0.026 & 19 & 36 & 0.08 & 15 & 28 & Sacrifice \\
\hline $1317 \mathrm{M}$ & 25 & 0.041 & 20 & 33 & 0.16 & 17 & 26 & Sacrifice \\
\hline $1315 \mathrm{M}$ & 25 & 0.047 & 22 & 31 & 0.04 & 17 & 28 & Sacrifice \\
\hline $1191 \mathrm{~F}$ & 35 & 0.658 & 26 & 32 & 0.13 & 18 & 22 & Pneumonia \\
\hline $1215 \mathrm{M}$ & 36 & 0.011 & 21 & 43 & 0.17 & 13 & 21 & Secrifice \\
\hline $1311 M$ & 37 & 0.036 & 13 & 31 & 0.22 & 21 & 32 & Secrifice \\
\hline $994 \mathrm{~F}$ & 42 & 5.024 & 17 & 45 & 0.50 & 18 & 18 & Addison's disease \\
\hline $970 \mathrm{~F}$ & 48 & 0.0022 & 20 & 34 & 0.36 & 16 & 24 & Sacrifice \\
\hline $1312 \mathrm{M}$ & 49 & 0.035 & 6.8 & 29 & 0.26 & 25 & 35 & Sacrifice \\
\hline $1143 \mathrm{M}$ & 49 & 6.331 & 11 & 43 & 2.0 & 15 & 22 & Bone tumor, lung tumor \\
\hline $1025 \mathrm{M}$ & 50 & 10.033 & 16 & 27 & 7.1 & 24 & 23 & Lung tumor \\
\hline $1064 \mathrm{M}$ & 51 & 8.427 & 13 & 48 & 1.9 & 15 & 20 & Bone tumor, lung tumor \\
\hline $1175 \mathrm{~F}$ & 52 & 3.641 & 14 & 31 & 0.08 & 25 & 26 & Lung tumor \\
\hline $1079 \mathrm{M}$ & 56 & 2.182 & 9.8 & 40 & 4.3 & 13 & 25 & Addison's disease \\
\hline $1096 \mathrm{~F}$ & 59 & 1.204 & 4.3 & 22 & 2.7 & 36 & 24 & Addison'e disease \\
\hline $1189 \mathrm{M}$ & 60 & 0.044 & 8.9 & 25 & 0.16 & 37 & 25 & Sacrifice \\
\hline $1115 \mathrm{~F}$ & 61 & 1.534 & 5.0 & 32 & 2.3 & 26 & 33 & Bone tumor \\
\hline $1162 \mathrm{~F}$ & 61 & 3.663 & 12 & 32 & 5.9 & 21 & 25 & $\begin{array}{l}\text { Bone tumor, } \\
\text { Addison's disease }\end{array}$ \\
\hline $1009 \mathrm{M}$ & 62 & 4.360 & 15 & 25 & 2.4 & 31 & 23 & Lung tumor \\
\hline $974 \mathrm{~F}$ & 64 & 1.465 & 5.1 & 24 & 5.9 & 33 & 29 & Bone tumor \\
\hline $1092 M$ & 65 & 1.515 & 2.1 & 26 & 9.1 & 29 & 30 & Bone tumor \\
\hline $975 \mathrm{~F}$ & 66 & 3.749 & 11 & 30 & 2.1 & 28 & 25 & Bone tumor, lung tumor \\
\hline $1042 F$ & 69 & 1.494 & 4.7 & 25 & 2.9 & 32 & 33 & Bone tumor, lung tumor \\
\hline $1037 \mathrm{M}$ & 69 & 2.417 & 7.1 & 27 & 7.8 & 28 & 27 & Bone tumor \\
\hline $1027 \mathrm{M}$ & 70 & 2.546 & 3.8 & 15 & 7.0 & 40 & 31 & Bone tumor, lung tumor \\
\hline $1006 \mathrm{~F}$ & 72 & 2.826 & 7.5 & 30 & 3.4 & 29 & 26 & Bone tumor, lung tumor \\
\hline $1057 M$ & 72 & 1.748 & 3.0 & 35 & 2.2 & 33 & 24 & Bone tumor \\
\hline $1082 M$ & 78 & 0.0083 & 2.4 & 20 & 0.31 & 40 & 34 & Paralysis \\
\hline $1081 \mathrm{M}$ & 80 & 0.361 & 4.6 & 15 & 0.48 & 47 & 29 & Hemangiosarcoma (heart) \\
\hline $1058 \mathrm{~F}$ & 80 & 1.000 & 2.0 & 18 & 4.4 & 31 & 41 & Bone tumor, adrenal tumor \\
\hline $1002 M$ & 84 & 1.786 & 2.9 & 31 & 2.0 & 31 & 28 & Bone tumor, lung tumer \\
\hline $1109 \mathrm{~F}$ & 86 & 0.885 & 0.93 & 23 & 4.0 & 34 & 35 & $\begin{array}{l}\text { Bone tumor, } \\
\text { Addison's disease, } \\
\text { lung tumor }\end{array}$ \\
\hline $1218 \mathrm{~F}$ & 86 & 0.678 & 2.7 & 23 & 4.1 & 42 & 25 & Bone tumor \\
\hline $1071 \mathrm{M}$ & 91 & 1.088 & 5.4 & 28 & 3.4 & 27 & 39 & Bone tumor, lung tumor \\
\hline $1063 \mathrm{M}$ & 94 & 0.00060 & 3.4 & 15 & 1.3 & 22 & 43 & Brain tumor, heart tumor \\
\hline $1160 \mathrm{~F}$ & 95 & 0.956 & 1.6 & 21 & 0.91 & 43 & 30 & Bone tumor, lung tumor \\
\hline $960 \mathrm{M}$ & 95 & 0.036 & 4.0 & 21 & 0.49 & 33 & 39 & Malignant lymphoma \\
\hline
\end{tabular}

(a) Includes trecheobronchial, mediastinal, and sternal lymph nodes.

(b) Includes hepatic, splenic, and mesenteric lymph nodes. 
TABLE 6. Continued

\begin{tabular}{|c|c|c|c|c|c|c|c|c|}
\hline \multirow[b]{2}{*}{$\begin{array}{l}\text { Dog } \\
\text { Number }\end{array}$} & \multirow[b]{2}{*}{$\begin{array}{l}\text { Time After } \\
\text { Exposure, } \\
\text { months } \\
\end{array}$} & \multirow[b]{2}{*}{$\begin{array}{l}\text { Final Body } \\
\text { Burden, } \\
\mu \mathrm{Ci} \\
\end{array}$} & \multicolumn{5}{|c|}{ Percent of Final Body Burden } & \multirow[b]{2}{*}{ Cause of Death } \\
\hline & & & Lungs & $\begin{array}{l}\text { Thoracic } \\
\text { Lymph } \\
\text { Nodes (a) } \\
\end{array}$ & $\begin{array}{l}\text { Abdominal } \\
\text { Lymph } \\
\text { Nodes (b) } \\
\end{array}$ & Liver & Skeleton & \\
\hline $1040 \mathrm{M}$ & 96 & 0.059 & 3.0 & 17 & 0.96 & 40 & 35 & Parathyroid adenoma \\
\hline $1140 \mathrm{M}$ & 97 & 0.504 & 3.8 & 18 & 7.7 & 37 & 30 & Bone tumor \\
\hline $989 F$ & 99 & 0.0017 & 5.1 & 11 & 1.2 & 22 & 29 & Bone tumor (fibrosarcoma) \\
\hline $1211 M$ & 99 & 0.895 & 1.3 & 29 & 4.7 & 39 & 23 & Bone tumor \\
\hline $1173 \mathrm{M}$ & 99 & 0.462 & 2.0 & 33 & 7.5 & 21 & 33 & Bone tumor \\
\hline $1043 \mathrm{~F}$ & 103 & 0.037 & 3.5 & 16 & 0.57 & 33 & 42 & $\begin{array}{l}\text { Empyema, piturtary tumor, } \\
\text { Cushing's }\end{array}$ \\
\hline $1192 F$ & 109 & 0.345 & 2.4 & 7.3 & 4.6 & 36 & 46 & Bone tumor \\
\hline $1178 \mathrm{M}$ & 110 & 0.594 & 0.86 & 17 & 2.0 & 33 & 42 & Bone tumor, lung tumor \\
\hline $1047 M$ & 115 & 0.241 & 1.4 & 7.8 & 11 & 28 & 48 & Herniated vertebral disc \\
\hline $1106 \mathrm{~F}$ & 117 & 0.0029 & 1.3 & 16 & 1.8 & 9.9 & 57 & Adrenal carcinoma \\
\hline $1103 \mathrm{~F}$ & 118 & 0.232 & 0.76 & 18 & 3.1 & 45 & 32 & Bone tumor, lung tumor \\
\hline $1188 \mathrm{M}$ & 119 & 0.0089 & 0.71 & 2.5 & 0.94 & 68 & 24 & Metastatic lung tumor \\
\hline $1066 \mathrm{M}$ & 121 & 0.035 & 1.1 & 4.4 & 0.52 & 57 & 32 & Melignant lymphoma \\
\hline $1069 \mathrm{~F}$ & 121 & 0.0022 & 9.1 & 2.1 & 1.6 & 51 & 34 & Malignant lymphoma \\
\hline $1030 \mathrm{~F}$ & 122 & 0.160 & 1.5 & 15 & 1.1 & 22 & 56 & Pneumonia \\
\hline $951 \mathrm{M}$ & 122 & 0.0023 & 3.3 & 8.9 & 0.77 & 47 & 35 & Anesthesia \\
\hline $1229 \mathrm{M}$ & 123 & 0.0060 & 0.94 & 11 & 0.73 & 35 & 49 & Pneumonia \\
\hline $1072 M$ & 124 & 0.079 & 0.65 & 4.1 & 1.6 & 57 & 34 & Radiation pneumonitis \\
\hline $1157 \mathrm{M}$ & 124 & 0.294 & 0.55 & 3.5 & 3.7 & 41 & 44 & Bone tumor \\
\hline $971 F$ & 125 & 0.0095 & 1.7 & 5.5 & 0.44 & 49 & 41 & Hemangiosarcoma (spleen) \\
\hline $1078 \mathrm{~F}$ & 125 & 0.025 & 0.98 & 9.6 & 0.60 & 46 & 41 & Meningioma \\
\hline $952 \mathrm{~F}$ & 125 & 0.106 & 1.0 & 4.4 & 2.1 & 39 & 48 & Bone tumor \\
\hline $1059 \mathrm{~F}$ & 126 & 0.050 & 4.2 & 7.4 & 0.99 & 45 & 39 & Melignant lymphoma \\
\hline $991 \mathrm{~F}$ & 126 & 0.058 & 1.8 & 14 & 0.81 & 36 & 41 & Urinary bladder tumor \\
\hline $1070 \mathrm{M}$ & 126 & 0.011 & 1.9 & 9.5 & 0.70 & 51 & 34 & Found cell sercoma (kidney) \\
\hline $1166 \mathrm{M}$ & 128 & 0.354 & 1.8 & 11 & 1.6 & 47 & 35 & Malignant lymphoma \\
\hline $983 \mathrm{M}$ & 132 & 0.274 & 1.5 & 5.9 & 2.9 & 47 & 37 & Adrenal tumor, pituitary tumor \\
\hline $1035 \mathrm{~F}$ & 132 & 0.172 & 2.8 & 10 & 1.9 & 19 & 53 & Bone tumor, Cushing's \\
\hline $1031 \mathrm{~F}$ & 134 & 0.025 & 1.9 & 13 & 0.97 & 17 & 65 & Pneumonia \\
\hline $1190 \mathrm{~F}$ & 134 & 0.033 & 0.84 & 4.4 & 1.2 & 49 & 41 & Lung tumor \\
\hline $1062 M$ & 135 & 0.270 & 0.63 & 2.6 & 3.9 & 46 & 44 & Bone tumor, lung tumor \\
\hline $1177 M$ & 136 & 0.142 & 0.77 & 5.0 & 0.89 & 36 & 53 & Bone tumor \\
\hline $959 M$ & 138 & 0.0025 & 3.4 & 14 & 0.62 & 33 & 48 & Liver abscess \\
\hline 992F & 139 & 0.264 & 0.73 & 8.0 & 2.7 & 42 & 42 & Bone tumor \\
\hline $1194 \mathrm{~F}$ & 140 & 0.0014 & 0.67 & 10 & 9.0 & 20 & 56 & Malignant lymphoma \\
\hline $1105 \mathrm{~F}$ & 140 & 0.00074 & 0.62 & 5.6 & 0.70 & 44 & 45 & Malignant lymphoma \\
\hline 1193F & 141 & 0.0097 & 0.58 & 9.2 & 1.0 & 37 & 48 & Immune hemolytic anemia \\
\hline $973 \mathrm{~F}$ & 142 & 0.127 & 3.7 & 7.0 & 1.8 & 44 & 39 & Bone tumor \\
\hline $1060 \mathrm{~F}$ & 142 & 0.011 & 0.61 & 10 & 0.86 & 39 & 47 & Pneumonia \\
\hline $1114 M$ & 143 & 0.272 & 0.51 & 7.4 & 2.9 & 39 & 47 & $\begin{array}{l}\text { Bone tumor, bile duct } \\
\text { cercinoma }\end{array}$ \\
\hline $1222 \mathrm{M}$ & 143 & 0.0051 & 8.5 & 4.0 & 0.82 & 36 & 47 & $\begin{array}{l}\text { Malignant.mesothelioma } \\
\text { (mediastinal) }\end{array}$ \\
\hline $1053 \mathrm{~F}$ & 143 & 0.061 & 1.9 & 5.0 & 0.83 & 45 & 41 & Cushing's disease \\
\hline $1176 M$ & 145 & 0.051 & 0.39 & 5.9 & 0.90 & 52 & 38 & Hemangioma (spleen) \\
\hline $1309 \mathrm{M}$ & 146 & 0.019 & 1.4 & 4.8 & 0.96 & 46 & 44 & Hemangiosarcoma (liver) \\
\hline $1230 \mathrm{M}$ & 150 & 0.0027 & 0.34 & 12 & 1.2 & 41 & 41 & Hemangiosarcoma (liver) \\
\hline $1198 \mathrm{M}$ & 151 & 0.156 & 0.52 & 2.4 & 4.5 & 59 & 30 & Acute pnaumonia, lung tumor \\
\hline $1219 \mathrm{~F}$ & 152 & 0.020 & 0.76 & 8.4 & 0.97 & 34 & 50 & Chronic nephropethy \\
\hline $1220 \mathrm{~F}$ & 152 & 0.136 & 0.74 & 7.7 & 1.1 & 38 & 48 & $\begin{array}{l}\text { Malignant lymphoma, } \\
\text { Addison's }\end{array}$ \\
\hline $1165 \mathrm{M}$ & 152 & 0.042 & 0.66 & 7.8 & 1.6 & 47 & 39 & Acute pneumonia \\
\hline
\end{tabular}

(a) Includes trecheobronchisl, mediastinal, and stemal lymph nodes.

(b) Includes hepatic, splenic, and mesenteric lymph nodes. 
TABLE 6. Continued

\begin{tabular}{|c|c|c|c|c|c|c|c|c|}
\hline \multirow[b]{2}{*}{$\begin{array}{l}\text { Dog } \\
\text { Number }\end{array}$} & \multirow[b]{2}{*}{$\begin{array}{c}\text { Time After } \\
\text { Exposure, } \\
\text { months }\end{array}$} & \multirow[b]{2}{*}{$\begin{array}{l}\text { Final Body } \\
\text { Burden, } \\
\\
\end{array}$} & \multicolumn{5}{|c|}{ Percent of Flnal Body Burden } & \multirow[b]{2}{*}{ Ceuse of Death } \\
\hline & & & Lungs & $\begin{array}{l}\text { Thoracic } \\
\text { Lymph } \\
\text { Nodes (a) } \\
\end{array}$ & $\begin{array}{l}\text { Abdominal } \\
\text { Lymph } \\
\text { Nodes (b) } \\
\end{array}$ & Llver & Skeleton & \\
\hline $1008 \mathrm{M}$ & 153 & 0.00049 & 1.4 & 13 & 0.57 & 34 & 47 & Fibrosarcoma (spleen) \\
\hline $1033 \mathrm{M}$ & 154 & 0.0042 & 0.93 & 5.3 & 0.84 & 19 & 70 & Lung tumor \\
\hline $1026 \mathrm{M}$ & 154 & 0.072 & 0.99 & 4.2 & 0.46 & 51 & 40 & Hepatic dysplasia \\
\hline $1065 \mathrm{~F}$ & 154 & 0.0035 & 0.72 & 8.9 & 0.69 & 27 & 60 & $\begin{array}{l}\text { Malignant lymphome, } \\
\text { lung tumor }\end{array}$ \\
\hline $1216 \mathrm{M}$ & 156 & 0.0096 & 2.5 & 6.9 & 1.4 & 49 & 37 & Malignant lymphoma \\
\hline $982 \mathrm{M}$ & 157 & 0.067 & 1.5 & 4.2 & 0.79 & 52 & 37 & Pneumonia, thyroid carcinoma \\
\hline 999F & 157 & 0.0045 & 0.53 & 8.3 & 0.66 & 40 & 46 & Nasal sarcoma, lung tumor \\
\hline $972 \mathrm{~F}$ & 159 & 0.024 & 1.4 & 9.5 & 1.1 & 40 & 47 & Allergic bronchitis \\
\hline $998 \mathrm{M}$ & 159 & 0.0010 & 1.4 & 13 & 0.56 & 46 & 35 & Lung tumor \\
\hline $1050 F$ & 159 & 0.0075 & 0.57 & 7.3 & 1.3 & 39 & 48 & Lung tumor \\
\hline $997 \mathrm{M}$ & 160 & 0.112 & 5.7 & B.9 & 0.85 & 42 & 40 & Lung tumor \\
\hline $1056 \mathrm{M}$ & 160 & 0.060 & 0.58 & 2.1 & 1.5 & 37 & 56 & Pneumonia, thyroid carcinoma \\
\hline $1195 \mathrm{M}$ & 161 & 0.099 & 0.57 & 2.1 & 1.0 & 52 & 43 & $\begin{array}{l}\text { Chronic nephropathy, bile } \\
\text { duct adenoma }\end{array}$ \\
\hline $1091 \mathrm{~F}$ & 161 & 0.078 & 2.9 & 5.1 & 3.3 & 28 & 54 & Thyroid carcinoma \\
\hline $1039 \mathrm{M}$ & 162 & 0.00079 & 0.71 & 5.8 & 0.50 & 54 & 36 & Heart failure \\
\hline $993 F$ & 162 & 0.0052 & 0.39 & 9.6 & 1.0 & 26 & 59 & Malignant lymphoma \\
\hline $1108 \mathrm{~F}$ & 164 & 0.027 & 0.85 & 6.2 & 0.78 & 37 & 50 & Posterior paralysis \\
\hline $1316 \mathrm{M}$ & 165 & 0.026 & 1.2 & 3.1 & 0.61 & 53 & 39 & Posterior paralysis \\
\hline $1090 \mathrm{~F}$ & 167 & 0.0054 & 0.39 & 3.6 & 0.74 & 43 & 49 & Heart failure \\
\hline $955 \mathrm{M}$ & 169 & 0.0084 & 2.3 & 5.4 & 0.45 & 36 & 53 & $\begin{array}{l}\text { Lung tumor, bile duct } \\
\text { adenoma }\end{array}$ \\
\hline $1003 \mathrm{M}$ & 170 & 0.00031 & 1.1 & 11 & 0.85 & 40 & 42 & $\begin{array}{l}\text { Transition cell carcinoma } \\
\text { (urinary bladder) }\end{array}$ \\
\hline $1095 \mathrm{~F}$ & 170 & 0.00066 & 0.67 & 2.9 & 0.88 & 50 & 42 & Chronic nephropathy \\
\hline $1036 \mathrm{~F}$ & 170 & 0.0061 & 0.57 & 4.1 & 0.80 & 40 & 50 & Malignant melanoma (oral) \\
\hline $1004 \mathrm{M}$ & 171 & 0.072 & 1.5 & 9.9 & 1.2 & 48 & 36 & $\begin{array}{l}\text { Malignant lymphoma, lung } \\
\text { tumor, cholangiocarcinoma }\end{array}$ \\
\hline $1212 \mathrm{~F}$ & 172 & 0.022 & 1.1 & 8.8 & 1.1 & 34 & 51 & Hepetocellular carcinoma \\
\hline $1055 \mathrm{M}$ & 172 & 0.00073 & 0.87 & 9.5 & 1.2 & 47 & 39 & Malignant melanoma (oral) \\
\hline $1221 \mathrm{~F}$ & 173 & 0.016 & 0.80 & 7.7 & 0.71 & 22 & 64 & $\begin{array}{l}\text { Malignant lymphoma, } \\
\text { cholangiosarcoma }\end{array}$ \\
\hline $1207 \mathrm{~F}$ & 174 & 0.012 & 0.76 & 2.7 & 0.45 & 62 & 32 & Herniated vertebral disc \\
\hline $1158 \mathrm{M}$ & 175 & 0.029 & 0.54 & 2.7 & 0.54 & 60 & 33 & Nasal carcinoma \\
\hline $1046 \mathrm{M}$ & 178 & 0.0091 & 1.7 & 4.7 & 0.65 & 46 & 43 & Lung tumor \\
\hline $1196 \mathrm{~F}$ & 178 & 0.0078 & 0.71 & 4.5 & 0.58 & 45 & 46 & $\begin{array}{l}\text { Salivary squamous carcinome, } \\
\text { lung tumor }\end{array}$ \\
\hline $1000 \mathrm{~F}$ & 179 & 0.018 & 0.55 & 3.5 & 0.61 & 54 & 39 & $\begin{array}{l}\text { Transitional cell carcinoma } \\
\text { (urinary bladder) }\end{array}$ \\
\hline $1204 \mathrm{M}$ & 180 & 0.0038 & 0.56 & 7.4 & 0.53 & 34 & 53 & $\begin{array}{l}\text { Transitional cell carcinoma } \\
\text { (Urethra) }\end{array}$ \\
\hline
\end{tabular}

(a) Includes tracheobronchial, mediastinal, and starnal lymph nodes.

(b) Includes hepatic, splenic, and mesenteric lymph nodes.

At 14 to 15 years after exposure, the fraction of the final body burden in the lungs of the ${ }^{238} \mathrm{Pu}$ exposed dogs was $\sim 1 \%$, compared to $16 \%$ in the ${ }^{239}$ Pu-exposed dogs (Table 6 ). At that time, $\sim 6 \%$ of the ${ }^{238} \mathrm{Pu}$ was in the thoracic lymph nodes, compared to $69 \%$ of the ${ }^{239} \mathrm{Pu}$. Livers of the ${ }^{238} \mathrm{Pu}$ exposed dogs contained $44 \%$ of the plutonium burden, compared to $7 \%$ in the livers of the ${ }^{239}$ Pu-exposed dogs. About $45 \%$ of the final body burden was in the skeletons of the ${ }^{238} \mathrm{Pu}$-exposed dogs, at that time, compared to $\sim 1 \%$ in the ${ }^{239} \mathrm{Pu}$ exposed dogs. Tissue distribution of ${ }^{238} \mathrm{Pu}$ in low-dose-level dogs did not differ from that in high-dose-level dogs. Figure 3 shows the ${ }^{238} \mathrm{Pu}$ 

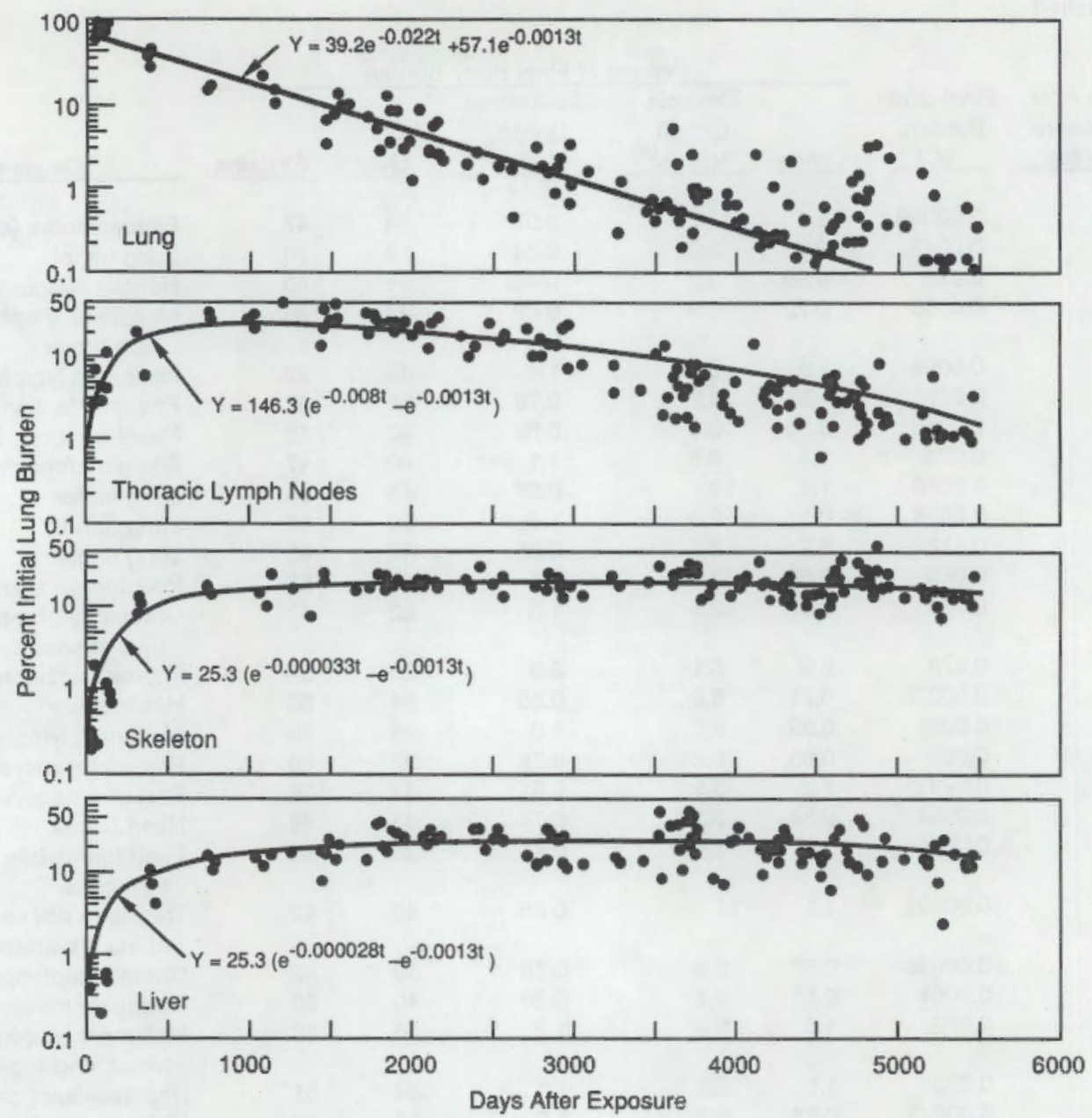

FIGURE 3. Plutonium in Tissues of Dogs After Inhalation of ${ }^{238} \mathrm{PuO}_{2}$. Points represent data from individual dogs. Uptake and retention curves and functions were based on dogs in which initial lung burdens were estimated from the final plutonium body burden, plus the plutonium excreted, minus that excretad in the feces during first 3 days after exposure or from external thorax counts at 14 and 30 days after exposure.

tissue distribution as percent of ILB for all dogs for which tissue radiochemical analyses are complete. The ILB and uptake and retention curves were estimated as described previously for ${ }^{239} \mathrm{Pu}$. The uptake and retention curves were based on dogs in which ILB were estimated from the final plutonium body burden, plus the plutonium excreted, minus that excreted in the feces during the first $\mathbf{3}$ days after exposure.

Of the 111 exposed dogs euthanized, 33 were killed because of bone tumors, 10 because of lung tumors, and 1 because of radiation pneumonitis. Thirteen of the dogs that had bone tumors also had lung tumors. Five dogs with lung tumors were euthanized for other causes; also, 1 control dog was euthanized for a lung tumor. Of 33 dogs with bone tumors, 31 had osteosarcomas; 1 dose-level Group 1 dog (989F) had a fibrosarcoma in the ilium, and 1 dose-level Group 4 dog (1103F) had a fibrosarcoma in a vertebra. None of the control dogs had bone tumors. All the exposed dogs with osteosarcomas were in dose-level Groups 4, 5, and 6. Lung tumors were observed in all doselevel groups. Of the 31 osteosarcomas, 13 were in vertebrae, 2 in femora, 4 in ribs, 3 in scapulae, 5 in the pelvis, 1 in the tibia, 1 in the sternum, 1 in the sacrum, and 1 in the humerus. 
One dose-level 3 dog died of hepatocellular carcinoma; one dose-level 1 and one dose-level 3 dog died of hemangiosarcomas in the liver. Three dose-level 4 dogs, one dose-level $3 \mathrm{dog}$, one dose-level 2 dog, and one control dog had bile duct carcinomas or adenomas as incidental observations at necropsy not related to the cause of death. Three exposed dogs with incidental liver tumors also had lung or bone tumors, and two were euthanized for other causes. The one control dog with liver tumors was also euthanized for other causes.

During the 3 to 15 years after exposure, 57 exposed dogs died or were euthanized as a result of causes presently thought to be unrelated to plutonium exposure; 31 died of various neoplastic diseases, and 26 of various other causes. One control dog was euthanized because of lung tumors, 1 of incidental liver tumors, 9 of various neoplastic diseases, and 3 of various other causes.

The lung tumors were classified as bronchioloalveolar carcinomas in 16 dogs, bronchioloalveolar adenoma in 1 dog, adenocarcinoma in 5 dogs, adenosquamous carcinoma in 4 dogs and epidermoid carcinoma in $1 \mathrm{dog}$. In one dog, three lung tumor types were observed: bronchioloalveolar, adenocarcinoma, and fibrosarcoma. Metastases were observed in the lungs; thoracic, hepatic, mesenteric, and axillary lymph nodes; vertebra; esophagus; stomach; liver; and adrenal of 1 dog with bronchioloalveolar carcinoma. Metastases were observed in the lungs; thoracic, hepatic, and splenic lymph nodes; trachea; esophagus; mediastinum; thyroid; diaphragm; and hearts of 2 dogs with pulmonary adenocarcinoma. One dog with adenosquamous carcinoma had metastases to the lung, thoracic lymph nodes, and heart. The dog with epidermoid carcinoma had metastases to the lungs, thoracic lymph nodes, and diaphragm. Bone tumor metastases were found in the lungs of 6 dogs; in 3 dogs, the bone tumor metastasized to lungs, thoracic lymph nodes, liver, spleen, and heart; in $1 \mathrm{dog}$, the bone tumor metastasized to the iliac lymph nodes; and in $1 \mathrm{dog}$, the bone tumor metastasized to the lungs, pleura, diaphragm and heart. The 6 dogs with Addison's disease, which were in dose-level Groups 4, 5, and 6 , had adrenal cortical atrophy.
In addition to the lesions associated with the cause of death, lesions in the lungs of the doselevel Groups 4, 5, and 6 dogs included focal alveolar histocytosis, alveolitis, alveolar epithelial cell hyperplasia, alveolar emphysema, pleural fibrosis, and interstitial fibrosis. Numerous alpha stars were observed, mainly in foci of fibrosis, and single alpha tracks were scattered throughout sections in foci of alveolar histocytosis and in alveolar septa. Sclerosing lymphadenopathy in the tracheobronchial and mediastinal lymph nodes was associated with high concentrations of plutonium observed as alpha stars in dose-level Groups 3, 4, 5, and 6. Similar but less severe lesions were seen in the hepatic lymph nodes. In dose-level Groups $\mathbf{5}$ and 6 , there were extensive alterations in bone, including multiple areas of focal atrophy of bone; endosteal, trabecular, and peritrabecular bone fibrosis; and osteolysis of cortical, endosteal, and trabecular bone. One dog had lesions of secondary hypertrophic osteoarthropathy.

Radioactivity in the bone was present as single tracks, generally scattered throughout the bone, cartilage, and bone marrow. The liver contained foci of hepatocellular fatty change, where small clusters of single tracks were seen. There was also mild, focal, nodular hyperplasia of hepatocytes in dose-level Groups 3, 4, 5, and 6. Elevated serum GPT levels, suggestive of liver damage, were observed in dose-level Groups 3, 4, 5, and 6 dogs.

Dose-related lymphopenia was observed in groups with mean lung ${ }^{238} \mathrm{PuO}_{2}$ deposition of $77 \mathrm{nCl}$ or more (Figure 4). The lymphocyte depression was more pronounced in magnitude and appeared earlier than in dogs exposed to similar doses of ${ }^{239} \mathrm{PuO}_{2}$. Through 126 months after exposure, mean lymphocyte values were significantly lower $(0<0.05)$ for dose-level Groups 4 and 5 than for the control group. However, lymphocyte values in the ${ }^{238} \mathrm{PuO}_{2}$-exposed dogs tended to increase sooner after reaching a minimum than in ${ }^{239} \mathrm{PuO}_{2}$-exposed dogs, and mean lymphocyte concentrations in Group 3 dogs were not significantly different from values of control dogs 86 to 94 months after exposure. As with ${ }^{239} \mathrm{Pu}$, lymphocyte values in the two lowest exposure groups (2.3 and $18 \mathrm{nCi}$ ) were not different from control values. A dose-related reduction in total leukocytes was 

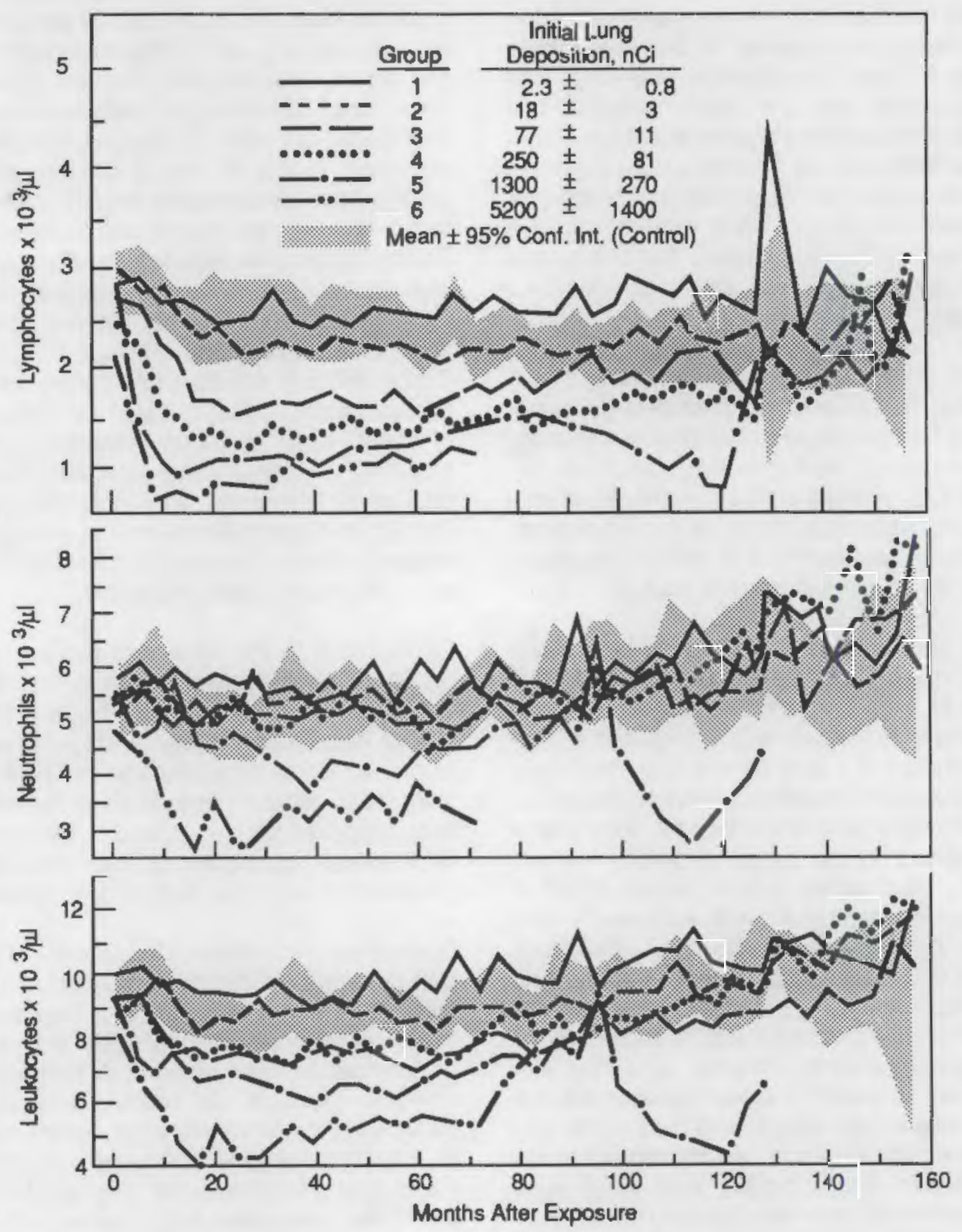

FIGUAE 4. Mean Leukocyle, Neutrophil, and Lymphocyte Values in Dogs After inhalation of ${ }^{238} \mathrm{PuO}_{2}$ 
evident, primarily because of lymphopenia, except in Groups 5 and 6, in which neutropenia was also observed. Through 118 months after exposure, mean leukocyte and neutrophil values were significantly lower $(0<0.05)$ for dose-level Group 5 than for the control group. No difference in monocyte values was seen in relation to dose levels. A significant and progressive reduction in eosinophils was evident only in Group 6 dogs following ${ }^{238} \mathrm{PuO}_{2}$ inhalation. No chronic effects have been observed in red cell parameters. By 14 years after exposure, too few dogs were alive for meaningful dose-group comparisons.

Lymphopenia, the earliest observed effect after inhalation of either ${ }^{239} \mathrm{PuO}_{2}$ or ${ }^{238} \mathrm{PuO}_{2}$, occurred after deposition of $\sim 80 \mathrm{nCi}$ plutonium in the lungs. On a concentration basis, the $80-\mathrm{nCi}$ dose level is about 40 times the $16-\mathrm{nCi}$ maximum permissible human lung deposition, based on 0.3 rem/week to the lung. Lymphopenia is thought to be related to the plutonium content of the tracheobronchial lymph nodes. Dose-level groups with initial lung burdens of $\sim 80 \mathrm{nCi}$ had lymphocyte counts less than controls by 12 months after exposure when the cumulative average lymph node doses were $\sim 320$ rad. Because of continuing transfer of plutonium to the lymph nodes, the dose rate at this time had increased to 620 rad per year.

In serum chemistry assays of ${ }^{238} \mathrm{PuO}_{2}$ dogs performed more than 120 months after exposure, ALP and GPT values were higher than those of the control group only in dose-level Groups 3, 4, and 5 dogs (Figure 5). For individual dogs, these elevations were biphasic with an early increase followed by a return to control values; a later effect was characterized by persistent increasing elevations of both ALP and GPT. Calculation of the cumulative average radiation dose to mean time after exposure when serum chemistry values were first observed to be different from controls for dose-level 4 and 5 dogs revealed a mean dose to liver of about 200 rad for the late effect. At this time the dose rate was $\sim 60$ rad per year. Elevations in GPT were consistent with liver histopathological findings and radiochemical analyses indicating ${ }^{238} \mathrm{PuO}_{2}$ translocation to the liver. Determination of gamma glutanyl transpeptidase concentrations and sulfobromphthalien sodium retention confirmed the presence of hepatic injury without functional impairment in dogs with chronically elevated GPT values. Alkaline phosphatase elevations occurred in some dogs with primary bone tumors and in others in which the increase was attributable to the liver (by heat inactivation of $A L P$ ) as the source of the largest portion of the ALP.

Using the uptake and retention curves shown in Figures 1 and 3 , cumulative radiation doses to death were estimated for the lungs of the ${ }^{239} \mathrm{Pu}$ dogs and the lungs and skeletons of the ${ }^{238} \mathrm{Pu}$ dogs (Table 7). For the dose calculations, mean plutonium concentration in the entire lung and skeleton was used. 


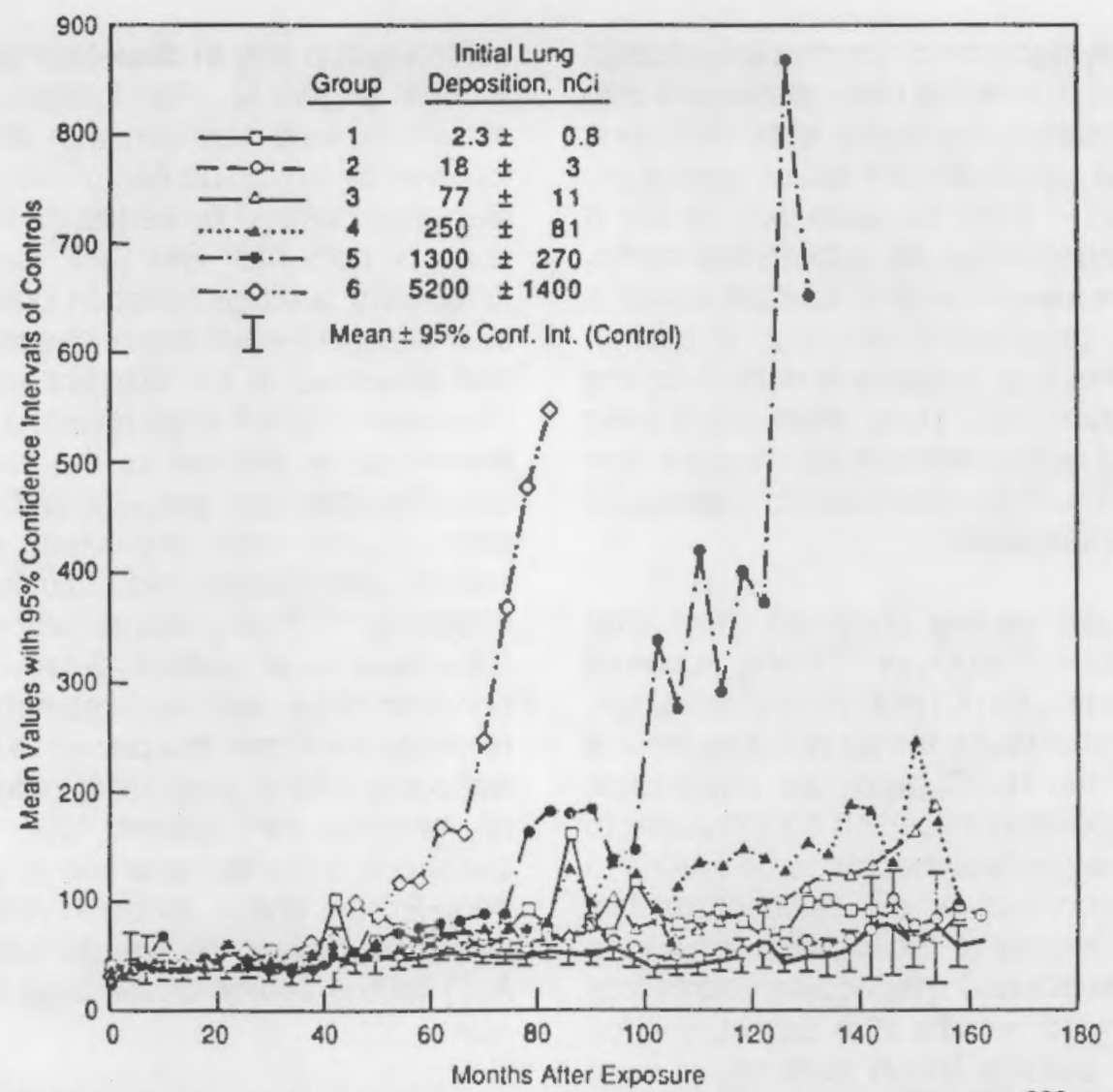

FIGUAE 5. Serum Glutamic Pyruvate Transerninase Values in Dogs After Inhaletion of ${ }^{230_{\mathrm{PuO}}}$

TABLE 7. Estimates of Cumulative Radiation Doses to Lungs (239 Pu-Exposed) or Lungs and Skeletone (233 PurExposed) of Dogs with Lung and/or Bone Tumors After Inhalation Exposure

\begin{tabular}{|c|c|c|c|c|}
\hline & $\begin{array}{l}\text { Dose Level } \\
\text { Group }\end{array}$ & $\begin{array}{l}\text { Number of Dogs } \\
\text { with Tumors }\end{array}$ & $\begin{array}{c}\text { Survival Time } \\
\text { Postexposure, months }\end{array}$ & $\begin{array}{l}\text { Cumulative Dose } \\
\text { to Organ, rad }\end{array}$ \\
\hline \multirow{6}{*}{${ }^{233} \mathrm{PuO}_{2}$ - Lung Tumors } & 6 & 1 & 69 & $7400^{(a)}$ \\
\hline & 5 & 20 & $37-115$ & $1700-4000$ \\
\hline & 4 & 16 & $93-177$ & $500-1500$ \\
\hline & 3 & 10 & $98-183$ & $150-480$ \\
\hline & 2 & 4 & $166 \cdot 191$ & $30-120$ \\
\hline & 1 & 1 & 182 & 4 \\
\hline \multirow[t]{6}{*}{${ }^{238} \mathrm{PuO}_{2}$ - Lung Tumoro } & 6 & 9 & $49-84$ & $2100-8900^{(a)}$ \\
\hline & 5 & 5 & $70-110$ & $1200-2600$ \\
\hline & 4 & 4 & $118-160$ & $190-440$ \\
\hline & 3 & 2 & $134-171$ & $70-100$ \\
\hline & 2 & 7 & $154-178$ & $7-33$ \\
\hline & 1 & 1 & 159 & 2 \\
\hline \multirow{6}{*}{${ }^{238} \mathrm{PuO}_{2}$ - Bone Tumors } & 6 & 9 & $49-84$ & $170-470^{(b)}$ \\
\hline & 5 & 16 & $61-132$ & $80-230$ \\
\hline & 4 & 7 & $118 \cdot 143$ & $40-110$ \\
\hline & 3 & 0 & 0 & - \\
\hline & 2 & 0 & 0 & - \\
\hline & 1 & 1 & 99 & $<1$ \\
\hline
\end{tabular}

(a) Dose to lungs.

(b) Dose to skeleton. 


\title{
Inhaled Plutonium Nitrate in Dogs
}

\section{Principal Investigator: G. E. Dagle}

\author{
Other Investigators: R. R. Adee, R. L. Buschbom, K. M. Gideon, E. S. Gilbert, \\ G. J. Powers, H. A. Ragan, C. O. Romsos, C. R. Watson, \\ R. E. Weller, and E. L. Wierman
}

\section{Technical Assistance: K. H. Debban, R. F. Flores, B. B. Kimsey, B. G. Moore, A. P. Schumacher, and M. J. Steele}

The major objective of this project is to determine dose-effect relationships of inhaled plutonium nitrate in dogs to aid in predicting health effects of accidental exposure in man. For lifespan dose-effect studies, beagle dogs were given a single inhalation exposure to ${ }^{239} \mathrm{Pu}\left(\mathrm{NO}_{3}\right)_{4}$ in 1976 and 1977 . The skeleton is generally considered the critical tissue with inhaled soluble plutonium that translocates to bone surfaces. Thus far, 12 years after exposure, 27 of 66 exposed dogs had bone tumors, 27 had lung tumors, and 5 had intrahepatic bile duct tumors.

The skeleton is generally considered the critical tissue after inhalation of "soluble" plutonium (e.g., plutonium nitrate), on the assumption that the plutonium will be rapidly translocated from the respiratory system to the skeleton. In several rodent studies, however, inhalation of "soluble" plutonium has resulted primarily in lung tumors. Skeletal tumors were seen less often, perhaps because they were not expressed within the short lifespan of the rodents. Therefore, beagle dogs were chosen for this study to compare relative risks with those from intravenously injected radionuclides in beagles at the University of Utah, inhalation studies with beta-, gamma-, and alpha-emitting radionuclides at the Inhalation Toxicology Research Institute (Lovelace), and external irradiation at the University of California (Davis) and at Argonne National Laboratory. More specifically, this study can be compared with inhaled ${ }^{239} \mathrm{PuO}_{2}$ and ${ }^{238} \mathrm{PuO}_{2}$ studies in beagle dogs at PNL (see Inhaled Plutonium Oxide in Dogs, this volume).

Six dose groups (105 dogs) were exposed, in 1976 and 1977 , to aerosols of ${ }^{239} \mathrm{Pu}\left(\mathrm{NO}_{3}\right)_{4}$ for lifespan observations (Table 1). In addition, 20 dogs were exposed to nitric acid aerosols as vehicle controls; 25 dogs were exposed to aerosols of ${ }^{239} \mathrm{Pu}\left(\mathrm{NO}_{3}\right)_{4}$ for periodic sacrifice to obtain plutonium distribution and pathogenesis data in developing lesions; 7 dogs were selected as controls for periodic sacrifice; and 20 dogs were selected as untreated controls for lifespan observations. The Appendix (at the end of this volume of the Annual Report) shows the current status of each dog on these experiments.

The average amount of plutonium in the lung decreased to less than $1 \%$ of the final body burden in dogs surviving 10 years or more (Table 2).

TABLE 1. Lifespen Dose-Effect Studies with Inhaled ${ }^{239} \mathrm{Pu}\left(\mathrm{NO}_{3}\right)_{4}$ in Beagles $(\mathrm{a})$

\begin{tabular}{|c|c|c|c|c|}
\hline \multirow{2}{*}{$\begin{array}{l}\text { Dose } \\
\text { Level } \\
\text { Group }\end{array}$} & \multicolumn{2}{|c|}{$\begin{array}{c}\text { Number of } \\
\text { Dogs }\end{array}$} & \multicolumn{2}{|c|}{ Initial Lung Deposition (b) } \\
\hline & Male & Female & $\mathrm{nCl}^{(\mathrm{C})}$ & $\mathrm{nCl} / \mathrm{g}$ Lung ${ }^{(C)}$ \\
\hline Control & 10 & 10 & 0 & 0 \\
\hline Vehicle & 10 & 10 & 0 & 0 \\
\hline 1 & 10 & 10 & $2 \pm 2$ & $0.02 \pm 0.02$ \\
\hline 2 & 10 & 10 & $8 \pm 4$ & $0.06 \pm 0.04$ \\
\hline 3 & 10 & 10 & $56 \pm 17$ & $0.5 \pm 0.2$ \\
\hline 4 & 10 & 10 & $295 \pm 67$ & $2 \pm 0.8$ \\
\hline 5 & 10 & 10 & $1709 \pm 639$ & $14 \pm 6$ \\
\hline 6 & 3 & 2 & $5445 \pm 1841$ & $47 \pm 17$ \\
\hline
\end{tabular}

(a) Exposed in 1976 and 1977.

(b) Estimated from external thoracic counts at 2 weeks postexposure and estimated lung weights $(0.011 \mathrm{x}$ body woight).

(c) Mean \pm standard deviation. 
TABLE 2. Tissue Distribution of Plutonium in Beagles After Inhalation of ${ }^{239} \mathrm{Pu}\left(\mathrm{NO}_{3}\right)_{4}$

\begin{tabular}{|c|c|c|c|c|c|c|c|c|}
\hline \multirow[b]{2}{*}{$\begin{array}{l}\text { Dog } \\
\text { Number }\end{array}$} & \multirow[b]{2}{*}{$\begin{array}{l}\text { Time After } \\
\text { Exposure } \\
\text { months (a) } \\
\end{array}$} & \multirow[b]{2}{*}{$\begin{array}{l}\text { Final Body } \\
\text { Burden, } \\
\text { بCl } \\
\end{array}$} & \multicolumn{5}{|c|}{ Percent of Final Body Burden } & \multirow[b]{2}{*}{ Cause of Death } \\
\hline & & & Lungs & $\begin{array}{l}\text { Thoracic } \\
\text { Lymph } \\
\text { Nodes (b) }\end{array}$ & $\begin{array}{c}\text { Abdominal } \\
\text { Lymph } \\
\text { Nodes (c) } \\
\end{array}$ & Llver & Skeleton & \\
\hline $1359 M$ & 0.1 & 0.080 & 90.50 & 0.15 & 0.06 & 2.46 & 3.20 & Sacrifice \\
\hline $1375 \mathrm{~F}$ & 0.1 & 0.073 & 89.61 & 0.14 & 0.01 & 0.97 & 4.68 & Sacrifice \\
\hline $1407 \mathrm{~F}$ & 0.1 & 0.092 & 51.87 & 0.41 & 0.13 & 10.99 & 18.70 & Sacrifice \\
\hline $1389 \mathrm{M}$ & 0.5 & 0.053 & 24.07 & 0.38 & 0.08 & 41.28 & 26.21 & Sacrifice \\
\hline $1390 \mathrm{M}$ & 0.5 & 0.051 & 24.62 & 0.32 & 0.11 & 20.05 & 44.45 & Sacrifice \\
\hline $1445 \mathrm{~F}$ & 0.5 & 0.057 & 26.42 & 0.32 & 0.11 & 21.28 & 44.73 & Sacrifice \\
\hline $1329 \mathrm{~F}$ & 1 & 0.485 & 70.05 & 0.16 & 0.04 & 8.28 & 18.79 & Sacrifice \\
\hline $1346 \mathrm{M}$ & 1 & 0.902 & 76.81 & 0.32 & 0.03 & 10.45 & 10.30 & Sacrifice \\
\hline $1347 \mathrm{~F}$ & 1 & 0.699 & 71.71 & 0.36 & 0.08 & 9.33 & 14.09 & Sacrifice \\
\hline $1336 \mathrm{M}$ & 1 & 0.032 & 71.38 & 0.22 & 0.05 & 5.72 & 19.73 & Sacrifice \\
\hline $1341 \mathrm{~F}$ & 1 & 0.022 & 64.43 & 0.29 & 0.10 & 12.92 & 18.63 & Sacrifice \\
\hline $1344 \mathrm{~F}$ & 1 & 0.052 & 58.68 & 0.25 & 0.04 & 21.87 & 16.09 & Sacritice \\
\hline $1335 \mathrm{M}$ & 1 & 0.003 & 19.52 & 0.07 & 0.06 & 6.68 & 25.04 & Sacrifice \\
\hline $1339 \mathrm{~F}$ & 1 & 0.001 & 19.08 & 0.13 & 0.08 & 20.92 & 45.47 & Sacrifice \\
\hline $1351 M$ & 1 & 0.002 & 40.68 & 1.22 & 0.09 & 17.09 & 28.89 & Secrifice \\
\hline $1522 \mathrm{~F}$ & 3 & 0.059 & 54.68 & 0.57 & 0.10 & 11.52 & 28.24 & Sacrifice \\
\hline $1529 \mathrm{~F}$ & 3 & 0.049 & 51.68 & 0.40 & 0.07 & 18.48 & 23.74 & Sacrifice \\
\hline $1539 M$ & 3 & 0.072 & 52.45 & 0.31 & 0.05 & 18.58 & 25.03 & Sacrifice \\
\hline $1564 \mathrm{~F}$ & 12 & 0.037 & 18.00 & 1.27 & 0.11 & 33.53 & 42.63 & Sacrifice \\
\hline $1571 \mathrm{~F}$ & 12 & 0.053 & 22.37 & 1.47 & 0.11 & 28.76 & 42.91 & Sacrifice \\
\hline $1588 \mathrm{M}$ & 12 & 0.053 & 13.14 & 0.40 & 0.12 & 35.85 & 46.18 & Sacrifice \\
\hline $1424 \mathrm{M}$ & 14 & 4.625 & 33.10 & 1.43 & 0.16 & 26.49 & 36.88 & Radiation pneumonitis \\
\hline $1517 \mathrm{~F}$ & 16 & 4.025 & 18.99 & 0.94 & 0.18 & 29.51 & 47.88 & Rediation pneumonitis \\
\hline $1510 \mathrm{~F}$ & 17 & 4.048 & 22.00 & 1.15 & 0.05 & 20.71 & 52.00 & Radiation pneumonitis \\
\hline $1420 M$ & 25 & 1.616 & 16.51 & 0.86 & 0.20 & 7.77 & 70.06 & Radiation pneumonitis \\
\hline $1471 M$ & 34 & 1.375 & 9.25 & 0.73 & 0.12 & 26.92 & 58.34 & Radiation pneumonitis \\
\hline $1518 \mathrm{M}$ & 42 & 1.880 & 6.87 & 0.24 & 0.07 & 21.34 & 67.51 & $\begin{array}{l}\text { Radiation pneumonitis, } \\
\text { lung tumor }\end{array}$ \\
\hline $1512 \mathrm{M}$ & 42 & 2.136 & 4.31 & 0.60 & 0.08 & 49.93 & 42.66 & Bone tumor \\
\hline $1508 \mathrm{M}$ & 43 & 1.730 & 3.24 & 0.62 & 0.08 & 41.53 & 52.70 & Bone tumor \\
\hline $1459 \mathrm{~F}$ & 51 & 1.567 & 4.40 & 0.15 & 0.12 & 30.86 & 61.41 & $\begin{array}{l}\text { Radlatlon pneumonitis, } \\
\text { lung tumor }\end{array}$ \\
\hline $1492 \mathrm{~F}$ & 52 & 1.202 & 2.81 & 0.20 & 0.17 & 27.02 & 66.38 & Bone tumor \\
\hline $1485 \mathrm{~F}$ & 54 & 1.052 & 0.82 & 0.35 & 0.07 & 31.13 & 63.94 & Bone tumor \\
\hline $1502 \mathrm{~F}$ & 55 & 3.113 & 0.80 & 0.39 & 0.09 & 33.33 & 62.51 & Bone tumor, lung tumor \\
\hline $1387 \mathrm{~F}$ & 55 & 0.167 & 1.41 & 0.22 & 0.12 & 45.46 & 49.10 & Bone tumor \\
\hline $1429 \mathrm{M}$ & 59 & 1.159 & 4.14 & 0.35 & 0.10 & 37.06 & 54.70 & Bone tumor, lung tumor \\
\hline $1598 \mathrm{~F}$ & 60 & 0.058 & 0.90 & 0.14 & 0.17 & 24.44 & 31.62 & Sacrifice \\
\hline $1576 \mathrm{M}$ & 60 & 0.065 & 1.54 & 0.36 & 0.13 & 46.23 & 39.15 & Sacrifice \\
\hline $1605 \mathrm{~F}$ & 60 & 0.025 & 1.87 & 0.11 & 0.12 & 52.32 & 39.37 & Sacrifice \\
\hline $1646 \mathrm{~F}$ & 60 & 0.806 & 0.72 & 0.20 & 0.40 & 46.92 & 46.42 & Bone tumor \\
\hline $1619 \mathrm{~F}$ & 62 & 1.361 & 0.55 & 0.59 & 0.13 & 37.87 & 58.63 & Bone tumor \\
\hline $1589 \mathrm{~F}$ & 63 & 0.029 & 0.68 & 0.04 & 0.13 & 46.43 & 50.32 & Sacritice \\
\hline $1636 \mathrm{M}$ & 66 & 0.634 & 1.21 & 0.27 & 0.52 & 53.97 & 39.09 & Bone tumor \\
\hline $1652 \mathrm{~F}$ & 68 & 0.658 & 1.46 & 0.23 & 0.29 & 50.47 & 44.32 & Bone tumor, lung tumor \\
\hline $1498 \mathrm{~F}$ & 69 & 0.845 & 0.59 & 0.32 & 0.13 & 26.63 & 53.37 & Bone tumor, lung tumor \\
\hline $1659 \mathrm{~F}$ & 69 & 0.738 & 1.14 & 0.34 & 0.40 & 38.90 & 55.89 & Bona tumor \\
\hline $1640 \mathrm{M}$ & 76 & 0.177 & 4.01 & 0.64 & 0.63 & 54.41 & 36.59 & Lung tumor \\
\hline $1419 M$ & 76 & 0.873 & 0.69 & 0.28 & 0.39 & 44.06 & 50.70 & Bone tumor, lung tumor \\
\hline $1660 \mathrm{M}$ & 82 & 0.854 & 0.76 & 0.53 & 0.53 & 37.51 & 56.17 & Bone tumor, lung tumor \\
\hline $1621 M$ & 84 & 0.840 & 0.94 & 0.56 & 0.29 & 40.87 & 54.55 & Bone tumor, lung tumor \\
\hline $1655 \mathrm{M}$ & 88 & 0.505 & 1.05 & 0.22 & 0.93 & 41.83 & 52.14 & Lung tumor, Bone tumor \\
\hline $1501 \mathrm{M}$ & 92 & 0.002 & 1.62 & 0.50 & 0.79 & 38.05 & 46.41 & Thyroid tumor \\
\hline $1648 \mathrm{M}$ & 92 & 0.639 & 1.12 & 0.25 & 0.73 & 42.83 & 50.61 & Bone tumor, lung tumor \\
\hline $1641 \mathrm{M}$ & 92 & 0.869 & 0.78 & 0 & 0.48 & 45.72 & 46.89 & Lung tumor \\
\hline
\end{tabular}


TABLE 2. Continued

\begin{tabular}{|c|c|c|c|c|c|c|c|c|}
\hline \multirow[b]{2}{*}{$\begin{array}{l}\text { Dog } \\
\text { Number }\end{array}$} & \multirow[b]{2}{*}{$\begin{array}{l}\text { Time After } \\
\text { Exposure } \\
\text { monthe (a) } \\
\end{array}$} & \multirow[b]{2}{*}{$\begin{array}{c}\text { Final Body } \\
\text { Burden, } \\
\\
\end{array}$} & \multicolumn{5}{|c|}{ Percent of Final Body Burden } & \multirow[b]{2}{*}{ Cause of Death } \\
\hline & & & Lungs & $\begin{array}{l}\text { Thoracic } \\
\text { Lymph } \\
\text { Nodes (b) } \\
\end{array}$ & $\begin{array}{c}\text { Abdominal } \\
\text { Lymph } \\
\text { Nodes }(c) \\
\end{array}$ & Liver & Skeleton & \\
\hline $1408 \mathrm{~F}$ & 93 & 0.181 & 0.60 & 0.19 & 0.37 & 49.47 & 45.52 & Bone tumor \\
\hline $1404 M$ & 93 & 0.217 & 0.82 & 0.28 & 0.72 & 46.24 & 48.62 & Pleuritis \\
\hline $1470 \mathrm{~F}$ & 95 & 0.001 & 1.11 & 0.48 & 0.34 & 43.21 & 50.23 & Meningioma \\
\hline $1489 \mathrm{~F}$ & 98 & 0.002 & 1.23 & 0.73 & 0.70 & 41.36 & 48.52 & Esophageal tumor \\
\hline $1565 \mathrm{~F}$ & 101 & 0.001 & 0.77 & 1.55 & 0.87 & 43.62 & 44.09 & Hemangiosarcoma \\
\hline $1385 \mathrm{M}$ & 101 & 0.362 & 0.62 & 0.51 & 0.42 & 46.38 & 49.36 & Bone tumor, lung tumor \\
\hline $1364 \mathrm{M}$ & 102 & 0.370 & 1.13 & 0.32 & 0.40 & 49.46 & 46.17 & Lung tumor \\
\hline $1503 \mathrm{~F}$ & 103 & 0.007 & 0.37 & 0.64 & 0.25 & 60.15 & 35.37 & Thyrold tumor \\
\hline $1645 \mathrm{~F}$ & 105 & 0.182 & 0.73 & 0.41 & 0.46 & 55.96 & 40.70 & Lung tumor \\
\hline $1587 \mathrm{M}$ & 106 & 0.027 & 0.65 & 0.74 & 0.51 & 20.11 & 74.97 & Hemangiosarcoma, lung tumor \\
\hline $1534 \mathrm{M}$ & 106 & 0.201 & 0.96 & 0.43 & 0.49 & 50.78 & 43.95 & Congestive heart failure \\
\hline $1521 \mathrm{~F}$ & 106 & 0.146 & 0.88 & 0.34 & 0.36 & 51.77 & 44.41 & Bone tumor, lung tumor \\
\hline $1599 \mathrm{~F}$ & 106 & 0.007 & 0.69 & 0.54 & 0.48 & 34.04 & 60.60 & Adrenal tumor \\
\hline $1413 F$ & 109 & 0.026 & 1.16 & 0.39 & 0.51 & 58.06 & 37.78 & Malignant lymphoma \\
\hline $1391 M$ & 111 & 0.004 & 1.21 & 0.34 & 0.47 & 50.40 & 45.49 & Thyroid tumor, lung tumor \\
\hline $1581 \mathrm{M}$ & 111 & 0.002 & 0.52 & 0.95 & 0.31 & 38.21 & 56.46 & Hemangiosarcoma \\
\hline $1602 \mathrm{M}$ & 111 & 0.006 & 1.95 & 1.29 & 0.97 & 42.80 & 46.45 & Epilepsy \\
\hline $1428 \mathrm{~F}$ & 114 & 0.230 & 0.72 & 0.62 & 0.56 & 35.16 & 60.14 & Bone tumor, lung tumor \\
\hline $1386 \mathrm{M}$ & 116 & 0.028 & 1.59 & 0.26 & 0.82 & 56.40 & 38.62 & Hemangiosarcoma \\
\hline $1568 \mathrm{M}$ & 118 & 0.034 & 0.93 & 0.50 & 0.54 & 42.27 & 52.10 & Pneumonia \\
\hline $1590 \mathrm{~F}$ & 119 & 0.003 & 0.48 & 0.35 & 1.00 & 59.61 & 31.23 & Marmmary tumor \\
\hline $1530 \mathrm{~F}$ & 122 & 0.017 & 0.89 & 0.77 & 0.84 & 42.50 & 50.30 & Bona tumor, lung tumor \\
\hline $1570 \mathrm{~F}$ & 122 & 0.001 & 0.34 & 0.91 & 0.42 & 30.80 & 63.13 & Stomach tumor \\
\hline $1535 \mathrm{~F}$ & 122 & 0.145 & 0.62 & 0.67 & 0.74 & 19.27 & 73.73 & Bone tumor, lung tumor \\
\hline $1446 \mathrm{~F}$ & 123 & 0.165 & 0.40 & 0.56 & 0.63 & 27.06 & 67.94 & Pyometra, Iver tumor \\
\hline $1540 \mathrm{M}$ & 124 & 0.037 & 0.61 & 0.45 & 0.38 & 39.21 & 55.37 & Lung tumor \\
\hline $1414 \mathrm{~F}$ & 126 & 0.121 & 1.29 & 0.42 & 0.54 & 44.44 & 49.50 & Bone, lung, and liver tumore \\
\hline
\end{tabular}

(a) Radioanalysis not completed in dogs that died more than 126 months after exposure.

(b) Includes tracheobronchial, mediastinal, and sternal lymph nodes.

(c) Includes hepatic, splenic, and mesenteric lymph nodes.

More than $90 \%$ of the burden translocated to the liver and skeleton; only about $1 \%$ translocated to thoracic and abdominal lymph nodes. This was in contrast to dogs that inhaled ${ }^{239} \mathrm{PuO}_{2}$ i in these dogs, $\sim 50 \%$ of the final body burden was present in thoracic lymph nodes, but only about $2 \%$ in the skeleton at 10 to 11 years after exposure.

The earliest observed biological effect was on the hematopoietic system: lymphopenia occurred at the two highest dose levels at 4 weeks after exposure to ${ }^{239} \mathrm{Pu}\left(\mathrm{NO}_{3}\right)_{4}$. Total leukocyte concentrations were reduced significantly in the two highest dose groups, that is, Group 5 (mean initial alveolar deposition, $\sim 1700 \mathrm{nCi})$, and Group $6(\sim 5500 \mathrm{nCi})$.
The reduction in white cells in Groups 5 and 6 results from an effect on most leukocyte types (neutrophils, lymphocytes, monocytes, and eosinophils). This is in contrast to the effects of both ${ }^{239} \mathrm{PuO}_{2}$ and ${ }^{238} \mathrm{PuO}_{2}$, which significantly depressed lymphocyte concentrations in groups with initial lung burdens of $\sim 80 \mathrm{nCi}$ or more. The lymphopenia at lower dose levels of plutonium oxides may be related to the more extensive translocation of plutonium oxide to the tracheobronchial lymph nodes and subsequent higher dosage levels to lymphocytes circulating through those lymph nodes. The results of these continuing evaluations are shown in Figure 1. 

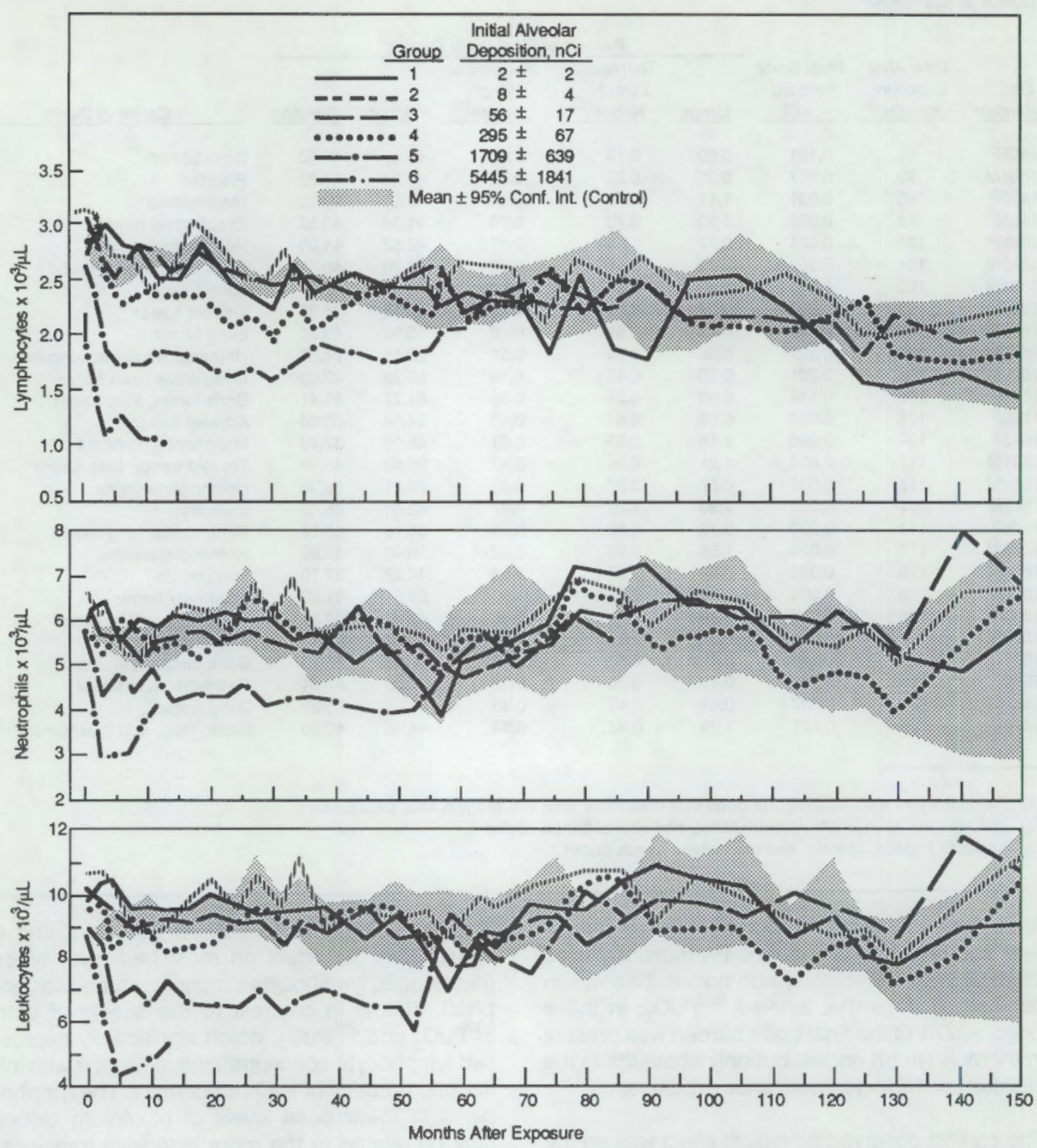

FIGURE 1. Mean Leukocyte, Neutrophil, and Lymphocyte Values in Dogs After Inhalation of ${ }^{239_{\mathrm{Pu}}\left(\mathrm{NO}_{3}\right)_{4}}$

Serum enzyme assays have been performed throughout the postexposure period in an attempt to identify specific damage to liver or bone by plutonium translocated from the lung. Evaluation of these data has revealed a biphasic elevation of serum alkaline phosphatase (ALP) and serum 
glutamic pyruvic transaminase (GPT) in individual dogs. There was an early increase followed by a retum to control values and then a late effect characterized by persistent, increased elevations of both ALP and GPT. Calculation of the cumulative average radiation dose to mean time after exposure, when serum chemistry values were first observed to be different from controls for doselevel 5 dogs, revealed a mean dose to liver of $280 \mathrm{rad}$ for the late effect, which occurred 4.1 years post exposure. At this time, the dose rate was 60 to 70 rads per year. Currently (more than 12 years after exposure), GPT and ALP values in dose-level groups 3 and 4 are still significantly $(p \leq 0.05)$ higher than those for the control group (Figures 2 and 3 ).

Table 3 summarizes, by dose-level group, the mortality and lesions associated with deaths through 12 years after exposure to ${ }^{239} \mathrm{Pu}\left(\mathrm{NO}_{3}\right)_{4}$. All five dogs at the highest dose level (Group 6) died from radiation pneumonitis 14 to 41 months after exposure. Histopathological examination of the lungs of these dogs revealed interstitial fibrosis, alveolar epithelial hyperplasia, increased numbers of alveolar macrophages, occasional small emphysematous cavities and, at times, very small nodules of squamous metaplasia at the termini of respiratory bronchioles. One dog at the highest dose level had a small bronchioloalveolar carcinoma as well as radiation pneumonitis.

All the dogs in dose-level Group 5 died or were euthanized 34 to 92 months after plutonium exposures. The principal cause of death at this exposure level was osteosarcoma, which occurred in 17 of 20 dogs; several had more than one site. The sites of the osteosarcomas were lumbar vertebrae (4 dogs), cervical vertebrae ( 3 dogs), thoracic vertebrae (2 dogs), humerus (5 dogs), pelvis (2 dogs), facial bones ( 2 dogs), ribs ( 2 dogs), and nasal turbinates (1 dog). Metastases to distal sites occurred in 6 dogs; these dogs also had radiation osteosis, generally characterized by peritrabecular fibrosis.

Other deaths in dose-level Group 5 were caused by radiation pneumonitis (two dogs) and multiple lung tumors (one dog). The multiple lung tumors, in different lobes, were papillary adenocarcinomas, combined epidermoid and adenocarcinoma, and bronchioloalveolar carcinoma; metastases were present in the tracheobronchial lymph nodes.

Malignant but nonfatal lung tumors were also present in nine dogs from dose-level Group 5 that died from osteosarcomas and in one dog that died from radiation pneumonitis. Typically, these arose subpleurally, proximal to areas of interstitial fibrosis or small cavities communicating with bronchioles. They consisted of bronchioloalveolar carcinomas in four dogs; papillary adenocarcinomas in two dogs; both bronchioloalveolar carcinoma and papillary adenocarcinoma in one dog; both papillary and tubular adenocarcinomas in one dog; a combined epidermoid and adenocarcinoma in one dog; and a bronchioloalveolar carcinoma, papillary adenocarcinoma, and a mixed lung tumor in one dog. No metastases of these lung tumors were observed.

In dose-level Group 4, 16 dogs have now died, 54 to 144 months after plutonium exposure. The causes of death included bone tumors (9 dogs), lung tumors (4 dogs), suppurative pleuritis ( $1 \mathrm{dog})$, congestive heart failure ( $1 \mathrm{dog})$, and pyometra (1 dog). Six dogs that died as a result of bone tumors also had nonfatal lung tumors. An intrahepatic bile duct carcinoma was present in 1 dog that also had bone and lung tumors; small solitary bile duct tumors were present in the livers of 2 additional dogs that died from other causes.

In dose-level Group 3, two dogs have died from lung tumors. Each of three dogs that died of a bone tumor, a thyroid tumor, and a hemangiosarcoma, respectively, also had a lung tumor. Two additional dogs had bile duct tumors. This is the lowest exposure level with a mortality rate or incidence of lesions that was different from that of control groups.

Although the skeleton is generally considered the critical tissue after inhalation of soluble plutonium, and 27 of 66 exposed dogs have died with bone tumors by 12 years after exposure, it should be noted that 27 of these 66 exposed dogs also had lung tumors. We have calculated that lung cancer risks for these dogs, based on estimated cumulative dose to the lung, are approximately 12 times higher for ${ }^{239} \mathrm{Pu}\left(\mathrm{NO}_{3}\right)_{4}$ than for inhaled ${ }^{239} \mathrm{PuO}_{2}$ and 50 times higher than for inhaled ${ }^{238} \mathrm{PuO}_{2}$. 


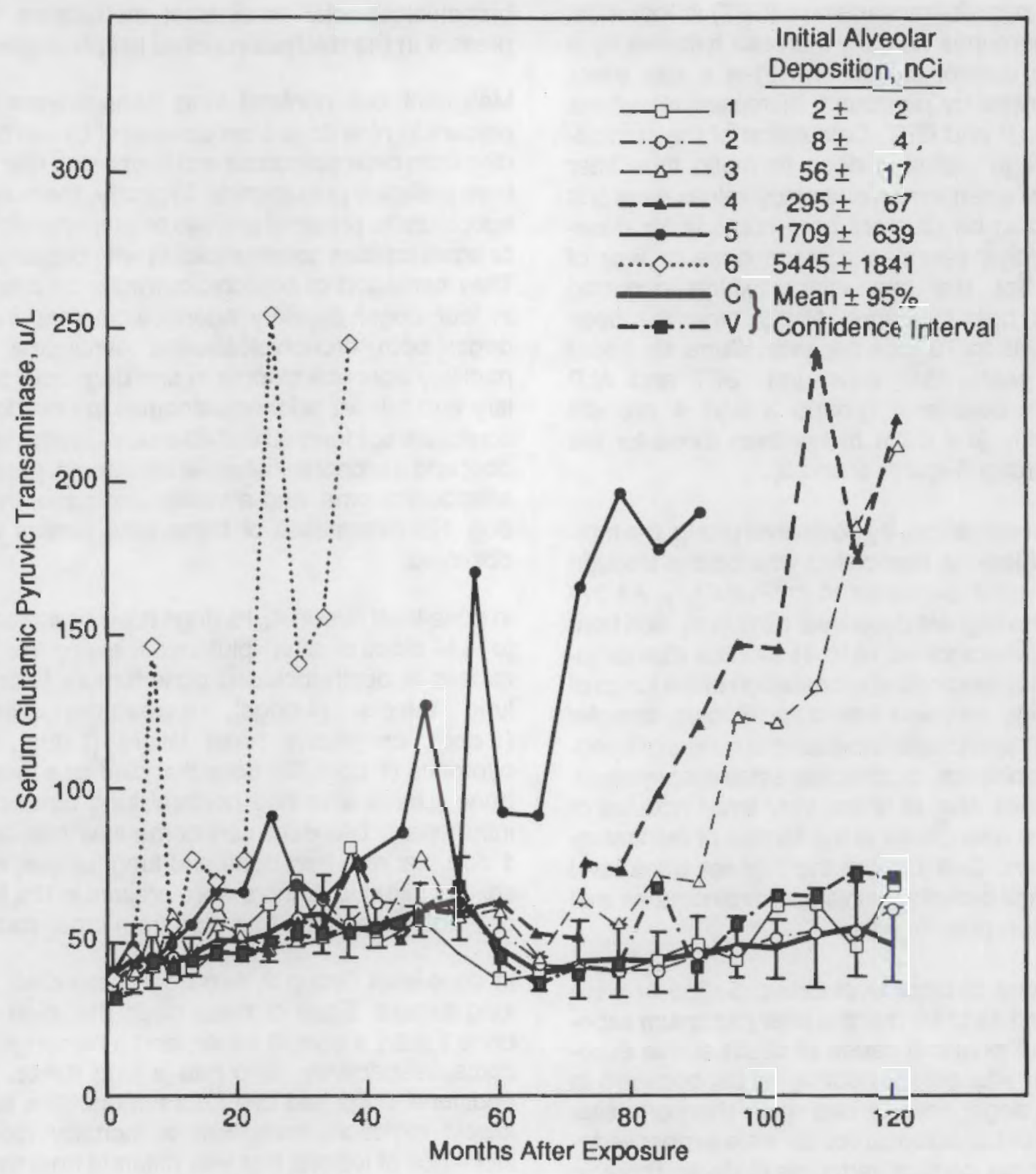

FIGURE 2. Serum Glutamic Pyruvic Transaminase (GPT) in Dogs After Inhalation of ${ }^{239} \mathrm{Pu}\left(\mathrm{NO}_{3}\right)_{4}$ 


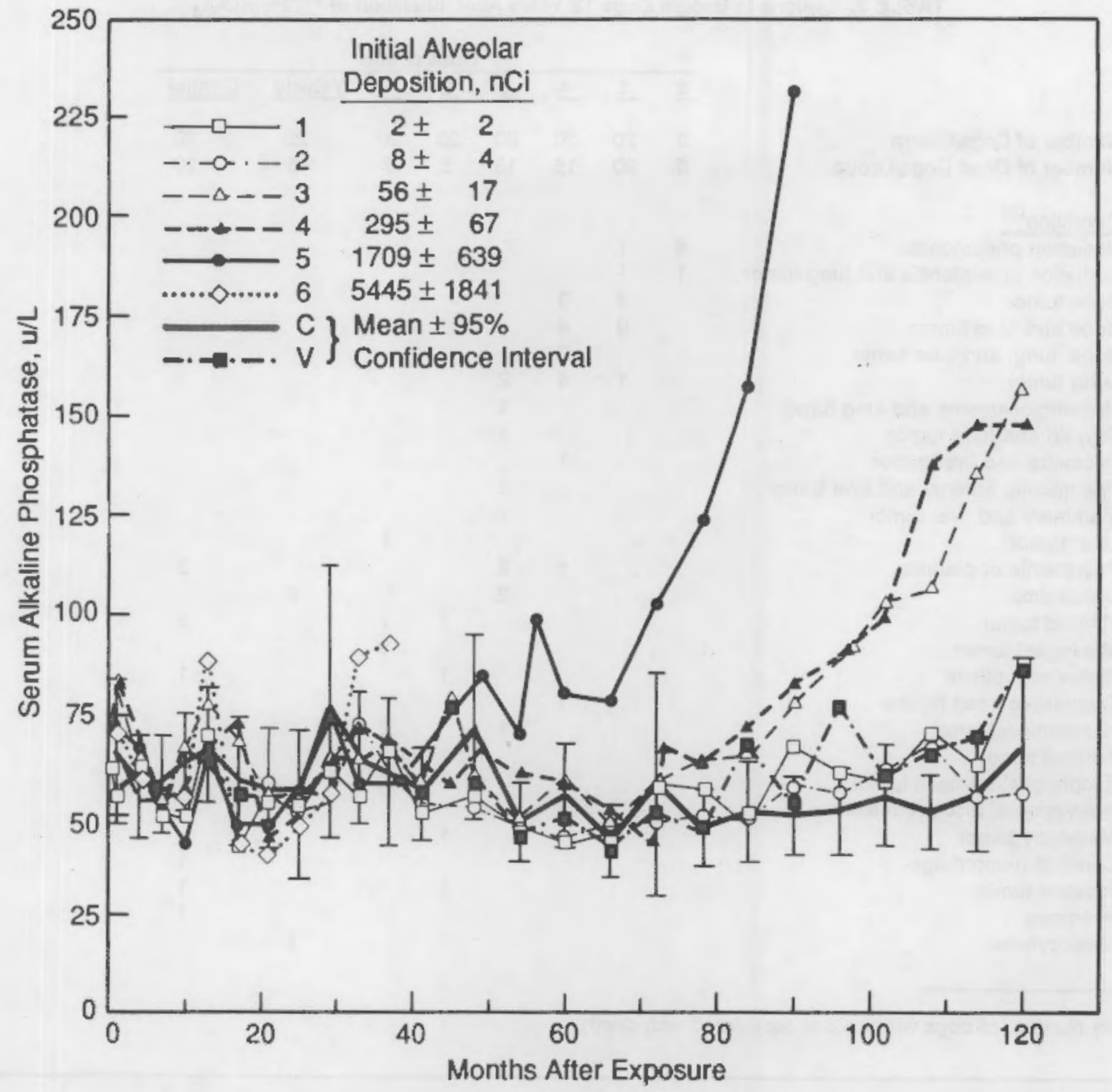

FIGURE 3. Serum Alkaline Phosphatase (ALP) in Dogs After Inhalation of ${ }^{239} \mathrm{Pu}\left(\mathrm{NO}_{3}\right)_{4}$ 
TABLE 3. Lesions in Beagle Dogs 12 Years After Inhalation of ${ }^{239} \mathrm{Pu}\left(\mathrm{NO}_{3}\right)_{4}$

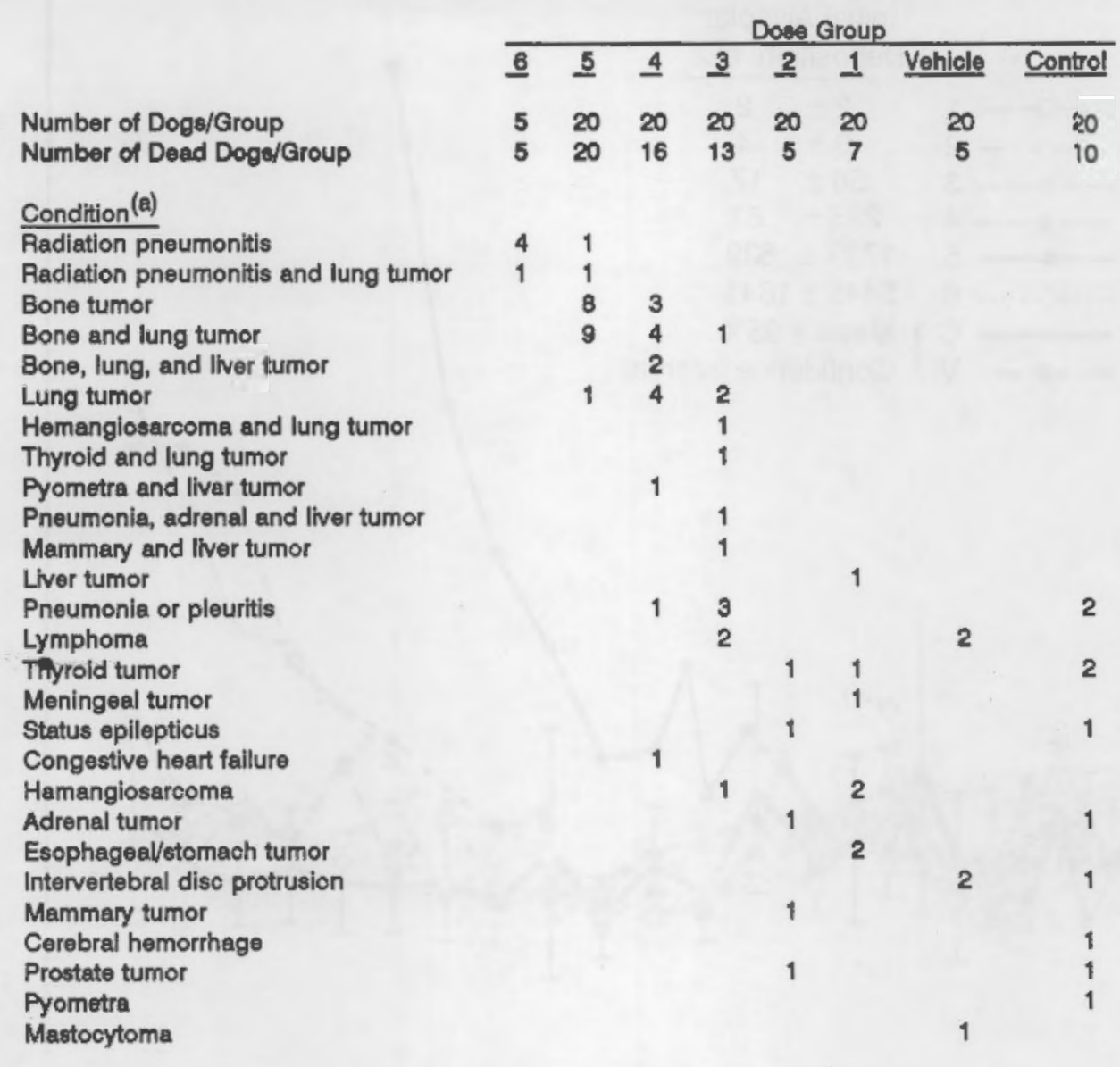

(a) Number of dogs with lesions associated with death. 


\title{
National Radiobiology Archives
}

\author{
Principal Investigator: C. R. Watson
}

\author{
Other Investigators: R. C. Thompson and M. T. Karagianes
}

The National Radiobiology Archives at PNL focus on integration, preservation, and continued use of information and materials from investigations in radiobiology. The initial product of this project was the book by Roy C. Thompson, Life-Span Effects of lonizing Radiation in the Beagle Dog, a summary account of four decades of research funded by the U.S. Department of Energy and its predecessor agencies. This year the project was expanded to include three additional tasks: 1) implementation of an interlaboratory computerized database containing summarized dose and effects results for each significant tissue type in each of the more than 6000 dogs exposed to ionizing radiation; 2) establishment of an archive of research documents such as logbooks, clinical nctes, and pathologists' observations; and 3) establishment of a repository for research materials such as tissue samples, histopathology blocks and slides, and radiographic films. Thus, this project has evolved into a comprehensive effort to gather and catalog tissues and documents related to radiobiology studies so that future researchers will have materials to analyze by advanced molecular biology techniques and information for statistical analysis.

\section{National Radiobiology Archives}

The National Radiobiology Archives focus on integration, preservation, and continued use of information and materials from investigations in radiobiology. Nearly 40 years ago, the U.S. Atomic Energy Commission made a far-reaching commitment to the support of lifespan radiation-effect studies in a relatively long-lived animal, the beagle dog, at five institutions. Consequently, about $\$ 200$ million has been spent on a program including closely related experiments that is only now coming to fruition. Conducted at the University of Utah ( $U$ of Utah), the University of California at Davis (UC Davis), Argonne National Laboratory (ANL), Pacific Northwest Laboratory (PNL), and the Inhalation Toxicology Research Institute (ITRI), these lifespan studies are the initial focus of Archive activities.

The activities summarized in this report are the initial steps toward a fully functioning Archives. A PNL building (331-G) has been modified as a repository for tissues and other materials, and a computational architecture for information storage, access, and distribution has been designed.

The Archives will be guided by an advisory committee consisting of representatives of the five institutions and other knowledgeable scientists. The advisory committee will meet twice in 1990; first, to establish policy, and second, to evaluate candidate materials at the $\mathrm{U}$ of Utah.

Because the National Radiobiology Archives is a new project, a major thrust of this first year has been to develop plans and establish good working relationships within the radiobiology research community. A primary topic of discussion has been the relative value of various types of archival materials. All parties agree that the summary information, raw data, tissue blocks, and histopathology slides should be included in the Archives. There was considerable debate over the cost-benefit utility of storing the tissue specimens. The consensus is that the large investment in producing these specimens coupled with rapid advances in molecular biology techniques mandates preservation of the specimens for future researchers. The plans presented at the site review conducted by the DOE in March included a timetable for specimen acquisition as studies are completed at each site.

\section{Review of Lifespan Dog Studies}

The first product of the Archives is a book providing a comprehensive view of the beagle studies. Life-Span Effects of lonizing Radiation in the Beagle Dog, by Roy C. Thompson, is primarily intended as a research management document rather than a technical evaluation of research 
results. The book describes what has been done and why, and presents results to date and their applications in a manner designed to display the total effort rather than details. The document provides an informed approach to the question, Where do we go from here?"

The book covers the major lifespan experiments conducted under AEC/ERDA/DOE sponsorship at the five institutions. Table 1 lists these experiments, the time period over which the exposures were conducted, the general nature of those exposures, and the number of dogs held for lifespan observation (total animals and those still alive). Many more animals were employed in preliminary and ancillary studies and in the maintenance of breeding colonies. In some earlier experiments, all animals are already dead; however, in none of the experiments have interpretations been completed, nor can they be considered fully completed until cross-comparisons are made among all experiments. Other radiationeffect studies with beagle dogs in these and other laboratories lasting less than the lifespan are discussed in the book only to place the major lifespan studies (Table 1) in proper perspective.

Dr. Thompson has provided a continuing broad viewpoint on the total effort rather than reporting individual experiments in individual laboratories. Thus, the chapter titles are Introduction, Historical Overview, The Experiments, Results: Dosimetric Considerations, Results: Biological Effects, Results of Ancillary Studies, Applications, Bibliography, and Appended Experiment Summaries. The book's structure emphasizes that these experiments were planned as a total program with important interactions.

A special effort was made to provide a complete bibliography, including brief biographical sketches of the principal scientists involved in the research. For some detailed information, only the year-byyear progress reports from the laboratories provide the total picture. These reports are listed in a separate section of the bibliography and are cross referenced to the individual experiments in the appendix.

TABLE 1. Summary of Lifespan Experimente in Beagle Dogs Exposed to Rediotoxic Insulte at DOE-Supported Laboratories

\begin{tabular}{|c|c|c|c|c|c|}
\hline \multirow[b]{2}{*}{ Laboratory (a) } & \multicolumn{2}{|c|}{ Exposure } & \multirow[b]{2}{*}{ Agent } & \multicolumn{2}{|c|}{ of Dogs } \\
\hline & Detes & Route & & Total & Live $(\mathrm{D})$ \\
\hline PNL & $1959-1977$ & Inhalation & $\mathrm{PuO}_{2}, \mathrm{Pu}\left(\mathrm{NO}_{3}\right)_{4}$ & 479 & 75 \\
\hline TRI & $1973-1982$ & Inhalation & $\alpha$ emitters & 599 & 199 \\
\hline & $1965-1975$ & Inhalation & B emitters & 916 & 3 \\
\hline UC Davis & $1963-1967$ & Injection & ${ }^{90} \mathrm{Sr}_{1}{ }^{226} \mathrm{Ra}$ & 379 & 0 \\
\hline & $1961-1967$ & Ingestion & $0_{\mathrm{Sr}}$ & 479 & 0 \\
\hline & $1952-1958$ & External & $X$ ray & 360 & 0 \\
\hline$U$ of Utah & $1952-1980$ & Injection & gemitters & 1148 & $-(c)$ \\
\hline & 1955-1966 & Injection & $90 \mathrm{c}$ & 100 & 0 \\
\hline ANL & $1968-1978$ & External & $X$ or $y$ rays & 710 & \\
\hline & $1960-1964$ & Injection & B emitters & $\underline{268}$ & $\underline{0}$ \\
\hline TOTAL: & & & & 5438 & 277 \\
\hline
\end{tabular}

(a) PNL, Pacific Northwest Laboratory; TRI, Inhalation Toxicology Research Institute; UC Davis, University of California at Davis; $U$ of Utah, University of Utah; ANL, Argonne National Laboratory.

(b) As reported by the institution's annual report for 1989.

(c) Surviving $U$ of Utah dogs exposed to $\alpha$ emitters were moved to ITRI in September 1987. 


\section{Biological Specimen Archive}

The biological specimen archive will contain collected research materials, such as tissues preserved in formalin or alcohol, tissue samples embedded in paraffin or plastic for histopathological analysis, tissues that have been reduced to ash and liquefied for dosimetric analysis, microscope slides, and radiographic films. Many of these materials are radioactive, and are associated with hazardous materials such as formalin, alcohol, and paraffin. An existing $1200-t^{2}$ cinder block building has been renovated and dedicated as the repository of these specimens. It contains a specimen manipulation laboratory and storage bays with an automatic fire suppression system.

immediate use of the tissue archive will be for cross-comparison of pathologists' observations. We will be able to supply tissue samples of known dosimetric and clinical history to molecular biologists for analysis by emerging techniques such as DNA amplification. As microdosimetric techniques are refined, archived tissues, especially radiolabeled bone and lung specimens, will be available for interpretation.

Materials nominated for inclusion in the Archives must be approved by peer review. The first such commiltee met at the UC Davis in December 1989 to review the existing collection of specimens and records. The committee recommended acceptance of only those materials related to the three lifespan studies, and also recommended that the UC Davis stafl harvest additional bones from the carcasses slated for disposal. The first contributions to the specimen archives will be moved from UC Davis early in 1990.

\section{Research Records Archive}

The research records archive will collect handwritten and printed documents associated with each study, as well as supporting documents.
These include "raw" data such as exposure logbooks, clinical notes, laboratory analysis forms, hematologic profiles, and caretakers' observations. "Summarized" data, usually reduced to computer files, are also to be included. Each document will be given an accession number and stored in a controlled environment. This material will be cataloged, using appropriate microcomputer software, for rapid selection and retrieval.

The primary users of the document archive will be statisticians performing cross-comparisons of these studies. The documents will also provide input to future analyses of effects of low-level radiation that are not necessarily amenable to current statistical methodology.

The first contribution to the records archive will be the extensive collection of supportive documentation that provided the basis for Radioactivity and Health, A History, by J. Newell Stannard. The UC Davis records will be shipped to the Archives in several years, at the conclusion of their contract with DOE.

\section{Summary Database}

The computerized summary database will contain the dose to, and the effect on, each significant tissue in each dog. This database was described as the "Interlaboratory Toxicology Data Base" in last year's report. No significant progress was made on the summary database this year because of the other activities reported here.

\section{Reference Cited}

Thompson, R. C. 1989. Life-Span Effects of lonizing Radiation on the Beagle Dog: A Summary Account of Four Decades of Research Funded by the U.S. Department of Energy and its Predecessor Agencies. PNL-6822, Pacific Northwest Laboratory, Richland, Washington. 



\title{
Low-Level ${ }^{239} \mathrm{PuO}_{2}$ Lifespan Studies
}

\author{
Principal Investigator: C. L. Sanders
}

\section{Other Investigators: $K$. E. Lauhala and K. E. McDonald}

A total of 3192 female Wistar, 198 male Wistar, 192 female Long-Evans, and 200 female Fischer-344 rats were either sham-exposed or given a single inhalation to ${ }^{239} \mathrm{PuO}_{2}$. Rats are being examined during their lifespan for spatial-temporal dose-distribution patterns and for lung tumor formation. The dose-response curve continues to be best fitted by a quadratic function and a "practical" threshold of $>1$ Gy; maximum lung tumor incidence is seen at about 8 Gy. An excellent fit of lung tumor data was provided by a twocomponent polynomial equation. Poorer fits of lung tumor incidences and radiation dose from inhaled $\mathrm{Pu}$ were seen in historical data for rats. The incidence of lung tumors in Wistar rats correlates well with the formation of large Pu particle aggregates. Likewise, the incidence of grossly appearing lung tumors in female Long-Evans and Fischer rats and in male Wistar rats appears to be related to the formation of large Pu aggregates, particularly in peribronchiolar regions of the lung. The radiation dose delivered to airways from $\mathrm{Pu}$ particles in nearby alveoli was delivered largely to smaller diameter airways from large $\mathrm{Pu}$ aggregates.

Previous lifespan studies in rats exposed to ${ }^{239} \mathrm{Pu}$ aerosols indicated that lung tumor incidence might be increased at radiation doses to the lung comparable to doses received by humans from a maximum permissible occupational lung deposition of $16 \mathrm{nCi}^{239} \mathrm{Pu}$. A total of 3192 young adult, female, specific-pathogen-free (SPF), Wistar rats were used in the initial lifespan study: 2134 were exposed to ${ }^{239} \mathrm{PuO}_{2}$ at initial lung burdens (ILB) ranging from $0.25 \mathrm{nCi}$ to about $180 \mathrm{nCi}$, and 1058 were sham-exposed controls. Histopathological analyses have been completed on 1775 of the 3192 rats, including 579 sham-exposed controls and 1196 exposed animals. All other lifespan rats have died, including 198 male Wistar rats, 192 female Long-Evans rats, and 200 female Fischer-344 rats. Autoradiographic and morphometric techniques were used to evaluate the spatial-temporal dose-distribution patterns in highdose male and female Wistar, female Long-Evans, and femaie Fischer-344 lifespan rats.

A total of 117 lung tumors were found in 1196 exposed rats, including 62 squamous cell carcinomas, 29 adenocarcinomas, 9 hemangiosarcomas, 8 adenomas, 3 adenosquamous carcinomas, 3 fibrosarcomas, 2 mesotheliomas, and 1 carcinosarcoma. To date, only 9 lung tumors have been found in 960 exposed rats with lung doses up to <1 Gy (malignant tumor incidence of $0.52 \%$ ), of which 4 are benign adenomas. A total of 108 lung tumors have been found in 236 rats with lung doses $>1 \mathrm{~Gy}$ (malignant tumor incidence of $44 \%$ ), of which 3 are adenomas. Four lung tumors have been found in 579 sham-exposed controls: 2 adenocarcinomas, 1 fibrosarcoma, and 1 mesothelioma (malignant tumor incidence of $0.69 \%)$. This continues to indicate the presence of a possible "practical" threshold dose of about $1 \mathrm{~Gy}$ for lung tumor formation from inhaled ${ }^{239} \mathrm{PuO}_{2}$, below which a tumor is much less likely to be seen (Table 1). The dose-response relationship appears to be well fitted by a quadratic function and a maximum lung tumor incidence at about $8 \mathrm{~Gy}$. We continue to propose that the lower dose range of the quadratic curve ( $<1 \mathrm{~Gy}$ ) represents primarily initiation (mutation) events, while the much steeper, higher dose portion of the curve (>1 Gy) represents mostly promotion events caused by $\mathrm{Pu}$ particle aggregation, resulting in the progressive expression of carcinogenesis (Figure 1).

The variability in relationship between lung dose and lung tumor incidence was examined in this study and in previously published studies with the rat. Correlations were made using a quadratic polynomial fit of the data. A poor fit $(r=0.35)$ was seen when historical data for all (solubie and insoluble) inhaled Pu compounds were plotted (Figure 2). A somewhat better fit $(r=0.70)$ was seen when only historical studies with inhaled ${ }^{239} \mathrm{PuO}_{2}$ were plotted (Figure 3). However, an excellent fit 
TABLE 1. Lung Tumors in Female Wistar Rats After Inhalation of ${ }^{239} \mathrm{PuO}_{2}$ Particles

\begin{tabular}{|c|c|c|c|c|c|c|c|c|}
\hline \multirow{2}{*}{$\begin{array}{l}\text { Dose to } \\
\text { Lung, } \\
\text { Gy }\end{array}$} & \multirow[b]{2}{*}{$\begin{array}{l}\text { Number } \\
\text { of rats }\end{array}$} & \multirow{2}{*}{$\begin{array}{l}\text { Time After } \\
\text { Exposyre, } \\
\text { days (a) } \\
\end{array}$} & \multicolumn{6}{|c|}{ Incldence of Pulmonary Pathological Lesione, $\%$} \\
\hline & & & $\begin{array}{l}\text { Squamous } \\
\text { Carcinoma }\end{array}$ & Adenoma & $\begin{array}{c}\text { Adeno- } \\
\text { carcinoma }\end{array}$ & $\begin{array}{l}\text { Hemangio- } \\
\text { sarcoma }\end{array}$ & $\begin{array}{l}\text { Other } \\
\text { Tumors (b) }\end{array}$ & Total \\
\hline $21.4 \pm 1.3$ & 9 & $398 \pm 135$ & 33.3 & 0 & 11.1 & 11.1 & 11.1 & 66.7 \\
\hline $18.5 \pm 0.97$ & 11 & $484 \pm 109$ & 54.5 & 0 & 18.2 & 0 & 0 & 72.7 \\
\hline $15.6 \pm 0.82$ & 14 & $482 \pm 168$ & 42.9 & 14.3 & 7.1 & 7.1 & 0 & 71.4 \\
\hline $13.0 \pm 0.55$ & 16 & $586 \pm 129$ & 62.5 & 0 & 18.8 & 12.5 & 6.3 & 100 \\
\hline $11.5 \pm 0.25$ & 15 & $592 \pm 186$ & 40.0 & 0 & 20.0 & 6.7 & 0 & 66.7 \\
\hline $10.0 \pm 0.51$ & 16 & $541 \pm 245$ & 43.8 & 0 & 12.5 & 6.3 & 0 & 62.5 \\
\hline $7.94 \pm 0.47$ & 20 & $647 \pm 150$ & 60.0 & 0 & 10.0 & 5.0 & 0 & 75.0 \\
\hline $5.93 \pm 0.63$ & 17 & $680 \pm 188$ & 23.5 & 0 & 11.8 & 11.8 & 5.9 & 52.9 \\
\hline $4.48 \pm 0.23$ & 17 & $705 \pm 176$ & 0 & 0 & 29.4 & 0 & 5.9 & 35.3 \\
\hline $3.40 \pm 0.28$ & 29 & $656 \pm 230$ & 10.3 & 3.4 & 10.3 & 0 & 0 & 24.1 \\
\hline $2.56 \pm 0.24$ & 35 & $685 \pm 199$ & 5.7 & 2.9 & 5.7 & 0 & 0 & 14.3 \\
\hline $1.40 \pm 0.32$ & 37 & $653 \pm 199$ & 0 & 0 & 0 & 0 & 0 & 0 \\
\hline $0.89 \pm 0.05$ & 34 & $699 \pm 191$ & 0 & 2.9 & 0 & 0 & 0 & 2.9 \\
\hline $0.68 \pm 0.06$ & 58 & $695 \pm 196$ & 0 & 0 & 0 & 0 & 0 & 0 \\
\hline $0.49 \pm 0.06$ & 55 & $662 \pm 163$ & 0 & 1.8 & 0 & 0 & 3.6 & 5.5 \\
\hline $0.28 \pm 0.05$ & 127 & $702 \pm 143$ & 0.8 & 0.8 & 0 & 0 & 0 & 1.6 \\
\hline $0.13 \pm 0.03$ & 171 & $736 \pm 161$ & 0 & 0 & 0 & 0 & 0 & 0 \\
\hline $0.07 \pm 0.02$ & 515 & $699 \pm 189$ & 0 & 0.2 & 0 & 0 & 0 & 0.4 \\
\hline 0 & 579 & $737 \pm 159$ & 0 & 0 & 0.3 & 0 & 0.3 & 0.7 \\
\hline
\end{tabular}

(a) Mean \pm standard deviation.

(b) Fibrosarcoma, mesothelioma, carcinosarcoma.

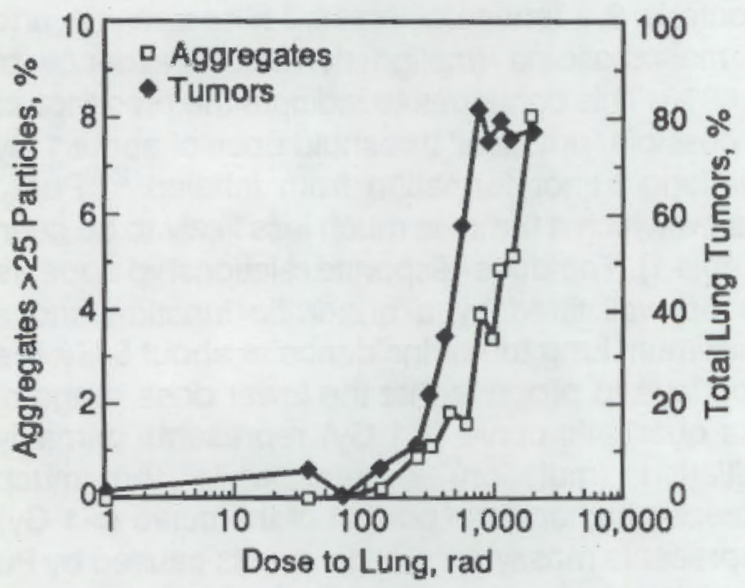

FIGURE 1. Relationship of Lung Tumor Incidence in Female Wiotar Rets and Formation of Large (>25 particles) Pu Aggregates After Inhalation of ${ }^{2 \mathrm{CP}} \mathrm{PuO}_{2}$

$(r=0.97)$ was obtained when data from this study were plotted (Figure 4). This indicates that variability from Pu solubility, animal strain, and sex, as well as dosimetric methodology, has a significant effect on characterization of the lung tumor

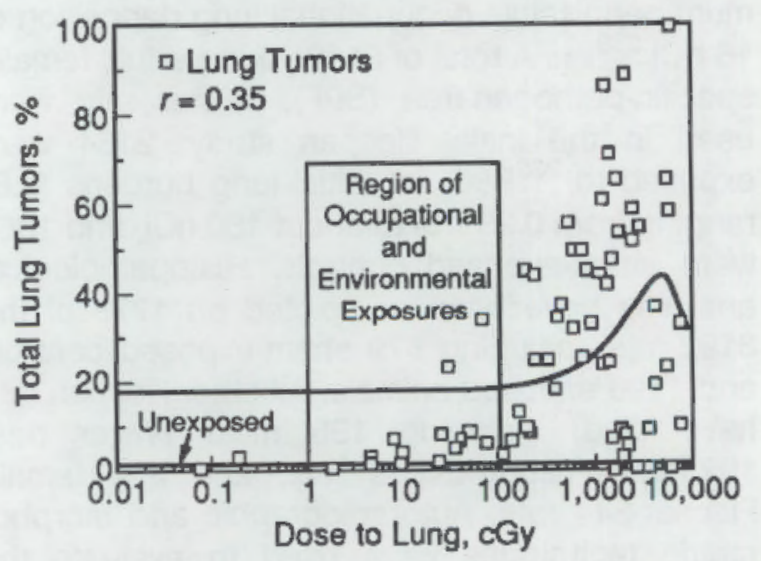

FIGURE 2. Incidence of Lung Tumors in Rats Exposed to Aerosols of Soluble and insoluble Pu Compounds. Variability results from animal otrain, dosimetry methodology and Pu solubility. Data were fitted by quadratic polynomial aquation.

response in rats. Great care should be used when combining data from different studies with rats exposed to Pu aerosols for purposes of radiation risk analyses. 


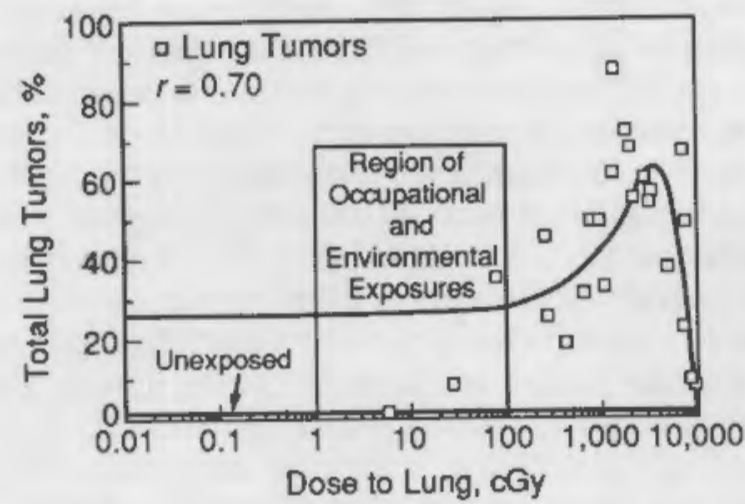

FIGURE 3. Incidence of Lung Tumors in Rats Exposed to Aerosols of ${ }^{239} \mathrm{PuO}_{2}$. Variability is related to animal strain, sex, and exposure, and to dosimetry methodology. Data were fitted by quadratic polynomiel equation.

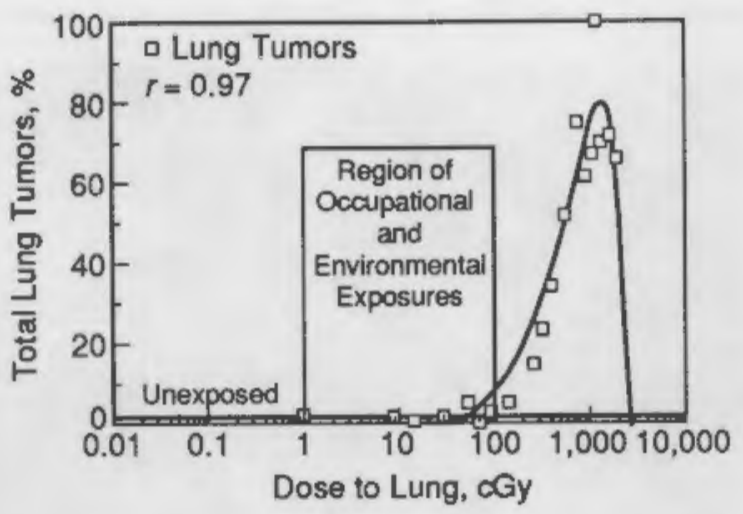

FIGURE 4. Incidence of Lung Tumors in Female Wistar Rats (this study) Exposed to Aerosol of ${ }^{239} \mathrm{PuO}_{2}$. Minimal variability is seen. Data were fitted by quadratic polynomial equation.

Scanning electron microscopic (SEM) and light quantitative autoradiographic techniques have been developed for examining the spatial-temporal dose-distribution pattern of Pu particles in the left lobe of the lung (Sanders et al. 1988, Radiat. Res. 116:393; Sanders et al. 1989, Exp. Lung Res. 15:755). All airways sectioned at an oblique angle, exposing a flat epithelial surface, were examined by SEM autoradiography. The total area of this flat surface was measured, and the number of alpha stars contained therein were counted. Particle concentration was evaluated in airways with areas $>1 \mathrm{~mm}^{2}$ and $<1 \mathrm{~mm}^{2}$. Stars were differentiated according to position on the epithelial surface or radiating through the mucosa from immediately adjacent alveoli. For all airways, about five times more alpha track exposure to the bronchiolar epithelium was delivered from plutonium particles found in peribronchiolar alveoli than from Pu particles on the bronchiolar surface. Little submucosal exposure was seen in airways $>1 \mathrm{~mm}^{2}$ (Figure 5), with alpha tracks being concentrated mostly in airways $<1 \mathrm{~mm}^{2}$ (Figure 6).

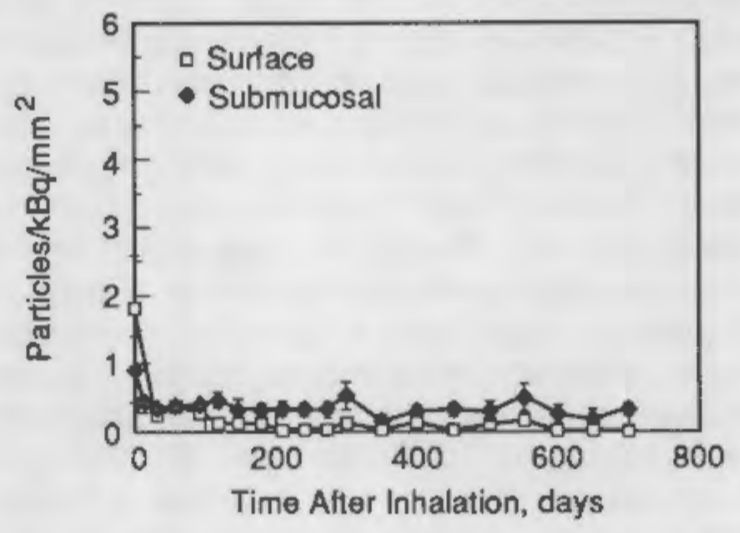

FIGURE 5. Quantitative Scanning Electron Microscopic (SEM) Autorediography of Pu Particle Distribution in Rat Lung Bronchioles After Inhalation of ${ }^{239} \mathrm{PuO}_{2}$ for Bronchioles $>1 \mathrm{~mm}^{2}$ in Surface Area. Values are means \pm standard error.

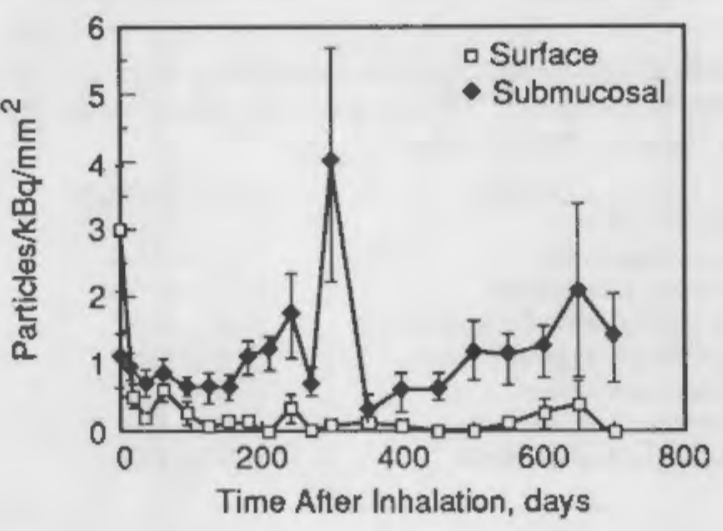

FIGURE 6. Quantitative Scanning Electron Microscopic (SEM) Autorediography of Pu Perticle Distribution in Rat Lung Bronchioles After Inhalation of ${ }^{239} \mathrm{PuO}_{2}$ for Bronchioles $<1 \mathrm{~mm}^{2}$. Values are means \pm standard error. 
Aggregated peribronchiolar Pu particles appeared to be more often retained in the lung because of associated inflammatory and fibrotic processes, while most other alveolar particles were more rapidly cleared from the lung. Prolonged peribronchiolar particle retention appeared to play a prominent role in the development of lung carcinomas. Primary lung carcinoma formation is preceded by a cellular evolution of focal inflammation, fibrosis, and epithelial hyperplasia and metaplasia associated with Pu aggregates. A much higher cell turnover is seen in pulmonary cells associated with $\mathrm{Pu}$ aggregates than in other areas of the exposed lung. Proliferative rates of hyperplastic, metaplastic, and neoplastic lesions, often associated with regions of $\mathrm{Pu}$ aggregation, were similar to those seen in alveolar tissues encompassing Pu aggregates (Table 2). Bronchiolarization appeared to be associated with $\mathrm{Pu}$ particle aggregation and to precede adenocarcinoma formation (Figure 7). Squamous metaplasia, a precursor proliferative lesion of squamous carcinoma, appeared to arise in areas of substantial alveolar fibrosis associated with aggregation of Pu particles. Morphological evidence indicates that type 2 alveolar epithelium may become ciliated and differentiated into "bronchiole-like" epithelial cells (Figure 8). If $\mathbf{s O}$ ciliated bronchiole-like cells may not arrive from migration from terminal bronchiolar epithelium but may be derived from alveolar epithelium. This would make the alveoli the target for most carcinomas, rather than the terminal bronchioles.

TABLE 2. Tritiated Thymidine-Labeled Pulmonary Cell Nuclel After Inhalation of ${ }^{239} \mathrm{PuO}_{2}$. Values are means \pm standard error $>100$ days after inhalation.

\begin{tabular}{lcc}
\multicolumn{1}{c}{ Tisaue } & & Labeled Nuclei, \% \\
\cline { 1 - 1 } Control alveoli & $0.21 \pm 0.03$ \\
Expoesd alveoli & & $0.51 \pm 0.08$ \\
Control bronchioles & & $0.40 \pm 0.06$ \\
Region of large Pu aggregates & & $3.03 \pm 0.42$ \\
Bronchiolarization lasions & & $3.00 \pm 0.66$ \\
Adenocarcinomas & $2.17 \pm 0.65$ \\
Squamous metaplasias & & $4.47 \pm 1.54$ \\
Squamous carcinemas & & $6.84 \pm 1.39$
\end{tabular}

Quantitative SEM and light autoradiography was carried out in the left lung lobe of female LongEvans and Fischer rats and male Wistar rats and compared with previously published data from female Wistar rats (Table 3 ). Mean radiation doses to the lung at death were similar (10 Gy for female Long-Evans and Fischer rats; 11 Gy for female
Wistar rats; 12 Gy for male Wistar rats). However, bronchiolar submucosal alpha-track exposure from Pu particles in peribronchiolar alveoli was substantially less in male Wistar and female Long-Evans rats (Figures 9 through 11, respectively). Likewise, the formation of large Pu particle aggregates was substantially less in male Wistar and female LongEvans rats. Strain and sex differences in plutonium particle distribution may result from differences in lung clearance. The incidence of lung tumors (by gross appearance only) was also related to SEM and light quantitative autoradiographic data. That is, male Wistar ( $55 \%$ incidence) and female LongEvans ( $35 \%$ incidence) rats had the lowest incidences of lung tumors as compared to female Wistar (73\% incidence) and Fischer ( $73 \%$ incidence) rats. The significance of these differences awaits further dosimetric and pathological analyses.

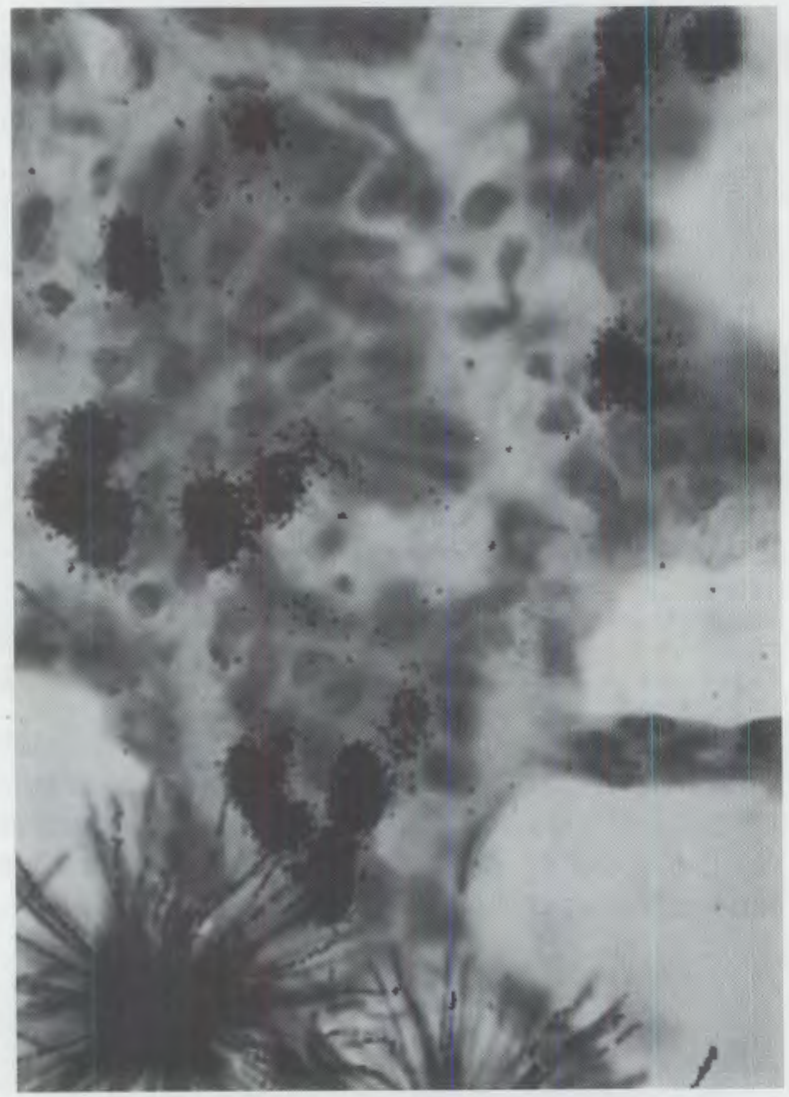

FIGURE 7. Area of Alveolar Bronchiolarization with High incidence of Nuclei Labelpd with Tritiated Thymidine (3-month exposure of autoradiogram) 

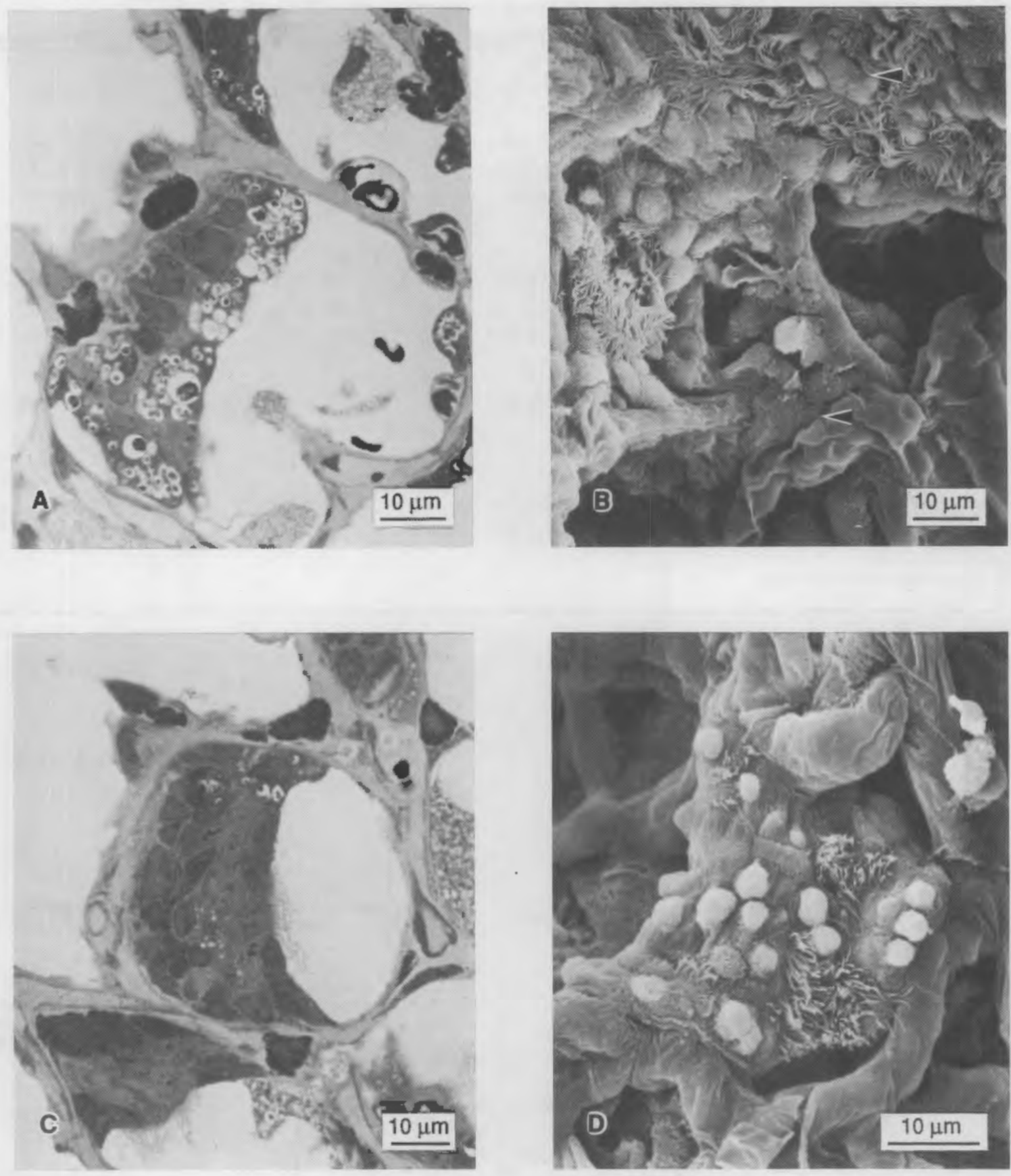

FIGURE 8. (A) Hyperplasia of Type 2 Alveolar Eplthelium at 210 Days After Pu Exposure; (B) SEM View of Type 2 Alveolar Epithelial Hyperplasia (arrowheads) Near a Terminal Bronchiole; (C) Alveolar Bronchiolarization Partially Filling Alveoli with Ciliated and Nonciliated Cells at 300 Days; (D) SEM View of Alveolar Bronchiolarization at 700 Days After Inhalation of Pu 
TABLE 3. Fole of Strain and Gender in Quantitative Scenning Electron Microscopic (SEM) and Light Autoradiographic Distribution of Inhaled ${ }^{239} \mathrm{PuO}_{2}$ in the Left Lung Lobe of the Rat. Values are means \pm standard error.

Number of Rats

Initial alveolar

deposition (kBq)

Dose to lung (Gy)

Time after exposure (days)

Incidence of lung

tumore (\%) (a)
Wistar Male

56

$3.4 \pm 0.1$

$12.2 \pm 0.4$

$566 \pm 14$

55.0
Wistar Female

39

$3.0 \pm 0.1$

$10.7 \pm 0.4$

$521 \pm 18$

72.9
Long-Evans Female

54

$2.8 \pm 0.1$

$9.8 \pm 0.3$

$607 \pm 22$

35.0

$6.2 \pm 0.5$

$15.4 \pm 1.4$

$0.01 \pm 0.01$

$7.9 \pm 1.3$

$<0.01$

Bronchiolar surface

particle concentration

(perticles/kBq/mm²)

Bronchiolar submucosal

particle concentration

(particles/kBq/mm²)
$0.01 \pm 0.03 \quad 0.27 \pm 0.04$
$7.6 \pm 0.4$

$9.3 \pm 1.2$

$0.01 \pm 0.01$

$0.05 \pm 0.02$

$50 \pm 11$

$100 \pm 8$

$1.5 \pm 0.5$

$5.4 \pm 0.6$

Percent aggregates

$65 \pm 10$

$1.6 \pm 0.4$

$3.6 \pm 0.6$

(a) By gross observation of lungs.

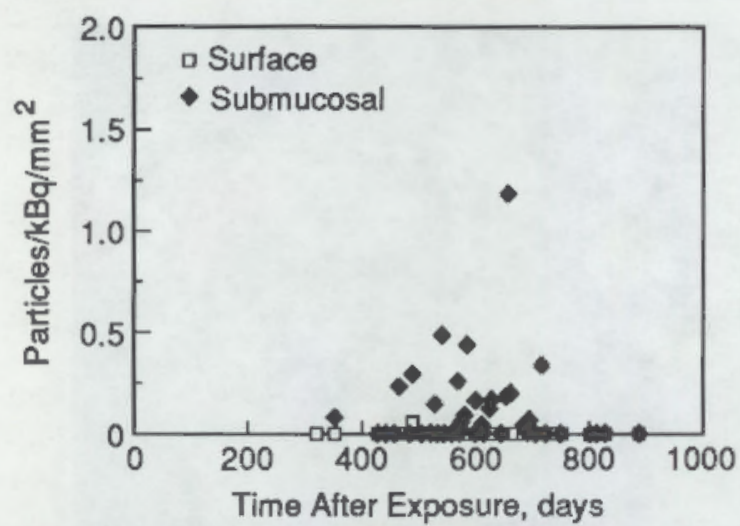

FIGURE 9. Quantitative Scanning Electron Microscopic (SEM) Autoradiography of Pu Particle Distribution in Bronchioles in Male Wistar Rats. Each point represents one animal. Solid bars on horizontal axis, composed of many overlying points, are zero values.

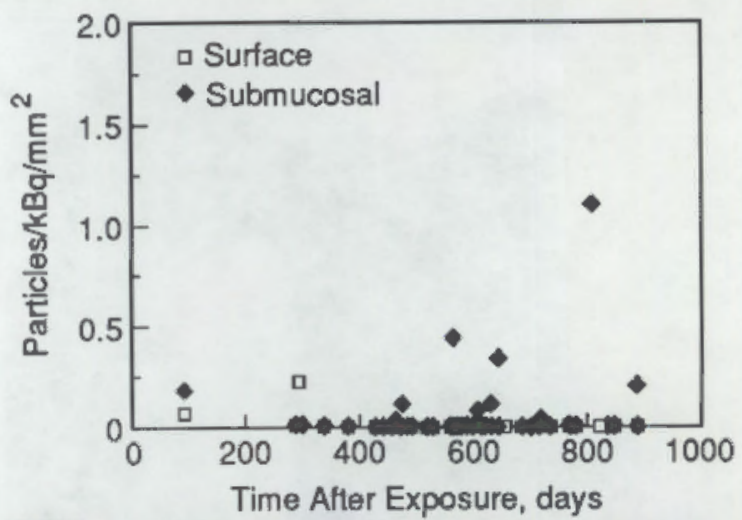

FIGUFE 10. Quantitative Scanning Electron Microscopic (SEM) Autoradiography of Pu Particle Distribution in Bronchioles in Female Long-Evans Rats. Each point represents one animal. Solid bars on horizontal axis, composed of many overlying points, are zero values.

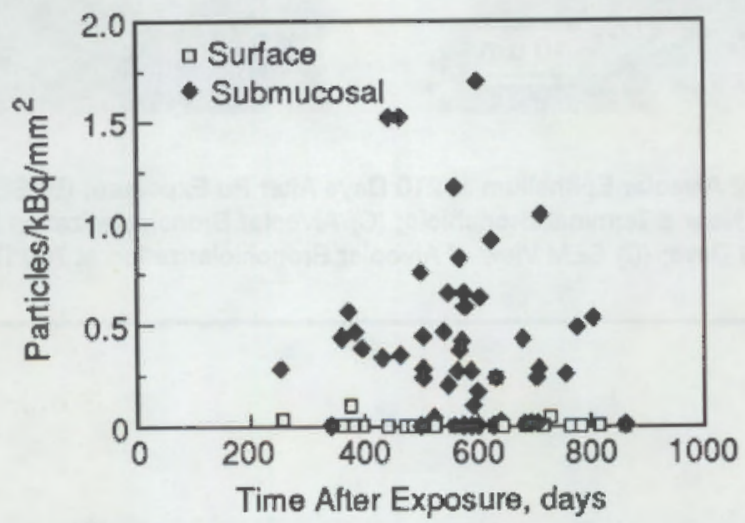

FIGUAE 11. Quantitative Scanning Elactron Microscopic (SEM) Autoradiography of Pu Particle Distribution in Bronchioles in Female Fischer Rate. Each point represents one animal. Solid bara on horizontal axis, composed of many overlying points, are zero values. 


\title{
Inhalation Hazards to Uranium Miners
}

\section{Principal Investigator: F. T. Cross}

\author{
Other Investigators: R. L. Buschbom, G. E. Dagle, K. M. Gideon, R. A. Gies, and \\ E. S. Gilbert
}

\section{Technical Assistance: C. R. Petty}

Using both large and small experimental animals, we are investigating levels of air contaminants that produce respiratory system disease in radon-exposed populations. Lung cancer incidence and deaths from degenerative lung disease are significantly elevated among uranium miners, but the cause-effect relationships for these diseases are based on inadequate epidemiological data. This project identifies agents or combinations of agents (both chemical and radiological), and their exposure levels, that produce respiratory tract lesions, including respiratory epithelial carcinoma, pneumoconiosis, and emphysema. Exposures of male rats to radon daughters, uranium ore dust, and cigarette-smoke mixtures $(11,000$ Series experiments) and of female rats to radon daughters and uranium ore dust (12,000 Series experiments) were completed. Histopathological data on previously completed 8000 Series animals showed that the risk of lung tumors decreases in proportion to cumulative radon-daughter exposures and remains elevated at exposures comparable to those found in houses [ 40 working-level months (WLM)]. Histopathological examination was completed on 11,000 Series animals serially sacrificed at 25 and 52 weeks from start of exposures. Thus far, lesions, including tumors, are most severe in rats receiving continuous rather than split-dose exposures to radon daughters and uranium ore dust. No tumors were observed in any of the groups with ancillary cigarette-smoke exposures; however, adenomatosis was more severe and prevalent in rats exposed to cigarette smoke after radon-daughter and uranium ore-dust exposures than before these exposures.

A search for nonrespiratory neoplasms following radon exposures of Wistar rats revealed a trend and excess of malignant kidney neoplasms versus cumulative radon-daughter exposure level similar to data reported on Sprague-Dawley rats elsewhere.

\section{Small-Animal Studies}

Exposure Protocols. The 6000 Series (1000working level; WL) and 7000 Series (100-WL) experiments (Table 1) are designed to develop the relationships between response and exposure to radon daughters (at two rates of exposure) and carnotite uranium ore dust. The 8000 Series (100WL) experiments (Table 2) are designed to extend the exposure-response relationships to cumulative exposure levels comparable to current conditions in the mines and to lifetime environmental exposures. The 9000 Series experiments (Table 3) continue the "low-dose" studies at exposure rates comparable to former occupational working levels (10 WL). They will help to further evaluate the hypothesis that the tumor probability per workinglevel-month (WLM) exposure increases with decreasing exposure rate. In addition, concurrent exposure to varying levels of uranium ore dust tests the hypothesis that irritants (both specific and nonspecific) act synergistically with radiation exposures. The exposures of 6000,7000 , and 8000 Series animals are completed. Exposures of 9000 Series animals are temporarily discontinued, ceasing with the $80-W L M$ and $15 \mathrm{mg} / \mathrm{m}^{3}$ ore-dust exposures, pending analyses of existing data. Exposures of rats to uranium ore dust alone (10,000 Series experiments; Table 4) are completed. The ore-dust studies address recent experimental data in rats (as well as human epidemiological data) linking silica exposures to 
TABLE 1. Exposure-Response Relationship Study for RadonDaughter Carcinogenesis in Rats (6000 and 7000 Series Experiments)

\begin{tabular}{|c|c|c|}
\hline $\begin{array}{l}\text { Number of } \\
\text { Animals }(\mathrm{a}) \\
\end{array}$ & Exposure Regimen $(b, c)$ & $\begin{array}{l}\text { Total } \\
\text { Exposyre, } \\
\text { WLM }^{(d)} \\
\end{array}$ \\
\hline 32 & $\begin{array}{l}1000-W L \text { radon daughters } \\
15 \mathrm{mg} / \mathrm{m}^{3} \text { uranium ore dust }\end{array}$ & 10,240 \\
\hline 32 & $\begin{array}{l}1000-W L \text { radon daughters } \\
15 \mathrm{mg} / \mathrm{m}^{3} \text { uranium ore dust }\end{array}$ & 5,120 \\
\hline 32 & $\begin{array}{l}1000-W L \text { radon daughters } \\
15 \mathrm{mg} / \mathrm{m}^{3} \text { uranium ore dust }\end{array}$ & 2,560 \\
\hline 32 & $\begin{array}{l}1000-W L \text { gadon daughters } \\
15 \mathrm{mg} / \mathrm{m}^{3} \text { uranium ore dust }\end{array}$ & 1,280 \\
\hline 64 & $\begin{array}{l}1000-W L \text { radon daughters } \\
15 \mathrm{mg} / \mathrm{m}^{3} \text { uranium ore dust }\end{array}$ & 640 \\
\hline 128 & $\begin{array}{l}1000 \mathrm{WL} \text { radon daughters } \\
15 \mathrm{mg} / \mathrm{m}^{3} \text { uranium ore dust }\end{array}$ & 320 \\
\hline 64 & Controls & \\
\hline
\end{tabular}

(a) Number of animals is surficient to detect the predicted incidence of lung tumors at the 0.05 to 0.1 level of significence, assuming linearity of response between 0 and 9200 WLM (see footnote d), end $0.13 \%$ spontaneous incidence.

(b) Exposure rate, $90 \mathrm{hr} / \mathrm{wk}$; planned periodic sacritice.

(c) Study will be repeated at 100-WL rate (without perlodic sacrifice) to augment previous limitad exposure-rete date (7000 Series experiments).

(d) Working level (WL) is defined as eny combinetion of the short-lived radon daughters in 1 liter of eir that will result in the ultimate emission of $1.3 \times 10^{5} \mathrm{MeV}$ of potential $\alpha$ energy. Working-level month (WLM) is en exposure equivalent to 170 hours at a $1-W L$ concentration. Previous exposura et 900 WL for $84 \mathrm{hr} / \mathrm{wk}$ to 9200 WLM produced an $80 \%$ incidence of carcinoma.

lung cancer. Because the silica content of the ore dust in the animal studies exceeds $60 \%$, this potential link in the response to combined oredust and radon-daughter exposures needs to be clarified. Exposures of rats to radon daughters, uranium ore dust, and cigarette-smoke mixtures [initiation-promotion-initiation (IPI; 11,000 Series) experiments; see Mechanisms of Radon Injury project, this volume] were completed this fiscal year. These experiments clarify the induction-promotion relationships of radon and cigarette-smoke exposures. Exposures of female rats $(12,000$
TABLE 2. Low Exposure-Response Relationship Study for Radon-Daughter Carcinogenesis in Rate (8000 Series Experiments)

\begin{tabular}{|c|c|c|}
\hline $\begin{array}{l}\text { Number of } \\
\text { Animals }(\theta) \\
\end{array}$ & Exposure Regimen (b) & $\begin{array}{c}\text { Total } \\
\text { Exposyre, } \\
\text { WLM } \\
\end{array}$ \\
\hline 64 & $\begin{array}{l}100 \mathrm{WL} \text { redon deughters } \\
15 \mathrm{mg} / \mathrm{m}^{3} \text { uranium ore dust }\end{array}$ & $640^{(d)}$ \\
\hline 64 & $\begin{array}{l}100 \mathrm{WL} \text { regdon daughters } \\
15 \mathrm{mg} / \mathrm{m}^{3} \text { uranium ore dust }\end{array}$ & $320^{(d)}$ \\
\hline 160 & $\begin{array}{l}100-W L \text { radon daughters } \\
15 \mathrm{mg} / \mathrm{m}^{3} \text { uranium ore dust }\end{array}$ & 160 \\
\hline 352 & $\begin{array}{l}100-\mathrm{WL} \text { radon daughtere } \\
15 \mathrm{mg} / \mathrm{m}^{3} \text { uranium ore dust }\end{array}$ & 80 \\
\hline 448 & $\begin{array}{l}100 \mathrm{WL} \text { radon daughters } \\
15 \mathrm{mg} / \mathrm{m}^{3} \text { uranium ore dust }\end{array}$ & 40 \\
\hline 512 & $\begin{array}{l}100 \mathrm{WL} \text { radon daughters } \\
15 \mathrm{mg} / \mathrm{m}^{3} \text { uranium ore dust }\end{array}$ & 20 \\
\hline 192 & Controls & \\
\hline
\end{tabular}

(a) Number of animals is sufficient to detect lung tumors at the 0.05 to 0.1 level of significance, assuming linearity of response between 0 and 640 WLM (see footnote c), and $0.13 \%$ spontaneous incidence.

(b) Exposure rate, $90 \mathrm{hr} / \mathrm{wk}$; planned periodic sacrifice.

(c) Previous exposures indicated a tumor incidence of $16 \%$ at 640 WLM. Working level (WL) is defined as any combination of the short-lived radon daughters in 1 liter of air that will result in the ultimete emission of $1.3 \times 10^{5}$ $\mathrm{MeV}$ of potential $\alpha$-energy. Working-level month (WLM) is en exposure equivalent to 170 houre at a 1-WL concentration.

(d) Repeat exposure le for normalization with Table 1 data.

Series experiments; Table 5) were also completed. These experiments provide comparative risk data to exposures of male animals.

Resplratory Tract Pathology. A current summary of primary tumors of the respiratory tract for 8000 Series animals is shown in Table 6. These sampled data show that the risk of lung tumors decreases in proportion to the decrease in cumulative radon-daughter exposure, and remains elevated at exposures comparable to those found in houses (40 WLM). Histopathological examinations are in progress on the remainder of tissues from 8000,9000 , and 10,000 Series animals. 
TABLE 3. Ultralow Exposure-Rate Study for Fadon-Daughter Carcinogenesis in Rats ( 9000 Series Experiments)

\begin{tabular}{|c|c|c|c|}
\hline $\begin{array}{l}\text { Num } \\
\text { Anim }\end{array}$ & $\begin{array}{l}\text { nber of } \\
\text { mals }(\mathrm{a}) \\
\end{array}$ & Exposure Regimen (b) & $\begin{array}{l}\text { Total } \\
\text { Exposyre, } \\
\text { WLM }{ }^{(c)} \\
\end{array}$ \\
\hline & 64 & $\begin{array}{l}\text { 10WL radon daughters } \\
15 \mathrm{mg} / \mathrm{m}^{3} \text { uranium ore dust }\end{array}$ & 320 \\
\hline & 64 & $\begin{array}{l}\text { 10WL radon daughters } \\
3 \mathrm{mg} / \mathrm{m}^{3} \text { uranium ore duet }\end{array}$ & 320 \\
\hline & 352 & $\begin{array}{l}\text { 10WL radon daughters } \\
15 \mathrm{mg} / \mathrm{m}^{3} \text { uranium ore dust }\end{array}$ & 80 \\
\hline & 352 & $\begin{array}{l}\text { 10-WL radon daughters } \\
3 \mathrm{mg} / \mathrm{m} \text { uranium ore dust }\end{array}$ & 80 \\
\hline & 512 & $\begin{array}{l}\text { 10-WL radon daughters } \\
15 \mathrm{mg} / \mathrm{m}^{3} \text { uranium ore dust }\end{array}$ & 20 \\
\hline & 512 & $\begin{array}{l}\text { 10-WL redon daughtere } \\
3 \mathrm{mg} / \mathrm{m}^{3} \text { uranium ore dust }\end{array}$ & 20 \\
\hline & 192 & Controls & \\
\hline 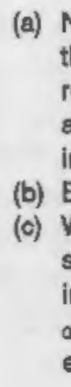 & \multicolumn{3}{|c|}{$\begin{array}{l}\text { Number of animals is sufficient to detect lung tumors at } \\
\text { the } 0.05 \text { to } 0.1 \text { level of significance, assuming linearity of } \\
\text { response between } 0 \text { and } 640 \text { WLM (tumor incidence is } \\
\text { approximately } 16 \% \text { at } 640 \text { WLM), and } 0.13 \% \text { sponteneous } \\
\text { incidence. } \\
\text { Exposure rete, } 90 \mathrm{hr} / \text { wk; planned periodic sacrifice. } \\
\text { Working level (WL) is defined as any combination of the } \\
\text { short-lived radon daughters in } 1 \text { liter of air that will result } \\
\text { in the ultimate emission of } 1.3 \times 10^{5} \mathrm{MeV} \text { of potential } \\
\alpha \text {-energy. Working-level month (WLM) is an exposure } \\
\text { equivalent to } 170 \text { hours at a } 1 \mathrm{WL} \text { concentration. }\end{array}$} \\
\hline
\end{tabular}

TABLE 4. Control Study for Uranium Ore-Dust Carcinogenesia in Rate $(10,000$ Saries Experiments)

$\begin{array}{ccc}\begin{array}{c}\text { Number of } \\ \text { Animals }\end{array} & & \text { Exposure Regimen (a) } \\ 96 & & 15 \mathrm{mg} / \mathrm{m}^{3} \text { urenium ore dust } \\ 64 & \text { Sham-exposed controls }\end{array}$

(a) Exposures, 12 to 18 monthe at 72 hrfwk; planned periodic secrifice.
TABLE 5. Exposure of Female Rats to Radon Daughters and Uranium Ore Dust (12,000 Serles Experiments)

Number of

Animals

96

100 WL radon daughtere; 640 WLM $5 \mathrm{mg} / \mathrm{m}^{3}$ uranium ore dust

96

Sham-exposed controls

(a) Exposure rate, $72 \mathrm{hr} / \mathrm{wk}$; planned periodic sacrifice. Working level (WL) is defined as any combination of the short-lived radon daughters in 1 liter of air that will result in the ultimate emission of $1.3 \times 10^{5} \mathrm{MeV}$ of potential $\alpha$-energy. Working-level month (WLM) is an exposure equivalent to 170 houre at a 1 WL concentration.

Histopathological exarnination was completed on $240 \mathrm{IPI}$-Series rats sacrificed at 25 and 52 weeks from beginning of mixed exposures to radon, radon daughters, uranium ore dust, and cigarette smoke (Table 7). Lesions were limited to the lungs and tracheobronchial lymph nodes (TBLN). At 25 weeks (which was also the time all except Group 1 exposures were completed), these consisted principally of aggregates of macrophages with phagocytosed dust in pulmonary alveoli and TBLN of all rats with exposures to uranium ore dust; minimal amounts of focal pulmonary interstitial reactions in $17 \%$ of the radon-daughter and uranium ore-dust-exposed rats; and a very slightly increased incidence of small amounts (or less) of focal adenomatous hyperplasia of alveolar epithelium. At 52 weeks, in addition to the phagocytosed dust, there was increased incidence and a slightly increased group average severity of interstitial reaction and adenomatous hyperplasia of alveolar epithelium; in addition, a very low incidence of small benign lung tumors occurred. The most severe lesions occurred in group 1 rats given continuous exposure for 8 weeks to radon daughters and uranium ore dust. Thus far, group 3 rats receiving split-dose radon-daughter and uranium ore-dust exposures show fewer tumors than the group 1 rats continuously exposed. No tumors were observed in groups 5 , 
TABLE 6. Current Summary of Primery Tumore of the Respiratory Tract ( 8000 Series Experiments)

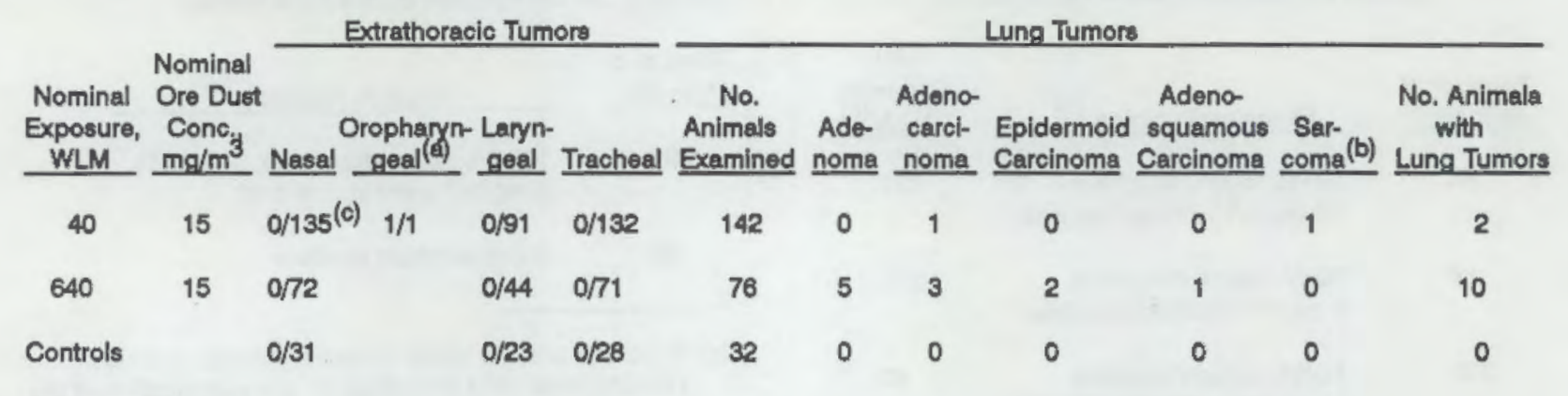

(a) One malignant hemangiosarcoma, considered radon-daughter-exposure-related; found in tissue nof routinely sectloned for histopathology.

(b) One malignant hemangiopericytoma, considered radon-daughter-exposure-related.

(c) Number tumors/number examined.

7,9, or 11 rats exposed concomitantly to cigarette smoke; however, adenomatosis (considered to be a preneoplastic lung lesion) was more prevalent and severe in group 7 rats exposed to cigarette smoke after radon-daughter exposures than in group 9 rats exposed to cigarette smoke before radon-daughter exposures. There was substantially less inflammatory reaction and essentially no proliferative activity of pulmonary epithelium in group 11 rats exposed to uranium ore dust and cigarette smoke without accompanying radondaughter exposures.

\section{Nonrespiratory Neoplasms Following Radon Exposure}

While data exist on a variety of neoplastic and preneoplastic lesions of the respiratory tract following inhalation of radon and daughters, there are very few data on nonrespiratory neoplasms. A group of 231 control rats and 1056 rats previously exposed to radon, radon daughters, and uranium ore dust at various levels and rates were selected for study. Apart from tracheobronchial lymph nodes (TBLN) and kidneys, no other organs or tissues were routinely searched for nonrespiratory neoplasms at necropsy. Neoplastic lesions reported in other organs or tissues, therefore, are incidental findings and may be underestimated in both control and exposed animals.

Neoplastic lesions were noted in the liver, spleen, kidney, TBLN, thyroid, adrenals, skin, bone, stomach, intestine, bladder, prostate, testes, thymus, mediastinum, and heart. No trend and excess of nonrespiratory benign neoplasms versus ore-dust concentration or radon-daughter exposure level or exposure rate were noted in any rat organ or tissue in these exposures. This was not the case for malignant neoplasms, however; a trend and excess of malignant kidney neoplasms were noted versus cumulative radon-daughter exposure level when all exposure rates were combined. These data are shown in Table 8 for those organs or tissues having an incidence of nonrespiratory malignant neoplasms of about $0.5 \%$ or greater. The kidney incidence data shown in boxes are significantly higher $(p \leq 0.05)$ than the incidence data in control animals. The types and incidences of kidney neoplasms are shown in Table 9. There was no significant trend in kidney malignant neoplasms attributable to radon-daughter exposure rate, radon-daughter exposure level at a fixed exposure rate, or uranium ore-dust concentration. The relatively small number of malignant kidney neoplasms may have precluded establishing significance versus radon-daughter exposure level at a fixed exposure rate.

The excess incidence of kidney neoplasms in Wistar rats at PNL corroborates that reported in Sprague-Dawley rats at the Compagnie Générale Des Matières Nucléaires Laboratoire in France following inhalation of radon and daughters. 
TABLE 7. Primary Lesions of the Lung in 25- and 52-Week Sacrifleed Rats $(11,000 \text { Serles IPI Experiments) })^{(a)}$

\begin{tabular}{|c|c|c|c|c|c|c|}
\hline \multirow[b]{2}{*}{ Group Number } & \multirow[b]{2}{*}{ Exposure Regimen (c) } & \multirow[b]{2}{*}{$\begin{array}{l}\text { Sacrifice } \\
\text { TIme, wk }\end{array}$} & \multicolumn{4}{|c|}{ Number of Rate (and Group Average Severity) ${ }^{(b)}$ of: } \\
\hline & & & $\begin{array}{l}\text { Interstitlal } \\
\text { Reaction }\end{array}$ & $\begin{array}{c}\text { Duot } \\
\text { Macrophages }\end{array}$ & Adenomatosis & Tumore \\
\hline \multirow[t]{2}{*}{1} & 320 & 25 & $5(0.5)$ & $10(1.9)$ & 0 & 0 \\
\hline & & 52 & $7(1.0)$ & $10(2.0)$ & $6(1.0)$ & 4 \\
\hline \multirow[t]{2}{*}{2} & Sham-exposed controls & 25 & 0 & 0 & $1(0.1)$ & 0 \\
\hline & & 52 & $2(0.2)$ & 0 & $2(0.3)$ & 0 \\
\hline \multirow[t]{2}{*}{3} & 160/Shelt/160 & 25 & $1(0.1)$ & $10(1.2)$ & $1(0.1)$ & 0 \\
\hline & & 52 & $5(0.5)$ & $10(2.0)$ & $3(1.4)$ & 1 \\
\hline \multirow[t]{2}{*}{4} & Sham-exposed controls & 25 & 0 & 0 & 0 & 0 \\
\hline & & 52 & $1(0.1)$ & 0 & $1(0.3)$ & 0 \\
\hline \multirow[t]{2}{*}{5} & $160 /$ Smoke/160 & 25 & 0 & $10(1.6)$ & $2(0.5)$ & 0 \\
\hline & & 52 & $8(1.6)$ & $10(2.0)$ & $5(1.2)$ & 0 \\
\hline \multirow[t]{2}{*}{6} & Sham-exposed controls & 25 & 0 & 0 & 0 & 0 \\
\hline & & 52 & $2(0.2)$ & 0 & 0 & 0 \\
\hline \multirow[t]{2}{*}{7} & $320 /$ Smoke & 25 & $3(0.4)$ & $10(2.0)$ & $1(0.1)$ & 0 \\
\hline & & 52 & $6(0.7)$ & $10(1.9)$ & $5(1.1)$ & 0 \\
\hline \multirow[t]{2}{*}{8} & Sham-exposed controls & 25 & 0 & 0 & 0 & 0 \\
\hline & & 52 & $2(0.3)$ & 0 & 0 & 0 \\
\hline \multirow[t]{2}{*}{9} & Smoke/320 & 25 & $1(0.1)$ & $10(1.9)$ & 0 & 0 \\
\hline & & 52 & $4(0.5)$ & $10(1.9)$ & $1(0.1)$ & 0 \\
\hline \multirow[t]{2}{*}{10} & Sham-exposed controls & 25 & 0 & 0 & 0 & 0 \\
\hline & & 52 & $1(0.2)$ & 0 & 0 & 1 \\
\hline \multirow[t]{2}{*}{11} & Ore dust/smoke & 25 & 0 & $10(2.0)$ & 0 & 0 \\
\hline & & 52 & $2(0.3)$ & $10(1.9)$ & 0 & 0 \\
\hline \multirow[t]{2}{*}{12} & Sham-exposed controls & 25 & 0 & 0 & 0 & 0 \\
\hline & & 52 & 0 & 0 & 0 & 0 \\
\hline
\end{tabular}

(a) Moderately low concentrations $\left(5 \mathrm{mg} / \mathrm{m}^{3}\right)$ of uranium ore dust $(2 \% \mathrm{U}$ content) accompanied radon exposures as a carrier aerosol for the daughters; 10 animals were sacrifliced in oach group at each sacrifice time.

(b) Group average lesion severity is given in parentheses: +1 (very slight); +2 (slight); +3 (moderate); +4 (marked); +5 (extreme).

(c) Radon-daughter exposures shown are nominal; $320=320-W L M(100-W L)$ radon daughters + uranium ore dust delivered in 8-wk exposure period $160 /$ Shelf $/ 160=160 \mathrm{WLM}(4 \mathrm{wk}) / \mathrm{Shelf}(17 \mathrm{wk}) / 160 \mathrm{WLM}(4 \mathrm{wk})$.

All exposures except group 1 were completed in 25 weeks; cigarette-smoke exposures were $1 \mathrm{hr} / \mathrm{d}, 5 \mathrm{~d} / \mathrm{wk}$ for 17 weeks at $0.5 \mathrm{mg} / \mathrm{L}$ total particulate masa concentration. Working level $\mathrm{WL}$ ) is defined as any combination of the short-lived radon daughtere in 1 liter of air that will result in the ultimate emiselon of $1.3 \times 10^{5} \mathrm{MeV}$ of potential $\alpha$-energy. Working-level month (WLM) is an exposure equivalent to 170 hours at a $1-W L$ concentration. 
TABLE 8. Percent Incidence of Nonrespiratory Malignant Neoplesm Vereus Radon-Peughter Exposure Level (all exposure rates combined) (a)

Exposure, WLM

Organ $0 \quad 320 \quad 640 \quad \underline{1280} \underline{2560} \underline{5120} \quad 10,240$

\begin{tabular}{|c|c|c|c|c|c|c|c|}
\hline Liver & 3.0 & 1.8 & 1.5 & - & 2.6 & 2.7 & - \\
\hline Spleen & 6.5 & 4.5 & 5.6 & 1.4 & 3.9 & 1.4 & 1.9 \\
\hline Kidney & 0.43 & 1.1 & 2.6 & 1.4 & 3.9 & - & - \\
\hline TBLN ${ }^{(b)}$ & 1.7 & 0.91 & 0.37 & - & - & - & - \\
\hline Thyroid & 0.87 & 0.68 & 0.75 & 4.3 & 0.66 & - & - \\
\hline Adrenal & 3.0 & 1.1 & 0.75 & - & 1.3 & - & - \\
\hline Skin & 6.1 & 5.2 & 4.9 & 10 & 7.2 & 4.1 & 9.6 \\
\hline Bone & 1.3 & 0.45 & - & - & 0.66 & - & - \\
\hline
\end{tabular}

(e) Data in boxes are significantly $(\rho \leq 0.05)$ higher than control animal data; the absence of data indicates no tumors were noted at necropsy. Uranium ore dust accompanied all radon exposures as a carrier aerosol for the daughters.

(b) TELN, tracheobronchial lymph nodes.
TABLE 9. Types and Incidences of Kidney Neoplasms Following, Uranium Ore-Dust and Radon-Daughter Exposure $($ e $)$

\begin{tabular}{|c|c|c|}
\hline Malignant Neoplasms & 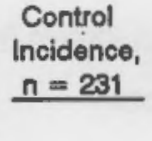 & $\begin{array}{r}\text { Exposed } \\
\text { Incidence, } \\
n=1056 \\
\end{array}$ \\
\hline $\begin{array}{l}\text { Liposarcoma } \\
\text { Malignant nephroma } \\
\text { Renal carcinoma } \\
\text { Hemangiosarcoma } \\
\text { Transitional cell carcinoma }\end{array}$ & $\begin{array}{l}0 \\
0 \\
0 \\
0 \\
1\end{array}$ & $\begin{array}{r}13 \\
1 \\
3 \\
1 \\
1\end{array}$ \\
\hline Benign Neoplasms & & \\
\hline $\begin{array}{l}\text { Nephroma } \\
\text { Adenoma }\end{array}$ & $\begin{array}{l}0 \\
1\end{array}$ & $\begin{array}{l}3 \\
4\end{array}$ \\
\hline
\end{tabular}

(a) Uranium ore dust ( 2 to $4 \% \mathrm{U}$ content) accompanied radon exposures as a carrier aerosol for the daughters; concentrations generally ranged between 3 and $15 \mathrm{mg} / \mathrm{m}^{3}$. 


\title{
Mechanisms of Radon Injury
}

\section{Principal Investigator: F. T. Cross}

\author{
Other Investigators: R. L. Buschbom, G. E. Dagle, E. W. Fleck, ${ }^{(a)}$ M. E. Frazier, \\ R. A. Gies, A. C. James, R. F. Jostes, F. C. Leung, \\ S. H. Moolgavkar, ${ }^{(b)}$ T. L. Morgan, L. G. Smith, and \\ G. L. Stiegler
}

\section{Technical Assistance: T. L. Curry and C. R. Petty}

In this project we conduct molecular, cellular, and whole-animal research relevant to understanding the mechanisms of radon and radon-daughter injury to the respiratory tract. The work specifically addresses the exposure-rate effect in radon-daughter carcinogenesis; the induction-promotion relationships associated with exposure to radon and cigarette-smoke mixtures; the role of oncogenes in radon-induced cancers; the effects of radon on DNA as well as on DNA repair processes; and the involvement of growth factors and their receptors in radon-induced carcinogenesis. Experiments revealed that there is abnormal expression of epidermal growth factor, as well as transforming growth factor- $\alpha$, in radon-induced rat lung epidermoid carcinomas.

Survival response data on Chinese hamster ovary cells (CHO-C18) exposed to radon and radon daughters revealed a $D_{37}$ value of about 75 -cGy dose to the cell nucleus. Southern blot analyses of radon-induced mutations at the CHO-HGPRT locus have shown predominantly deletion-type events in contrast to a low percentage of deletion-type events in spontaneous mutants. Chromosome deletions in human peripheral blood lymphocytes increased as metaphases were collected at later time intervals following radon and radon-daughter exposures. Initiation-promotion-initiation experiments continued in male SPF Wistar rats exposed to radon and cigarette-smoke mixtures. Carcinogenesis modeling of PNL experimental data on radon-induced lung tumors in rats also continued.

\section{Growth Factor and Growth Factor Receptor Studies}

We are using immunocytochemical assays to examine the involvement of growth factors (GF) and growth factor receptors (GFR) in radoninduced and spontaneously occurring lung tumors that have been preserved in paraffin block sections.

The lungs of 32 sham-exposed control rats and 32 rats nominally exposed to $15 \mathrm{mg} / \mathrm{m}^{3}$ uranium ore dust and 5120 working-level months (WLM) of radon daughters at an exposure rate of 50 WLM/ wk were examined for epidermal growth factor

(a) Whitman College, Walla Walla, Washington.

(b) Fred Hutchinson Cancer Peesearch Certer, Seattle, Washington.
(EGF) and transforming GF- $\alpha$ (TGF- $\alpha$ ) expression. One of 32 control rats and 25 of 32 exposed rats had tumors; positive, specific EGF and TGF- $\alpha$ tumor staining was present only in epidermoid carcinomas (Table 1). These data and other radon-related GF and GFR data are discussed further in the report on Growth Factors in Radiation Carcinogenesis (this volume).

\section{In Vitro Radon Cell-Exposure System and Cellular Studies}

The PNL in vitro radon cell-exposure system was extensively employed in PNL experiments as well as in several collaborative and intercalibration experiments with other laboratories. A real-time exposure monitor system for cells irradiated in culture medium was designed, and studies to determine cellular microdosimetry continued (see Microdosimetry of Radon Daughters, this volume). 
TABLE 1. Epidermal Growth Factor (EGF) and Transforming Growth Factor- $\alpha$ (TGF- $\alpha$ ) Staining in Primary Lung Tumors of Sham-Exposed Control Rats and Rats Exposed to $15 \mathrm{mg} / \mathrm{m}^{3}$ Uranium Ore Dust and 5120WLM Radon Daughters at 50 WLM/wk (a)

Histological Type
Epidermoid carcinoma
Adenocarcinoma
Adenoma
Adenosquamous
carcinoma
Histiogytoma
(c)

Number Positive/Number Examined

$\begin{array}{ccc}\text { EGF } & & \text { TGF- } \alpha \\ 14 / 14 & & 13 / 14 \\ 0 / 7 & & 0 / 7 \\ 0 & & 0 \\ 1 / 1 \text { (b) } & 1 / 1 \text { (b) }\end{array}$

(a) Tumor tlssue obtained from 7000 Series experimente (8ee Inhalation Hezards to Uranium Miners, this volume).

(b) Positive staining noted only in squamous carcinoma portion.

(c) A malignent histlocytoma wes found in one control and in one expoeed ret.

Intercalibration experiments employed a common cell line (CHO-C18) and biological endpoint (cell survival). Survival response data are shown in Figure 1 for ${ }^{222} \mathrm{Rn}$ and daughters, ${ }^{212} \mathrm{Bi}$, and 250-kVp [half-value layer (HVL), 1.06-mm Cu] x-ray exposure. $\mathrm{A} \mathrm{D}_{37}$ value of approximately 75-cGy dose to the cell nucleus was determined at PNL for ${ }^{222} \mathrm{Rn}$ and radon-daughter exposure. Similar values were noted at Case Western Reserve University $\left({ }^{222} \mathrm{Rn}\right.$ and daughters); Argonne National Laboratory ${ }^{222} \mathrm{Rn}$ and daughters); and the University of Chicago $\left({ }^{212} \mathrm{Bi}\right)$. A slightly lower value was obtained at Los Alamos National Laboratories using a ${ }^{238} \mathrm{Pu}$ source.

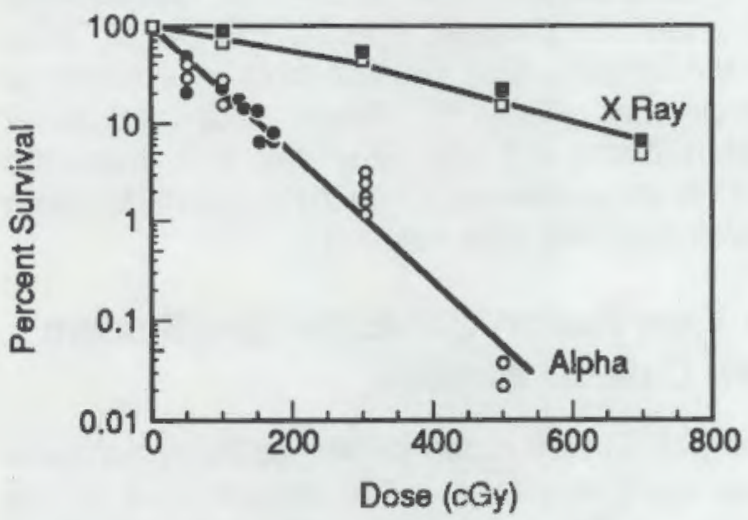

FIGUAE 1. $\mathrm{CHO}$ - 18 Cell Survival After Exposure to ${ }^{222} \mathrm{Rn}$ and Daughters, ${ }^{212} \mathrm{Bi}$, and $250-\mathrm{kVp}$ (hali-value layer (HVL), 1.06-mm Cu] X Rays (PNL, ${ }^{222} \mathrm{Rn}$ and daughters: $\bullet$, $x$ rays: ${ }^{\text {; }}$ University of Chicago, ${ }^{212}$ Bi: $O ; x$ rays: $\square$ ).
Radon-induced mutations at the CHO-HGPRT locus have been isolated after two 100-cGy exposures and have been evaluated using Southern blot techniques. Mutations obtained at this locus after radon and radon-daughter exposure are predominantly deletion events (50\%), with $23 \%$ showing no change from the parental line and $27 \%$ showing a rearrangement of the banding patterns. In contrast, spontaneous mutants exhibit a low percentage of deletion-type events $(13 \%)$ compared with $50 \%$ alterations and $37 \%$ showing no change. $X$-ray-induced mutations are being evaluated as a low-LET control.

The time course of aberration induction has been investigated following radon and radon-daughter exposure of cycling human peripheral blood lymphocytes. We have noted previously that low doses of radon induce a substantial mitotic delay (more than 3 hours with doses less than $20 \mathrm{cGy}$ ). This is in contrast with a 1-hour delay per $100 \mathrm{cGy}$ typically seen with low-LET $x$ rays and is in agreement with the longer delays reported after alpha irradiation. Figure 2 shows the increase in chromatid aberrations when metaphases were collected at increasing time intervals after radon exposure. In general, a dose response existed between 6 and $17.6 \mathrm{cGy}$. This may indicate that more damaged cells are released from the $G_{2}$ block at increasing time intervals. Experiments are planned to evaluate the dose response in mitoses collected before the $\mathrm{G}_{2}$ block as well as the cells irradiated in $G_{0}$ and collected 72 hours after irradiation.

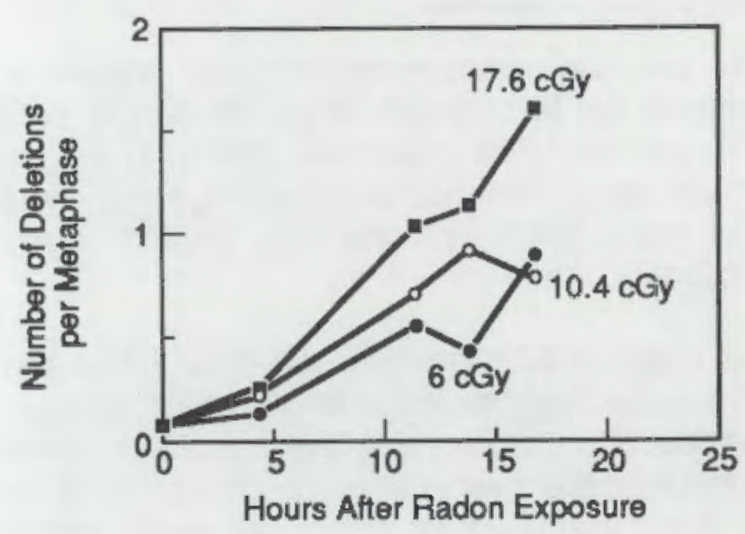

FIGUAE 2. Chromosome Deletions in Human Peripheral Blood Lymphocytes Collected at Various Time Intervals After Radon and Redon-Daughter Exposure 


\section{Initiation-Promotion-Initlation and Carcinogenesis Modeling Studies}

Initiation-promotion-initiation (IPI) experiments continue in male SPF Wistar rats with radon and cigarette-smoke mixtures. Our objective is to determine: 1) the respective roles of radon and cigarette smoke in lung tumorigenesis, and 2) whether these lung tumors are consistent with the two-mutation recessive oncogenesis model. The exposure protocols are shown in Table 2.

TABLE 2. Inkiation-Promotion-Inltiation Protocol for Padon (P), Dust (D), and Clgarette-Smoke (S) Inhalation Exposure of Pate $($ a)

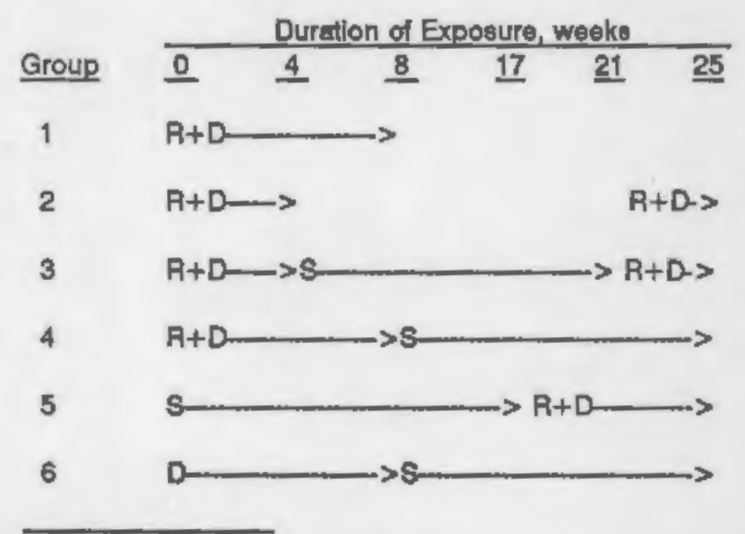

(a) Moderately low concentrations of uranium ore dust (D) accompany radon exposures as the carrier aerosol for radon daughters; sham-exposed control animals (not shown) are included in each exposure group. Animals from each group are killed at 25,52 , and 78 weeks to evaluate developing lesions. Protocol may be repeated for different redon-daughter exposure rates and levels.

Initial radon-daughter exposures were at 100-WL concentrations with cumulative levels of 320 WLM; uranium ore-dust concentrations ranged from 4 to $6 \mathrm{mg} / \mathrm{m}^{3}$. Cigarette smoke from Kentucky 1R4F cigarettes, in exposures of $1 \mathrm{hr} /$ day, 5 days/week, for 17 weeks, contained total particulate mass concentrations of about $0.5 \mathrm{mg} / \mathrm{L}$ and carbon monoxide concentrations between 600 and $700 \mathrm{ppm}$. Mean plasma concentrations of nicotine and cotinine were about 260 and $125 \mathrm{ng} / \mathrm{ml}$, respectively, in cigarette-smoke-exposed animals; carboxyhemoglobin levels were about $30 \%$. Blood samples were obtained within 15 minutes after exposures ended.

Exposures of 64 animals each in groups 1 to 6 (including sham-exposed control animals) were completed, and 10 animals in each group were sacrificed at 25,52 , and 78 weeks from start of exposures. Histopathological examination was completed on sacrifice groups at 25 and 52 weeks. These data are reported under Inhalation Hazards to Uranium Miners (this volume).

An analysis was completed of PNL experimental data on radon-induced lung tumors in rats within the framework of the two-mutation recessive oncogenesis model. This biological model incorporates two features: 1) transition of target stem cells into cancer cells via an intermediate stage in two ratelimiting and hereditary (at the level of the cell) steps, and 2) growth and differentiation of normal target and intermediate (mutated) cells. The two rate-limiting steps may be identified with mutations that lead to homozygous loss of anti-oncogene function, a mechanism substantiated in human tumors.

The model described the lung tumor data well. The results indicated that fractionation of exposure increased the lifetime probability of tumors. This may be explained by the relative effects of radon daughters on the mutation rates and on the kinetics of growth of initiated cells. The first mutation rate and the net growth rate of intermediate cells were strongly dependent on the rate of exposure to radon daughters, but the second mutation rate was much less so, suggesting that the nature of the mutational events is different. The results were also consistent with the view that radon daughters have no direct effect on the second mutation rate, and that the increase in risk results from the increased proliferation of the intermediate cells working in conjunction with the spontaneous mutational events in the animal. The model makes predictions that can be tested in future experiments. 



\title{
Microdosimetry of Radon Daughters
}

\author{
Principal Investigator: D. R. Fisher
}

\author{
Other Investigators: F. T. Cross, T. E. Hui, A. C. James, R. F. Jostes, and \\ J. W. Poston, $\mathrm{Sr}^{(a)}$
}

The purpose of this project is to develop more precise methods for calculating radiation doses to living cells from alpha particles emitted by radon and daughter products. The cell nuclei are considered important biological targets at risk for radiation-induced lung cancer in persons exposed to environmental radon and daughters. Important cells for dosimetric analysis include the secretory and basal cells of the tracheobronchiolar epithelium and various lines of cultured mammalian cells irradiated during laboratory experiments. Alpha-particle doses to small biological targets such as cell nuclei are highly variable because of the physical characteristics of alpha-particle tracks and their interaction probability with such targets. This variability is described in terms of a probability density in specific energy. A microdosimetric approach to the dosimetry of alpha emitters also provides the mean dose to selected targets, the hitfrequency distribution, and the probability that targets are completely missed. This information is necessary for assessing the relationship between radiation dose and biological effects so that risks may be better understood and predicted. Microdosimetry, therefore, is an important tool for studying the mechanistic effects of alpha-particle irradiation on living cells.

The dose-response relationship for cells at risk from alpha particles must be determined to evaluate the risk of lung cancer from inhalation of radon and its daughters. Last year we reported progress on the development of methods for calculating the microdosimetry of radon and daughters in the human respiratory tract (Fisher 1989). We continued this year to improve those techniques and the basic assumptions used to estimate lung deposition and mucociliary clearance, diffusion through tissue, and absorption into blood. The next phase of our work has involved the development of methods for calculating the microdosimetry of cells irradiated in vitro by alpha particles.

Much important information about the biological effects of alpha-particle radiation may be obtained experimentally by irradiating cultured mammalian cells in vitro. Previous cell irradiation studies have provided information about the likelihood of effects such as cell killing, mutation, chromosome aberration, primary DNA damage, and transformation as functions of the absorbed dose. The reported studies have not, however, provided useful

(a) Texas A\&M Univeraity, College Statlon, Texas. information about the actual energy imparted to individual cells or cell nuciei or the probability that cells are hit or missed by alpha radiation. Because alpha dosimetry is complex, there is also the problem that the radiation dosimetry reported for such studies may not be wholly reliable.

The absorbed dose is merely a "mean" dose that does not reflect the actual energy deposited in individual target cells. Alpha particles have short ranges and are highly ionizing; thus, the actual amount of radiation energy imparted to individual cells or cell nuclei is nonuniform and highly variable. Experimental data (Fisher et al. 1985) show that different leveis of biological effectiveness may result from the same absorbed dose, even for the same quality of radiation.

Another important parameter for evaluating the radiobiology of alpha emitters is the number of hits to target cells or cell nuciei. However, the hit probability does not tell the complete story because a cell nucleus may be hit several times with short traversal paths and receive less total energy than is imparted by a single traversal through the center. 
Dose-response relationships for cell survival and transformation probability should be determined as functions of specific energy $z$. The following parameters are important for evaluating biological effects from alpha-particle radiation:

- the frequency distribution of the energy deposited

- the average (absorbed) dose

- the fraction of target cells that are hit or missed

- the average number of hits

- the frequency distribution of the number of hits.

During the past year, we developed calculational methods for determining these parameters for cells irradiated in vitro.

\section{Experimental Designs for Cell Irradiation Studies}

Source-target geometries determine the probability of alpha-particle traversals and the total amount of energy imparted to each cell nucleus. Three typical experimental configurations are used to irradiate cells using alpha-particle sources: 1) the flask with cells and sources in a liquid suspension (Figure 1), 2) the gas-flow system with Mylar barrier, and 3) a plane or disk source beneath a Mylar barnier. Each requires special dosimetric considerations.

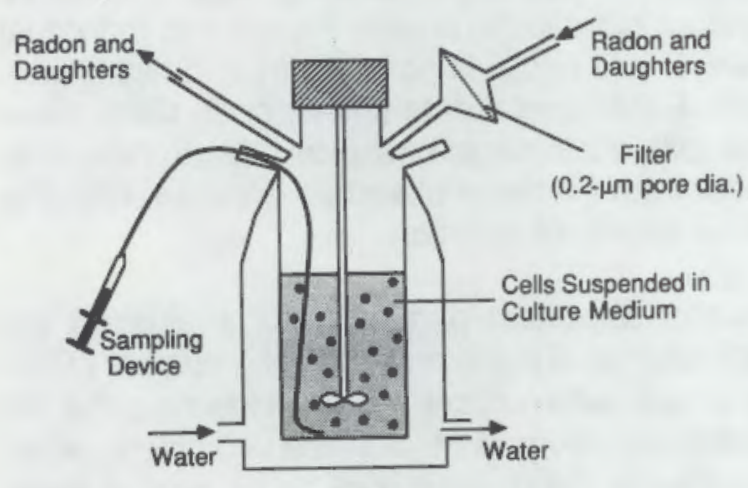

FIQURE 1. Schematlo Representation of Flesk for Exposing Cello Suepended in Culture Medium to Radon and ths Deughtero
Cells are exposed at PNL to radon and daughters using the flask design in which cells and radon plus daughters are suspended uniformly within the nutrient medium (Cross 1988). Some radon and daughters may enter the cells, and this consideration must be factored into the dose calculation. The calculation in this case will rely on the accuracy of the measurements of the radon and daughters in the culture medium and incorporated into cell membranes and cytoplasm, both of which may vary during the exposure experiment. An alpha probe-detector system (Figure 2) was designed and built to continuously monitor the activity of radon and daughters in the exposure flask. Alpha particles may traverse the Mylar layer at the tip of the alpha probe, pass through a vacuum region, and strike the detector. The energy spectrum of detected alpha particles results from the sum of contributions of various exit energies from radon and daughters.

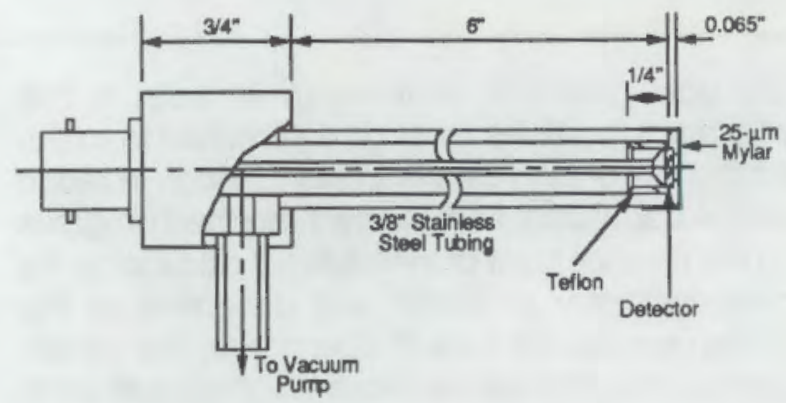

FIGURE 2. Diegram of Alpha Probe Detector for Continuous Meseurement of Concentrations of Radon and Daughters in Culture Medium

Figure 3 shows the calculated energy spectra from individual radionuclides and the sum spectrum. These spectra make it possible to unfold the sum spectrum and determine the spatial distribution of radionuclides in the culture medium.

The second experimental design is the gas-flow system. Cells grow on a Mylar layer in culture medium. Air containing radon and daughter products passes through the chamber beneath the Mylar, irradiating the cells. If the alpha-particle source is a solid material such as ${ }^{238} \mathrm{Pu}$ or ${ }^{241} \mathrm{Am}$ (third experimental design), the source may be thinly plated on a platinum disk and placed 
directly beneath the Mylar layer holding the cells. Spatial relationships between the distribution of alpha-particle sources and cell nuclei have been modeled mathematically for each exposure design.

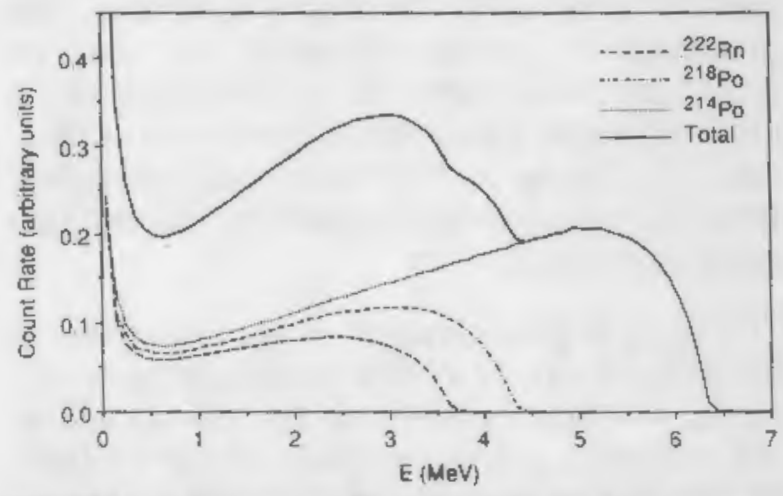

FICUAE 3. Calculated Alpha Energy Spectra of Radon and Daughtere for the Alpha Probe Detector

\section{Microdosimetry Calculations}

Probability densities in specific energy for cells irradiated by radon and daughter products were calculated by 1) modeling the spatial distribution of sources and target cell nuclei using chordlength distributions, 2) determining the specific energy imparted to target cell nuclei by point sources at every distance within particle range, and 3 ) combining the specific energies from all point sources by convolution. Contributions from each alpha emitter $\left({ }^{222} \mathrm{Rn},{ }^{218} \mathrm{Po}\right.$, and $\left.{ }^{214} \mathrm{Po}\right)$ were calculated separately and then combined mathematically by convolution. The probability of alphaparticle "hits" was also calculated, as was the delta function $(\delta)$, the probability that the target nuciei were completely missed by alpha particles.

Microdosimetry calculations were performed for cell-irradiation experiments, and one example with results is given here for the flask design. Cells were exposed to radon and daughters, present in the nutrient medium, for 2 hours. The concentrations of alpha activity in the nutrient medium were $10^{6} \mathrm{dpm} / \mathrm{cm}^{3}{ }^{222} \mathrm{Rn}, 2 \times 10^{6} \mathrm{dpm} / \mathrm{cm}^{3}{ }^{218} \mathrm{Po}$, and $3 \times 10^{6} \mathrm{dpm} / \mathrm{cm}^{3214} \mathrm{Po}$. Concentrations in the cell cytoplasm were ${ }^{222} \mathrm{Rn}$ (negligible), and $0.05 \mathrm{dpm} / \mathrm{cm}^{3}{ }^{218} \mathrm{Po}$ and ${ }^{214} \mathrm{Po}$. The cells were spherical in suspension with diameters of $14.5 \mu \mathrm{m}$ and spherical nuclei $6.5 \mu \mathrm{m}$ in diameter.

Figure 4 shows the calculated probability density in specific energy for cell nuclei from irradiation by 1) activity in the nutrient medium only, and 2) activity in both the nutrient medium and cell cytoplasm. Each cell received a unique dose depending on the amount of alpha energy imparted and the number of hits. The absorbed (average) dose to cell nuclei was 0.73 Gy from activity in the nutrient medium alone and $1.06 \mathrm{~Gy}$ from both the nutrient medium and the cell cytoplasm. Thus, the contribution from the activity in the cytoplasm was found to be approximately one-third of the total absorbed dose. The actual dose to single cell nuclei ranged from zero gray (if totally missed) to several gray (if hit multiple times by alpha particles; the frequency distribution of dose is shown in Figure 4.

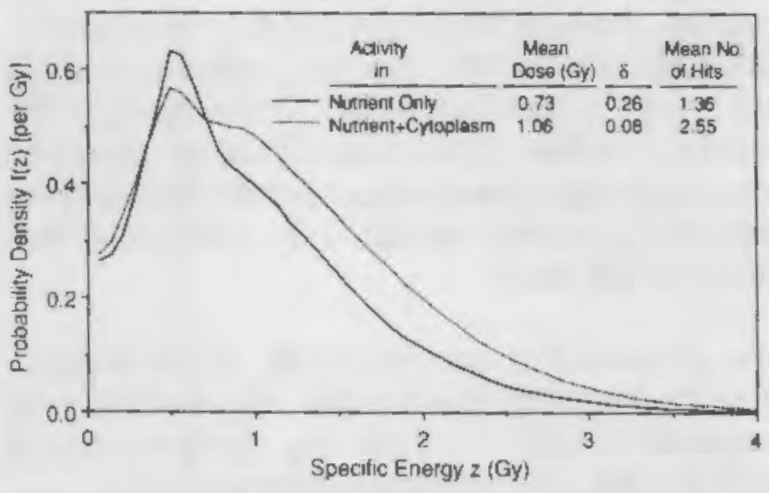

FIGURE 4. Speclfic Energy Distributione for Terget Cell Nuclei Irradiated In Vitro by Radon and its Daughters

These results show that the radon daughters incorporated into the cytoplasm contribute significantly to the probability of aipha-particle hits and energy imparted to cell nuclei. The delta function was found to be 0.26 if only the activity in the nutrient medium was considered. If the activity in both the nutrient medium and the cytoplasm were considered, the delta function fell to 0.08 (meaning that $8 \%$ of cell nuclei were missed by alphaparticle radiation during the experiment). The calculated hit probabilities are shown in Table 1. 
TABLE 1. Calculated Frequency of Alphe-Particle Hite to Cell Nuclei

\begin{tabular}{ccc} 
& \multicolumn{2}{c}{ Frequeney } \\
\cline { 2 - 3 } No. of Hits & Nutrient Only & $\begin{array}{c}\text { Nutrient }+ \\
\text { Ortopleam }\end{array}$ \\
\hline $0^{(a)}$ & 0.26 & 0.08 \\
1 & 0.35 & 0.20 \\
2 & 0.23 & 0.25 \\
3 & 0.10 & 0.22 \\
4 & 0.04 & 0.14 \\
5 & 0.01 & 0.07 \\
26 & 0.01 & 0.04 \\
Mean & 1.36 & 2.55 \\
\hline
\end{tabular}

(a) Delta function ( $\delta$ ), the probablity of cell nuclei mlased by radiation.

\section{Dose Response as a Function of Specific Energy}

The relationship between probability density in specific energy and biological endpoint for internal alpha emitters has not been fully developed. Theoretically, the specific energy distribution should be the basis for determining the survival probability $s(z)$ and the transformation probability $\Omega(z)$. The survival fraction $S(D)$ measured at an absorbed dose $D$ is determined without actually knowing the amount of energy imparted to cell nuclei that result in cell death.

We propose that the probability of cell survival, $s(z)$, for each cell as a function of specific energy imparted is related to $S(D)$, the mean fraction of cells surviving an absorbed dose $D$ :

$$
S(D)=\int_{0}^{\infty} s(z) f(z ; D) d z
$$

where $f(z ; D)$ is the probability density in specific energy. Even though the functional form of $s(z)$ is not known, if many irradiation experiments were performed, each giving a substantially different $f(z ; D)$, then $s(z)$ may be unfolded from Equation (1).

If the probability of cell transformation is $\Omega(z)$ for a specific energy $z$ to the cell nucleus, then we propose that the transformed fraction of cells, $L(D)$, at an absorbed dose $\mathrm{D}$, is given by

$$
L(D)=\int_{0}^{\infty} \Omega(z) f(z ; D) d z
$$

The fraction of cells transformed, $L$, can be measured directly by experimentation. The probability density in specific energy $\mathrm{f}(\mathrm{z})$ may be calculated for well-defined irradiation conditions. The probability of cell transformation $\Omega(z)$ may be unfolded from Equation (2). Observations of the survival fraction $S(D)$ and the transformation fraction $L(D)$ apply to the target cell population, whereas the microscopic quantities $s(z)$ and $\Omega(z)$ apply to individual cells.

This study applies concepts of microdosimetry to the interpretation of in vitro cell irradiation experiments. It is important to note that the determination of specific energy distribution $\mathrm{f}(\mathrm{z})$ is the basis for determining survival probability $s(z)$ and transformation probability $\Omega(z)$. These microscopic quantities are functions of the actual amount of energy imparted to cell nuclei, and are therefore more closely related to the probability of radiobiological effects at the cellular level than the absorbed dose $\mathrm{D}$. These quantities are not directly measurable, but may be calculated when $f(z)$ is known.

If $f(z)$ can be obtained for cells irradiated by radon and daughters in the human respiratory tract (Fisher 1989), then the fraction of cells transforming into cancer precursor cells may be estimated. This information is essential for improving the estimates of the risk of lung cancer from inhalation of radon and daughters.

\section{References Clted}

Cross, F. T. 1988. Mechanisms of radon injury. In: Pacific Northwest Laboratory Annual Report for 1987 to the DOE Office of Energy Research, pp. 39-40. PNL-6500, Pt. 1, Pacific Northwest Laboratory, Richland, Washington.

Fisher, D. R. 1989. Microdosimetry of radon daughters. In: Pacific Northwest Laboratory Annual Report for 1988 to the DOE Office of Energy Research, pp. 45-48. PNL-6800, Pt. 1, Pacific Northwest Laboratory, Richland, Washington.

Fisher, D. R., M. E. Frazier, and T. K. Andrews, Jr. 1985. Energy distribution and the relative biological effects of internal alpha emitters. Radiat. Prot. Dosim. 13:223-227. 


\title{
Growth Factors in Radiation Carcinogenesis
}

\author{
Principal Investigator: F. C. Leung
}

Other Investigators: J. R. Coleman, G. E. Dagle, and F. T. Cross

Our research examines the involvement of growth factors (GF) and their receptors in radiation-induced carcinogenesis of the lung in animais. We have developed a radioreceptor binding assay for examining epidermal growth factor receptor (EGFR) in dog lung tumors obtained from necropsy. Variability in lung tumors and limited availability of tumor tissue suggested we also develop immunocytochemical assays to detect GF and GFR in paraffin block sections of lung tumors from dogs and rats exposed to inhaled radionuclides including ${ }^{239} \mathrm{PuO}_{2},{ }^{238} \mathrm{PuO}_{2},{ }^{239} \mathrm{Pu}\left(\mathrm{NO}_{3}\right)_{4}$, and radon daughters. Results by immunocytochemical assay showed abnormal expression of EGFR in radiation-induced dog lung tumors was primarily associated with epidermoid carcinoma. Our immunocytochemical assay results also demonstrated abnormal expression of epidermal growth factor (EGF), transforming growth factor-alpha (TGF- $\alpha$ ), and bombesin in radon-induced rat lung tumors, also mainly associated with epidermoid carcinoma. Data from these assays on tissues from previous dose-effect relationship studies with inhaled radionuclides will provide basic molecular and cellular understanding of how radiation produces lung tumors in animals.

Polypeptide growth factors (GF) and their receptors (GFR) regulate normal cell growth and differentiation, mainly acting through the autocrine and paracrine mechanisms. Activation of these receptors by growth factors leads to gene activation, transcription, and ultimately to cell division. The gene structure, cDNA structure, and complete amino acid sequence of several growth factors have been reported, and many more growth factors have been identified, isolated, and characterized. It seems likely that additional growth factors, or new families of growth factors, will be identified soon.

Growth factors and their receptors are synthesized and secreted by normal cells. Circumstantial and direct experimental evidence supports the hypothesis that abnormal expression of GF and GFR can lead to malignant transformation. Many types of tumor cells synthesize and secrete GF when cultured in vitro, and many types of tumor cells have abnormally high numbers of GFR, altered receptors, or altered postreceptor signaling pathways. It has been hypothesized and supported by experimental observations that abnormal expression of GF and GFR can be viewed as transforming protein. Using gene transfer techniques, many investigators have reported the transforming potential of normal GF and GFF when they produce abnormally high expression in nontumorigenic cells in vitro. It has been well documented that lung tumors produce many polypeptide hormones including GF and GFR.

Recent studies have also shown abnormal expression of EGFR in human epidermoid carcinomas and bombesin in small cell carcinomas of human lung. We hypothesized that radiation- and chemical-induced lung tumors, in both animals and humans, would have different, unique, and specific profiles of abnormally expressed GF or GFR. Our experimental strategy was to identify the abnormally expressed GF or GFA and to establish a profile in radiation-and chemical-induced animal lung tumors. Because amplification of a GF or GFR gene did not necessarily increase the transcription of mRNA and increase the protein production, we first examined GF and GFR at the protein level. If the protein was abnormally expressed, we then examined the mRNA or the DNA of the GF and GFR.

\section{Plutonium-Induced Dog Lung Tumors}

We have compared specific EGFR binding in lung tumor tissue with that in normal lung tissue from tumor-free dogs. The specific EGFR binding was significantly higher in tumor tissue than that found in normal lung tissue: $31.38 \pm 9.62 \%$ versus $3.76 \pm 0.91 \%, p<0.01$ (Figure 1). We have also 
determined that the increased EGFA binding found in tumor tissue results from the increase of receptor capacity without significant change in receptor affinity. The advantage of the radioreceptor binding assay (RRA) is that it is quantitative, but RRA data will not address lung tumor heterogeneity. We have developed immunocytochemical assays to examine the specific cell type associated with the abnormal expression of EGFR in paraffin block sections. Using a monocional antibody against human EGFR, and the Vectastain ABC kit Nector Laboratories, Burlingame, California) as the enzyme detection system, we have demonstrated that high levels of EGFP binding are mainly associated with epidermoid carcinomas in dog lung tumors. With the immunocytochemical assay, we can identify the cell type that is associated with the abnormal expression; however, it is not quantitative and is less sensitive than RRA and radioimmunoassay. Using EGFR monoclonal antibody at a dilution that does not give positive staining to normal lung tissue, we have obtained positive staining of EGFR in three lung tumor samples from dog 955 (Figure 2). The immunocytochemical assay also enables us to examine the possibility of multiple expression of GF and GFR. We have examined the expression of EGFR, EGF, TGF- $\alpha$, and bombesin with specific antibodies against the specific GF and GFR in immunocytochemical assays of serial sections. A representative tumor stained with specific antibodies generated against EGFR, EGF, TGF- $\alpha$, and bombesin is shown in Figure 3.

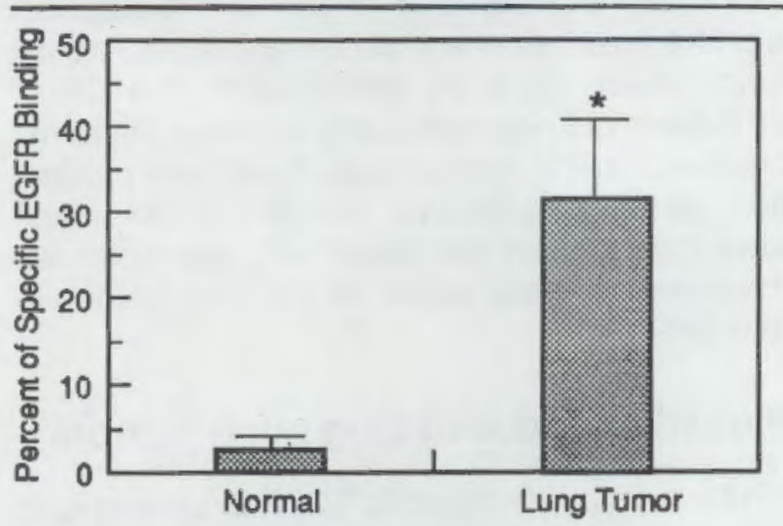

FIGURE 1. Specific Epidermal Growth Factor Receptor (EGFR) Binding in Normal and Tumorous Lung Tissue from Dogs. Normal, $\mathrm{N}=13$; lung tumor, $\mathrm{N}=8$. Symbol: *, $p<0.01$ between normal and lung tumor (Student's $t$ test).

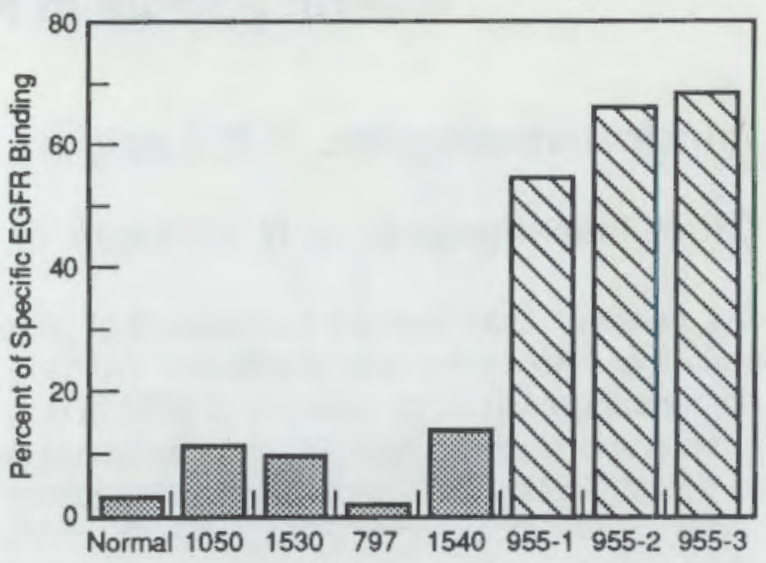

FIGURE 2. Specific Epidermal Growth Factor Receptor Binding (EGFP) in Normal and Tumorous Lung Tissue from Dogs. Diagonal shaded bars represent positive staining and stippled (gray) bars represent negative staining for EGFR in dog tumorous tissue by immunocytochemical assay.

\section{Radon-Induced Rat Lung Tumors}

We applied immunocytochemical assays to serial paraffin block sections to examine the expression of EGFR, EGF, TGF- $\alpha$, and bombesin in a limited number of radon-induced rat lung tumors. We have examined 32 rats exposed to 100 working level (WL) of radon daughters, $15 \mathrm{mg} / \mathrm{m}^{3}$ uranium ore dust, a total exposure of $\mathbf{5 1 2 0}$ working-level months (WLM), and 32 control rats for EGFR, EGF, TGF- $\alpha$, and bombesin expression (Table 1). Positive, specific EGFR, EGF, TGF- $\alpha$, and bombesin staining were present only in epidermoid carcinomas (Figure 4); none of the other histopathological types of lung tumors stained positive (Figure 5). No positive EGFR, EGF, and TGF- $\alpha$, or bombesin staining was seen in any lung tissues obtained from 32 control rats.

We have demonstrated that GF and GFR are abnormally expressed in radiation-induced dog and rat lung tumors. Further investigation will be required to elucidate the biological significance of abnormal GF and GFR expression in radiationinduced lung tumors. 

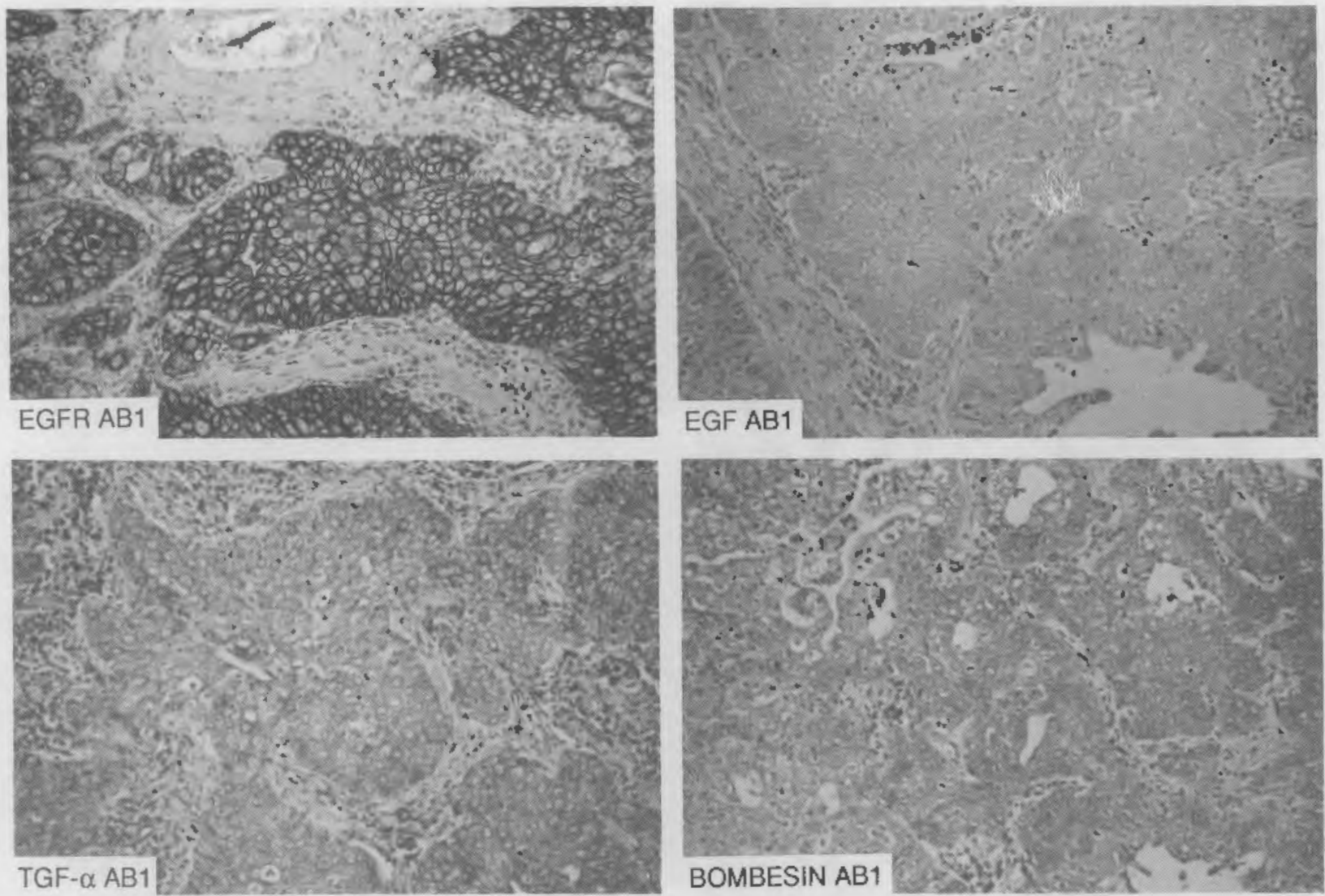

FIGURE 3. Serial Sections of Plutonium-Induced Epidermoid Carcinema of Dog Lung Specifically Immunocytochemically Stained with Antibodies for EGFF, EGF, TGF- $\alpha$, and Bombesin

TABLE 1. Expression of GF and GFA in Primary Lung Tumors in Rets Exposed to Radon Daughters ${ }^{\left({ }^{(}\right)}$

\begin{tabular}{|c|c|c|c|c|}
\hline \multirow[b]{2}{*}{ Tumor Type/Lesion } & \multicolumn{4}{|c|}{ Number Positive/Number Examined } \\
\hline & EGFR & EGF & TGF- $\alpha$ & Bombesin \\
\hline idern & $12 / 14$ & $14 / 14$ & $13 / 15$ & $14 / 14$ \\
\hline Adenoc & $0 / 17$ & $0 / 17$ & $0 / 17$ & $0 / 17$ \\
\hline Adenoma & $0 / 7$ & $0 / 7$ & O/7 (h) & $0 / 7$ \\
\hline $\begin{array}{l}\text { Adenosquamous } \\
\text { carcinoma }\end{array}$ & $0 / 1$ & $1 / 1^{(b)}$ & $1 / 1^{(b)}$ & $0 / 1$ \\
\hline Sarcoma (histlocytome) $)^{(c)}$ & $0 / 1$ & $0 / 1$ & $0 / 1$ & $0 / 1$ \\
\hline
\end{tabular}

(a) We found 25 animals with lung tumors of 32 examined.

(b) Positive staining located only in squamous carcinoma.

(c) One sarcoma (histiocytoma) was found in control group of 32 animals. 

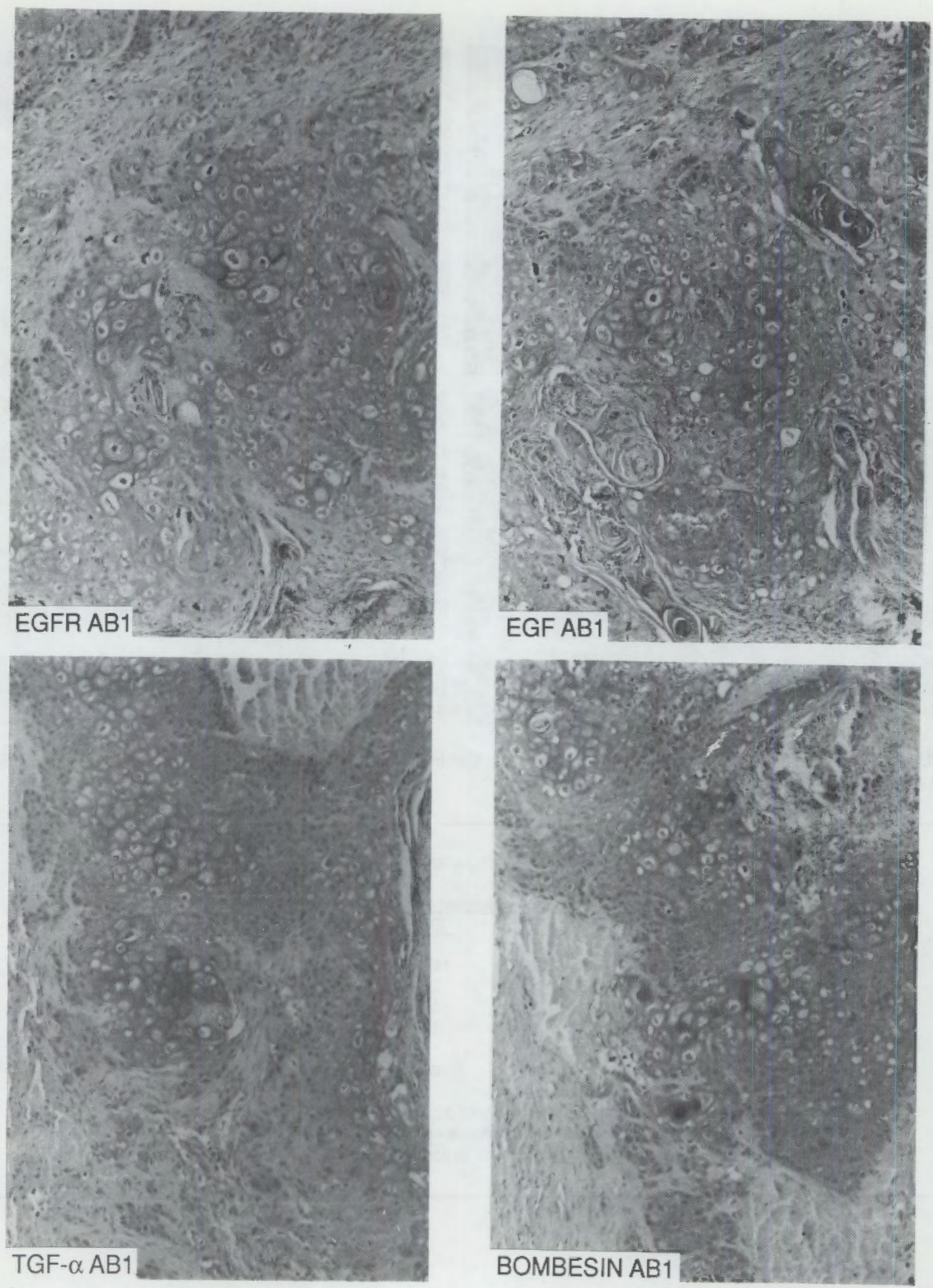

FIGURE 4. Serial Section of Radon-Induced Epidermoid Carcinoma of Rat Lung Specifically Immunocytochemically Stained with Antibodies for EGFR, EGF, TGF-a, and Bombesin 

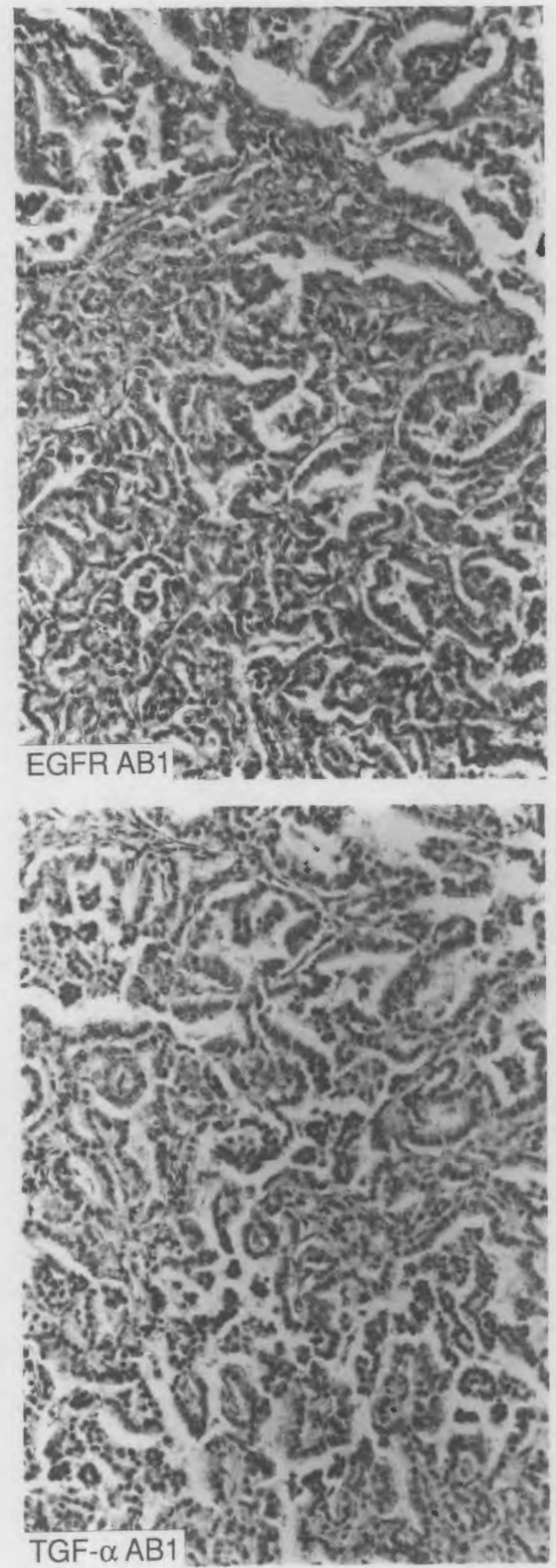
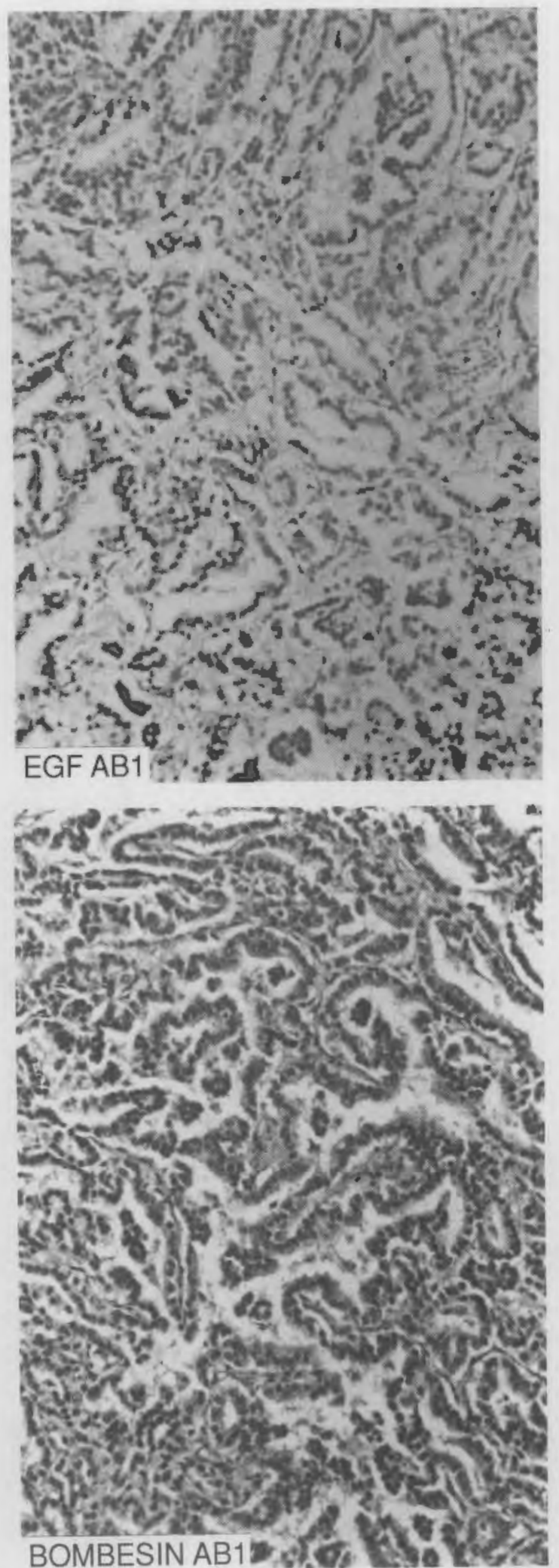

FIQURE 5. Serial Section of Radon-induced AdenocarcInoma of Rat Lung Speefflcelly Immunocytochemically Stained with Antlbodies for EGFR, EGF, TQF-a, and Bombeoin 


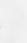




\title{
Oncogenes In Radiation-Induced Carcinogenesis
}

\author{
Principal Investigator: $M$. E. Frazier
}

Other Investigators: G. L. Stiegler, R. P. Schneider, and J. E. Morris

\author{
Technical Assistance: E. Sisk
}

Lung tumors obtained from studies of lifespan, dose-effect relationships in dogs exposed to plutonium by inhalation are being used to examine the role of oncogenes in radiation-induced carcinogenesis. In the tumors examined thus far, radiation and chemicals activate the ras genes by different mechanisms. Chemicals usually activate ras genes by causing specific and reproducible single-point mutations. The ras genes from radiation-induced tumors did not usually have point mutations. Radiation appears to activate the ras genes by causing gene rearrangements that result in their overexpression.

Many oncogenes have been identified and some have been partially characterized. None has been totally biochemically defined as to specific cellular function, but oncogenes are connected in some manner to cellular proliferation or to specific developmental processes. The genetic expression of proto-oncogenes (the precursors to oncogenes) involves specific information that affects cell proliferation and cellular differentiation. The protooncogenes become activated by means of point mutations, translocations, or deletions such that the resulting gene protein product is modified, thus affecting its normal cellular function. These modified oncogenes play a central role in the development of malignant tumors.

The goal of this research is to identity the molecular mechanisms by which radiation causes cancer. Our approach is to examine how radiation brings about activation of a proto-oncogene to create a dominantly acting transforming gene (oncogene). By examining radiation-activated oncogenes, we hope to detect specific pathways of activation that will provide a means for distinguishing between radiation-induced and chemically induced cancer.

Our analysis of plutonium-induced canine lung tumors indicates that dominant-acting oncogenes are present in the DNA prepared from the canine tumors. These results were obtained by performing a number of NIH 3T3 assays using isolated canine lung tumor DNA for transformation. Data from other researchers have shown that many of the activating genes bringing about NIH 3 T3 transformation are from the ras gene family. There is additional evidence of ras gene activation in the radiation-induced canine tumors; specifically, we found tumor-specific restriction fragment-length polymorphisms and elevated levels of ras gene transcription (above the steady-state levels of control tissue) in some of these radiation-induced tumors.

The ras oncogene family contains a group of oncogenes well characterized at both molecular and biochemical levels. The published information about the chemical activation of these genes provides our studies of radiation activation with a large database for comparison. For example, mammalian ras genes are activated and acquire transforming potential by alterations in their coding sequence, which are most often brought about by single-point mutations. These point mutations have been localized in codons $12,13,59$, and 61 . The presence of a glycine residue at position 12 appears to be necessary for the normal gene function, and substitution of any other amino acid, with the exception of proline, results in gene activation. Missense mutations surrounding codon 61 are also involved in activation. Substitution of glutamic acid at codon 61 by any other amino acid residue, except proline or glutamine, yields an activated ras gene. The exact function of the ras proteins is not known but these proteins closely resemble $G$ proteins in biochemical properties. $\mathrm{G}$ proteins are 
involved in the modulation of signal transduction through transmembrane signaling systems. Through these systems, ras proteins play a role in cell proliferation and possibly terminal differentiation. Identification of the receptor and effector systems that interact with the ras proteins has, thus far, been elusive, although some experimental evidence connects ras and the epidermal growth factor that enhances the ras protein guanine diphosphate (GDP) binding activity.

Sufficient tumor material is available at PNL to provide a large database of information on radiation-induced ras gene activation. This tumor material is archived lung tissue that has been embedded in paraffin or preserved by freezing or formalin fixation. By using the polymerase chain reaction $(\mathrm{PCR})$, this material is now available for detailed molecular analysis. The PCR method has an advantage over other analytical methods in that it uses small amounts of valuable tumor DNA ( $<1 \mu \mathrm{g}$ of DNA is required per assay). The PCR is a process of exponential amplification of a targeted gene region by which millions of copies of a defined sequence can be obtained and analyzed in molecular detail by DNA sequence analysis. Immediate use of the PCR method is focusing on ras gene activation in archived radiation-induced tumor material. DNA isolated from archived tissue embedded in paraffin blocks is used for amplification and specific molecular analysis of the first and second exons of the $\mathrm{H}$-ras and $\mathrm{N}$-ras genes.

The PCR procedure is only applicable to DNA targets whose sequences are known; thus, we are isolating and characterizing canine protooncogene sequences. A canine genomic library of liver origin was screened, and we obtained a canine cDNA library from dog pancreas for canine oncogenes. These studies isolated the canine $\mathrm{N}$-, $\mathrm{K}$, and $\mathrm{H}$-ras genes. We have now obtained DNA sequences of the first and second exons of the dog N-ras. cDNA clones having homology with the human epidermal growth factor receptor have also been isolated.

The canine $\mathrm{N}$-ras first exon DNA sequence has a shared homology with human $\mathrm{N}$-ras of $100 \%$ and a homology of $94 \%$ for the second exon. The comparisons of the predicted amino acid sequences show a percent identity of $100 \%$ and
$96 \%$ for the first and second exons, respectively. The sequence of the ras gene family is highly conserved throughout eucaryotes. In fact, a comparison of the canine $\mathrm{N}$-ras with human K-ras shows a nucleic acid homology of $90 \%$ in the first exon and $82 \%$ in the second exon, with predicted amino acid identity of $97 \%$ and $93 \%$ for the first and second exons, respectively (Figure 1). Most of the DNA sequence changes are conserved and occur at the third nucleotide base (or degenerate position) of the 3-bp amino acid codon.

$$
\begin{aligned}
& \text { EintExon }
\end{aligned}
$$

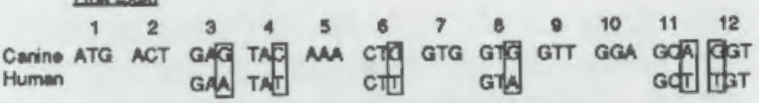

$$
\begin{aligned}
& \begin{array}{llllllllllll}
13 & 14 & 15 & 16 & 17 & 18 & 19 & 20 & 21 & 2 & 23 & 24
\end{array}
\end{aligned}
$$

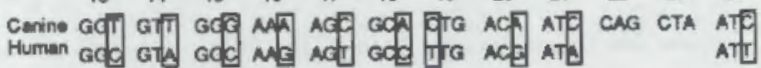

$$
\begin{aligned}
& \begin{array}{llllllllllll}
25 & 26 & 27 & 20 & 20 & 90 & 31 & 32 & 30 & 34 & 35 & 36
\end{array}
\end{aligned}
$$

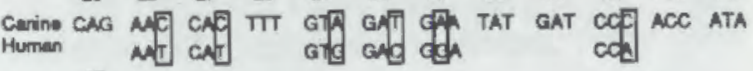

$$
\begin{aligned}
& 37 \\
& \text { Carine GAG } \\
& \text { Second Exen }
\end{aligned}
$$

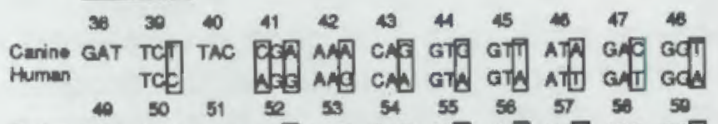

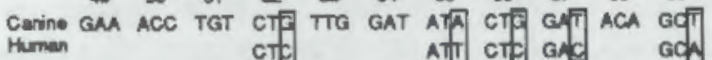

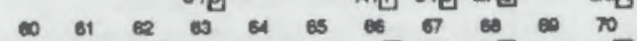

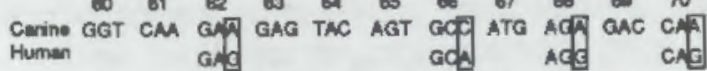

$$
\begin{aligned}
& \begin{array}{lllllllllll}
\pi & 72 & 73 & 74 & 75 & 7 & \pi & 70 & \pi & 0 & 81
\end{array}
\end{aligned}
$$

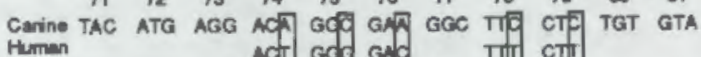

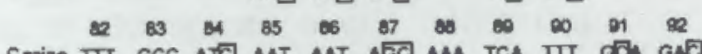

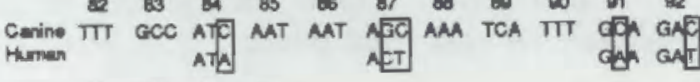

$$
\begin{aligned}
& 8 \text { s a } 85 \\
& \text { Gerine ATा TAC वाC TAP }
\end{aligned}
$$

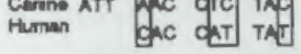

FIGURE 1. First and Second Exon Sequence for Canine N-ras

We also have sequence determination for a clone that showed similarity with the human epidermal growth factor receptor (EGFR). The canine cDNA clone has approximately $2 \mathrm{kbp}$, and preliminary sequence information has shown extensive homology between the canine clone and the published human EGFR nucleotide sequence (Figure 2).

The primers to be used in the PCR method were developed using the sequence information 
available from the canine $\mathrm{N}$-ras sequence shown in Figure 1. The initial set of primers bracketed the $5^{\prime}$ - and $3^{\prime}$-ends of the dog $\mathrm{N}$-ras first and second exons, incorporating the first 20 bases of each end of the exon for the priming sequence. In addition to the priming sequences we have also introduced a unique Sall restriction endonuclease site onto the $5^{\prime}$ terminal nucleotides of each PCR sequence. This $5^{\prime}$ extension does not affect the priming ability, and it allows for direct cloning, archiving, and additional statistical analysis of amplified sequences.

Canine CAGT COACCC G GMTGCCCTGCC C CAGGCCATGAACAT A Human CAGT GCCATCC A GAGTGCC TGCC T CAGGCCATGAAGAT C

Canine ACCTGCACAGGacGgGG G $\propto$ G GAC TG CTG Human ACCTGCACAGGACGGG A $C$ C

FIGURE 2. Comparison of Dog and Human Epidermal Growth Factor Receptor (EGFR) Sequence. Region of DNA sequence of cloned canine EGFR cDNA shows extensive homology with human EGFR. Boxed regions indicate base changes.

The DNA isolated from frozen canine lung tumors was examined by nucleotide sequence analysis using the PCR procedure. The dog $\mathrm{N}$-ras second exon sequence appears to be identical with the normal canine sequence in six lung tumors examined; an example of the analysis is shown in Figure 3 . The first exon has been examined in eight canine lung tumors. Seven of the eight sequences have the normal $\mathrm{N}$-ras nucleotide sequence pattern (Table 1); one tumor has an altered sequence that appears as a mixture of bases at nucleotide positions 44 and 46 , altering the 15th and 16th codons, respectively, of the first exon (Figure 4). The mixture of bases that appear in the generated DNA sequence ladder is an expected result. The pattern of multiple bases may occur because tumors are often composed of a mixed cell population, some displaying a mutant tumor and others a normal phenotype. The observed sequence changes would cause an amino acid change in the 15th codon, exchanging glycine for alanine, and in the 16th codon, where glutamine would be substituted for lysine. This observation is preliminary, and more detailed analysis of the tumor
1234

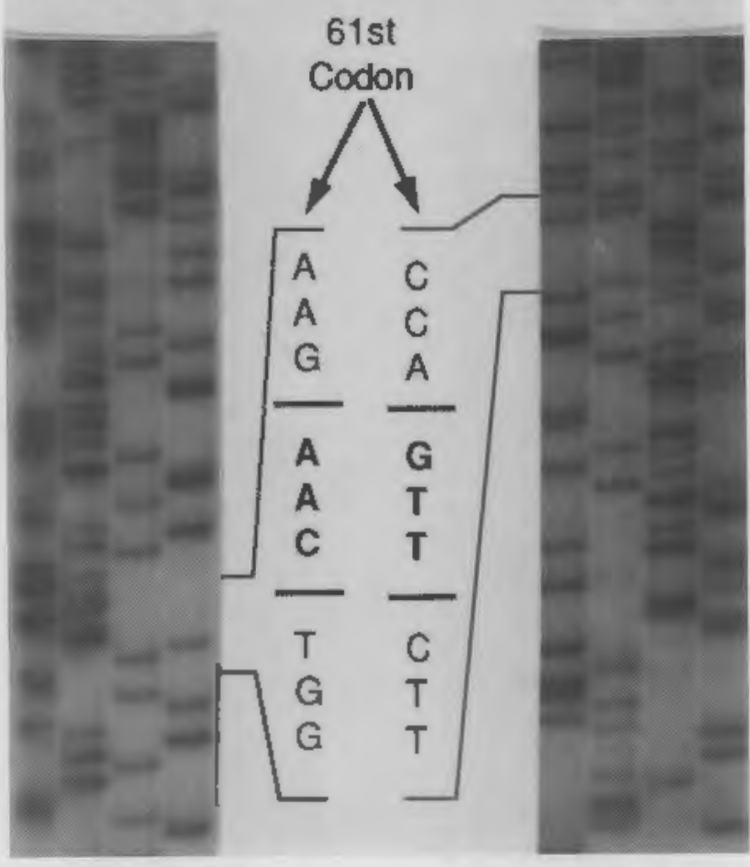

FIGURE 3. Second Exon Sequence for Canine N-ras. Autoradiograms show dideoxy-determined nucleotide sequence around 61 st codon, which is diagrammed as determined on autoradiograms on left and right. Sequencing lenes (left to right): lane 1, G; lane 2, A; lane 3, T; lane 4,C. Unique sequence petterns result from random orientations of Sall fragment and sequencing from both ends.

TABLE 1. Canine Lung Tumors Analyzed at the First Exon ${ }^{(a)}$

\begin{tabular}{|c|c|c|}
\hline Dog & Exon & Mutation \\
\hline 1033 & First & None observed \\
\hline $\begin{array}{l}1342 \\
\text { Tumor } 1\end{array}$ & First & None observed \\
\hline $\begin{array}{l}1342 \\
\text { Tumor } 2\end{array}$ & First & None observed \\
\hline 1569 & First & None observed \\
\hline 1050 & First & None observed \\
\hline 1540 & First & None observed \\
\hline 797 & First & $\begin{array}{l}\text { Mutations at the } \\
15 \text { th and } 16 \text { th codons }\end{array}$ \\
\hline 786 & First & None observed \\
\hline
\end{tabular}

(a) Mixed population of amplified sequences wes analyzed by the chemical cleavage method. 


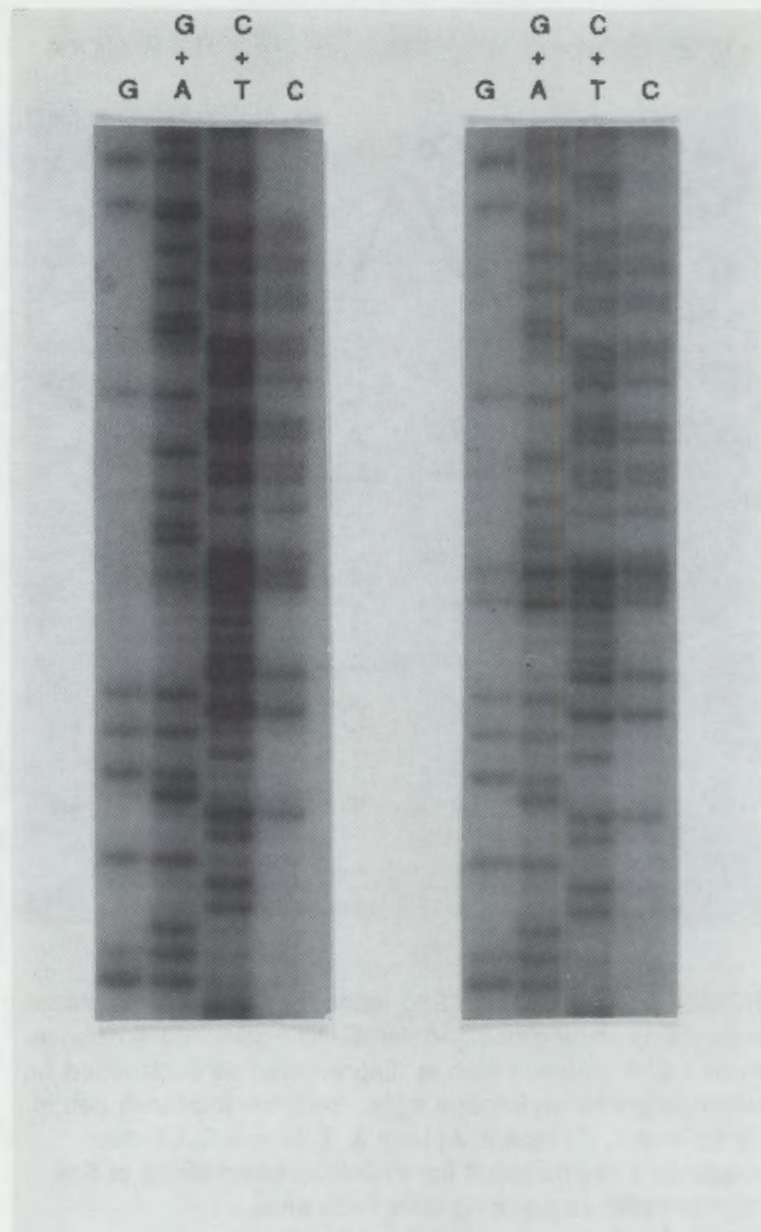

T TGT CAG TGC GCT TIT CCC AAC ACC ACC TOC TCC MAC CAC CAC

Sequence read in a 5 to $3^{\prime}$ drection and separaled irto codons (reveree compiement of the above sequence).

15 th 16 th

GTG GTG GTT CGA GCA GSGT GOT GTT GGG AMA NOC GCA CTG ACA A

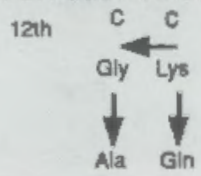

FIGURE 4. First Exon Sequence from Canine DNA Determined from Autoradiogram Shows Alterations in 15th and 16th Codons (see text)

must be conducted. Other researchers have not reported activation of the $\mathrm{N}$-ras gene by point mutations occurring in the 15th and 16 th codons. However, many radiation-induced tumors must be examined before we can state that these mutations are specific for radiation-induced damage.
In addition to direct sequence analysis, we have used the PCR method to obtain additional canine gene sequences. As discussed previously, the ras genes are highly conserved between species showing extensive protein and DNA sequence homology. We have taken advantage of the DNA sequence similarities to design ras gene-specific probes that allow amplification of ras sequences across species. For example, the canine H-ras second exon sequence was determined by using primers based on the mouse $\mathrm{H}$-ras second exon sequence (Figure 5). The canine-specific sequence between the primers has extensive sequence similarity with the mouse $\mathrm{H}$-ras sequence ( $95 \%$ at the nucleotide level). We intend to use conserved oncogene sequences for designing synthetic oligonucleotide primers. These primers will be used to amplity similar gene sequences from the canine CDNA library by the PCR method, thus providing a procedure for obtaining the entire coding region of a given oncogene sequence (Figure 6). In essence, we will isolate DNA that represents the entire CDNA gene library and amplity gene sequences between a specific oncogene primer and universal primers corresponding to sequences in the cloning vector. These sequences bracket the vector's multiple cloning sites, which contain the cDNA insert. The end result of this amplification will provide the molecular clone of the coding sequence of any chosen oncogene.

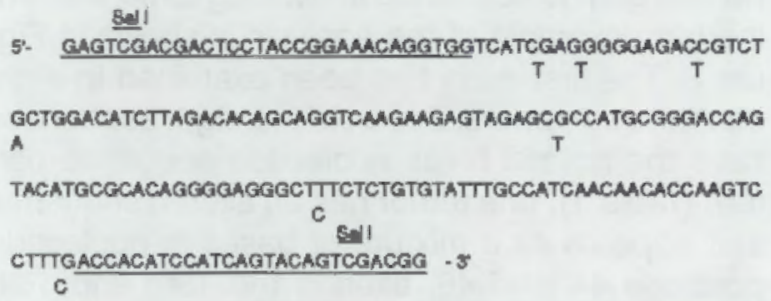

FIGURE 5. Second Exon Sequence for Cenine H-ras. Mouse $\mathrm{H}$-ras primer sequences ere underlined. Sequence between primers is amplified dog $\mathrm{H}$-ras DNA. Sequence differences between dog and mouse are shown beneath dog sequence.

In a second aspect of this study, we have developed an immunohistochemical assay to assess expression of both the altered and the mutated ras oncogene product in normal and malignantly transformed cells. The determination of quantitative changes in ras expression is important 
because evidence suggests that the level of expression of the ras oncogene controls the expression of the transformed phenotype. Quantitation is based on the immunoprecipitation of radiolabeled ras protein by a pan-ras antibody and separation of the $21,000-\mathrm{kDa}$ protein (p21) fraction by electrophoresis. Southern blots of the transfectants are carried out to verify the presence of a transfected ras gene. The immunoprecipitation of the ras allows us to determine whether the transfected ras gene is expressed and, if so, the level of expression.

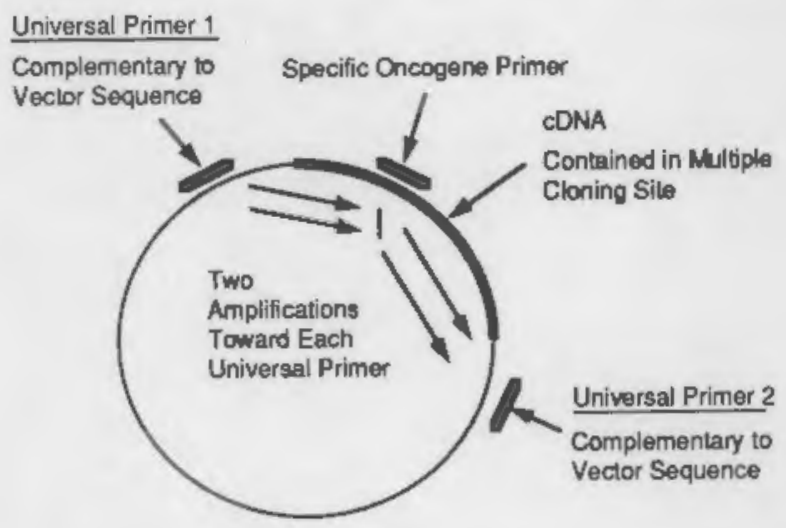

FIGURE 6. Schematic for Obteining Complete cDNA Gene Sequences by Priming with Synthetic Specific Oncogene Sequence Between Two Vector Universal Primers

One-dimensional sodium dodecyl sulfate (SDS) polyacrylamide gel electrophoresis and Western blot analysis were used to detect ras proteins in cell extracts. For the Western blot analysis, proteins were electrophoretically transferred from SDS polyacrylamide gels to nitrocellulose membranes. The membranes were incubated with horseradish peroxidase- (HRP-) conjugated goat anti-mouse IgG to indicate the location of the ras proteins. Our data indicate that cellular ras genes are normally not active in 3 T 3 cells, but on transfection (with
DNA from a tumor) with a dominantly activated ras oncogene the cells become transformed and the ras gene expression is increased.

Several studies indicate that ras may be involved in early stages of carcinogenesis. Our studies show that we can assay this biologically relevant transformation-inducing protein (p21) in cell cultures (Figure 7). Earlier studies have shown increased levels of ras gene transcription in the plutonium-induced lung tumors. During the coming year we will attempt to assay p21 in archived tissue sections from animals with radiation-induced lung tumors to determine the relationship between ras p21 expression and the biological potential of the tumor. If there is a correlation and the p21 does appear early in tumor development, the p21 will be examined as a tumor marker.

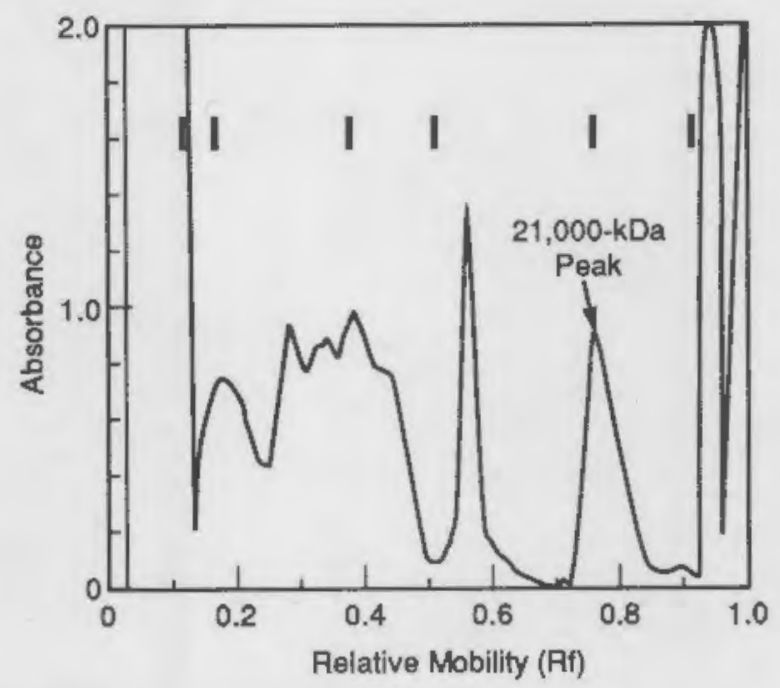

FIQURE 7. SDS Polyacrylamide Gel Electrophoresis of Extract of CT-24 Bladder Cancer Cells. Material in $21,000-\mathrm{kDa}$ band was reactlve with antibody specific for ras oncogene family of proteins by Western blot analysis. Large bars represent migration position of protein standards used for molecular weight estimation. 



\title{
Molecular Events During Tumor Initiation
}

\section{Principal Investigator: D. L. Springer}

\author{
Other Investigators: J. E. Hulla and D. B. Mann
}

For this new project, we have begun studies to identify structural and functional changes in chromatin associated with formation of bulky adducts during tumor initiation. We selected a simple model, the $5 S$ rRNA gene, which forms a single fixed-position nucleosome. The pXP-14 plasmid that contains this gene has been grown and purified. Primers have been prepared for polymerase chain-reaction amplification of the $5 S$ rRNA and SP-6 promoter portions of the gene. In addition, the plasmid has been adducted with benzo[a]pyrene-diol-epoxide and by benzo[a]pyrene (BaP) metabolites obtained from incubation with freshly isolated hepatocytes. Results indicated that the DNA was adducted predominantly at the deoxyguanosines. The plasmid remained intact during hepatocyte incubations, suggesting that this procedure can be used to prepare BaP-derived DNA adducts under conditions that closely resemble tumor initiation; similarly, adducts of carcinogens other than $\mathrm{BaP}$ are possible with this technique. These procedures will be used to map the location of bulky adducts to the $5 S$ rRNA gene and to determine the influence of bulky adducts to DNA on nucleosome positioning and gene expression.

Several lines of evidence support the hypothesis that tumor initiation and development may involve adduct-induced changes in chromatin structure. It has been well established that many carcinogens either bind directly to DNA or are converted by mixed-function oxidases to reactive intermediates that covalently attach to the DNA. Although the relationship between covalent binding and tumor yield is only loosely correlated, this mechanism for tumor initiation has been widely accepted. Other studies designed to obtain fundamental information about the way the three-dimensional structure of chromatin is involved in gene regulation have indicated that actively transcribed chromatin is more loosely coiled than other forms of chromatin and thus is more susceptible to nuclease digestion. Thus, it is not surprising that certain oncogenes have sensitivity to nuclease digestion that increases throughout tumor progression.

Nucleosome positioning was recently demonstrated to be DNA sequence dependent, and the placement of nucleosomes along the chromatin fiber may be involved in regulation of gene activation or inactivation. Further, it has been shown that Z-DNA is a more rigid structure and that regions containing this DNA conformation do not form nucleosomes. It has also been reported that benzo[a]pyrene-diol-epoxide (BPDE) adducts stabilize DNA structure in the B conformation in the area proximal to the adduct and destabilize distal base pairing so that the transition of the $B$ to $\mathrm{Z}$ conformation is favored (Chen, Biochemistry 24:6219-6227, 1985). Thus it follows that chromatin structure and possible gene expression may be altered in regions where bulky adducts are present.

In an attempt to elucidate some of the regulatory processes involved in tumor development, we are conducting studies to determine the influence of BPDE adducts with respect to nucleosome positioning and other structural changes in chromatin. For this we have chosen the $5 S$ rRNA gene as a model system because the gene has been cloned into a plasmid and is readily available, as is sequence information. In addition, it has been shown that the gene will form a single nucleosome either by incubation with core histone particles or by exchange with chick erythrocyte chromatin. The position of this nucleosome is known with respect to the DNA sequence, and the positioning is fixed with respect to location along the $5 S$ rRNA gene. The model therefore allows manipulation of bulky adducts and lends itself to experimental designs that address questions on the influence of bulky adducts on nucleosome positioning. 
For these studies we obtained a preparation of the pXP-14 plasmid, which contains the Xenopus borealis 5S rRNA gene and the SP-6 promoter (this sample was provided by Dr. Donald Brown of the Carnegie Institute). The plasmid was grown in Escherichia coli in LB media containing ampicillin. Incubation of 2 liters resulted in isolation of approximately $4 \mathrm{mg}$ of purified plasmid. This purified plasmid was used as a template to amplify the $5 S$ rRNA gene. Six primers were prepared using an DNA synthesizer (model 381A, Applied Biosystem, Foster City, California). The coupling efficiency at each cycle of the synthesis was monitored by spectrophotometric analysis. Before being used as primers for the polymerase chain reaction (PCR), the sequences were purified on oligonucleotide purification columns. In addition, the primers were $5^{\prime}{ }^{32} \mathrm{P}$ end labeled using T4 polynucleotide kinase, separated by acrylamide gel electrophoresis, and autoradiographed. Primers coded \#1, \#2, and \#3 consisted of sequences that complement the transcribing strand of the plasmid; $\# 4,5$, and 6 complemented the nontranscribing strand (Figure 1). Regions of the plasmid-bracketed sequences were selected on the basis of their location relative to the promoter and $5 S$ rRNA gene. For example, by using primers \#1 and \#6, a 430-bp fragment coding for both the SP-6 promoter and the 5S rRNA gene will be amplified by PCR. Likewise, by using primers \#3 and \#5, a 200-bp fragment containing only the $5 S$ rRNA gene will be amplified. These primers were selected so that microgram quantities of variously sized fragments could be obtained, sequenced, and adduct map locations prepared.

Samples of the plasmid were incubated with radiolabeled ( \pm ) r-7,t-8-dihydroxy-t9,10-epoxy-7, $8,9,10$-tetrahydrobenzo[a]pyrene (anti-BPDE) and repurified by solvent extraction techniques. Under these conditions binding was linear with concentration from 5 to $125 \mu \mathrm{M}$ anti-BPDE. At $125 \mu \mathrm{M}$ anti-BPDE, the DNA was adducted at 6.5 adducts per plasmid molecule. When the plasmid was digested with the restriction enzyme Hinfl, eight fragments 65 to $1199 \mathrm{bp}$ in length were produced. Radioactivity measurement indicated that adduct binding was approximately equal in all fragments when calculated as picocuries per base pair, demonstrating that adduction was random among fragments. When the plasmid was enzymatically digested to nucleosides, the predominant adduct was anti-BPDE-deoxyguanosine (dGuo), which was consistent with results from similar experiments with calf thymus DNA.

In mouse skin, where tumors are produced by BaP exposure, adducts are formed to reactive intermediates other than anti-BPDE; thus, it will be important to conduct studies with DNA that is adducted under conditions that closely resemble tumor initiation. We previously demonstrated that incubation of freshly isolated hepatocytes with $\mathrm{BaP}$ and calf thymus DNA resulted in adduct profiles essentially identical to those for mouse skin. Using
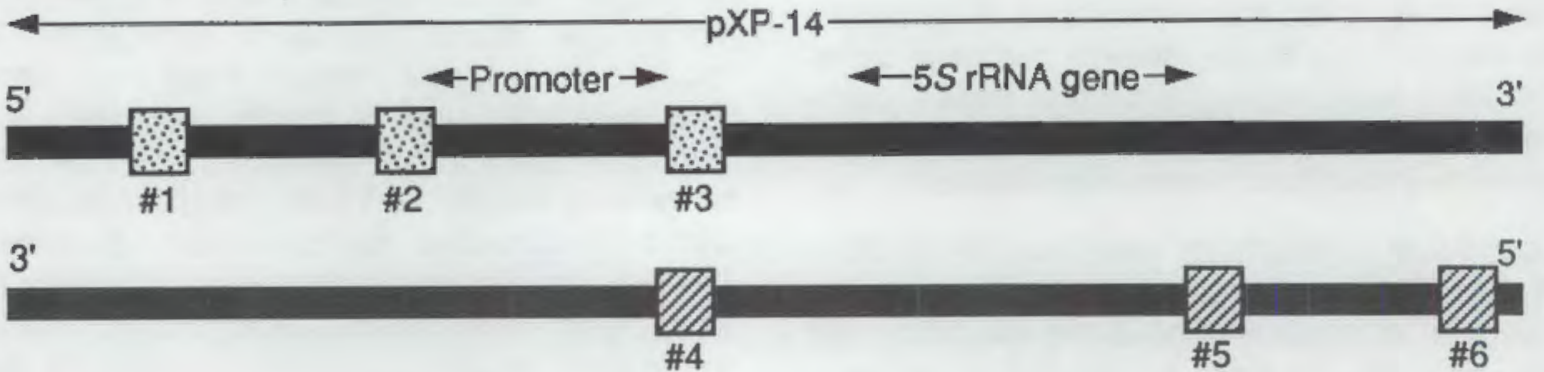

Primers \#1, \#2, and \#3 Complement Transcribing Strand

Primers \#4, \#5, and \#6 Complement Nontranscribing Strand

FIGURE 1. Schematic of SR6 and $5 S$ rRNA Gene Portion of PXR-14 Plasmid Shows Location of Primers. Primers were syntheeized so that various portions of plasmid could be amplified with polymerase chain-reaction technique. 
a similar procedure and replacing the calf thymus DNA with our plasmid, we have demonstrated that $70 \%$ of the DNA could be recovered from the hepatocyte preparation (Figure 2). When this preparation was purified on an agarose gel, $40 \%$ of the radiolabel applied to the gel co-electrophoresed with the plasmid, indicating that a substantial portion of the DNA survived the hepatocyte incubation. Future studies will take advantage of this procedure using polymerase chain-reactionamplified fragments.

We are currently implementing methods to determine the location of BaP-derived adducts on the fragments just described. For this we are using the T4 polymerase assay, which has $3^{\prime}-5^{\prime}$ exonuclease activity and digests the DNA until it encounters a base with a covalently bound bulky adduct. This method has the advantage of digesting nonadducted DNA fragments to nucleotides and very short $5^{\prime}$-end fragments. This limits the sample to fragments with attached adducts, eliminating interfering nonadducted DNA and enhancing electrophoretic separation and analytical analysis. These preparations will be run on a polyacrylamide sequencing gel together with the Maxam-Gilbert sequence of the fragment to give the location of the bulky adducts on each fragment. Using this approach we will locate adduction sites on the $5 S$ rRNA gene and the promoter region. (This work is being conducted in collaboration with Dr. Michael Smerdon at Washington State University.) When adduction and frequencies of adduction have been identified, we will determine the influence of bulky adducts on nucleosome positioning using a reconstituted nucleosome of the $5 S$ rRNA gene.

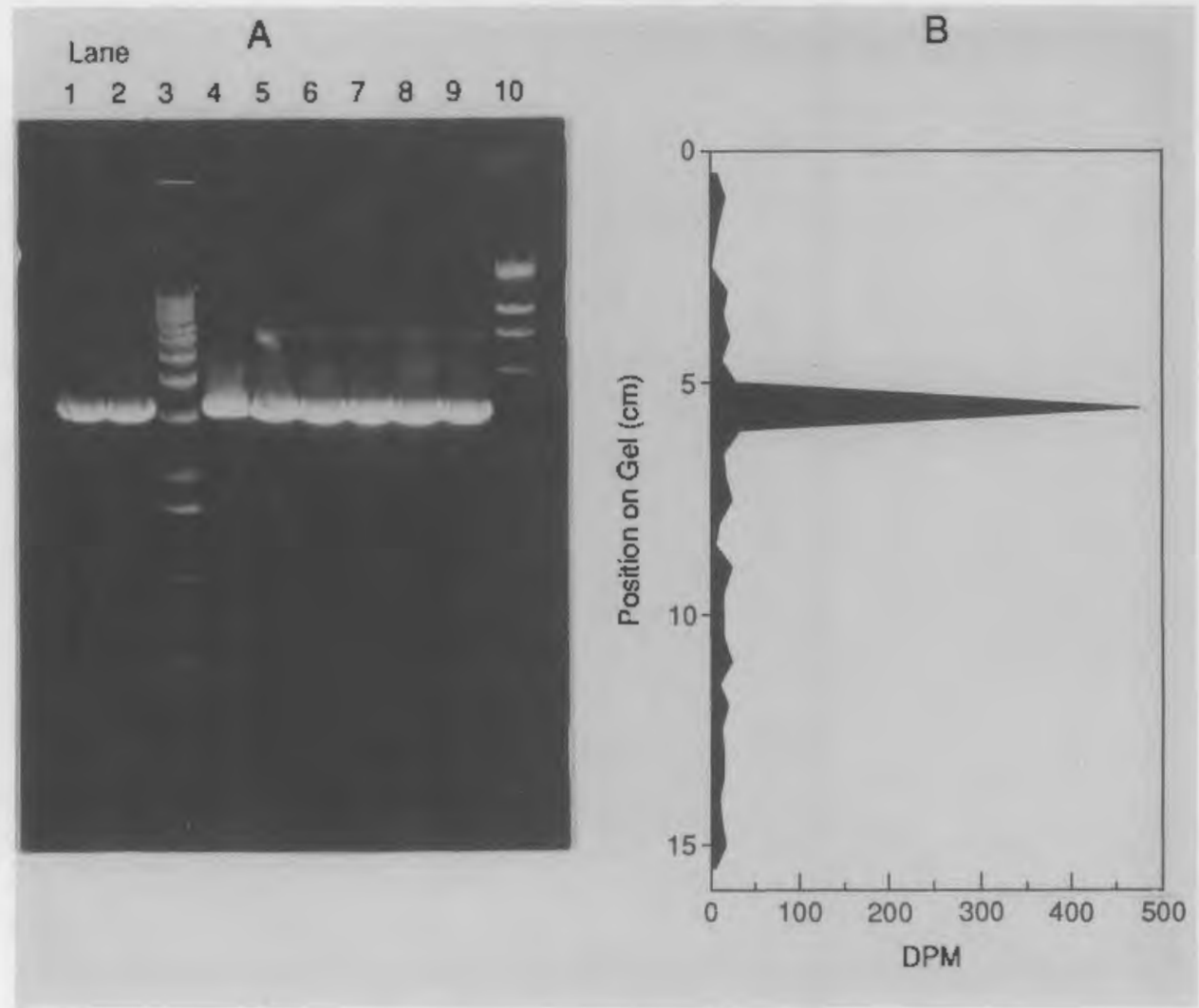

FIGURE 2. Photograph and Radiograph of Agarose Gel of pXP14 Plasmid Demonatrates That Most (70\%) of Adducted DNA Was Recovered After Incubation with Freshly Isolated Hepatocytes. In addition, $40 \%$ of radioactivity applied to gel co-purified with DNA. Lanes 1,2 , and 4 contain linearizad plasmid; lane 3 contains DNA molecular weight ladder; lanes 5 to 9 contain plasmid adducted by [ $\mathrm{H}] \mathrm{BaP}$ metabolites produced by freshly isolated hepatocytes; lane 10 cortains Hindlil-digestad lambde DNA as molecular weight markers. Large radioactivity peak at $5.5 \mathrm{~cm}$ (right) corresponds to bright band in photograph (lett). 



\section{Mutation of DNA Targets}

\section{Principal Investigators: $R$. A. Pelroy (R. P. Schneider, current PI)}

\section{Other Investigators: $L$. K. Fritz}

We have constructed and tested a plasmid for detecting and analyzing mutations in synthetic DNA targets. The target introduces a frameshift that inactivates the lac operon genes in the plasmid. Thus, mutants of Salmonella typhimurium Ames strains can be selected by their ability to grow on lactose.

The DNA sequences of mutated plasmids from three targets exposed to 6-aminochrysene have been analyzed. Mutants with a target (pGC1) consisting of $\left(5^{\prime}\right.$ to $\left.3^{\prime}\right)$ a polylinker cloning site, a core of GCGCCC, and a stop codon showed no change in the DNA sequence of the target region. Mutants with a target that was a tandem repeat of pGC1 showed complete deletions of the target sequence. Three of 11 mutants with a target core of six G's contained a 14-bp insert that was a repeat of a portion of the target. This work has shown that the plasmid provides a new approach to study frameshift mutations and the relationships of mutation to DNA sequence.

Spontaneous and chemically induced mutations do not occur randomly within genomes. They mostly occur at mutation hotspots or sequences that have mutation frequencies tens or hundreds of times higher than does the rest of the genome. In many cases the mutability of the hotspots depends on the mutagen, that is, hotspots may be mutable for one kind of mutagen but not another. Known hotspots have been identified by genetic and sequence analysis of genes that allow selection of reverse or forward mutations. This analysis has provided a successful approach but is dependent on naturally occurring hotspot sequences within the sequences being studied.

We have designed and verified an experimental system that permits study of mutation of synthetic DNA targets of any desired sequence in Salmonella Ames strains. These targets are inserted into a plasmid (Figure 1) that contains the lac operon for selection of mutants. The target insert changes the reading frame, thus inactivating the lac operon; therefore, mutations that correct the reading frame allow Salmonella to grow on lactose. Reading-frame mutations $3^{\prime}$ to the target are prevented by a stop codon at the $3^{\prime}$-end of the inserted target. The system was described in greater detail in the 1988 Annual Report.

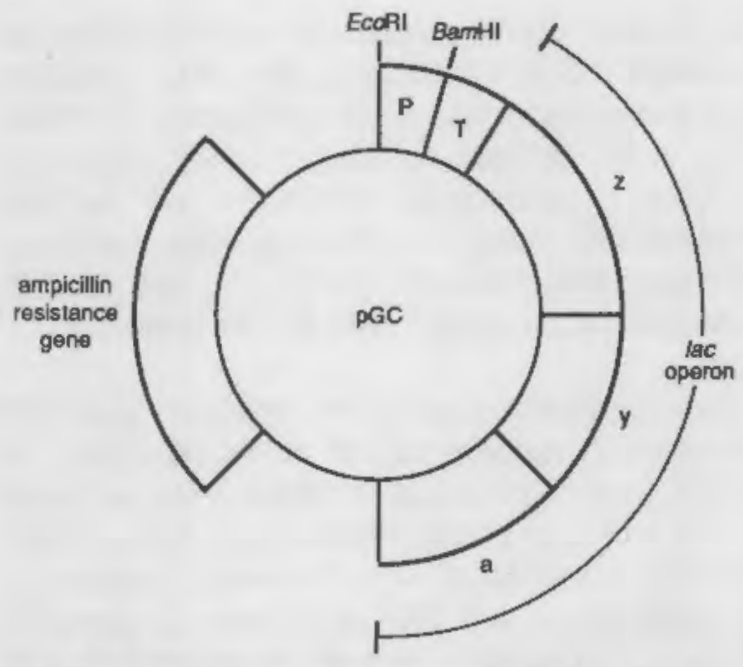

FIGURE 1. Exposure System Was Constructed from Parent Plasmid pSKS107, Which Contains Gene Conferring Ampicillin Resistance, Co/El Origin of Replication, and the Structural Genes of the lac Operon with M13 Multicloning Linker at Extreme $5^{\prime}$ End of the lacZ Gene. However, the operon had no promoter. P, Synthetic promoter designed from Ipp (lipoprotein) promoter in $E$. coll. This promoter was designed to drive operon structural genes $z, y$, and $a$. It was cloned into the EcoRI site at the extreme $5^{\prime}$ end of lacZ. T, target sequence, synthetic oligo designed to take lac $Z$ out of reading frame by adding +1 mutation. Target consists of core region (mutational hotspot) and translational stop codon in +1 reading frame. These targat sequences were ligated into the BamHI site. 
Five synthetic targets have been synthesized and tested in Salmonella Ames strain (TA 1538). One of these, with a core of $6 \mathrm{~A}$ 's, was not mutagenically active, and another with the same flanking sequence but a core of ATATAT had too high a rate of spontaneous mutation to be usable. Three other targets were found to be mutable by 6-aminochrysene (6-AC) and 2-aminoanthracene (2-AA) and, although less so, by benzo[a]pyrene $(\mathrm{BaP})$. The clones of mutants that were able to grow on lactose as a carbon source were further studied by analysis of their growth rate and B-galactosidase levels (see 1988 report). Plasmids from revertant clones were used to transform Salmonella typhimurium SL4213 so that we could separate mutated from nonmutated plasmids. The DNA from SL4213 was then purified by $\mathrm{CsCl}$ gradient centrifugation, and the target region was sequenced by the dideoxy chain termination method using the double-stranded plasmid as template.

The plasmid pGC1 contains a core sequence of six bases that are alternating $G$ and $C$, modeled after the mutationally active sequence in Ames tester strain TA 1538 mutation D 3052 . Sequence analysis of revertants that grew on lactose revealed no change in the sequence, perhaps indicating that the stop codon did not confine mutations to the target insert in this construct.

A strain containing another construct (pGC21) contained a tandem repeat of target pGC1. It exhibited the highest mutation rate, when exposed to 6-AC, of any plasmid tested and had a high spontaneous mutation rate. The insert regions of the plasmids of five revertants were sequenced (Table 1). In plasmids from two spontaneous and two 6-AC-exposed revertants, the target (or insert) was completely deleted.

Plasmid pLG6 contained a core sequence of six G's, a sequence suspected of being mutagenically active in Ames tester strain TA 97, mutation hisD 6610. The sequence analysis of mutant plasmids of pLG6 yielded unexpected results (Table 2). The background and induced mutation rate of this construct was high. Retransformation of Escherichia coli strain MC1116 rec; $\triangle$ lac 1POZYA) by DNA from the SL 4213 clones was performed until all colonies on media containing $\mathrm{X}$ gal were blue, indicating an active lac operon. When plasmid DNA from these clones were analyzed, base sequence changes that corrected the frameshift were revealed. Thus even after the transformation of Sa/monella SL 4213 by plasmid DNA from mutant clones that grew on lactose, the transformed clones contained mixed populations of plasmids, both mutated and nonmutated. Further transformation of rec $E$. coli was required to establish clones of only mutant plasmids. Of 11 6-AC-induced and spontaneous mutants, 8 contained a single GC deletion (Table 2). The remaining 3 contained an insert that was a partial repeat of the target sequence. These are the only insertion mutants found in the clones analyzed. More research is required to formulate a mechanism by which the addition occurred. It did not depend on a mutagen because a revertant containing plasmid from an exposure to $\$-9$ enzymes, but not added promutagen, also had the insert.

New target sequences have been synthesized, ligated into plasmids, and used to transform strain TA 98. This strain has a plasmid (pMK 101) that

TABLE 1. Sequence Analysis of Lectose Revertants of pGC21

Original Target Sequence:

\begin{tabular}{ccc} 
CORE STOP & CORE STOP \\
5 '-GATCCTITACCGCGCGCCCCTAACGGATCCCTITACCGCGCGCCCCTAACG-3' \\
\hline
\end{tabular}

\begin{tabular}{lccl} 
Mutagen & Clone Number & & DNA Sequence Analysis \\
\cline { 2 - 3 } $6-A C$ & 9 & & Total insert deletion \\
$6-A C$ & 11 & & Total insert deletion \\
Control & 1 & Total insert deletion \\
Control & 2 & Total insert deletion
\end{tabular}


TABLE 2. Sequence Analyois of Lactose Revertante of pLG6

\begin{tabular}{ccc}
\multicolumn{3}{c}{ Original Target Sequence: } \\
\hline 5'-ATGGCGAATTCCCGGGGATCCTTACCCGGGGGGCCCTAACG 3' \\
\hline Mutagen & Clone Number & DNA Sequence Analysis \\
\hline G-AC & 1 & Deletion, one G from core \\
GAC & 2 & Deletion, one G from core \\
GAC & 3 & Deletion, one G from core \\
G-AC & 4 & Insertion (e) \\
GAC & 5 & Deletion, one G from core \\
GAC & 10 & Deletion, one G from core \\
A-AC & 11 & Insertion (e) \\
Control & 3 & Deletion, one G from core \\
Control & 8 & Deletion, one G from core \\
Control & 9 & Deletion, one G from core \\
Control & 10 & Insertion (a)
\end{tabular}

(a) Insert contained a partial repeat (in box) of target sequence:

ATGGCQAATTCCCGGGGATCCTITA| CCEGGGATCCTITA|CCGGGGGGCCTAACGQATCC

carries genes analogous to the error-prone repair system which enhances sensitivity to chemical mutagenesis in E. coli. Because PMK 101 confers ampicillin resistance, a gene that confers chloramphenicol resistance (cat) was added to the plasmid used as a target vector. In so doing, the ampicillin resistance gene was inactivated in the target vector. This provides selective pressure to maintain both plasmids in the cell; otherwise, one plasmid could be lost because either one would allow growth on ampicillin. +1 and +2 frameshifts are created in the new targets by only changing the alternating GC core length and keeping the flanking sequences constant.

We have no explanation for the lack of sequence change in pGC1. Plasmid DNA from Salmonella $S L 4213$ was used to transform $E$. coli MC1116, and only blue clones were selected for sequence analysis. The sequencing gels suggested that the template used for sequencing reactions was homogeneous, but another transformation yielded both white and blue clones on $X$ gal. Further study is required to clarify this paradox.

The target (pGC21) containing a tandem repeat of the pGC1 target was highly mutable, and deletion of the entire target was the cornmon frameshift-correcting mechanism. Deletions in regions of DNA characterization by direct repeat sequences have been commonly observed in other mutagenesis studies.

The addition of the 14-bp insert into pGC6 occurred in 3 of 11 mutants analyzed. Because both the core and flanking sequences differed from the other targets, we are unable to attribute the insertion to a specific sequence. A recombinational event may have been responsible for the addition, but we cannot postulate why it occurred only in this target.

The genetic construction described in this report provides another approach to study molecular mechanisms of mutagenesis and its relationship to DNA sequence. It has revealed a wide spectrum of frameshift mutations, including deletions of a single base pair, larger deletion, and an insertion of 14 base pairs. Further investigation is needed to understand why lactose revertants with GC1 have unaltered target sequence. This may be the result of mutations not confined to the target by the stop codon. However, we found no evidence of this in plasmids with other target sequences. Mutations causing the frameshift sequence changes were dependent on the sequence of the target. This relationship suggests that this system is useful for studying mechanisms of mutagenesis. 
In the future, we will investigate the pGC1 revertants by repeating the entire experiment, including repeated transformation of the plasmid into $E$. coli and extension of the DNA sequence analysis to include more of the lacZ gene. We will also examine the effect of error-prone repair functions of plasmid pMK 101 (Ames strain TA 98) on mutagenesis. The role of flanking sequences will be studied by varying them while using the same core target. 


\title{
Fetal and Juvenile Radiotoxicity
}

\author{
Principal Investigator: M. R. Sikov
}

Other Investigators: R. L. Buschbom, G. E. Dagle, D. R. Kalkwarf, D. D. Mahlum, H. K. Meznarich, and D. N. Rommereim

\section{Technical Assistance: J. P. Bramson and B. G. Moore}

This project compares information concerning the deposition, dosimetry, and toxicity of radionuclides in animals relative to their prenatal or postnatal age. These relationships are being modeled to obtain values to establish radiological protection practices for pregnant women and for rapidly growing infants and children.

Fetoplacental radionuclide uptake correlates with physicochemical and biological factors and displays a similarity to fractional absorption from the gastrointestinal tract. Binding and transport processes, metabolic specificities, and concentration gradients explain both similarities and differences.

To investigate the mechanisms of radiation teratogenesis, we developed an in vitro/in vivo mouse limb bud system. Experiments have shown that a dose range below $1 \mathrm{~Gy}$ is appropriate for demonstrating effects on limb development in vitro, such as cell death and altered histology, in addition to histochemical changes in cartilage differentiation and altered structure as seen in scanning electron microscopy. Further evaluations will provide comparisons with ultramicroscopic and immunocytochemical alterations and furnish parallel information about the processes of radionuclide deposition in fetal bone.

Examination of specimens and statistical analysis of data relative to placental transfer, perinatal toxicity, and fetoplacental dose demonstrate differences in mammary tumor development relative to the time of intravenous injection of ${ }^{239} \mathrm{Pu}$ in pregnant or postnatal rats. The incidence of tumors in rats was increased by radionuclide exposure in the prenatal, weanling, and adult groups, although incidence was not significantly affected by exposure level. There were also significant dosedependent trends toward earlier tumor development in these age groups (Figure 1). Reduced longevity among rats injected with the highest dose obscured determination of the significance of any possible effect on incidence or latency in the newborn group. The increased tumor incidence in these experimental prenatal groups, as well as after injection at even earlier stages of gestation in related experiments, indicated that the oncogenic action must have occurred before mammary tissues had formed. This observation raises questions concerning the dose to specific target tissues for oncogenesis in prenatal life (presumptive mammary tissues, in this instance) that have mechanistic implications and illustrate the need for microdosimetric evaluation of the embryo and fetus.

The Annual Reports for 1987 and 1988 described some correlations between radionuclide characteristics and their placental transfer and some modeling approaches. Another approach is that used by groups concerned with radiological protection (e.g., ICRP), in which the fractional amounts of radionuclides that are absorbed from the gastrointestinal (Gl) tract or from the lung are estimated, expressed as $f_{1}$ values, and used in models for the resulting distribution and radiation dose in tissues. Because analogous values would be useful for placental transfer, fetoplacental deposition, and dose, we have begun introducing empirical and derived values into the models. Composite values from data in earlier reports, including clearance measurements by placental perfusion, short-term serial sacrifice experiments, and measurements of fetoplacental deposition that 
did not involve actual kinetic or transport determinations, have been calculated. These composite values, which are proportional to fractional placental transfer, are tentatively denoted $r$ (tau), both to avoid semantic problems and to avoid conveying implications beyond warranted limits (Table 1).
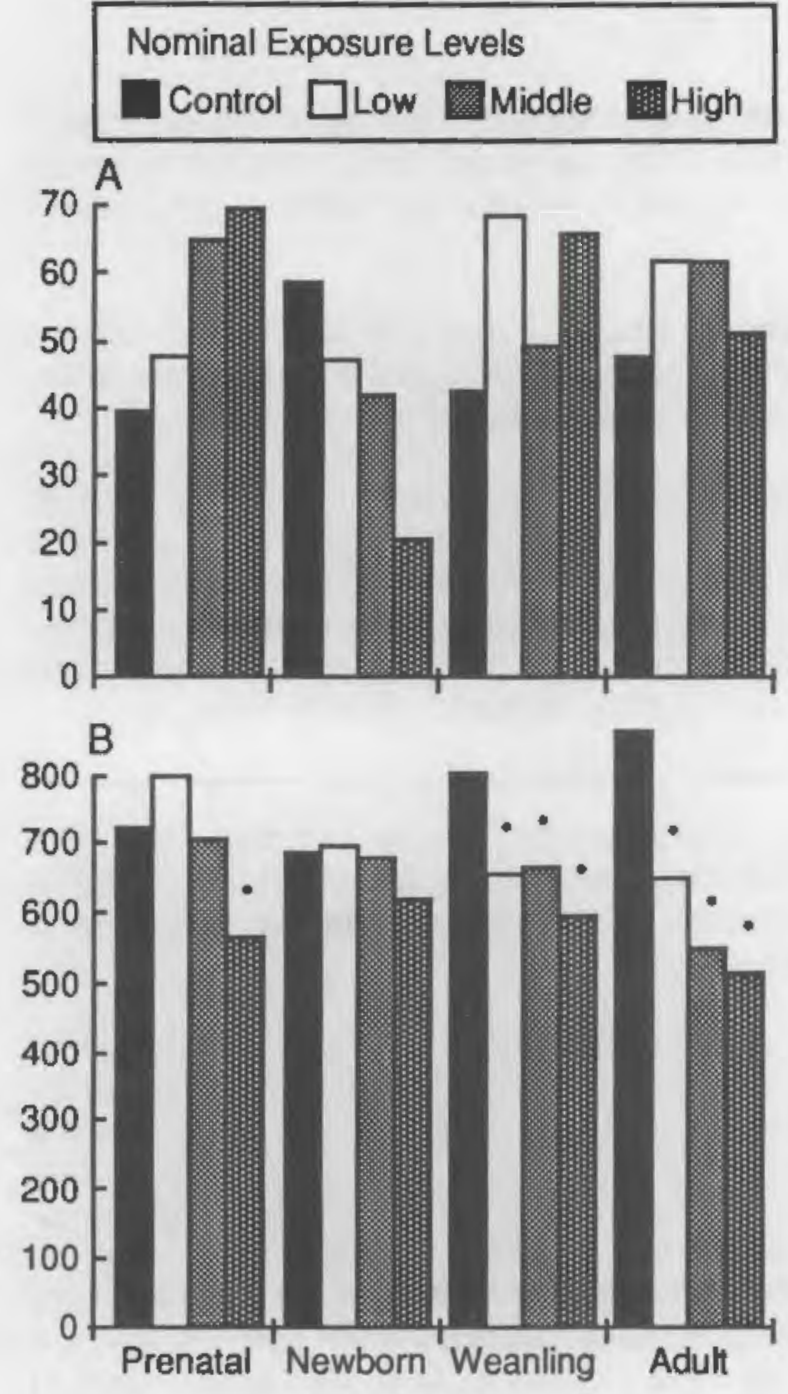

FIGURE 1. Effect of Age and Exposure Level to ${ }^{239} \mathrm{Pu}$ on Percentage of Rats with Mammary Tumors (A, upper panel) and Median Ages at Which First Tumors Were Detected in Age-Exposure Group (B, lower panel). Dose-dependent trends toward earlier development in age groups are indicated by one or more dote $(\bullet)$ above series; dot $(\bullet)$ above individual bar indicates significantly decreased latency relative to its corresponding control.
TABLE 1. Tentative Estimates of Relative Degree to Which Selected Elemente Cross the Placenta Are Expressed as a Derived Term, $\tau$, to Avoid Semantic and Operational Limitations (see text)

\begin{tabular}{|c|c|c|}
\hline$\underline{z}$ & Element/Form & $\tau$ \\
\hline 1 & Hydrogen, water & $\gamma^{(a)}$ \\
\hline 1 & Hydrogen, organic & $0.555^{(b)}$ \\
\hline 6 & Carbon & 0.555 \\
\hline 6 & Carbon, oxide & 0.444 \\
\hline 6 & Carbon, oxide $\times 2$ & 0.444 \\
\hline 7 & Nitrogen & 0.444 \\
\hline 8 & Oxygen & 0.444 \\
\hline 11 & Sodium & 0.777 \\
\hline 15 & Phosphorus & 0.9 \\
\hline 16 & Sultur & 0.9 \\
\hline 17 & Chlorine & $0.7 \pi$ \\
\hline 19 & Potassium & 1 \\
\hline 20 & Calcium & 0.47 \\
\hline 23 & Vanadium & 0.1 \\
\hline 26 & Iron & 0.777 \\
\hline 27 & Cobalt, inorganic & 0.222 \\
\hline 27 & Cobalt, organic $B_{12}$ & 1 \\
\hline 36 & Krypton & 1 \\
\hline 38 & Strontium & 0.42 \\
\hline 44 & Ruthenium & $0.001^{(c)}$ \\
\hline 48 & Cadmium & 0.62 \\
\hline 53 & lodine & 1 \\
\hline 55 & Cesium & 1 \\
\hline 58 & Cerium & 0.06 \\
\hline 59 & Praseodymium & $0.06^{\text {(d) }}$ \\
\hline 71 & Lutecium & $0.06^{(d)}$ \\
\hline 80 & Mercury, inorganic & 0.02 \\
\hline 80 & Mercury, methyl & 0.8 \\
\hline 82 & Lead & 0.2 \\
\hline 84 & Polonium & 0.01 \\
\hline 90 & Thorium & 0.001 \\
\hline 92 & Uranium & 0.03 \\
\hline 93 & Neptunium & 0.06 \\
\hline 94 & Plutonium & 0.063 \\
\hline 95 & Americium & 0.006 \\
\hline 96 & Curium & 0.009 \\
\hline 99 & Einsteinium & 0.024 \\
\hline
\end{tabular}

(a) Values of 1 are used to represent freely moving materials, although equilibrium may exist.

(b) Values are presented as 0 .\#\#\# to indicate approximations for which refinements are needed.

(c) Because of inability to achieve greater precision, 0.001 is used to Indicate minimal transfar.

(d) Following ICRP approach, most intervening elements are assumed to be similar to cerium.

As shown in Figure 2, many initial relationships between these $r$ values and the tabulated $f$ values for the GI-tract-absorbed fraction show generally consistent correlations, but differences in either direction are seen for some materials. Examinations of these differences provided mechanistic 
inferences and suggested areas for further study for both physiological and developmental toxicology. First, the theoretical bases underlying $r$ and $f$ values are not completely comparable. Second, there are physiological differences: placental transfer processes are bidirectional, more complex than absorption, may involve different transport proteins, and may be more affected by changing biological conditions. Third, there are important differences between approaches appropriate for metabolic as contrasted with dosimetric considerations. From the metabolic standpoint, it is necessary to distinguish between equilibrium and net transfer, and the calculations of the absorption of relatively insoluble materials differ for the small absorbed fraction that enters the blood and is available for placental transfer. In this case, we consider only the soluble fraction, or materials that are involved with transport protein or a chelate. Radiation dose may relate to external sources or in situ deposition, and involves decay scheme and energy, important considerations that are independent of transfer.
Radiation was among the first prenatal agents for which cause-and-effect and dose-response relationships for teratogenesis were demonstrated; these early studies also identified critical periods or stage dependence. However, there has been little research on the mechanisms of radiogenic derangements of development. Alterations of cell proliferation or differentiation may be mediated through changes in such factors as genomerelated control processes, interactions between nuclear, cytoplasmic, and extracellular molecules, and cell-surface phenomena, including cell-cell interactions. Information concerning limb teratogens suggests that inhibition of communication between limb mesenchymal cells may interfere with chondrogenesis, and these processes are susceptible to radiogenic interference. Mechanistic investigation of these processes requires in vitro/in vivo methods.

Our approach was based on results of our earlier studies that compared in vitro/in vivo effects and repair following irradiation of fetal lung and liver in
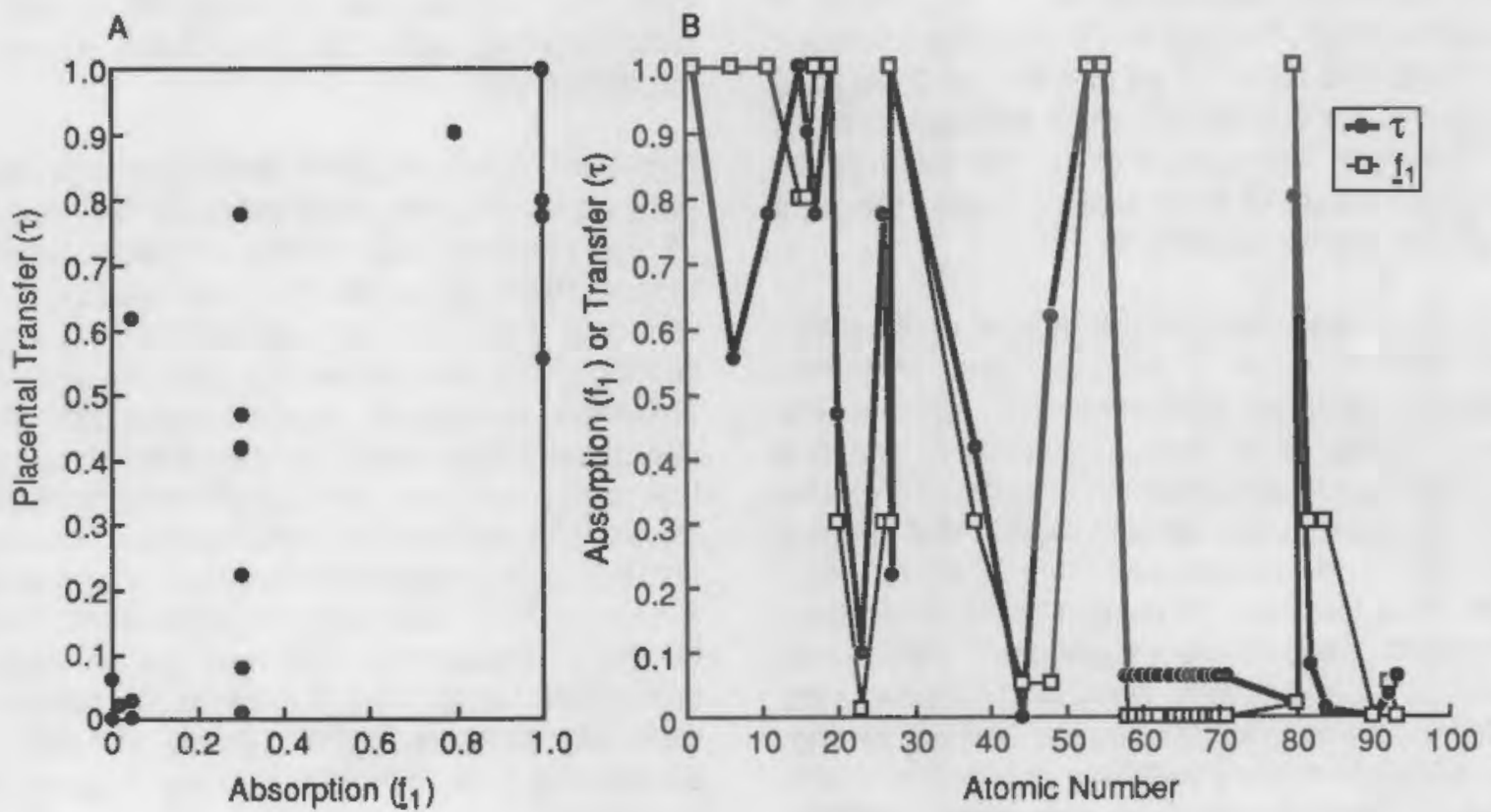

FIGURE 2. Pelationships Between Estimates of Placental Transfer and Corresponding Gastrointestinal Absorption Values (A, left panel) and Variation of These Values with Increasing Atomic Number (B, right panel) 
rats. We had implemented these techniques during prior years, and successfully converted them for use with the embryonic mouse this year, as well as adding methods for use with limb bud, brain, and yolk sac. We used the in vitro limb bud system for initial experiments on the mechanism of radiogenic developmental derangements; this system will also provide a means to examine the integrated morphological and molecular basis for the sequential development of receptor sites and processes for bone-seeking radionuclides during prenatal and neonatal life.

The dose and stage relationships for limb teratogenesis are well defined for irradiation in vivo but not in vitro. Mouse forelimb buds in organ culture provided a facile and reproducible test system because the specimens were readily accessible to manipulation; furthermore, one limb bud could be irradiated while the contralateral bud served as a control to reduce confounding by stage variability, and direct sequential evaluations could be made without killing the pregnant animal. In the initial experiments, embryos were obtained from timed-pregnant CD-1 mice, and their forelimbs were explanted into culture at 11 or 12 days of gestation (dg). The left forelimbs were irradiated with 1,2 , or 3 Gy at $11 \mathrm{dg}$ or with 1 or 2 Gy at 12 $\mathrm{dg}$, to induce a graded degree of developmental abnormalities for determining the appropriate range for study of molecular changes; the right forelimbs served as controls.

Limb buds were fixed at the time of explantation and after 1, 2, or 3 days in vitro, and from embryos removed from untreated dams at the same stages of in vivo development. The first methodological approaches concentrated on use of whole mounts with various fixation and staining procedures. In subsequent experiments, most limb buds were fixed in $10 \%$ neutral buffered formalin; histological sections were stained with H\&E or with alcian blue/PAS, and unstained slides were retained for immunocytochemical staining as suggested by histochemical stains and electron microscopy. Glutaraldehyde-fixed limb buds were prepared for SEM and TEM; the latter was preceded by preliminary thick sectioning and toluidine blue staining. This allows us to develop additional ways to evaluate cartilage and its induction, morphological organization, and molecular precursors.
The extent of growth and differentiation in culture depended on the stage of the donor embryos, as observed previously, and development was less in limb buds explanted at $11 \mathrm{dg}$ than in those explanted at $12 \mathrm{dg}$. Likewise, in vitro cultures showed less differentiation of mesenchymal cells into chondroblasts and less deposition of intercellular substances than parallel material from in vivo embryos.

The mesenchymal condensations that will form the radius and metacarpals of forelimb buds are present at $12 \mathrm{dg}$; the mesenchymal cells proliferate and differentiate to chondrocytes; forming cartilage for long bones and digits. Metacarpals are present after 1 day of incubation, and there is a broad layer of cells in the ectoderm region. At 3 days, death of ectodermal cells results in the indentations that contribute to the formation of the digital rays. Some mesenchymal cells differentiate and mature to chondrocytes, and glycogen and lipids are deposited in the matured chondrocytes in the central region of cartilage. Alcian blue interacts with the extracellular matrix materials, and an accumulation of materials staining positively with alcian blue is observed around the mesenchymal cells in their initial phase of condensation.

Exposure to $1 \mathrm{~Gy}$ at either gestational age had no early gross morphological effect. On the day after $12 \mathrm{dg}$ irradiation, aggregation of prechondrocytic mesenchyme destined to form cartilage was reduced. Both H\&E- and alcian blue/PAS-stained sections from the irradiated groups showed more cell death among the mesenchymal cells in the noncartilaginous areas, as compared to the control group, and less cell-to-cell contact, possibly because of reduced cell proliferation. Differentiation into chondrocytes continued through 3 days in culture, with deposition of extracellular matrix, but the arrangement of cells was less well ordered in irradiated cells than in controls. Mesenchymal cells of nonchondrogenic areas showed little development or differentiation by 3 days after irradiation.

We concluded that 1 Gy was the upper limit for mechanistic studies because the limb buds were visually smaller than those of controls after exposure to 2 or $3 \mathrm{~Gy}$, and most had severely retarded 
development. After 2 Gy at $12 \mathrm{dg}$, approximately $80 \%$ of the mesenchymal cells in noncartilaginous areas appeared necrotic on the next day as well as at 3 days after exposure. Aggregation of mesenchyme was initially reduced in the presumptive cartilage of these cultures, and there was a subsequent delay in their progression to chondrocytes and cartilage formation relative to that of controls, as well as increased cell death and a reduction of hematogenous elements. The appearance of limb buds that were explanted at $11 \mathrm{dg}$ was a generalized distribution of mesenchymal cells, with a covering layer of ectodermal cells. Early prechondrocytic cells of the mesenchyme could be recognized on the following day in control cultures, but the beginnings of their aggregation and cartilage formation were not apparent until 3 days. Exposure to 1 Gy had little gross effect. Proliferation was greater in nonchondrocytes than in prechondrocytes, and prechondrocytes seemed more radiosensitive, with a higher incidence of cell death and at lower doses. Cell death occurred among the mesenchymal cells of areas not involved in cartilage formation at $1 \mathrm{~Gy}$. Chondrocytes were more resistant; they showed only slight suppression of differentiation and maturation to cartilage (Figure 3 ). There was a high incidence of necrosis of mesenchymal cells after a 2-Gy exposure, and essentially all were killed by 3 Gy at $11 \mathrm{dg}$.
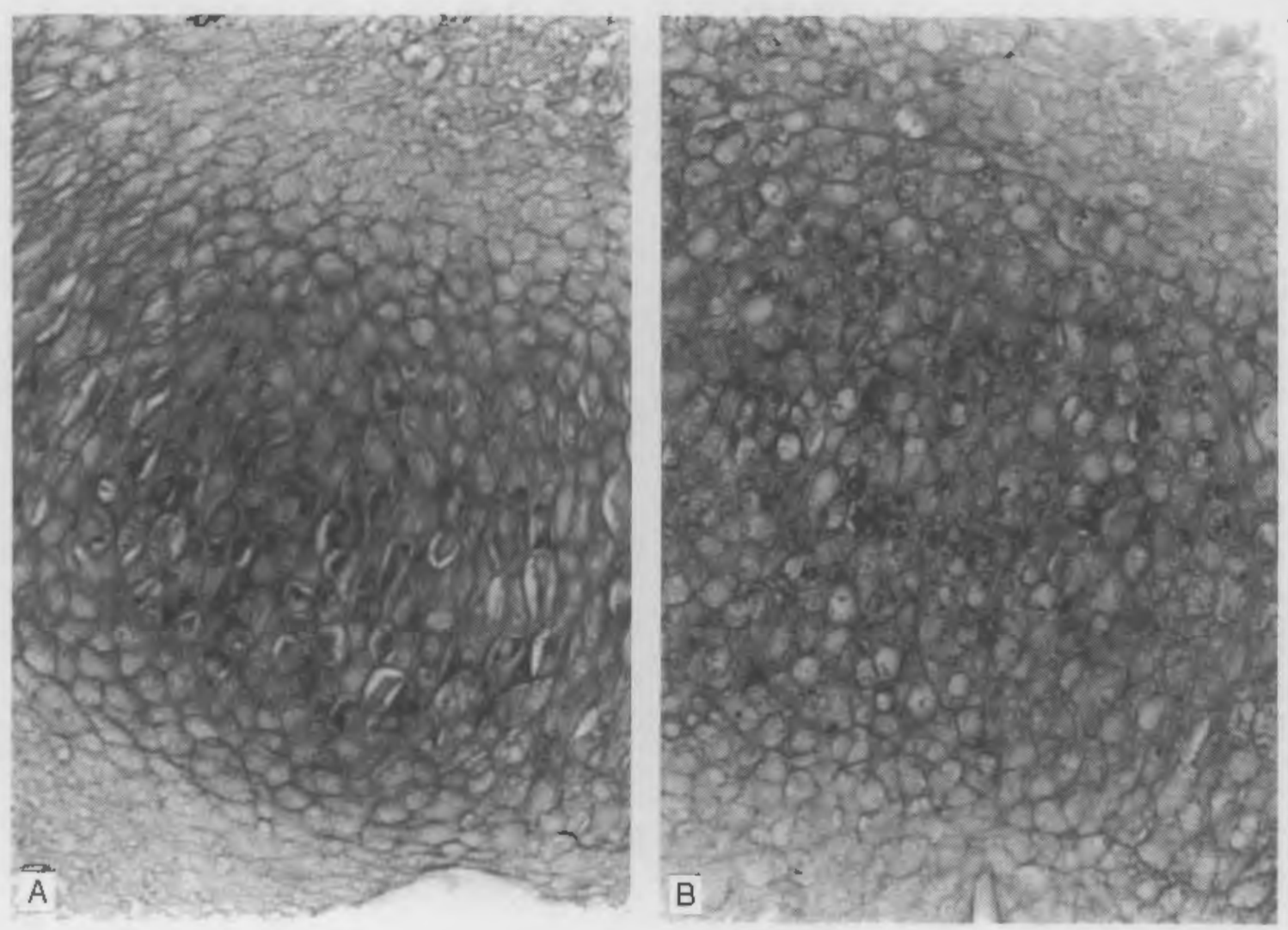

FIGURE 3. Photomicrographs of Limb Bud Cultures from 11-dg Mouse Embryo After 3 Days In Vitro. Control (A, left panel) shows typical appearance of cartilage developing into long bone, with noncartilaginous mesenchymal cells in adjacent areas. Irradiation at time of explantation (B, right panel) leads to reduced size and organization of cartilage and lower density of noncartilaginous mesenchymal cell population. 
These findings generally agree with our earlier experiments in which radiation effects on fetal lungs were more pronounced with in vivo than in vitro irradiation. Although growth suppression was detectable, the morphological effects on the in vitro limb bud were less than expected from in vivo results. This suggested questions about processes that occur in vivo and lead to a greater responsiveness than with in vitro exposure. Similarly, recovery of embryonic lung from the radiation damage was more rapid and successful with continued in vivo development than after in vivo irradiation and subsequent in vitro development.

This research was coordinated with that of PNL staff who were implementing approaches for irradiation of single cells of the 2- to 4-cell embryo with microbeams of charged particles. Standard procedures for harvesting and culturing 2-cell mouse embryos to the blastocyst stage were modified to conditions appropriate to our laboratory and the irradiation facility. Preimplantation mouse embryos were selected for this project because of the accessibility of their cells and because these cells and subsequent progenitor tissues must undergo a precise sequence of interactions to attain recognizable developmental endpoints. Thus, the 2- to 4-cell embryo will provide a system for studying biological mechanisms of radiation damage and control of intercellular interactions during early development; further, such a system should provide comparative data complementary to those obtained with irradiation during organogenesis. 


\section{Aerosol Technology Development}

\section{Principal Investigator: $A$. C. James}

Other Investigators: B. J. Greenspan, J. K. Briant, J. R. Decker, C. L. Leach, C. J. Driver, P. J. Boyd, L. G. Smith, L. L. Eyler, and

D. D. Frank ${ }^{(a)}$

The purpose of this project is to develop and transfer aerosol and inhalation technology to basic and applied research in biology and chemistry, especially in the areas of health and environmental effects of energy-related materials.

We report here advances in providing uniform exposures of laboratory animals to reactive vapors, and in electric-field nebulization, in the development of a respiratory physiology laboratory, in the determination of aerosol particle mobility in mixtures of gases to help interpret studies of the fluid dynamics of the respiratory tract, and in the numerical simulation of aerosol particle transport in the respiratory tract.

\section{Exposure of Animals to Reactive Vapors}

The Hazelton 2000 (Harford Division of Lab Products, Aberdeen, Maryland) whole-body exposure chamber, designed at PNL, has become the standard for large-scale exposures of rodents to vapors and aerosols. The mixing of air flow within the chamber that is induced by the excrement catch pans is sufficient to achieve uniform concentrations for a wide variety of materials. However, if the test material (e.g., ozone and glutaraldehyde) reacts with the animal's fur and excrement, or is able to condense on chamber surfaces (e.g., unattached radon daughters), the uniformity of exposure is compromised.

We have overcome nonuniform diffusional losses of test materials from the chamber air, while still maintaining an acceptable environment for the exposed animals, by developing a recirculation system to increase the level of mixing within the chamber (Figure 1). The chamber is usually operated at an air-flow rate of $15 \mathrm{~cm}$, which gives approximately 15 air changes per hour. The recirculation system increases the effective air-flow rate through the chamber to approximately $70 \mathrm{cfm}$. This requires neither additional air, which would have to be conditioned for temperature and relative humidity, nor a substantial increase in the concentration of test material supplied by the generator.

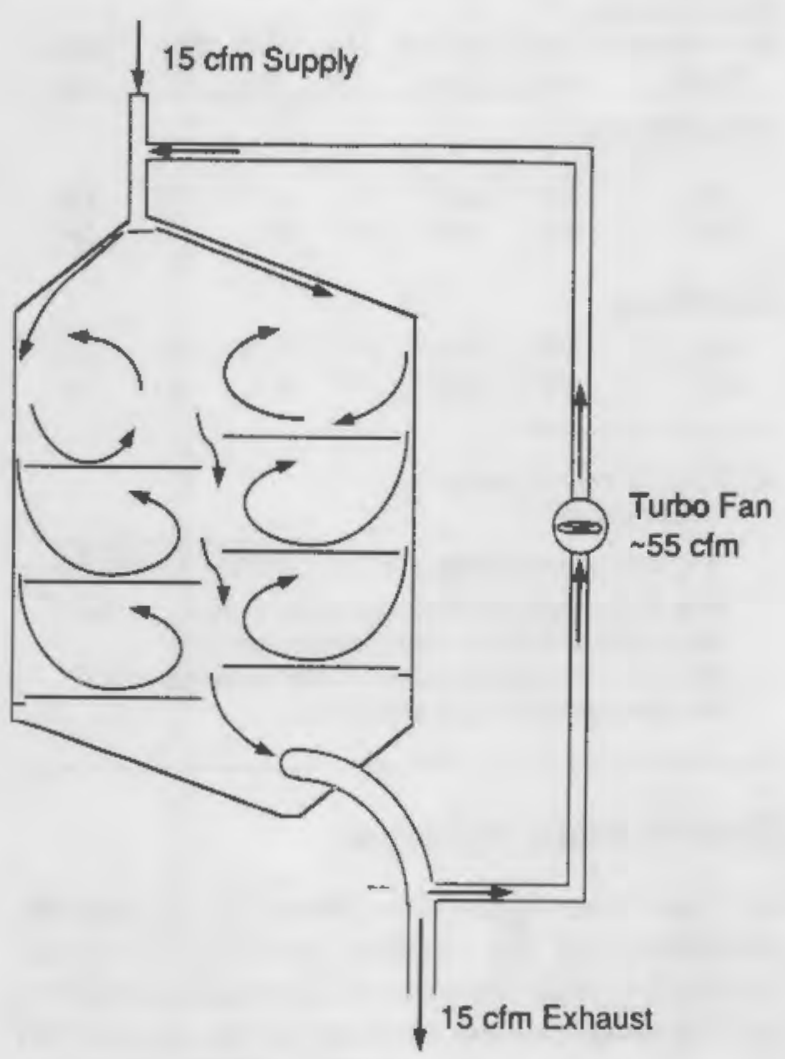

FIGUAE 1. Turbo Fan Recirculation System Developed to Increase Mixing in the Hazelton 2000 Chamber to Achieve Uniform Exposures to Reactive Vapors

(e) NORCUS Research Student. 
The results given in Table 1 illustrate the reduction in variability of exposure to ozone achieved by adding the turbo fan recirculation system to the Hazelton 2000 chamber. When ozone was delivered to an empty chamber, the variability of the concentration measured at 12 sampling locations (expressed as the percent relative standard deviation) was $1.2 \%$ without the turbo fan and $0.5 \%$ with the fan operating. However, when ozone was delivered normally to 96 large rats, the variability in concentration within the chamber increased to $21.4 \%$ (14.0\% temporal and $16.2 \%$ spatial components). Use of the turbo fan reduced the variability in ozone concentration to an acceptable level of $7.1 \%$.

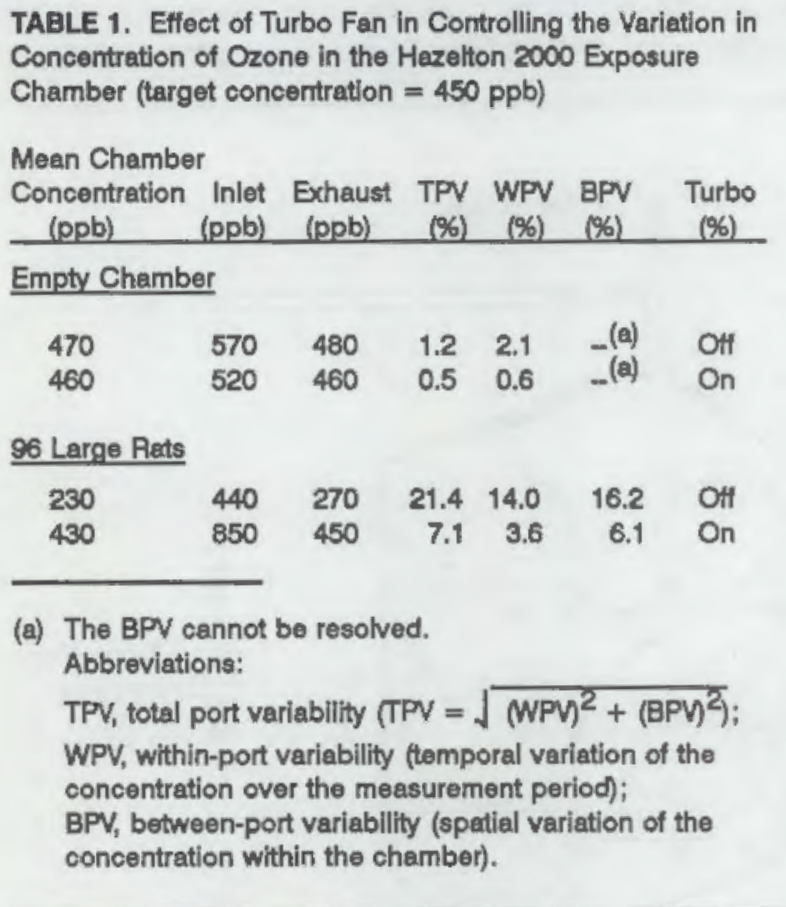

\section{Electric-Field Nebulizer}

We have investigated the effects of varying the dimensions of the capillary used to inject the source fluid into the electric-field nebulizer (EFN) and the electrical properties of the source fluid on the performance of the device for aerosolizing various materials. Tests with saline solutions showed that a fluid conductivity less than $100 \mu \mathrm{mho} \mathrm{cm}^{-1}$ is necessary to produce a reliable and stable fan spray from a 0.004 -in.-ID stainless steel capillary tube. The ability to produce a stable fan spray from low-conductivity, deionized distilled water was found to depend on the rate of injection through the capillary tube. The 0.004 -in.-ID capillary gave a stable fan spray, whereas using an 0.001 -in.-ID tube to increase the injection rate caused the output of the aerosol to fluctuate. It was found that the viscosity of the fluid also affected the aerosol output. A $1 \%$ solution of glycerol sprayed from a 0.006 -in.-ID capillary gave a volumetric output rate of $10 \mu \mathrm{L} \mathrm{min}$, whereas $20 \%$ glycerol in a 0.004 -in.-ID tube yielded $0.9 \mu \mathrm{L} \mathrm{min}^{-1}$. The performance of the EFN was found to depend on the electrode configuration, which is now being optimized.

\section{Respiratory Physiology of Laboratory Animals}

We have assembled equipment and developed techniques to perform a wide range of pulmonary function tests on rats, mice, guinea pigs, hamsters, birds, and nonhuman primates. Tests are carried out noninvasively on awake animals, using whole-body, double-flow plethysmography. The tests include breath-by-breath evaluations of specific airway resistance and conductance, peak expiratory flow, tidal volume, respiratory rate, minute volume, and inspiratory, expiratory, and relaxation times. In addition, we can measure transpulmonary pressure, and dynamic compliance and resistance, using a surgically implanted intrapleural catheter.

The physiology laboratory will establish baseline data for the animal species and strains used at PNL in toxicological studies. This will enable both acute and chronic effects of exposure to pollutants on pulmonary function to be detected and monitored. Also, the laboratory will enable the effects of pollutants on an animal's capacity to respond to respiratory stress to be measured.

We have completed, for the U.S. Environmental Protection Agency, a study of pulmonary physiology in the bobwhite quail, from the 9-day-old chick to young adulthood at about 50 days. This species provides a useful model to monitor the effects of poliutants and agricultural chemicals on wildlife exposed at ground level. To illustrate the data obtained, Figures 2 and 3 show the undisturbed tidal volume and respiratory frequency, respectively, measured in bobwhite quail as a function of 
age. The figures show variability in the mean values measured for several individual birds. The variability from breath to breath in each bird was found to be markedly lower than that between individuals, for all respiratory parameters. Monitoring of individual birds can therefore detect subtle changes in pulmonary function in response to pollutant exposure.

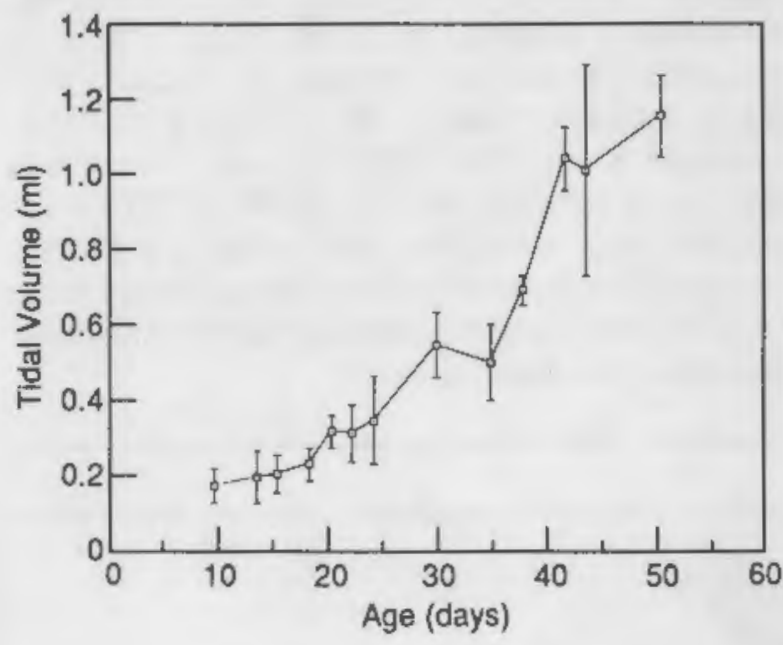

FIGURE 2. Tidal Volume of Bobwhite Quail Measured as Function of Age (mean \pm SD between individual birds)

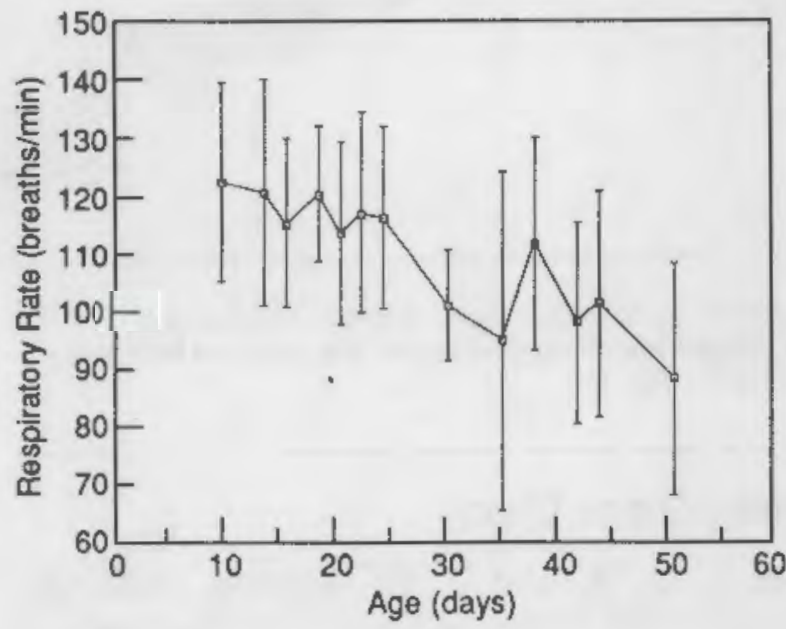

FIGURE 3. Respiratory Rate of Bobwhite Quail Measured as Function of Age (mean \pm SD between individual birds)

\section{Aerosol Particle Mobility in Gas Mixtures}

Particles of minimum intrinsic mobility are used to trace convective gas transport in the human lung and to detect changes in airway caliber in response to disease or irritant exposures. However, many variable factors influence the transport and dispersion of tidal air and thus the deposition of particles in the lung. To elucidate the fluid mechanical phenomena involved, experimental studies must fix as many variables as practicable, and then measure the effect of varying one controlled parameter. A promising approach is to fix the depth and velocity of inhalation, minimize the particle intrinsic mobility, and alter the behavior of the ventilating gas by varying its kinematic viscosity. However, studies that have adopted this approach have used inconsistent methods to evaluate the size of particles that have equivalent (and minimum) mobility in the test gases.

We have reviewed the theoretical basis for calculating the particle size of equivalent mobility in different mixtures of gases. The calculated value is found to depend strongly on the method used to formulate the mean velocity of the gas molecules, c. Consideration of the kinetic theory of gases determines that the mean velocity is defined by weighting the average molecular speeds of the component gases in the mixture by their mole fractions. Other investigators have evaluated c from the average molecular weight of the gas mixture. This results in a calculated equivalent mobility diameter 10 times greater than our calculated value of $0.38 \mu \mathrm{m}$ for comparison of the commonly used mixture of $80 \%$ helium and $20 \%$ oxygen with air. We have submitted a paper on our proposed formal computational method, entitled Calculation of Equivalent Aerosol Particle Mobility in Different Mixtures of Gases, to the Journal of Aerosol Science.

\section{Numerical Simulation of Particle Transport}

We have carried out exploratory research to apply PNL's comprehensive fluid flow simulation package, TEMPEST-TX8, to the calculation of flow velocity vectors and particle transport in airways of the respiratory tract. This package was developed for 
DOE to calculate fluid and thermal flows in reactor systems. We have applied the Battelle proprietary code TOOLCHEST ${ }^{\text {m }}$ to compile three-dimensional graphic images of airway boundaries and to generate the internal computational boundaries for export to TEMPEST-TX8. The code then solves the Navier-Stokes equations numerically to evaluate the flow velocity vectors continuously in time and space.

The flow pattern that develops in a channel with diverging walls is complex, particularly under the unsteady conditions that pertain when the fluid is oscillated with no bulk flow. We have found that the TEMPEST-TX8 code successfully predicts the flow patterns that have been measured as a function of time in such a channel. The typical flow profile, and the displacement of particles used to trace the fluid motion that was found by Gaver and Grotberg (1986) to develop over several oscillations, are shown in Figure 4. For comparison with these measured values, the figure also shows the amplitude of displacement calculated by TEMPEST-TX8. The simulation is in good agreement with the data.

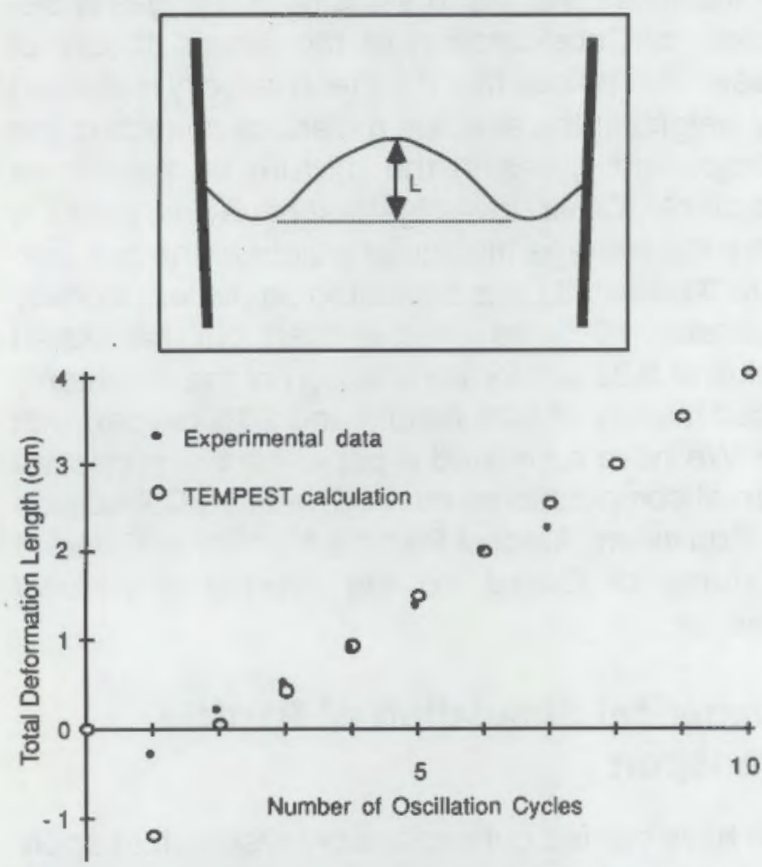

FIGURE 4. Typical Flow Deformation Profile Developed by Oscillating a Fluid in a Diverging Channel, with the Flow Displacements Measured by Gaver and Grotberg (1986) over Several Oscillatory Cycles and Simulated by TEMPEST-TX8
The three-dimensional flow field that develops in a diverging channel of circular cross section is much more complex than in the two-dimensional channel. Figure 5 shows a typical displacement pattern calculated by TEMPEST-TX8 after the air in a divergent tube has been oscillated six times. In this case there are no experimental data to test the numerical simulation. However, Godleski and Grotberg (1988) were able to solve the NavierStokes equations analytically for this radially symmetrical system. We have found that their theoretically predicted patterns of displacement are simulated closely by the numerical methods employed in the TEMPEST-TX8 code. From these results, we consider that the TEMPEST-TX 8 code is capable of calculating flow fields in the more complex airway structures of the respiratory tract, for which analytical solutions of the Navier-Stokes equations are impossible.

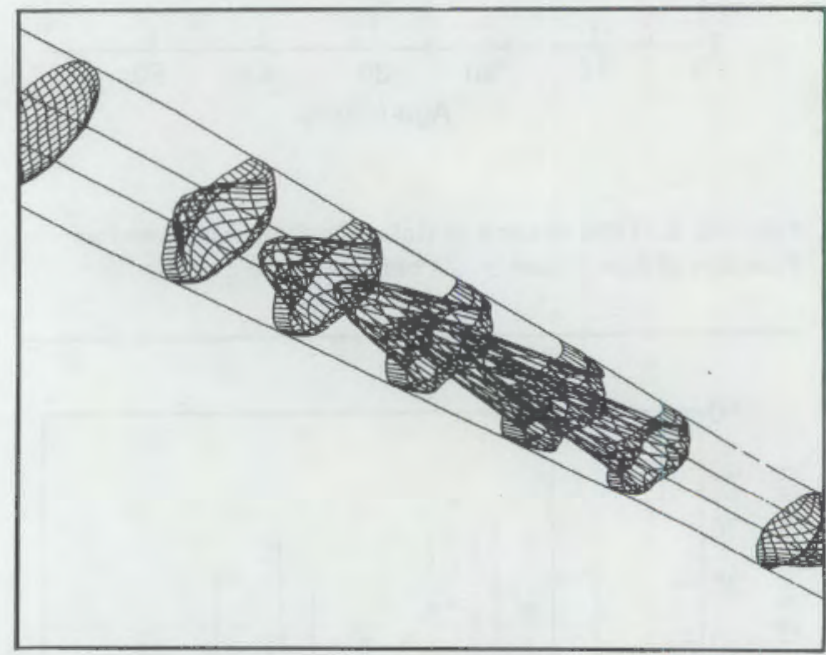

FIGURE 5. Flow Deformation Profiles Simulated by TEMPEST-TXB for Six Oscillations of a Fluid in a Divergent Circular Tube

\section{References Cited}

Gaver, D. P., and J. B. Grotberg. 1986. An experimental investigation of oscillating flow in a tapered channel. J. Fluid Mech. 172:47-61.

Godleski, D. A., and J. B. Grotberg. 1988. Convection-diffusion interaction for oscillatory flow in a tapered tube. J. Biomech. Eng. 110:283-291. 
General Life Sciences Research 


\title{
Synthesis of Human Genome Information
}

\author{
Principal Investigator: J. E. Schmaltz
}

As a detailee to OHER, I provide computer science expertise to the Human Genome Task Group. The Human Genome community uses the term "informatics" to refer to the computation, analysis, and database components of this multidisciplinary effort. My major role is in the area of informatics, and includes reviewing research proposals, facilitating interagency and interlaboratory cooperation, liaising with the Human Genome newsletter group at Oak Ridge National Laboratory, and representing the U.S. Department of Energy at various technical meetings.

\section{Research Proposal Review}

As a member of the OHER staff, I attend meetings of the OHER Research Committee, which makes technical decisions on funding of research proposals on the basis of mail-in, technical peer reviews that they request, programmatic considerations, and funding availability. The OHER programs that process large numbers of similar research proposals, as does the Human Genome Program, have convened review panels to efficiently process these proposals.

An important aspect of my position on the Human Genome Task Group is to provide high visibility for the informatics component of the Human Genome Program. One measure of this visibility is the number of informatics preproposals received by the DOE Human Genome Program each year (Table 1).

TABLE 1. DOE Human Genome Program Proposals

Year Total Preproposals Informatics Preproposals

$\begin{array}{llcl}\text { FY88 } & 50 & 9 & (18 \%) \\ \text { FY89 } & 51 & 7 & (14 \%) \\ \text { FY90 } & 54 & 15 & (28 \%)\end{array}$

The Small Business Innovative Research (SBIP) program also involves review of genome proposals. The SBIR proposals are solicited only in specific areas of energy research, for example, genome-related computation and instrumentation.

\section{Interagency Cooperation}

Cooperation and coordination among the various agencies involved is a cornerstone of the national
Human Genome Program. At the beginning of my detailee assignment, I visited the Howard Hughes Medical Institute (HHMI), the National Library of Medicine (NLM), and the National Science Foundation (NSF) to discuss informatics.

Also, I joined with representatives from the DOE, $\mathrm{NIH}, \mathrm{HHMI}, \mathrm{NLM}$, and NSF who had been meeting regularly as an ad hoc interagency working group on databases and computation. This group had previously organized two workshops: "Repository, Data Management, and Quality Assurance Needs for the National Gene Library and Genome Ordering Projects" (Pleasanton, California, August 26-27, 1987) and "Data Management for Physical Mapping" (Bethesda, Maryland, May 12-13, 1988). I helped plan and organize the third workshop, "Nomenclature for Physical Mapping of Complex Genomes" (Rockville, Maryland, April 13-14, 1989). This series of workshops has helped to define the complex issues facing the human genome computational community.

Activities of this ad hoc group have been supplanted by the evolution of a formal DOE/NIH Joint Informatics Task Force. The DOE and the NIH formalized their coordination and cooperation with a Memorandum of Understanding in October 1988, and the DOE Human Genome Steering Committee and the NIH Human Genome Program Advisory Committee appointed informatics subcommittees. These subcommittees have met informally twice (Crystal City, Virginia, July 10,1989, and Herndon, Virginia, Novernber 8,1989 ), resulting in a document on genome informatics needs and goals and a recommendation on the makeup of the formal Joint informatics Task Force. This Task Force will be formally constituted after action by the two parent agency committees. 


\section{Interlaboratory Cooperation}

The Human Genome Task Group is also concerned with coordination and cooperation between the National Laboratories. I have visited Lawrence Berkeley Laboratory (LBL), Los Alamos National Laboratory (LANL), and Lawrence Livermore National Laboratory (LLNL) to meet the informatics researchers and to see the current state of their projects. During the year, I visited LBL, LLNL, and Pacific Northwest Laboratory (PNL) when the opportunity arose during trips for other purposes. In April I attended a meeting between Sybase Corporation and LBL, LANL, and LLNL at which pricing policies and areas for possible cooperation were discussed.

In September 1989 / again visited LBL, LANL, and LLNL to view progress and to discuss informatics presentations at the upcoming DOE Human Genome Contractor/Grantee Workshop in November. For the workshop I set up workstations so the informatics posters could include demonstrations, and heid an informal reception for the informatics participants.

\section{Oak Ridge Liaison}

In February 1988, the Human Genome Task Group initiated a project at Oak Ridge National Laboratory (ORNL) called Human Genome Management Information System (HGMIS). The project began with four components: 1) a quarterly newsletter, 2) an annual DOE program report, 3) technical reports, and 4) an electronic bulletin board. I am serving as the primary DOE contact with the Task Leader for ORNL.

Two newsletters have been produced to date and a third is in preparation. The first copies of the newsletter were well received. The mailing list, which has grown from 850 to more than 2100 names, includes scientists, administrators, staff of other agencies, members of the press, upper DOE and National Laboratory management, and Congressional staff. A great compliment was paid by the NIH Human Genome group when they approached the DOE about contributing news from their program to the newsletter and making it a joint publication. This joint venture is currently being negotiated.
A subcontract has been let for the writing of the first technical report on instrumentation. The bulletin board has been running in test mode but is not yet open to the public. We are also producing a revision of the annual program report. The program report is shaping up as a professional, full-color document that will present the progress and future of the DOE program.

\section{Meetings}

Interest in the national human genome initiative has engendered a number of meetings and sessions at tangentially related meetings. The DOE sends representatives to many of these meetings to make presentations and report back to the Task Group. In response to invitations, I attended a number of informatics-related meetings.

- BioMatrix Advisory Committee Meeting, Herndon, Virginia, October 14, 1988. The BioMatrix group is interested in applying the latest computer science techniques to a synthesis of biological knowledge.

- Workshop on Advanced Computer Technologies and Biological Sequencing, Argonne National Laboratory, November 3-5, 1988. This small workshop brought together biologists and computer scientists, some new to the human genome community. ANL wants their computer group to be more involved in the genome activities.

- The Interface Between Computational Science and Nucleic Acid Sequencing, Santa Fe, New Mexico, December 12-16, 1988. The biggest informatics meeting of the year, this brought together the key players to share their latest progress.

- Chromosome 16 Workshop, New Haven, Connecticut, June 8-9, 1988. This is one of many single chromosome meetings sponsored by $\mathrm{DOE}$ and $\mathrm{NIH}$ to promote information exchange among research groups.

- Second E. coli Database Workshop, Chicago, Illinois, June 28-29, 1989. This was the second in a series of meetings sponsored by NLM and NSF to bring together $E$. coli researchers to discuss development and connection of multiple databases. 
- First Canadian Workshop on Bioinformatics, Ottawa, Ontario, July 6-7, 1989. This meeting featured speakers from the United States and Europe in an effort to generate interest among Canadian scientists.

- Macromolecules, Genes, and Computers: Chapter Two, Waterville Valley, New Hampshire, August 13-18, 1989. A major, well-attended meeting; presentations were oriented more toward biology than computation.

- BioMatrix '89, Waterville Valley, New Hampshire, August 18-20, 1989. This meeting included a first-time representation of plant taxonomists, who are computerizing their plant genome databases.

- U.S. Department of Agriculture (USDA) Plant Genome Mapping Coordinating Committee, Washington, D.C., August 30-31, 1989. The plant genome effort is in its infancy, and this community is eager to learn from the experiences of the human genome community.

- Laboratory Informatics for the Human Genome Project, Bethesda, Maryland, October 27, 1989. In this informal meeting, people from six major sequencing/mappinggroupsdiscussed "laboratory notebook' software.

I also attend regular meetings of two groups as an observer for OHER and the Human Genome Task Group. The ESnet (Energy Sciences network) Steering Committee (ESSC) is an effort to consolidate several existing special-purpose networks within Energy Research programs and at the same time significantly upgrade the network capacity. The OHEA research community is becoming a more significant user of this network. The ESSC observed a technical review of the ESnet plan in March 1989. After the September 1989 ESSC meeting, I briefed the OHEA Director and Division Directors on what ESnet was and how it might affect their programs. In addition to a DOE stalf observer, each program is also expected to be represented by a researcher. I intend to conduct a survey of current and future OHER networking needs and to identify a ESSC representative from the OHER community.

I also attend the semiannual GenBank Advisors meeting as an OHER observer. This meeting is of interest to the DOE because of its relevance to the genome program and because part of the contract is carried out at LANL. I also attend the GenBank Sponsor's Forum; after each Advisors meeting, the NIH GenBank staff review the Advisors meeting with other agency staff.

I attended the first meeting of the "Biotechnology Information Group" at the National Agricultural Library (NAL), a group collecting biotechnology information (e.g., NAL and NLM). The DOE activities do not have much to offer them, but their efforts may be of some use to genome researchers.

\section{Structural Biology Task Group}

In the fall of 1988, OHER organized a Structural Biology Task Group of which I serve as a member. Existing and planned unique facilities at DOE sites can make an important contribution to elucidating biological structure and function. The charge of the task group was to prepare an initiative for the FY91 budget that would provide the resources required for increased use of the current and planned structural biology facilities. The task group worked on the initiative during winter 1988 , and a meeting was held in Chicago on May 2, 1989 , to gather input from the user community and finalize the initiative. The initiative did not pass internal DOE review for inclusion in the FY91 budget, but the task group will continue to refine it for FY92.

\section{Miscellaneous}

The human genome program is highly visible and is often a major topic in briefings to the Director of Energy Research, the Secretary of Energy, the Office of Management and Budget, and Congress. I have helped prepare materials for these briefings. Similar materials were used for a special review of the biology program in OHER, which was held in June 1989 at the request of the Director of Energy Research.

The OHER staff must document that 'Work for Others' at DOE facilities is complementary to and will not interfere with DOE-funded research. I have helped produce these memoranda.

When the Olfice of Energy Research's Scientific Computing Staff was preparing presentations for a site review at the LLNL supercomputer center, I helped arrange for presentations by OHER supercomputer users. 



\title{
GnomeView: A Graphical Interface to the Human Genome
}

\author{
Principal Investigator: R. J. Douthart \\ Other Investigator: $D$. A. Thurman
}

The purpose of this project is to develop a graphical user interface to display and manipulate the vast amounts of information produced by the Human Genome Initiative. The user interface presents graphical representations of chromosomes, genetic and physical maps, and DNA sequences on a graphics workstation. The user can browse and query such representations, instead of scanning long lists of text, to learn more about genomic data.

An examination of any compendium of genetic maps, textbooks, and journals about modern genetics and molecular biology attests to the fact that the preferred method of presenting genomic information is pictorial: for example, chromosomes, physical maps, and regions related to DNA sequence are drawn as boxes, shaded regions, etc., on a linear map, and objects are identified with labels on drawings. If there are too many objects, their location is defined by some metric, such as chromosome band or base number, and they are listed in a table.

\section{System Design}

The GnomeView graphical user interface provides scientists with graphical representations of genomic maps. It provides access to many types of maps, from chromosomes and genetic maps to physical maps and DNA sequence. Ancillary information such as description of loci and genetic objects and bibliographic information is also available to the user.

GnomeView uses db_VISTA, a network-model database management system, to store and manipulate genomic mapping data. This type of database is excellent for storing and accessing the object relationships inherent in genomic data. Various genetics objects can be stored as the same record type, and maps are stored as collection of these objects linked together through ownership definitions and map metrics. Objects common to more than one mapping need to be stored only once in the database. Various querying mechanisms are being developed to locate objects, maps, and descriptive information. The system allows simultaneous display of maps at different levels in the hierarchy and of conflicting and contradictory maps. Hybrid or new maps can be created by the user and saved as user-specific objects in the database.

We are developing the user interface on a SUN workstation in portable-C using the UNIX operating system. The graphics display is written using the network-transparent, device-independent $X$-window system.

\section{Progress}

A generic map X-window "map widget" has been written that in principle will draw genomic maps at any level in the genome hierarchy. The map widget has been used to display the entire human chromosome karyotype of 23 chromosomes. Three representative chromosomes at two band resolutions are shown in Figure 1. Mapping representation for the superoxide dismutase (SODI) locus, including a 100-kb restriction enzyme map and sequence information from GenBank, has been completed (Figure 2).

Physical mapping data are currently entered by digitizing maps from figures printed in the literature, a slow and unsatisfactory process. We have developed collaborations with participating national laboratories [Lawrence Livermore National Laboratory (LL.NL) and Los Alamos National Laboratory (LANL)] and selected academic researchers to obtain input data for the location and span (size) of objects that have been mapped and the mapping metric that has been used. A collaboration has been established with the Human Genome Mapping Library (HGML) at Yale. 


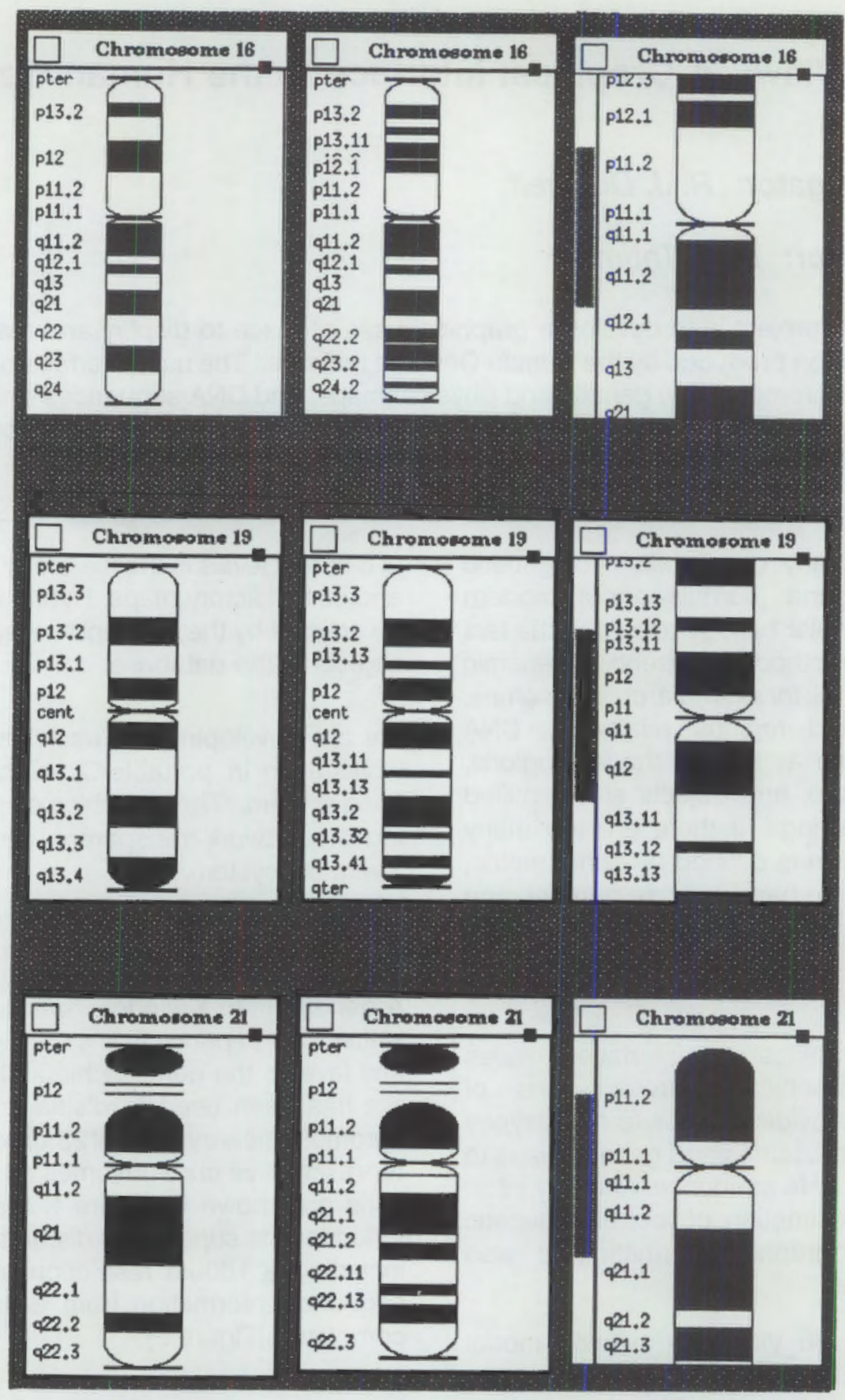

FIGURE 1. GnomeView Representation of Three Human Chromosomes. Human chromosomes 16, 19, and 21 shown at 400 and 550 band resolution. Chromosomes are displayed by map widget. Each band is kept as object in database, allowing editing, changing, and eventual computer construction of hybrid and aberrant chromosomes. Also shown is higher magnification of each high-resolution banding pattern. Every band is labeled only at higher magnification. GnomeView avoids graphics ovenwrite by displaying only nonoverlapping labels at lower magnifications. Hidden object labels can be made visible by selecting objact with the mouse (see Figure 2).

We plan later to provide an editor that will customize a map by choosing and defining objects from a set of standard icons. This utility will allow creation of hybrid maps that can be stored in a user-specific component of the database. 


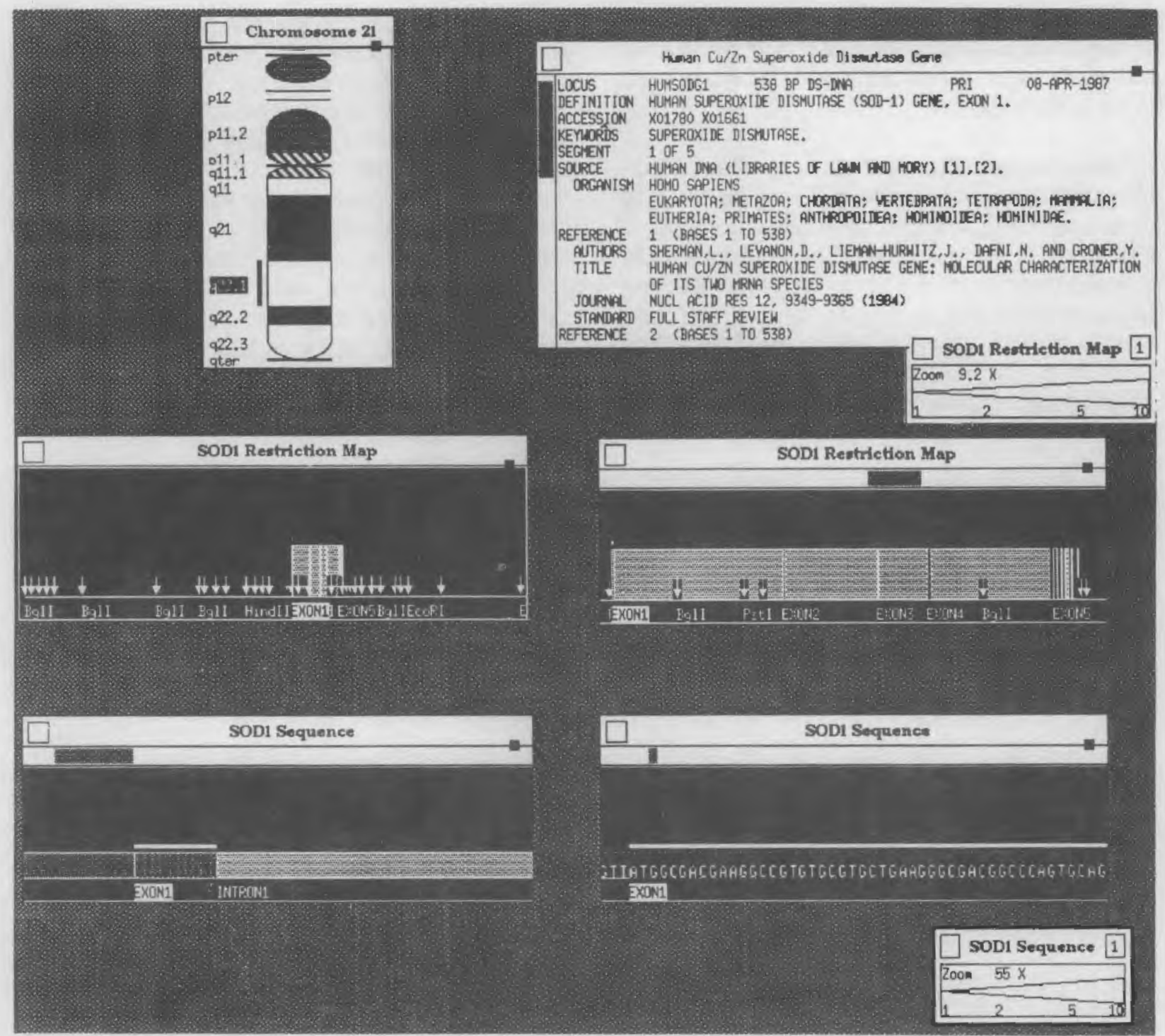

FIGURE 2. Superoxide Dismutase Mapping Hierarchy. The SODI (superoxide dismutase) locus is located on band q22.1 of chromosome 21. Portions of SODI restriction enzyme map are shown at two magnifications. Exon 1 has been keyed on and is shown at two magnifications at sequence level. Highest magnification shows actual DNA bases. Also shown ia GenBank information header describing exon 1. These maps were constructed by linking objects together in the GnomeView networkmodel database. The "map widget" accepts streams of data from database and draws appropriate maps. Zoom controllers (shown) are used to obtain different magnifications.

The following specific graphics tools have been implemented.

1. A pull-down menu for each window with the following choices at the chromosome level: Zoom, Search, List maps, Query, Redisplay, Change resolution, Help, and Quit.

2. A zoom controller that allows zooming to different magnifications within a window by pointing and clicking (mouse).
3. The ability to select objects or regions from the graphics representation for further information or queries.

4. A color index for each window that presents the color code for objects within that window.

GenBank headers can now be accessed at the sequence level, and features can be drawn automatically on the sequence representation (see Figure 2). Some simple pattern location tools for 
finding specific short sequences with mismatch scoring have been implemented. A complete set of analysis tools will need to be implemented (at the sequence level).

We have also developed a dictionary of terms, currently containing 23 words, that can be used to query objects in the database for chromosome mapping. Words have been chosen to have both a generic meaning and a specific quality reflecting the nature of the mapped object, and can be combined to retrieve a list that will include the desired object from the database. A similar dictionary, limited to about 20 words, will be developed for each level in the mapping hierarchy.

As research on the human genome progresses, it is anticipated that the number of objects located on any region of a particular map will increase dramatically. GnomeView displays objects on maps in response to user queries. Although queries filter displays to some extent, direct graphics display of all desired objects as regions with labels is still virtually impossible. Therefore, we have written code that tabulates objects in response to a query and displays the results as a color-coded histogram on a map representation. The histogram can be further queried, resulting in a list of objects contained in the histogram that can be used for further querying or displays. Work is in progress to develop the histogram representation for objects located at the chromosome level by using the chromosome map dictionary as the query. 
Medical

Applications 


\section{Radioisotope Customer List}

\section{Principal Investigator: R. A. Peloquin}

\section{Other Investigator: N. C. Van Houten}

This project has continued to provide technical assistance to the U.S. Department of Energy (DOE) Office of Energy Research, Office of Health and Environmental Research, by preparing the annual DOE radioisotope customer list. The report describes radioisotope distribution from DOE facilities to private firms, both domestic and foreign, as well as to other DOE facilities.

Information summarizing the FY 1988 commercial radioisotope production and distribution activities at DOE facilities was compiled using a computerized database management system to aid in tracking the quartities and subsequent revenues generated from the sale of radioisotopes produced at DOE facilities. A total of 1407 shipments of radioisotopes was distributed from DOE facilities during FY 1988 with a value of $\$ 11 \mathrm{M}$, an increase in revenues of $3 \%$ from FY 1987. The total dollar values of domestic shipments, foreign shipments, and shipments within DOE from 1974 through 1978 are given in Figure 1. In FY 1988, 61\% of the revenue was from sales to domestic private firms, $35 \%$ from sales to foreign private firms, and $4 \%$ from transfer to other DOE facilities.

This information was summarized in the document entitled U.S. Department of Energy Radioisotope Customers with Summary of Radioisotope Shipments, FY 1988, which contains information on isotope suppliers, customers (domestic and foreign private firms as well as other DOE facilities), geographic locations of customers, and isotopes purchased, sold, and transferred. The DOE facilities included in the document are Argonne National Laboratory, Brookhaven National Laboratory, Idaho National Engineering
Laboratory, Los Alamos National Laboratory, Oak Ridge National Laboratory, Pacific Northwest Laboratory, Savannah River Operations Office, and Westinghouse Hanford Company. This document was the twenty-fifth report in a series dating from 1964.

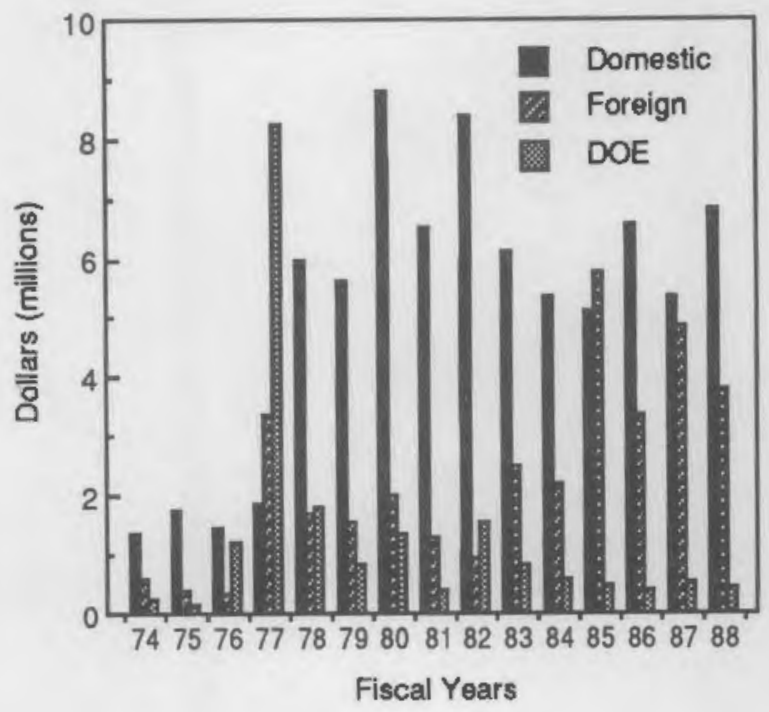

FIGURE 1. 15-Year Trend Analysis of Radioisotope Shipments from DOE Facilities (total dollar value) 



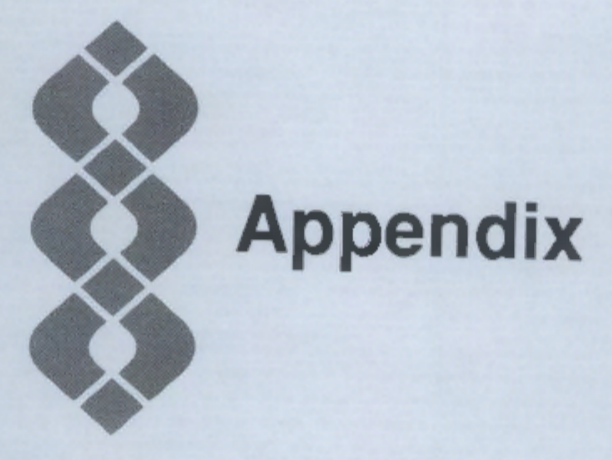




\section{Appendix}

\section{Dose-Effect Studies with Inhaled Plutonium in Beagles}

On the following pages (pp. 103-118), data are presented for all dogs assigned to current life-span doseeffect studies with inhaled ${ }^{239} \mathrm{PuO}_{2},{ }^{238} \mathrm{PuO}_{2}$ and ${ }^{239} \mathrm{Pu}$ nitrate. Information is presented on the estimated initial lung deposition, based on external thorax counts and on estimated lung weights $(0.011 \times$ body weight) at time of exposure. Information is also provided on the current interpretation of the most prominent clinicopathological features associated with the death of animals. These data represent information presently available, and are presented as reference material for scientists who desire to follow in detail the progress of these experiments. 


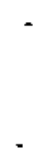


DOSE-EFFECT STUDIES WITH INHALED PU-239 OXIDE IN BEAGLES

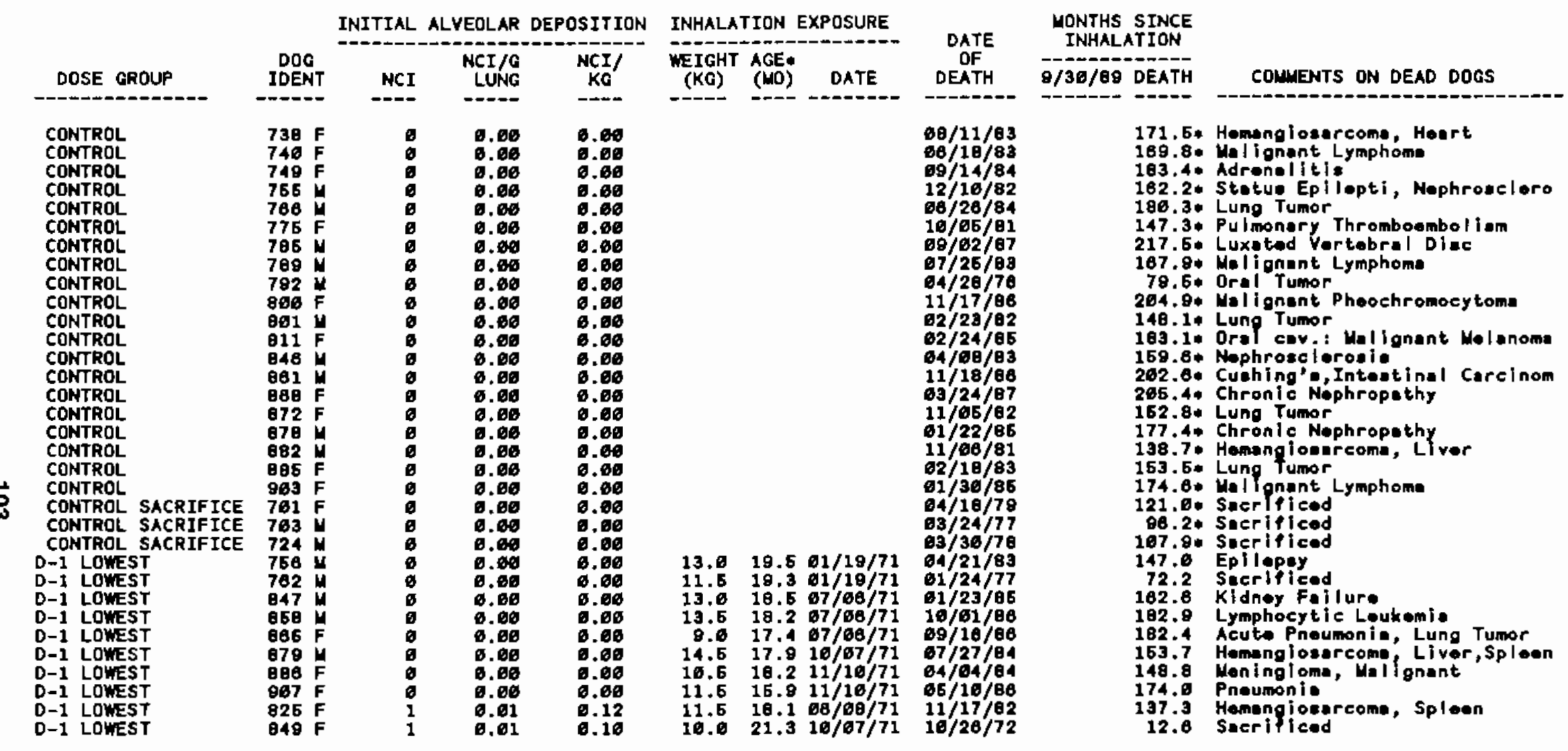


DOSE-EFFECT STUOIES WITH INHALED PU-239 OXIDE IN BEAGLES

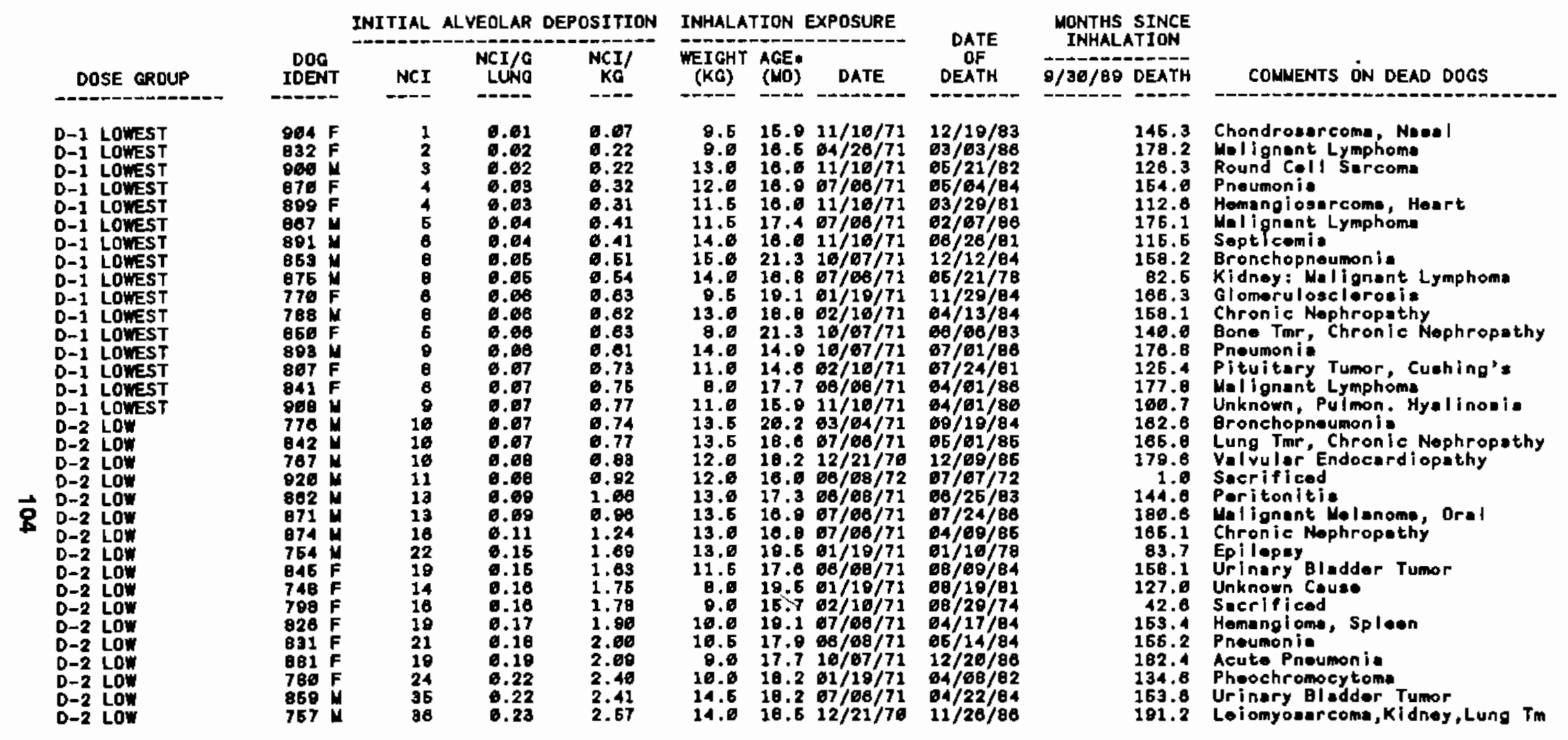


DOSE-EFFECT STUDIES WITH INHALED PU-239 OXIDE IN BEAGLES

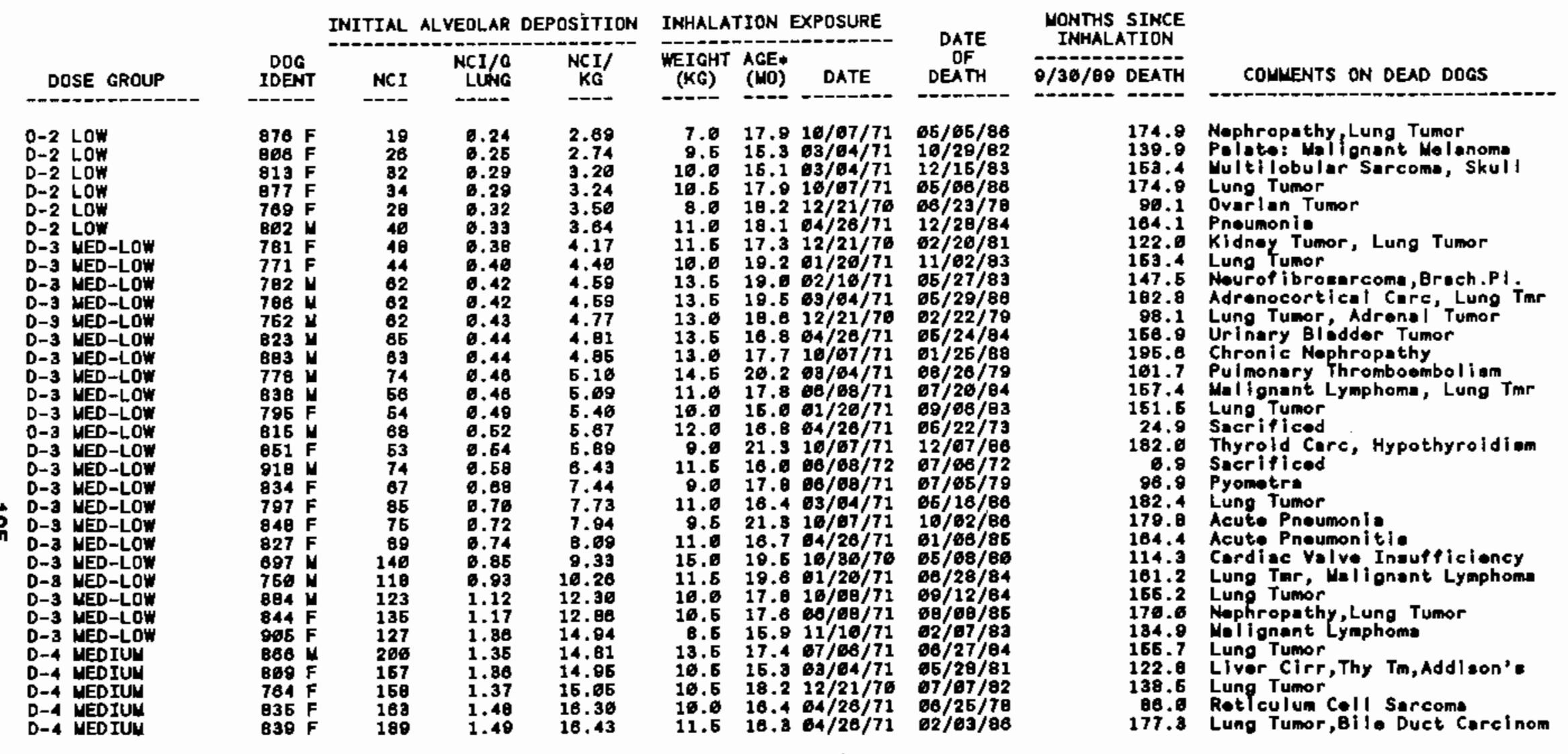


DOSE-EFFECT STUDIES WITH INHALED PU-239 OXIDE IN BEAGLES

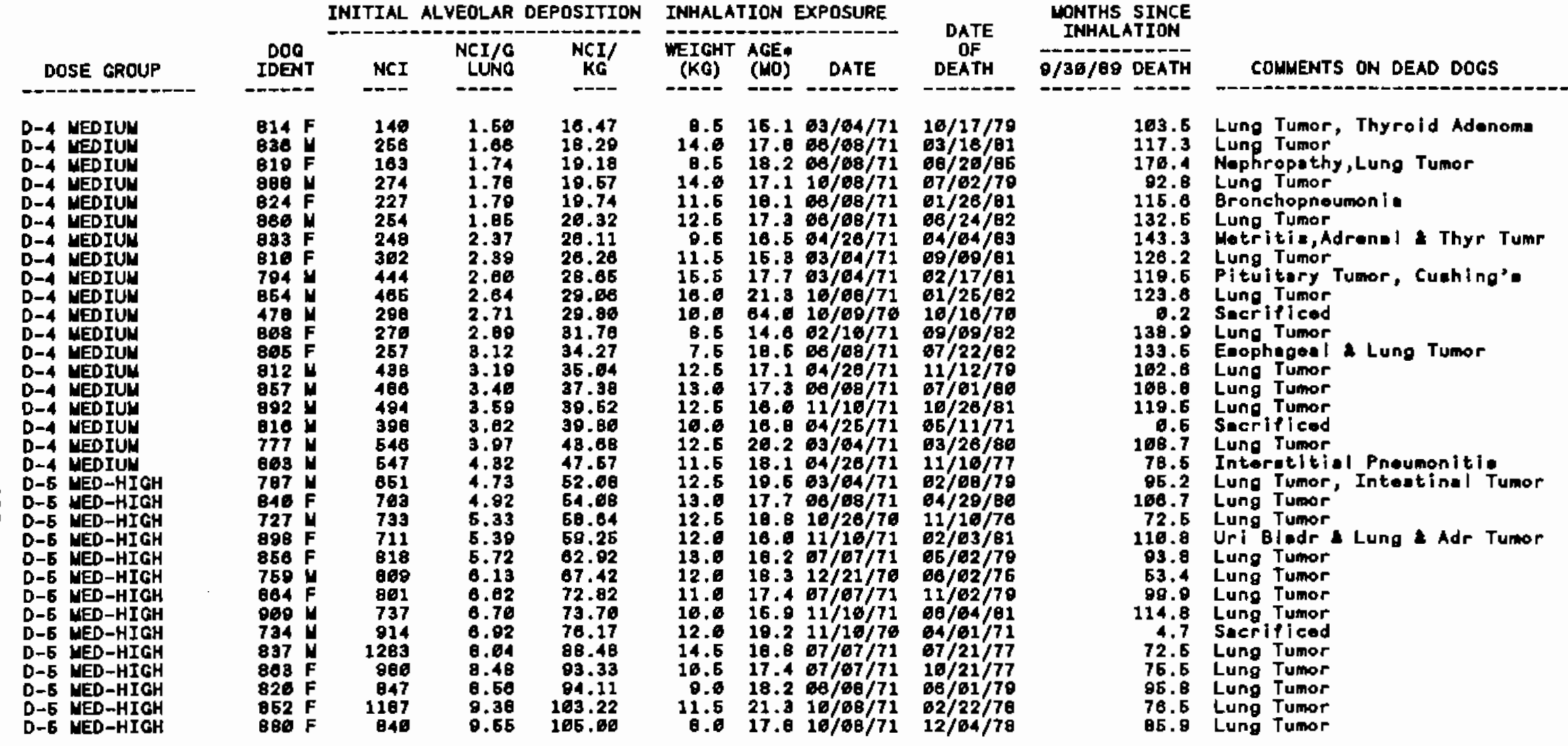

- Indicetes age in monthe eince birth, 11 other sges are in monthe since oxposure. 
DOSE-EFFECT STUDIES WITH INHALED PU-239 OXIDE IN BEAGLES

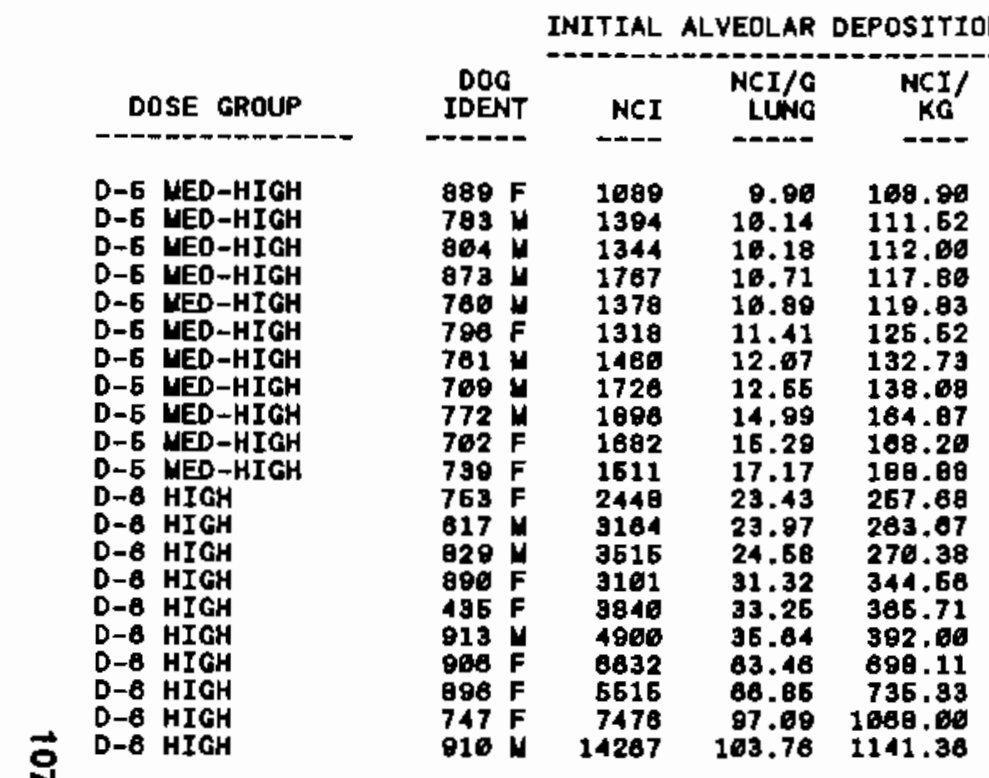

INHALATION EXPOSURE
WEIGHT AGE* DATE (KG) (NO) DATE DEATH

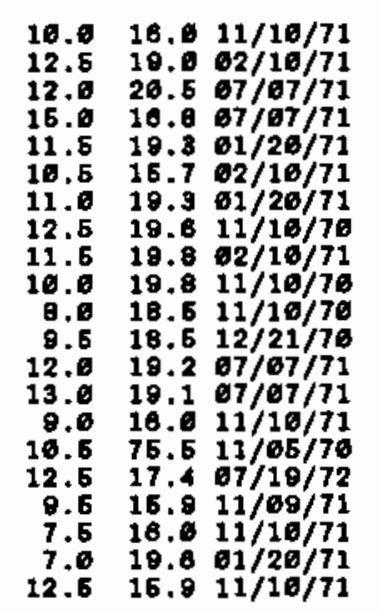

$10.016 .11 / 10 / 71 \quad 08 / 20 / 70$ $12 / 63 / 75$ $68 / 18 / 74$ $69 / 63 / 78$ $68 / 16 / 73$ $68 / 17 / 75$ $11 / 62 / 78$ 637317 $60 / 26 / 76$ 0410171 19/01/71 10/78/73 $03 / 26 / 73$ $2813 / 7$ $11 / 12 / 76$ $11 / 12 / 76$ $11 / 22 / 72$ $11 / 22 / 72$ 272 $16 / 12 / 72$
MONTHS SINCE INHALATION O/36/80 DEATH

COMUENTS ON DEAD DOGS

94.3 Lung Tumor, Oetoosethropothy 67.7 Lung Tumor

97.4 Lung Tumor, Red. Pneumonltis

1.8 Lung Tumor

5E.2 Lund Tumor, Ootooerthropothy Lung Tumor

52.6 Lung Tumor, Oeteoserthropethy

4.6 Secrificed

4.7 Secrificed

29 Lung Tumor

作

on Pnoumon tila

1.2 Secrificed

12.5 Rediotion Pnoumonitio

16.1 Rediation Pnoumonitis

11.8 Radiation Pnoumonitie

11.1 Radiation Pnoumonitia

- Indicetes oge in monthe since birth, -11 other ogese are in monthe elnce exposure. 
DOSE-EFFECT STIDIES WITH INHALED PU-238 OXIDE IN BEAGLES

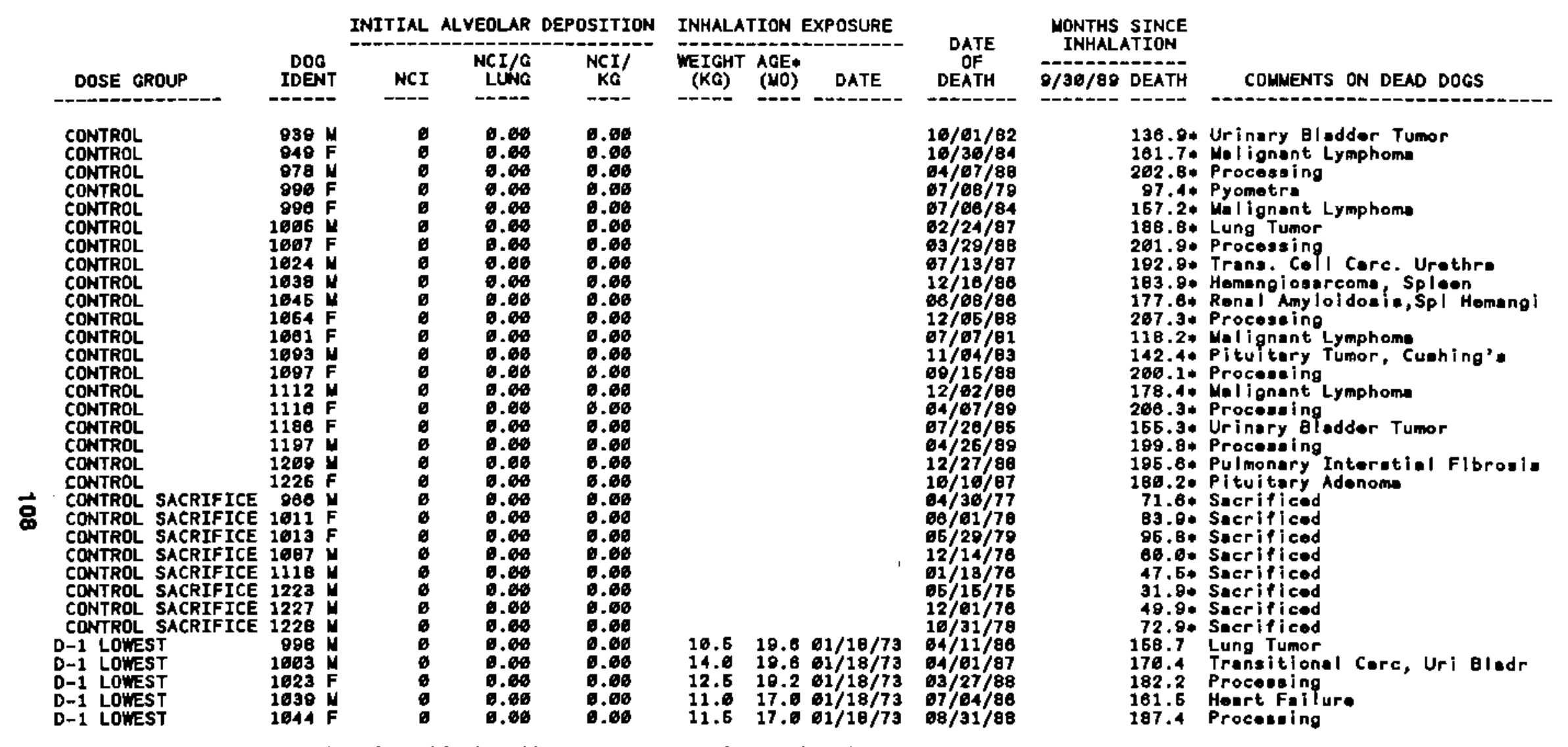


DOSE-EFFECT STUDIES WITH INHALED PU-239 OXIDE IN BEAGLES

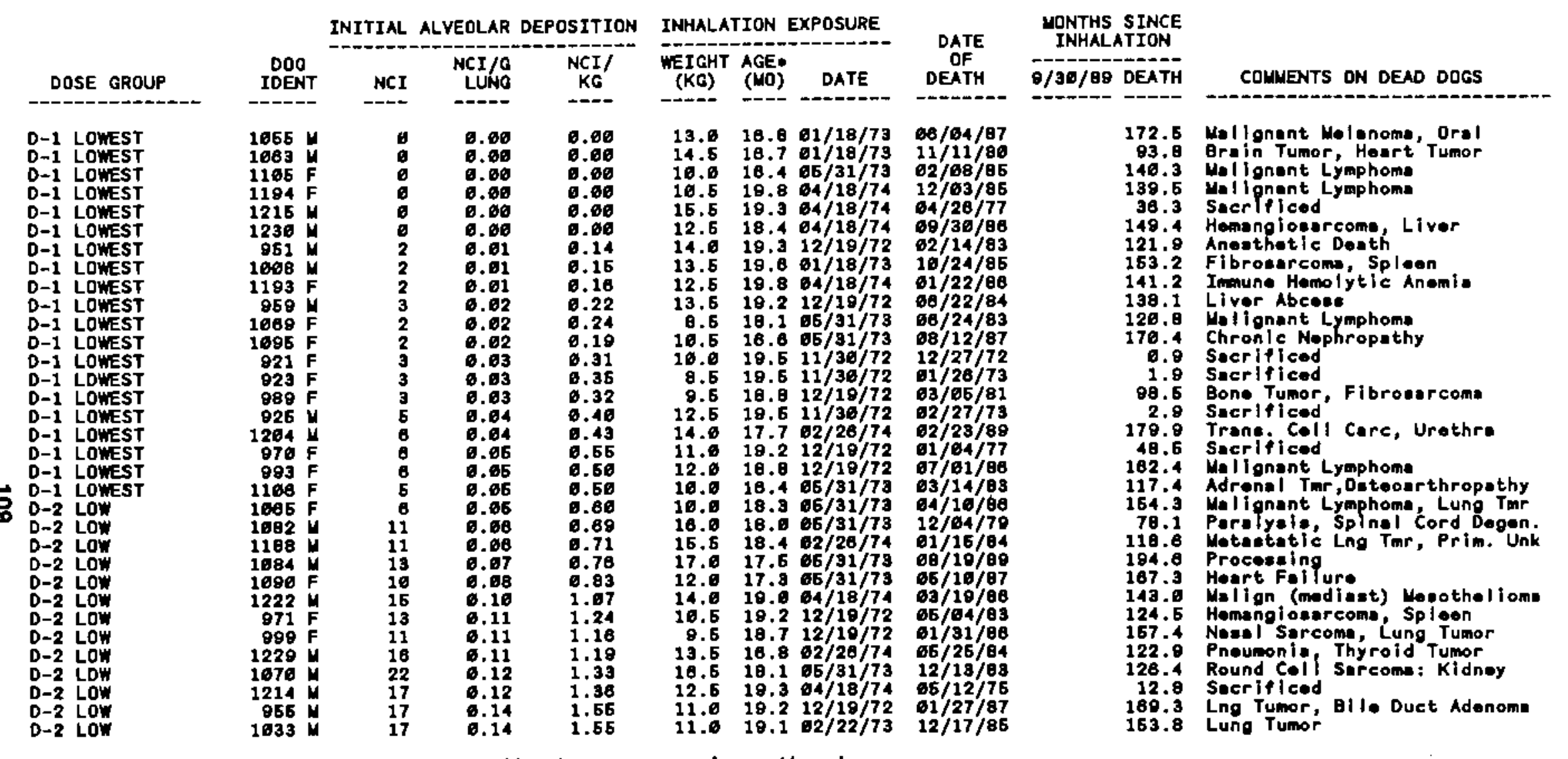


DOSE-EFFECT STUDIES WITH INHALED PU-238 OXIDE IN GEAGLES

\begin{tabular}{|c|c|c|c|c|c|c|c|c|c|c|}
\hline \multirow[b]{2}{*}{ DOSE GROUP } & \multirow[b]{2}{*}{$\begin{array}{l}\text { DOG } \\
\text { IDENT }\end{array}$} & \multicolumn{3}{|c|}{ INITIAL ALVEOLAR DEPOSITION } & \multicolumn{3}{|c|}{ INHALATION EXPOSURE } & \multirow{2}{*}{$\begin{array}{c}\text { DATE } \\
\text { OF } \\
\text { DEATH }\end{array}$} & $\begin{array}{l}\text { YONTHS SINCE } \\
\text { INHALATION }\end{array}$ & \multirow[b]{2}{*}{ COMMENTS ON DEAD DOGS } \\
\hline & & NCI & $\begin{array}{r}\text { NCI/O } \\
\text { LUNO }\end{array}$ & $\begin{array}{c}\mathrm{NCI} / \\
\mathrm{KG}\end{array}$ & $\begin{array}{l}\text { WEIGHT } \\
\text { (KG) }\end{array}$ & $\stackrel{\text { AGE }}{\text { (HO) }}$ & DATE & & 9/30/89 DEATH & \\
\hline 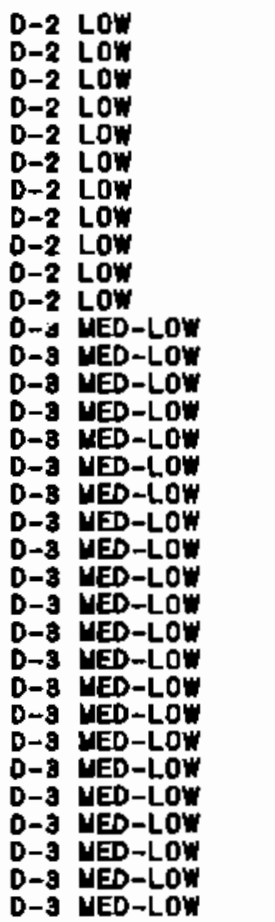 & 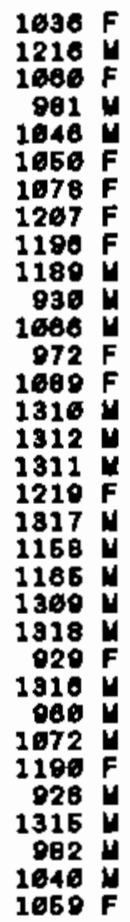 & $\begin{array}{l}16 \\
23 \\
22 \\
38 \\
27 \\
22 \\
29 \\
22 \\
28 \\
38 \\
38 \\
64 \\
40 \\
41 \\
54 \\
68 \\
54 \\
46 \\
72 \\
73 \\
76 \\
90 \\
67 \\
41 \\
84 \\
88 \\
88 \\
71 \\
75 \\
90 \\
70 \\
84 \\
71\end{array}$ & $\begin{array}{l}0.14 \\
0.16 \\
0.10 \\
0.21 \\
0.22 \\
0.22 \\
0.22 \\
0.24 \\
0.25 \\
6.26 \\
0.27 \\
0.31 \\
0.33 \\
0.34 \\
0.34 \\
0.94 \\
0.30 \\
0.46 \\
0.41 \\
6.43 \\
6.43 \\
0.44 \\
6.45 \\
0.60 \\
0.53 \\
0.54 \\
0.54 \\
0.64 \\
0.55 \\
0.55 \\
0.60 \\
0.61 \\
0.65\end{array}$ & $\begin{array}{l}1.52 \\
1.77 \\
2.06 \\
2.31 \\
2.45 \\
2.44 \\
2.42 \\
2.69 \\
2.80 \\
2 . \theta 1 \\
2.92 \\
3.38 \\
3.64 \\
8.73 \\
8.72 \\
3.74 \\
4.06 \\
4.38 \\
4.60 \\
4.71 \\
4.76 \\
4.06 \\
4.96 \\
5.47 \\
6.79 \\
5.91 \\
5.94 \\
5.02 \\
6.06 \\
8.66 \\
6.33 \\
6.72 \\
7.10\end{array}$ & $\begin{array}{r}16.5 \\
13.0 \\
11.6 \\
13.0 \\
11.0 \\
9.6 \\
12.6 \\
8.5 \\
16.6 \\
13.5 \\
13.6 \\
18.0 \\
11.0 \\
11.6 \\
14.5 \\
16.5 \\
13.5 \\
16.6 \\
16.6 \\
16.6 \\
16.0 \\
12.6 \\
13.6 \\
7.6 \\
14.5 \\
11.5 \\
16.5 \\
12.6 \\
12.5 \\
15.6 \\
12.6 \\
12.6 \\
16.6\end{array}$ & $\begin{array}{l}18.2 \\
18.3 \\
17.8 \\
10.0 \\
18.1 \\
18.1 \\
18.6 \\
17.6 \\
17.8 \\
26.6 \\
10.2 \\
18.3 \\
19.2 \\
17.3 \\
10.5 \\
18.5 \\
18.5 \\
19.6 \\
18.1 \\
17.7 \\
17.3 \\
18.5 \\
18.1 \\
19.2 \\
18.1 \\
18.2 \\
18.1 \\
18.1 \\
19.5 \\
18.1 \\
18.6 \\
18.2 \\
17.0\end{array}$ & 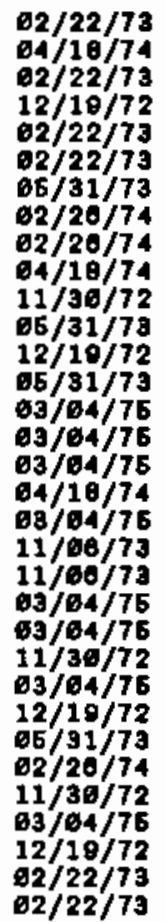 & 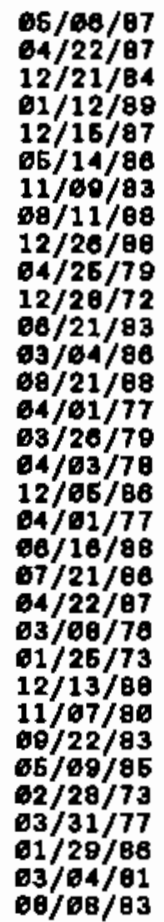 & $\begin{array}{r}170.4 \\
156.1 \\
141.9 \\
192.8 \\
177.7 \\
158.7 \\
125.3 \\
173.5 \\
178.9 \\
80.2 \\
6.9 \\
120.7 \\
158.5 \\
182.7 \\
24.9 \\
48.7 \\
37.6 \\
151.6 \\
24.8 \\
175.3 \\
352.4 \\
145.8 \\
12.2 \\
1.9 \\
165.4 \\
94.6 \\
123.7 \\
134.4 \\
3.6 \\
24.8 \\
157.3 \\
98.3 \\
126.5\end{array}$ & 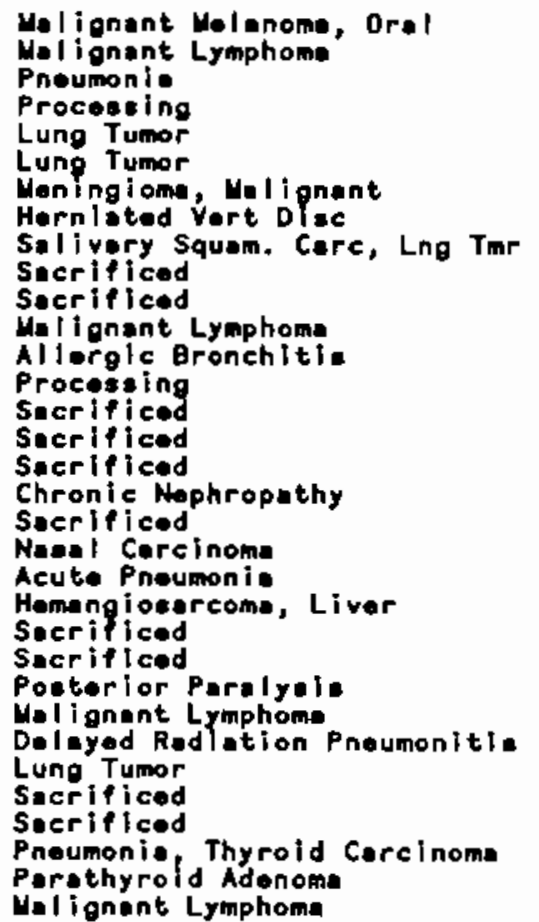 \\
\hline
\end{tabular}


DOSE-EFFECT STUDIES WITH INHALED PU-238 OXIDE IN GEAGLES

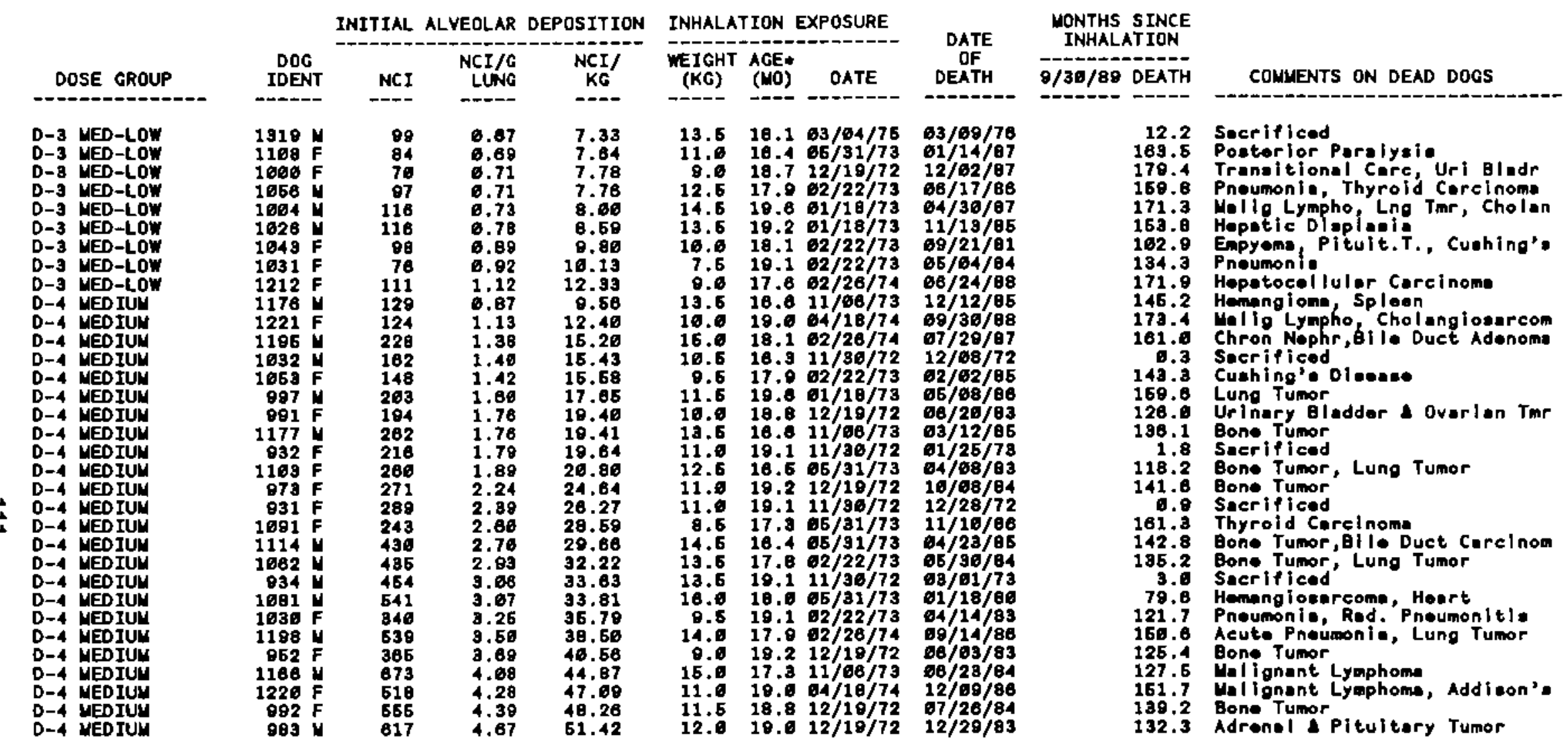


DOSE-EFFECT STUDIES WITH IMHALED PU-238 OXIDE IN BEAGLES

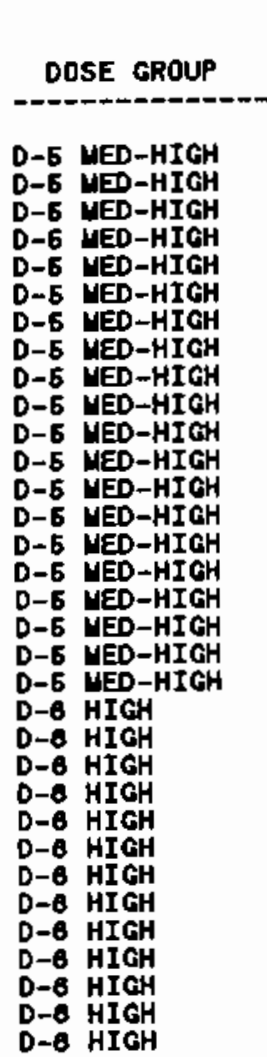

\begin{tabular}{|c|c|c|c|}
\hline $\begin{array}{l}\text { DOQ } \\
\text { IDENT }\end{array}$ & NCI & $\begin{array}{l}\text { NCI } / G \\
\text { LUNG }\end{array}$ & $\underset{\mathrm{KG}}{\mathrm{NCI} /}$ \\
\hline 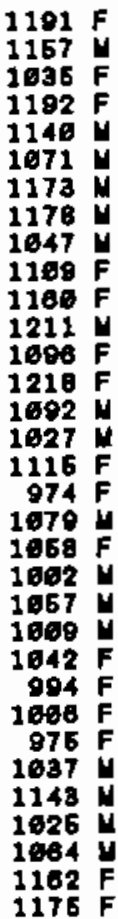 & $\begin{array}{r}591 \\
760 \\
571 \\
754 \\
1614 \\
1269 \\
1923 \\
1125 \\
966 \\
1119 \\
1344 \\
1764 \\
1476 \\
1716 \\
1848 \\
2148 \\
1885 \\
1718 \\
2626 \\
1967 \\
2907 \\
3116 \\
9696 \\
2959 \\
3453 \\
3910 \\
3988 \\
4854 \\
7691 \\
6479 \\
9463 \\
6958 \\
8201\end{array}$ & 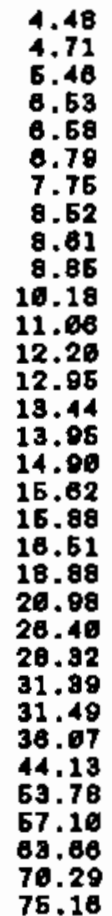 & 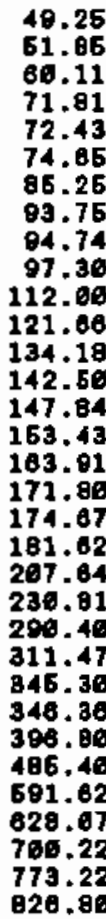 \\
\hline
\end{tabular}

\begin{tabular}{|c|c|c|c|}
\hline $\begin{array}{l}\text { EIGr } \\
\text { (KG) }\end{array}$ & $\begin{array}{l}\text { AGE } \\
\text { (MO) }\end{array}$ & DATE & $\begin{array}{c}\text { OF } \\
\text { DEATH }\end{array}$ \\
\hline 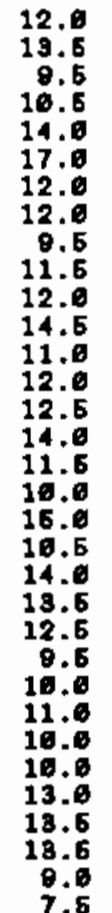 & $\begin{array}{l}19.8 \\
17.7 \\
18.2 \\
18.1 \\
18.2 \\
18.1 \\
17.3 \\
16.6 \\
18.1 \\
16.4 \\
17.3 \\
17.6 \\
18.6 \\
17.3 \\
17.9 \\
19.2 \\
16.1 \\
26.2 \\
18.6 \\
17.8 \\
19.6 \\
17.8 \\
19.6 \\
18.1 \\
19.6 \\
18.6 \\
26.2 \\
18.2 \\
18.2 \\
18.2 \\
16.7\end{array}$ & 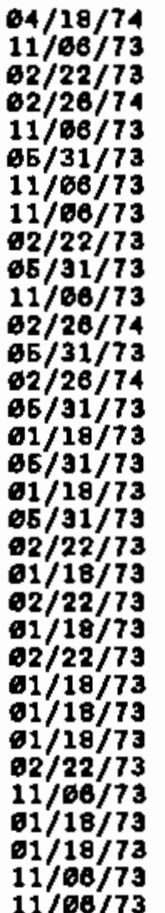 & 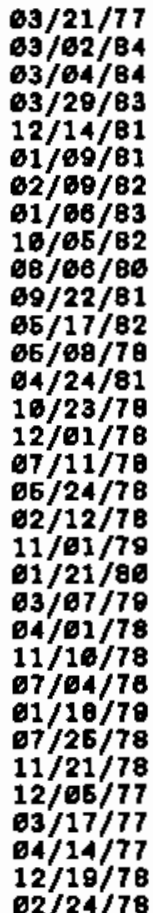 \\
\hline
\end{tabular}

\begin{tabular}{|c|c|c|}
\hline $9 / 36 / \theta \theta$ DEATH & COMLENTS & ON DEAD DOGS \\
\hline $\begin{array}{r}35.1 \\
123.6 \\
132.3 \\
109.6 \\
97.2 \\
91.3 \\
99.1 \\
110.6 \\
115.4 \\
86.2 \\
94.6 \\
98.6 \\
69.2 \\
65.8 \\
64.8 \\
76.4 \\
61.3 \\
64.1 \\
66.4 \\
86.3 \\
84.1 \\
72.4 \\
62.4 \\
68.6 \\
41.5 \\
72.6 \\
66.2 \\
68.9 \\
49.6 \\
49.9 \\
56.8 \\
61.4 \\
51.6\end{array}$ & 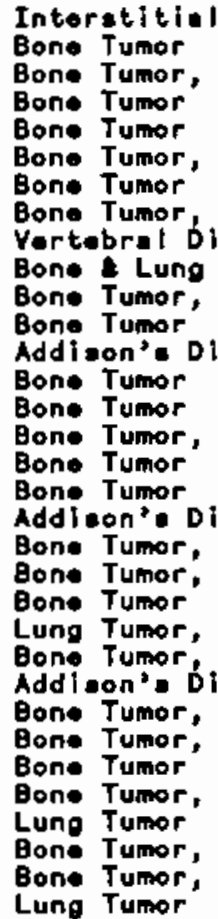 & 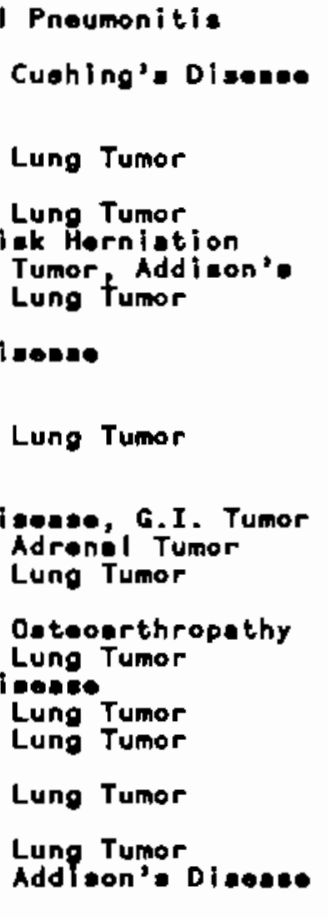 \\
\hline
\end{tabular}

- Indicotes age in monthe oince birth, 1 ll other ages ere in monthe since exposure. 
INHALED PLUTONIUM NITRATE IN DOGS

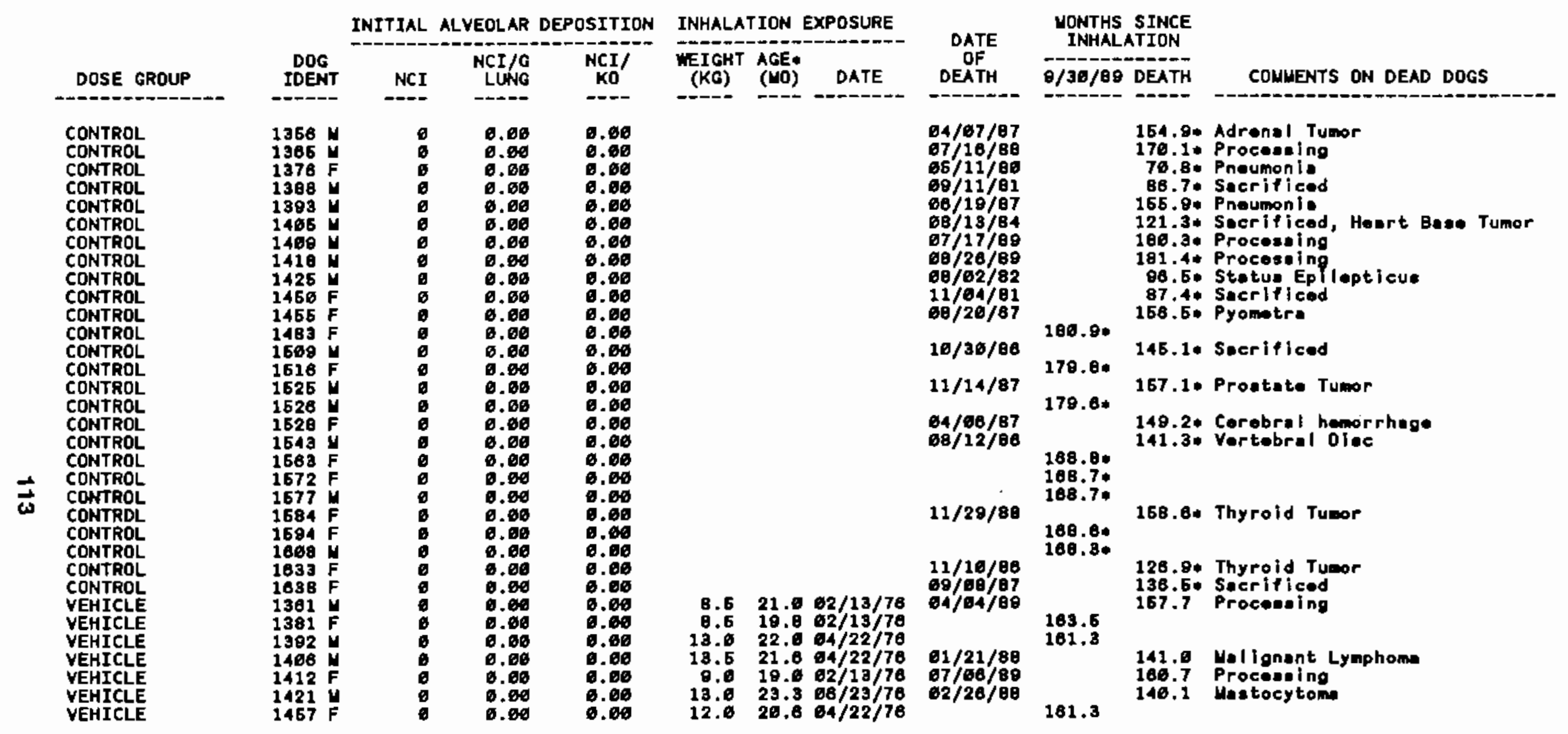


INHALED PLUTONIUN NITRATE IN DOGS

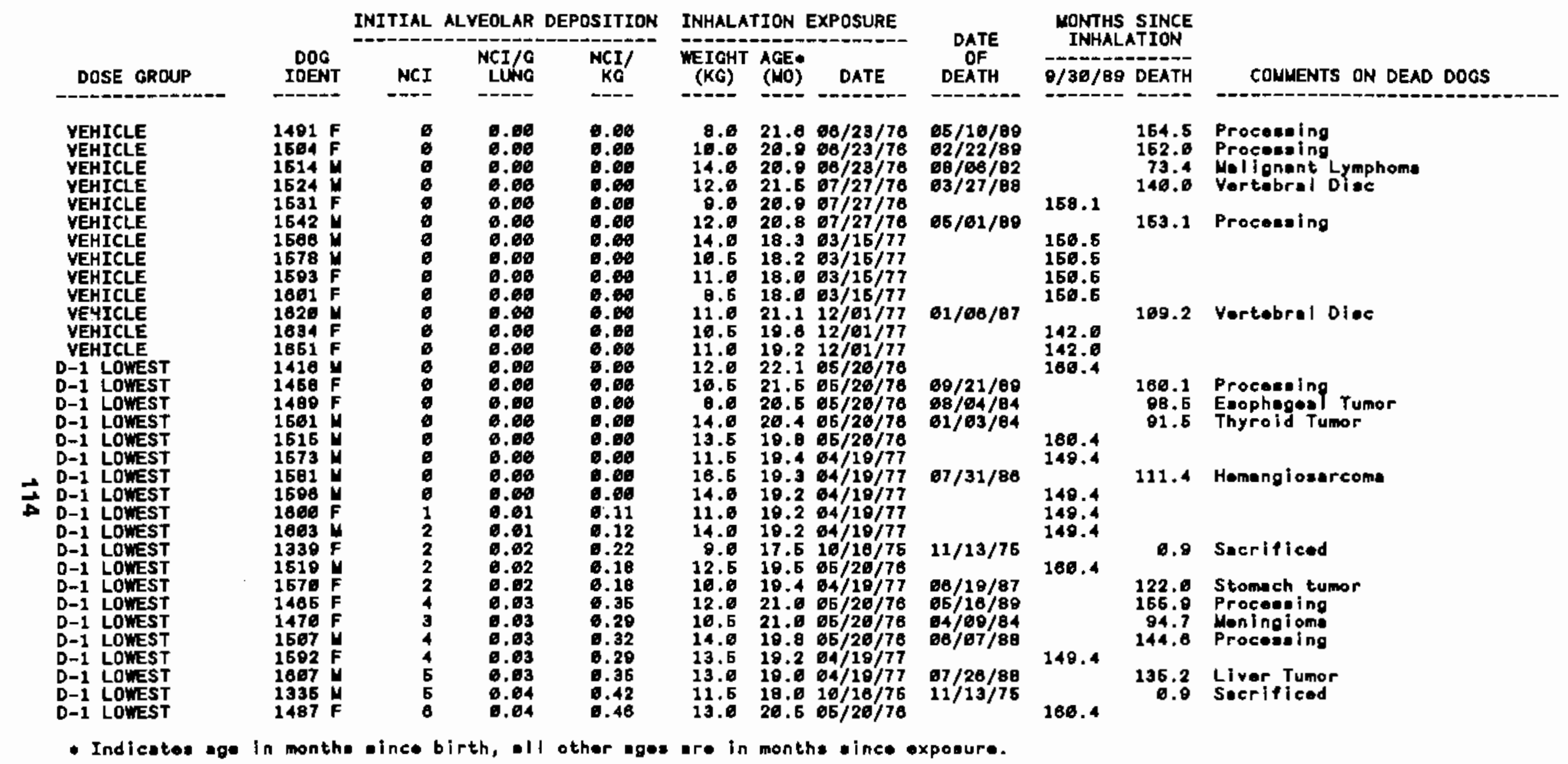


INHALED PLUTONIUM NITRATE IN DOGS

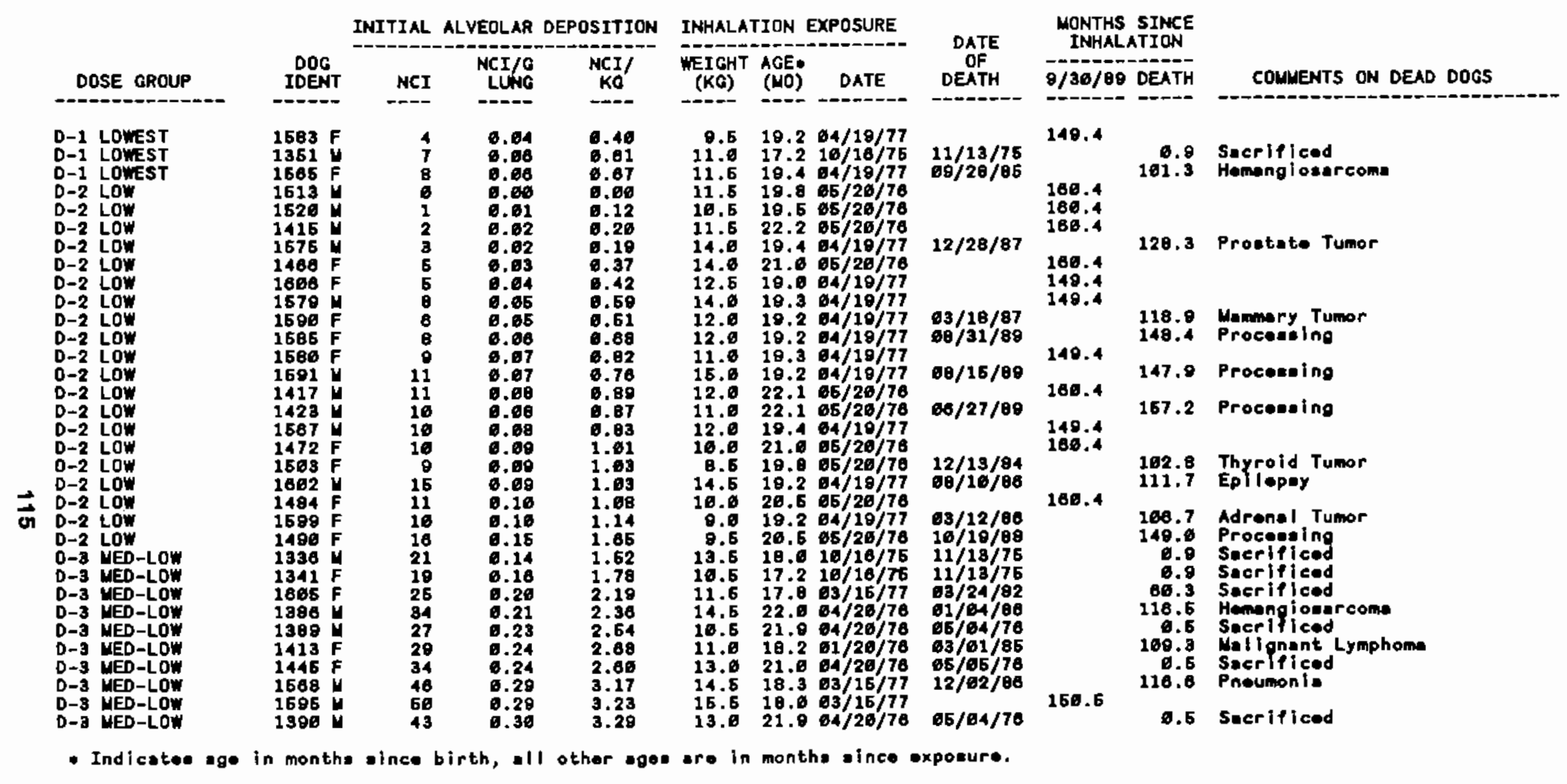


INHALED PLUTONIUN NITRATE IN DOGS

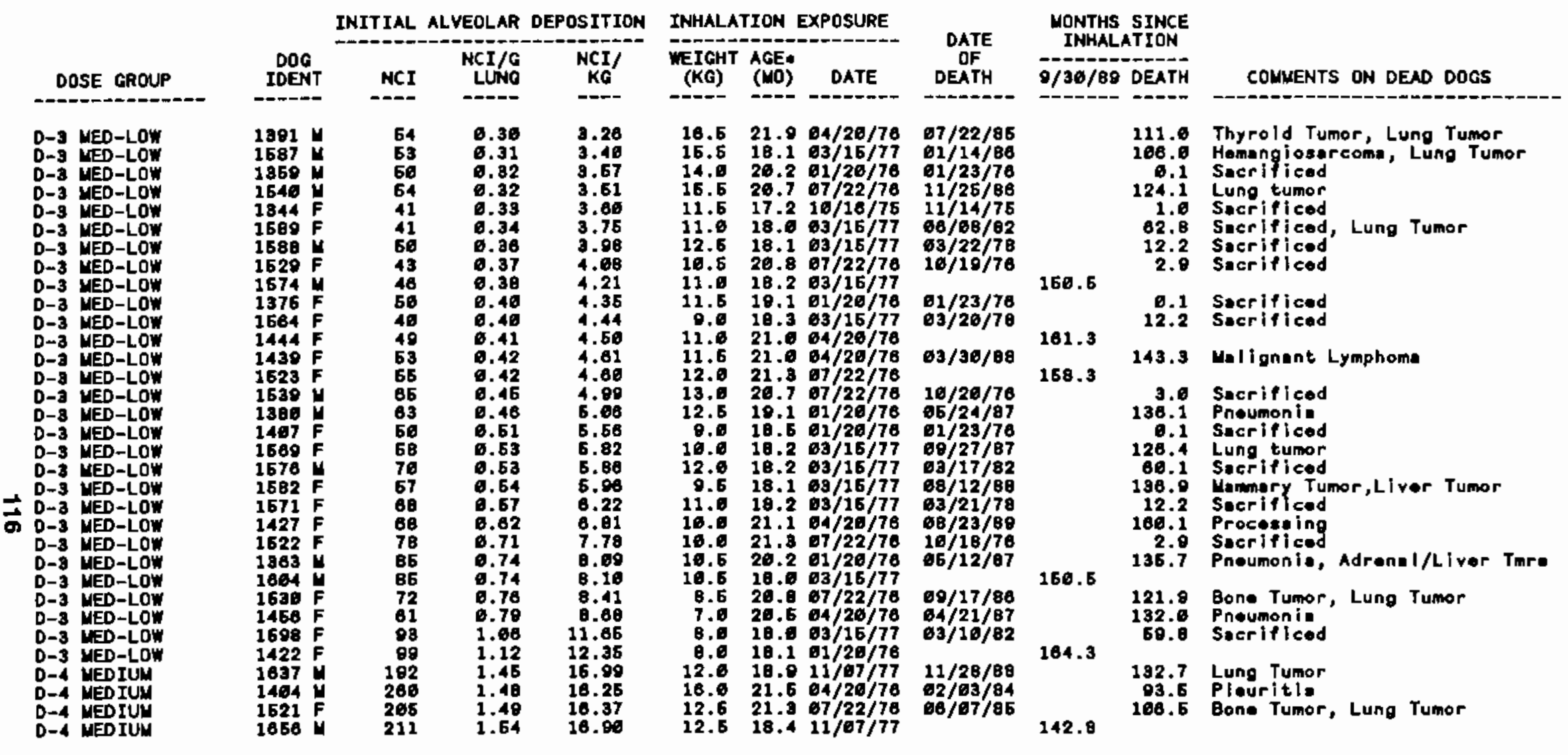

- Indicates ege in monthe eince blrth, 11 other sges ore in monthe ince exposure. 
INHALED PLUTONIUN NITRATE IN DOGS

\begin{tabular}{|c|c|c|c|c|c|c|c|c|}
\hline \multirow[b]{2}{*}{ DOSE GROUP } & \multirow[b]{2}{*}{$\begin{array}{c}\text { DOG } \\
\text { IDENT }\end{array}$} & \multicolumn{3}{|c|}{ INITIAL ALVEOLAR DEPOSITION } & \multicolumn{3}{|c|}{ INHALATION EXPOSURE } & \multirow{2}{*}{$\begin{array}{c}\text { DATE } \\
\text { OF } \\
\text { DEATH }\end{array}$} \\
\hline & & NCI & $\begin{array}{l}\text { NCI } / G \\
\text { LUNG }\end{array}$ & $\begin{array}{c}\text { NCI/ } \\
\text { KG }\end{array}$ & $\begin{array}{l}\text { WEIGHT } \\
\text { (KG) }\end{array}$ & $\begin{array}{l}\text { AGE* } \\
(\mathrm{MO})\end{array}$ & DATE & \\
\hline 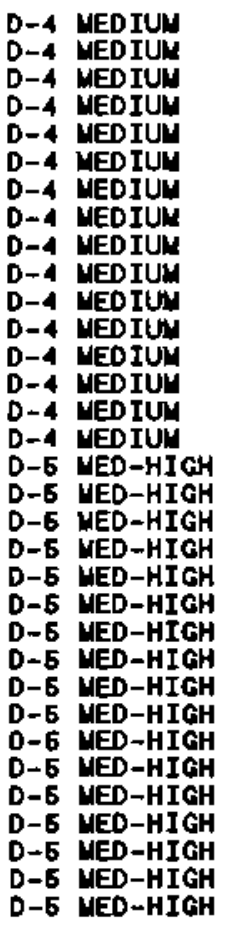 & 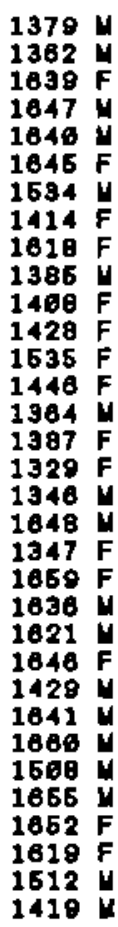 & $\begin{aligned} 278 \\
287 \\
248 \\
294 \\
367 \\
257 \\
296 \\
233 \\
277 \\
373 \\
331 \\
378 \\
345 \\
354 \\
463 \\
345 \\
363 \\
656 \\
611 \\
688 \\
996 \\
1212 \\
1334 \\
1981 \\
1376 \\
1275 \\
1518 \\
1716 \\
1994 \\
1329 \\
1490 \\
2411 \\
1659\end{aligned}$ & $\begin{array}{r}1.74 \\
1.87 \\
2.65 \\
2.66 \\
2.96 \\
2.13 \\
2.14 \\
2.35 \\
2.46 \\
2.42 \\
2.62 \\
3.12 \\
3.13 \\
3.22 \\
3.24 \\
4.48 \\
3.36 \\
4.42 \\
6.96 \\
6.96 \\
7.32 \\
8.48 \\
8.68 \\
8.77 \\
9.82 \\
8.66 \\
16.22 \\
10.76 \\
11.65 \\
12.96 \\
12.32 \\
14.61 \\
14.82\end{array}$ & $\begin{array}{r}19.16 \\
26.54 \\
22.67 \\
22.58 \\
22.71 \\
23.39 \\
23.57 \\
25.66 \\
26.36 \\
26.63 \\
28.77 \\
94.36 \\
34.46 \\
36.40 \\
35.65 \\
49.36 \\
36.27 \\
48.69 \\
64.96 \\
76.47 \\
89.51 \\
99.25 \\
95.26 \\
96.45 \\
165.85 \\
166.24 \\
112.41 \\
118.97 \\
121.66 \\
131.95 \\
195.66 \\
166.71 \\
164.11\end{array}$ & 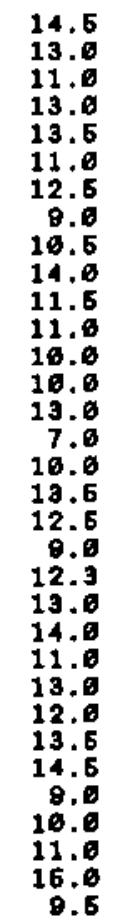 & 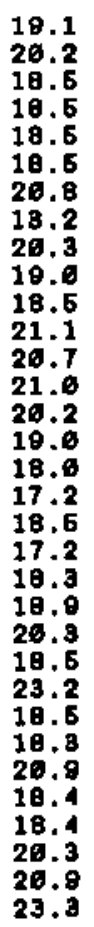 & 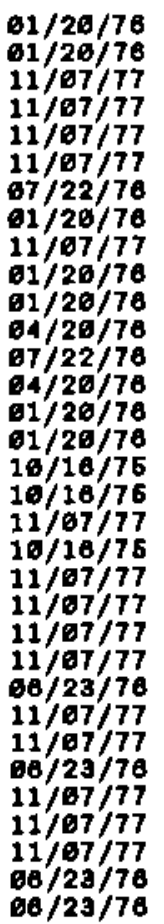 & 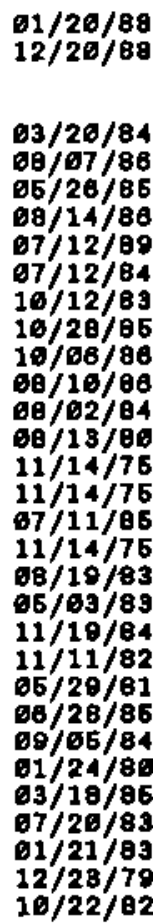 \\
\hline
\end{tabular}

MONTHS SINCE

INHALATIOH

O/3\%/09 DEATH

COMAENTS ON DEAD DOGS

144.0 Liver, Lung, Bone Tumors

165.0 Procensing

142.8

76.4 Lung Tumor

106.1 Congestive Heart Failure

ung, and Liyer tumora

140.1 Bone Tumor

161.7 Bone Tumor, Lung Tumor

92.7 Bone Tumor

114.3 Bone Tumor Lung Tumor

122.6 Bone and lung tumore

123.7 Pyometre, Liver tumor

162.4 Lung Tumor

64.8 Bone Tumor

1.0 Secrificed

1.0 Secrificod

Q2.1 Bone Tumor, Lung Tumor

1.0 Secriflead

09.4 Bone Jumor

84. 4 Bone Tumor Lung

84.4 Bone Tumor, Lung Tumor

59.2 Bone Tumor, Lung Tumor

59.2 Bone Tumor, Lung Tumor

81.9 Bone Tumor, Lung Tumor

8.

6. 5 Bone Tumor, Lung Tumor

$12.70 n$ Tumor

76.t Bone Tumor, Lung Tumor

- Indlcetes ege in monthe elnce birth, oll other ages ore in monthe eince expoeure. 
INHALED PLUTONIUY NITRATE IN DOGS

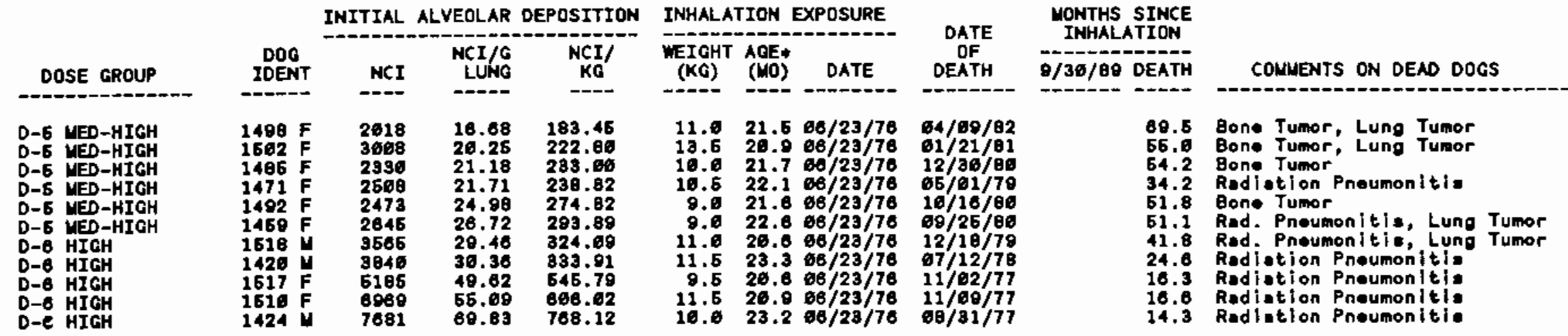

- Indlcetee ege In monthe elnce birth, all other oges are in monthe since expoure. 
Publications and Presentations 


\section{Publications}

\section{8}

Bender, M. A., A. A. Awa, A. L Brooks, H, J. Evans, P. G. Groer, L. G. Littlefield, C. Pereira, R. J. Preston, and B. W. Wachholz. 1988. Current status of cytogenetic procedures to detect and quantify previous exposures to radiation. Mutat. Res. 19:103-159.

Brooks, A. L, S. W. Jordan, K. K. Bose, J. Smith, and D. C. Allison. 1988. The cytogenetic and hepatotoxic effects of dioxin on mouse liver cells. Cell Biol. Toxicol. 4:31-40.

Cross, F. T. 1988. Animal studies with radon. In: Proceedings of the 1988 Toxicology Forum Summer Meeting, pp. 206-219, July 18-22, 1988, Given Institute of Pathobiology, Aspen, Colorado. Toxicology Forum, Inc., Washington, D.C.

Cross, F. T. 1988. Contributions to Summary and Volumes I, II, and III of Final Environmental Impect Statement on New Energy-Efficient Homes Program (Assessing Indoor Air Quality Options), DOE/EIS0127F, August 1988. U.S. Department of Energy, Bonneville Power Administration, Portland, Oregon.

Cross, F. T. 1988. Radon Heath Effects, A Pacific Northwest Division (PNWD) Performance Report to Battelle Memorial Institute. Pacific Northwest Laboratory, Richland, Washington.

Cross, F. T. 1988. Radon inhalation studies in animals. Radiat. Prot. Dosim. 24:463-466.

Cross, F. T. 1988. Radon inhalation studies in animals (an executive summary). American institute of Biomedical Climatology (AlBC) Bulletin 1, October 1988, pp. 3-4. American institute of Biomedical Climatology, Philadelphia, Pennsylvania.

Cross, F. T. 1988. Radon Inhalation Studies in Anima/s. DOE/ER-0396. Report prepared for the U.S. Department of Energy, Otfice of Health and Environmental Research, Washington, D.C. NTIS, Springfield, Virginia.

Dungan, C. F., and R. A. Elston. 1988. Histopathological and ultrastructural characteristics of bacterial destruction of the hinge ligaments of cultured juvenile Pacific oysters, Cressostrea giges. Aquaculture 72:1-14.

Elston, R. A., M. L Kent, and A. S. Drum. 1988. Progression, lethality and remission of hemic neoplasia in the bay mussel Mytilus edulis. Dis. Aquat. Org. 4:135-142.

Elston, R. A., M. L Kent, and A. S. Drum. 1988. Transmission of hemic neoplasia in the bay mussel Mytilus edulis using whole cells and cell homogenate. Dev. Comp. Immunol. 12:719-727.

Farley, C. A., P. H. Wolf, and R. A. Elston. 1988. A long-term study of 'Microcell' disease in oysters with a description of a new genus, Mikrocytos (g. n.), and two new species, Mikrocytos mackini (sp. n.) and Mikrocytos roughieyi (sp. n.). Fish. Bull. 86(3):581.

Filipy, R. E., J. R. Decker, Y.-L Lai, K. E. Lauhala, R. L Buschbom, M. D. Hlastala, D. R. McGee, J. F. Park, E. G. Kutfel, H. A. Ragan, W. C. Cannon, S. S. Yaniv, and B. R. Scott. 1988. Inhaled ${ }^{239} \mathrm{PuO}_{2}$ and/or Total-Body Gamma Radiation: Early Mortality and Morbidity in Rats and Dogs. NUREG/CR-5198/PNL-6586. Pacific Northwest Laboratory, Richland, Washington. U.S. Nuclear Regulatory Commission, Washington, D.C.

Hay, W. W., Jr., and H. K. Meznarich. 1988. Use of fetal streptozotocin injection to determine the role of normal levels in fetal insulin in regulating uteroplacental and umbilical glucose exchange. Pediatr. Res. 24:312-317.

Hay, W. W., Jr., C. C. Lin, and H. K. Meznarich. 1988. Effect of high levels of insulin on glucose utillzation and glucose production in pregnant and nonpregnant sheep. Proc. Soc. Exp. Biol. Med. 189:275-284.

Hay, W. W., Jr., H. K. Meznarich, J. E. DiGiacomo, K. Hirst, and G. Zerbe. 1988. Effects of insulin and glucose concentrations on glucose utilization in fetal sheep. Pediatr. Res. 23:381-387. 
Kent, M. L, C. F. Dungan, R. A. Elston, and R. A. Holt. 1988. Cytophaga sp. (Cytophagales) infection in seawater pen-reared Atlantic salmon Salmo salar. Dis. Aquat. Org. 4:173-179.

Kent, M. L, M. S. Myers, D. E. Hinton, W. D. Eaton, and R. A. Elston. 1988. Suspected toxicopathic hepatic necrosis and megalocytosis in pen-reared Atlantic salmon Selmo saler in Puget Sound, Washington, USA. Dis. Aquet. Org. 4:91-100.

Kitchin, R. M., W. E. Bechtold, and A. L Brooks. 1988. The structure-function relationships of nitrofluorenes and nitrofluorenones in the Selmonella mutagenicity and $\mathrm{CHO}$ sister-chromatid exchange assays. Mutat. Res. 206:367-377.

Lauhala, K. E., C. L Sanders, and K. E. McDonald. 1988. Scanning electron microscopic autoradiography of lung. Scanning Microsc. 2:1631-1634.

Leach, C. L, N. S. Hatoum, H. V. Ratajczak, C. R. Zeiss, D. M. Talsma, and P. J. Garvin, 1988. Evidence of immunologic control of lung injury induced by inhaled trimelitic anhydride. Am. Rev. Respir. Dis. 137:186-191.

Leung, F. C., S. Abernethy, and M. Welt. 1988. Exogenous bovine growth hormone (BGH) increases body weight and length of trout. $\mathrm{Am}$. Zool. 28:144A

Nuclear Energy Agency Expent Group on Gut Transter Factors (M. F. Sullivan, Member). 1988. Gastrointestinal Absorption of Selected Radionuclides, A Report by an NEA Expert Group. OECD Nuclear Energy Agency, Paris.

Overstreet, J. W., S. J. Samuels, P. Day, A. G. Hendrickx, S. Prahalada, T. Mast, D. F. Katz, and C. Sakai. 1988. Early indicators of male reproductive toxicity. Risk Anad. 9:21.

Pien, L C., C. R. Zeiss, C. L Leach, N. S. Hatoum, D. Lovitz, P. J. Garvin, and R. Patterson. 1988. Antibody response to trimellityl hemoglobin in trimellitic anhydride-induced lung injury. J. Aflergy Clin. Immunol. 82:1098-1103.

Rhoads, K., J. P. Geraci, J. A. Mahattey, B. W. Killand, and C. L Sanders. 1988. Effect of external irradiation on the clearance and fate of transuranic oxides deposited in rat lung. In: Inhaled Perticles VI, Proceedings of the Sixth International Symposium in Conjunction with the Second Intermational Workshop on Lung Dosimetry, Britlsh Occupational Hygiene Association, September 1985, Cambridge, England. Ann. Occup. Hyg. 32 (Suppl. 1):997-1006.

Roesijadi, G., M. E. Unger, and J. E. Morris. 1988. Immunochemical quantification of metallothioneins of a marine mollusc. Can. J. Fish. Aquat. Sci. 45:1257-1263.

Rushlow, K, A McNab, K Olsen, F. Maxwell, I. Maxwell, and G. Stiegler. 1988. Nucleotide sequence of porcine rotavirus (osu strain) gene segments 7, 8, and 9. Nucleic Acids Res. 16:367368.

Sanders, C. L, K. E. McDonald, and K. E. Lauhala, 1988. Plutonium particlé aggregation and promotion of pulmonary carcinogenesis from inhaled plutonium. In: Radiation Protection Practice, Proceedings of the Seventh International Congress of the International Radiation Protection Association, Vol. 1, pp. 178-181, April 10-17, 1987, Sydney, Australia. Pergamon Press, Sydney, Australia.

Sanders, C. L, K. E. McDonald, and K. E. Lauhala. 1988. Promotion of pulmonary carcinogenesis by plutonium particle aggragation following inhalation of ${ }^{239} \mathrm{PuO}_{2}$. Radiet. Res. 116:393-405.

Sanders, C. L, K E. McDonald, and K. E. Lauhala. 1988. Quantitative scanning electron microscopic autoradiography of inhaled ${ }^{239} \mathrm{PuO}_{2}$. Health Phys. 56:321-325.

Stannard, ل. N. 1988. Radioactivity and Heafth: A History. DOE/RL/01830-T59 (DE-88013791), Pacific Northwest Laboratory, Richland, Washington.

States, J. B., P. J. Mellinger, and D. D. Mahlum. 1988. Indoor air pollution. VIIl. Benzo[a]pyrene (BaP). MEDICEF Direct Information 1:300-323.

Sullivan, M. F., and P. S. Ruemmler. 1988. Absorption of ${ }^{233} \mathrm{U},{ }^{237} \mathrm{~Np},{ }^{238} \mathrm{Pu},{ }^{241} \mathrm{Am}$ and ${ }^{244} \mathrm{Cm}$ from the gastrointestinal tracts of rats fed an iron-deficient diet. Heath Phys. 54:311-3t6. 
Talsma, D. M., C. L Leach, N. S. Hatoum, R. D. Gibbons, J.-C. Rogers, and P. J. Gavin. 1988. Reducing the number of rabbits in the Draize eye irritancy test: A statistical analysis of 155 studies conducted over six years. Fundam. Appl. Toxicol. 10:146-153.

Tentorde, T. S. 1988. Biological interactions and human health effects of extremely low-frequency magnetic fields. Am. Inst. Biomed. Climatol. Bull. 1:4-12.

Tenforde, T. S. 1988. Interaction mechanisms, biological effects and biomedical applications of static and extremely low-frequency magnetic fields. In: Proceedings of the 22nd Annuel Meeting of the National Council on Radiation Protection and Measurements: Nonionizing Radiation and Ultrasound, pp. 181-217, April 2-3, 1986, Washington, D.C. NCRP, Bethesda, Maryland,

Tenforde, T. S., and R. P. Liburdy. 1988. Magnetic deformation of phospholipid bilayers: Effects on liposome shape and solute permeability at prephase transition temperatures. $J$. Theor. Biol. 133:385-396.

Weller, R. E. 1988. Commentary--Cisplatin in veterinary oncology--2. Adv. Small Anim. Med. Surg. 1:5.

Zeiss, C. R., C. L Leach, L J. Smith, D. Levitz, N. S. Hatoum, P. J. Garvin, and R. Patterson. 1988. A serial immunologic and histopathologic study of lung injury induced by trimellitic anhydride. Am. Rev. Respir. Dis. 137:191-196.

\section{9}

Bair, W. J., J. F. Park, G. E. Dagle, and A. C. James. 1989. Overview of biological consequences of exposure to plutonium and higher actinides, Rediat. Prot. Dosim. 26:125-135 (invited paper).

Bean, R. M., B. L Thomas, D. A. Dankovic, D. B. Mann, G. A. Ross, and D. L Springer. 1989. Analysis of classical and nonclassical adducts. In: Multilevel Health Effects Research: From Molecules to Man, J. F. Park and R. A. Pelroy, eds., pp. 429-434, Proceedings of the 27th Hanford Sym- posium on Health and the Environment, October 18-21, 1988, Richland, Washington. Battelle Press, Columbus, Ohio.

Bower, S. M., D. J. Whitaker, and R. A. Elston. 1989. Detection of the abalone parasite Labyrintholoides haliotides by a direct fluorescent antibody technique. J. Invertebr. Pathol, 53:281-283.

Brooks, A. L, and W. C. Griffith. 1989. Chromosomal binding and clearance of benzo[a]pyrenediol-epoxdde. In: Muttilevel Health Effects Reseerch: From Molecules to Man, J. F. Park and R. A. Pelroy, eds., pp. 307-312, Proceedings of the 27th Hanford Symposium on Health and the Environment, October 18-21, 1988, Richland, Washington. Battelle Press, Columbus, Ohio.

Brooks, A. L, R. L Hanson, F. A. Seiler, and R. F. Henderson. 1989. In vitro genotoxicity of dyes present in colored smoke munitions. Emiron. Mol. Mutegen. 13:304-314.

Cross, F. T. 1989. Evidence of lung cancer risk from animal studies. In: Twenty-Fourth Annual Meeting of the National Council on Radiation Protection and Measurements (NCRP), pp. 129-140, March 30-31, 1988, Washington, D.C. NCRP Publications, Bethesda, Maryland.

Cross, F. T. 1989. Modeling of PNL RadonInduced Lung Tumor Data in Rats. Submission for R. W. Wood's Biweekly Report to R. O. Hunter, Jr., Director, Office of Energy Research. U.S. Department of Energy, Washington, D.C.

Cross, F. T. 1989. Radon Background. Submission to B. Manowittz, Brookhaven National Laboratory, for DOE Office of Energy Research White Paper on Radon. Brookhaven National Laboratory, Upton, Long Island, New York.

Cross, F. T., G. E. Dagle, and R. A. Gies. 1989. Reply to Dr. Archer's comment on "A Histologic Study of the Influence of Cigarette Smoking in Suppressing Fin Daughter Carcinogenesis in Dogs." Health Phys. 56:256 (Correspondence).

Dagle, G. E., J. F. Park, E. S. Gilbert, and R. E. Weller. 1989. Risk estimates for lung tumours from inhaled ${ }^{239} \mathrm{PuO}_{2},{ }^{238} \mathrm{PuO}_{2}$, and ${ }^{239} \mathrm{Pu}\left(\mathrm{NO}_{3}\right)_{4}$ in beagle dogs. Radiat. Prot. Dosim. 26:173-176. 
Dankovic, D. A., C. W. Wright, R. C. Zangar, and D. L Springer. 1989. Complex mixture effects on the dermal absorption of benzo[a]pyrene and other polycyclic aromatic hydrocarbons from mouse skin. J. Appl. Toxicol. 9:239-244.

Dankovic, D. A., D. L Springer, D. B. Mann, L G. Smith, B. L. Thomas, and R. M. Bean. 1989. Preparation of microgram quantities of BaP-DNA adducts using isolated rat hepatocytes in vitro. Cercinogenesis 10:789-791 (Short Communication).

Dankovlc, D. A., B. L. Thomas, R, C. Zangar, D. W. Later, and D. L Springer. 1989. Inhibition of benzo[a]pyrene-7,8-diol formation in vitro by complex organic mixtures. Toxicology 55:93-102.

Dungan, C. F., R. A. Elston, and M. H. Schiewe. 1989. Evidence for colonization and destruction of hinge ligaments in cultured juvenile Pacific oysters (Crassotrea gigas) by cytophaga-like bacteria. Appl. Environ. Microbiol. 55(5):1128-1135.

Filipy, R. E., K E. Lauhala, D. R. McGee, W. C. Cannon, R. L. Buschbom, J. R. Decker, E. G. Kuffel, J. F. Park, H. A. Ragan, S. S. Yaniv, and B. R. Scott. 1989. Inhaled ${ }^{147} \mathrm{Pm}$ and/or Total-Body Gamma Radiation: Early Mortality and Morbidity in Rats. NUREG/CR-5353. Pacific Northwest Laboratory, Richland, Washington. U.S. Nuclear Regulatory Commission, Washington, D.C.

Frazier, M. E. 1989. State of the Art Address: Oncogenes and tumor-suppressing genes. In: Proceedings of the American College of Veterinery Intemal Medicine, G. Pidgeon, ed., pp. 896-904, Seventh Annual Veterinary Medical Forum. Omnipress, Madison, Wisconsin.

Frazier, M. E., T. M. Seed, L. L. (Scott) Whiting, and G. L Stiegler. 1989. Evidence for oncogene activation in radiation-induced carcinogenesis. In: Multilevel Health Effects Research: From Molecules to Man, J. F. Park and R.A. Pelroy, eds., pp. 197205 , Proceedings of the 27th Hanford Symposium on Health and the Environment, October 18-21, 1988, Richland, Washington. Battelle Press, Columbus, Ohio.
Gilbert, E. S. 1989. lasues in analyzing the effects of occupational exposure to low levels of radiation. Stat. Med. 8:173-187.

Gilbert, E. S., and F. T. Cross. 1989. Radon risks in animals with reference to man. In: Multilevel Hearth Effects Research: From Molecules to Man, J. F. Park and R. A. Pelroy, eds., pp. 359-371, Proceedings of the 27th Hanford Symposium on Health and the Environment, October 18-21, 1988, Richland, Washington. Battelle Press, Columbus, Ohio,

Gilbert, E. S., J. F. Park, and R. L Buschbom. 1989. Time-related factors in the study of risks in animals and humans. In: Modeling for Scaling to Man: Biology, Dosimetry, and Response, Proceedings of the 26th Hantord Life Sciences Symposium, October 20-23, 1987, Richland, Washington. Health Phys. 57:379-385 (Special Issue).

Gilbert, E. S., G. R. Petersen, and J. A. Buchanan. 1989. Mortality of workers at the Hanford Site: 1944-1981. Health Phys. 56:11-25.

Gilbert, E. S., S. A. Fry, L D. Wiggs, G. L. Voelz, D. $L$ Cragle, and G. R. Petersen. 1989. Analyses of combined mortality data on workers at the Hartiord Site, Oak Ridge National Laboratory, and Rocky Flats Nuclear Weapons Plant. Radiat. Res. 120:1935.

Goldman, M., L A. Anspaugh, J. O. Blanton, L J. Bollinger, R. G. Cuddihy, N. H. Cutshall, M. D. Hoover, G. M. Marmaro, T. P. McCras, R. C. Nelson, W. S. Osburn, J. F. Park, J. E. Pinder, and W. L. Templeton. 1989. Interagency Nuclear Sefety Review Panel Biomedical and Emironmental Elfects Subpanel Report for Galileo. INSRP 89-06, Interagency Nuclear Safety Roview Panel, Washington, D.C.

Guilmette, R. A., N. A. Gillet, A. F. Eidson, W. C. Griffith, and A. L Brooks. 1989. The influence of non-unitorm alpha irradiation of Chinese hamster iver on chromosome damage and the induction of cancer. In: Risks from Radium and Thorotrast, D. M. Taylor, C. W. Mays, G. B. Gerber, and R. G. Thomas, eds., pp. 142-148, BIR Report 21. British Institute of Radiology, London. 
Hay, W. W., Jr., and H. K Meznarich. 1989. Effect of matemal glucose concentration on uteroplacental glucose consumption and transfer in pregnant sheep. Proc. Soc. Exp. Biol. Med. 190:6369.

Hay, W. W., Jr., H. K. Meznarich, and A. L. Fowden. 1989. The effects of streptozotocin on rates of glucose utilization, oxidation and production in the sheep fetus. Metabolism 38:30-37.

James, A. C. 1989. Evaluation of the Efficacy of the Armwey Pureflow Air Treatment System (APATS) in Mitigating Dose from Radon Daughters. PNWD1440. Prepared by Pacific Northwest Laboratory, Richland, Washington, for Amway Corporation, Ada, Michigan.

James, A. C., and A. Birchall. 1989. Progress in lung modeling by the ICRP Task Group. Rediat. Prot. Dosim. 25(1/4):227-235.

James, A. C., and A. Birchall. 1989. Progress in lung modeling by the ICRP Task Group. Radiat. Prot. Dosim. 26:227-235.

Jarnes, A. C., A. Birchall, F. T. Cross, A. G. Cuddihy, and J. R. Johnson. 1989. The current approach of the ICRP task group for modeling doses to respiratory tract tissues. In: Modeling for Scaling to Man: Biology, Dosimetry, and Response, Proceedings of the 26th Hanford Lffe Sciences Symposium, October 20-23, 1987, Richland, Washington. Health Phys. 57:271-282 (Special Issue).

Kent, M. L., A. A. Elston, M. T. Wilkinson, and A. S. Drum. 1989. Impaired defense mechanisms in bay mussels, Mytilus edulis, with hemic neoplasia. J. Invertebr. Pathol. 53:378-386.

Leach, C. L, N. S. Hatoum, C. R. Zeiss, and P. J. Garvin. 1989. Immunologic tolerance in rats during thirteen weeks of inhalation exposure to trimellitic anhydride. Fundam. Appl. Toxicol. 12:519529.

Leach, C. L., N. S. Hatoum, R. L Sherwood, C. R. Zeiss, and P. J. Garvin. 1989. The pulmonary cellular and antibody response to trimelitic anhydride inhalation. Inhal. Toxicol. 1:37-47.
Leung, F. C., and G. Saccomanno. 1989. Expression of epidermal growth-factor receptor and bombesin in archived paraffin-block uranium-miner lung tumors. In: Multilevel Health Effects Research: From Molecules to Men, J. F. Park and R. A. Pelroy, eds., pp. 373-382, Proceedings of the 27th Hanford Symposium on Health and the Emvronment, October 18-21, 1988, Richland, Washington. Battelle Press, Columbus, Ohio.

Leung, F. C., J. R. Coleman, G. E. Dagle, and F. T. Cross. 1989. Imvolvement of growth factors and their receptors in radiation-Induced carcinogenesis. In: Multilevel Heolth Effects Research: From Molecules to Man, J. F. Park and R. A. Pelroy, eds., pp. 207-218, Proceedings of the 27th Hanford Symposium on Health and the Environment, October 18-21, 1988, Richland, Washington. Battelle Press, Columbus, Ohio.

Mahaffey, J. A, ed. 1989. Modeling for Scaling to Men: Biology, Dosimetry, and Response, Proceedings of the 26th Hanford Life Sciences Symposium, October 20-23, 1987, Richland, Washington. Health Phys. 57:1-461 (Special issue).

Mahlum, D. D., D. B. Mann, D. A. Dankovic, and D. L. Springer. 1989. Can carcinogenicity be predicted from chemical analysis and DNA adduction? In: Multilevel Health Effects Research: From Molecules to Man, J. F. Park and R. A. Pelroy, eds., pp. 453-462, Proceedings of the 27th Hanford Symposium on Health and the Environment, October 18 21, 1988, Richland, Washington. Battelle Press, Columbus, Ohio.

Mann, D. B., G. L. Stiegler, and D. L. Springer. 1989. Mapping of BaP adducts to the 5S rRNA gene carried on a plasmid target. In: Muttilevel Health Effects Research: From Molecules to Man, J. F. Park and R. A. Peiroy, eds., pp. 435-440, Proceedings of the 27th Hanford Symposium on Health and the Environment, October 18-21, 1988, Richland, Washington. Battelle Press, Columbus, Ohio.

Masse, R., and F. T. Cross. 1989. Risk considerations related to lung modeling. In: Modeling for Scaling to Man: Biology, Dosimetry, and Response, Proceedings of the 26th Hanford Life Sciences Symposium, October 20-23, 1987, Richland, Washington. Hea/th Phys. 57:283-289 (Special Issue). 
Mast, T. J., R. L. Rommereim, J. R. Coleman, and F. C. Leung. 1989. Fetal pulmonary development in the rat: Effect of chemical mixtures on cellular morphology and growth factors. In: Multilevel Health Effects Research: From Molecules to Man, J. F. Park and R. A. Pelroy, eds., pp. 257-266, Proceedings of the 27th Hanford Symposium on Health and the Environment, October 18-21, 1988, Fichland, Washington. Battelle Press, Columbus, Ohio.

Perry, R. E., R. E. Weller, and G. E. Dagle. 1989. Transitional cell carcinoma of the bladder with skeletal metastases in a dog. J. Am. Anim. Hosp. Assoc. 25:547-551.

Perry, R. E., R. E. Weller, R. L. Buschbom, G. E. Dagle, and J. F. Park. 1989. Radiographically determined growth kinetics of primary lung tumors in the dog. In: Proceedings of the Veterinary Cancer Society Ninth Annual Conference, pp. 4142, October 16, 1989, Raleigh, North Carolina. North Carolina State University Press, Raleigh, North Carolina.

Ragan, H. A. 1989. Markers of renal function and injury. In: Clinical Chemistry of Laboratory Animals, W. F. Loeb and F. W. Quinby, eds., pp. 321-343. Pergamon Press, New York.

Fithidech, K, B. T. Chen, J. L. Mauderly, E. B. Whorton, Jr., and A. L. Brooks. 1989. Cytogenetic effects of cigarette smoke on pulmonary alveolar macrophages of the rat. Environ. Mol. Mutagen. 14:27-33.

Sanders, C. L., K. E. Lauhala, and K. E. McDonald. 1989. Scanning electron microscopy of lung following alpha irradiation. Scanning Microsc. 3(3):907-918.

Sanders, C. L, K. E. Lauhala, and K. E. McDonald. 1989. Tritiated thymidine labeled bronchioalveolar cells and radiation dose following inhalation of plutonium in rats. Exp. Lung Res. 15:755-769.

Sanders, C. L., K E, McDonald, and R. R. Adee. 1989. Phagocytosis of pulmonary deposited particles by type I alveolar epithelium. In: Proceedings of the 47th Annual Meeting of the Electron Microscopy Society of America, pp. 922-923, August 6-11, 1989, Electron Microscopy Society of America, San Antonio, Texas.
Sanders, C. L, K. E. McDonald, K. E. Lauhala, and M. E. Frazier. 1989. Use of archived tissues for studies of plutonium-induced lung tumors. In: Multilevel Health Effects Research: From Molecules to Man, J. F. Park and R. A. Pelroy, eds., pp. 189-196, Proceedings of the 27th Hanford Symposium on Health and the Environment, October 1821, 1988, Richland, Washington. Battelle Press, Columbus, Ohio.

Sasser, L. B., D. L. Lundstrom, R. C. Zangar, D. L. Springer, and D. D. Mahlum. 1989. Elevated blood pressure and heart rate in rats exposed to a coal-derived complex organic mixture. J. Appl. Toxicol. 9:47-52.

Scott, B. R., R. E. Filipy, and E. F. Hahn. 1989. Models for Pulmonary Lethality and Morbidity Atter Irradiation from Internal and External Sources. NUREG/CR-5351, Lovelace Biomedical and Environmental Research Institute, Albuquerque, New Mexico, and Pacific Northwest Laboratory, Richland, Washington. U.S. Nuclear Regulatory Commission, Washington, D.C.

Seed, T. M., L. V. Kaspar, D. V. Tolle, T. E. Fritz, and M. E. Frazier. 1989. Analyses of critical target cell responses during preclinical phases of evolving chronic radiation-induced myeloproliferative disease: Exploitation of a unique canine model. In: Multilevel Health Effects Research: From Molecules to Man, J. F. Park and R. A. Pelroy, eds., pp. 245-255, Proceedings of the 27th Hanford Symposium on Health and the Environmem, October 18-21, 1988, Richland, Washington. Battelle Press, Columbus, Ohio.

Sikov, M. R. 1989. Tumour development following internal exposures to radionuclides during the perinatal period. In: Perinatal and Multigeneration Carcinogenesis, N. P. Napalkov, J. M. Rice, L. Tomatis, and H. Yamasaki, eds., pp. 403-419, IARC Scientific Publications No. 96. Imternational Agency for Research on Cancer, Lyon, France.

Sikov, M. R., and B. J. Kelman. 1989. Factors affecting the placental transfer of actinides. In: Modeling for Scaling to Man: Biology, Dosimetry, and Response, Proceedings of the 26th Hanford Life Sciences Symposium, October 20-23, 1987, Richland, Washington. Hea/th Phys, 57:283-289 (Special Issue). 
Sikov, M. R., D. D. Mahlum, G. E. Dagle, J. L. Daniel, and M. Goldman. 1989. Mechanistic explanations for the elevated susceptibility of the perinatal thyroid gland to radiogenic cancer. In: Multilevel Heelth Effects Reseerch: From Molocuies to Men, J. F. Park and R. A. Pelroy, eds., pp. 289 293, Proceedings of the 27th Hanford Symposium on Health and the Environment, October 18-21, 1988, Richland, Washington. Battelle Press, Columbus, Ohio.

Smith, L. G., R. H. Busch, R. L. Buschbom, W. C. Cannon, S. M. Loscutoff, and J. E. Morris. 1989. Effects of sulfur dioxide or ammonium sulfate exposure, alone or combined, for 4 or 8 months on normal and elastase-impaired rats. Environ. Res. 49:60-78.

Springer, D. L, and A. C. Zangar. 1989. Influence of imprinting agents on cytochrome P-450 expression. In: Multilevel Health Effocts Reseerch: From Molecules to Man, J. F. Park and R. A. Pelroy, eds., pp. 239-244, Proceedings of the 27th Hanford Symposium on Health and the Environment, October 18-21, 1988, Richiand, Washington. Battelle Press, Columbus, Ohio.

Springer, D. L., D. B. Mann, D. A. Dankovic, B. L Thomas, C. W. Wright, and D. D. Mahlum. 1989. influences of complex organic mixtures on tumorinitiating activity, DNA binding and adducts of benzo[a]pyrene. Carcinogenesis 10:131-137.

Stahihofen, W., G. Rudolt, and A. C. James. 1989. Intercomparison of experimental regional aerosol deposition data. J. Aerosol Med. 2:285-308.

Stevens, R. G., D. Y. Jones, M. S. Micozzi, and P. R. Taylor. 1989. Response to correspondence: Body iron stores and the risk of cancer. N. Engl. J. Med. 320:1012-1014.

Stiegler, G. L., and M. E. Frazier. 1989. Molecular analysis of specific DNA sequences using the polymerase chain-reaction method. In: Muttilevel Health Effects Research: From Molecules to Man, J. F. Park and R. A. Pelroy, eds., pp. 119-125, Proceedings of the 27th Hanford Symposium on Health and the Ervironment, October 18-21, 1988,
Richland, Washington. Battelle Press, Columbus, Ohio.

Tenforde, T. S. 1989. Applications, dosimetry and biological interactions of static and time-varying magnetic fields. ICRU Nows 1:17-20.

Tenforde, T. S. 1989. Biological effects of magnetic energy storage systems. Publication No. AES, Vol. 9, Superconductivity Advances and Applt cations, 1989, D. N. Palmer, ed, pp. 1-5. American Society of Mechanical Engineers, United Engineering Center, New York.

Tenforde, T. S. 1989, Biological responses to static and time-varying magnetic fields. In: Electromagnetic Interaction with Biological Systems, J. C. Lin, ed., pp. 83-107. Plenum Press, Now York.

Tenforde, T. S. 1989. Electroreception and magnetoreception in simple and complex organisms. Bioelectromagnetics 10:215-221.

Tenforde, T. S., V. J. Montoya, S. M. J. Afzal, S. S. Parr, and S. B. Curtis. 1989. Response of rat rhabdomyosarcoma tumors to split doses of mixed high- and low-LET radiation. Int. J. Radiat. Oncol. Biol. Phys. 16:1529-1536.

Thompson, A. C. 1989. Lite-Span Effects of Ionizing Radiation in the Beagle Dog. Pacific Northwest Laboratory, Richland, Washington.

Tibbs, J. F., R. A. Elston, R. W. Dickey, and A. M. Guarino. 1989. Studies on the accumulation of antibiotics in shellfish. Northwest Environ. J. 5(1).

Van Houten, N. C. 1989. U.S. Department of Energy Radioisotope Customers with Summary of Radioisotope Shipments, FY 1988. PNL-6934, Pacific Northwest Laboratory, Richland, Washington.

Weller, R. E. 1989. Diagnosis and management of endocrine gland neoplasms. In: Proceedings of the Seventh Annual Veterinary Medical Forum of the American College of Veterinary Internal Medicine, pp. 873-880, May 26, 1989, San Diego, California. Omnipress, Madison, Wisconsin. 
1990

Hobbs, C. H., and F. T. Cross. 1990. Health effects of radon exposure in laboratory animals. Fundam. Appl. Toxicol. 13:630-632.

Moolgavkar, S. H., F. T. Cross, G. Luebeck, and G. $E$. Dagle. 1990. A two-mutation model for radoninduced lung tumors in rats. Radiat. Res. 121:2837.

Tenforde, T. S, 1990. Biological interactions and human heath effects of extremely low frequency magnetic fieids. In: Extremely Low Frequency Electromagnetic Fields: The Question of Cancer, B. W. Wilson, A. G. Stevens, and L. E. Anderson, eds., pp. 291-315. Battelle Press, Columbus, Ohio.

\section{In Press}

Bean, A. M., B. L Thomas, E. K. Chess, J. G. Pavlovich, and D. L. Springer. Quantitative determination of polycyclic aromatic hydrocarbon adducts to deoxyribonucleic acid using GC/MS techniques. In: Polynuclear Aromatic Hydrocarbons: 11th International Symposium, NBS, September 23-25, 1987, Gaithersburg, Maryland. Lewis Publishers, Chelsea, Michigan (in press).

Brooks, A. L., W. C. Griffith, N. F. Johnson, G. L. Finch, and R. G. Cuddihy. The induction of chromosome damage in $\mathrm{CHO}$ cells by beryllium and radialion given alone and in combination. Radiat. Res. (in press).

Cross, F. T. Health effects and risks of radon exposure. In: Environmental Radon: Occurrence, Control and Health Hezards, S. K. Majumdar, R. F. Schmalz, and E. W. Miller, eds. Academy of Science, Easton, Pennsylvania (in press).

Egan, M. J., W. Nixon, N. I. Robsinon, A. C. James, and $\mathrm{A}$. F. Phalen. Inhaled aerosol transport and deposition calculations for the ICRP Task Group. J. Aerosol Sci. (in press).

Elston, R. A., A. S. Drum, and S. K. Allen. Progressive development of circulating polyploid cells in Mytilus with hemic neoplasia. Dis. Aquat. Org. (in press).
Finch, G. L., A. L Brooks, J. M. Benson, M. D. Hoover, J. A. Mewhinney, A. F. Eidson, R. G. Cuddihy, R. F. Henderson, and C. H. Hobbs. Influence of physiochemical properties of beryllium and nickel compounds on cultured cell toxicity. In: Effects of Mineral Dusts on Cells, Fourth International Workshop, B. T. Mossman, and A. O. Begin, eds., NATO ASI Series, Vol. H3O. SpringerVerlag, Berlin and Heidelberg (in press).

Fisher, D. R. Alpha-particle emitters in medicine. In: Dosimetry of Administered Radionuclides. American College of Nuclear Physicians, Washington, D.C. (in press).

Frazier, M. E., T. M. Seed, L. L. Scott, and G. L. Stiegler. Oncogenes in radiation carcinogenesis. Radiat. Res. (in press).

Gilbert, E. S., S. A. Fry, L. D. Wiggs, G. L Voelz, D. $L$. Cragle, and G. R. Petersen. Methods for anahyzing combined data from studies of workers exposed to low doses of radiation. Am. J. Epidemiol. (in press).

Hoover, M. D., F. A. Seller, G. L. Finch, P. J. Haley, A. F. Eidson, J. A. Mewhinney, D. E. Bice, A. L. Brooks, and R. K. Jones. Beryllium toxicity: An update. In: Proceedings, Sixth Symposium on Space Nuclear Power Systems (in press).

Hui, T. E., D. R. Fisher, and J. W. Poston. The microdosimetry of radon decay products in the respiratory tract. Radiat. Prot. Dosim. (Special Issue; in press).

Jostes, R. F., J. A. Reese, J. E. Cleaver, M. Molero, and W. F. Morgan. Quiescent human lymphocytes do not contain DNA strand breaks detectable by alkaline elution. Exp. Cell Res. (in press).

Kelly, G., P. R. Kerkof, A. L. Brooks, and P. J. Haley. Oncogene activation in radiation-induced lung tumours. In; Low Dose Radiation-Biological Bases of Risk Assessment, Proceedings of the 14th L. H. Gray Conference, September 11-15, 1988, New College, Oxtord, England (in press).

Kelman, B. J., and M. R. Sikov. Estimating fetal exposure to toxic materials. Toxicologist (in press), 
Kelman, B. J., and M. R. Sikov, Evaluation of changes in placental function produced by ultrasound exposure. In: Trophoblest Research, Proceedings of the 11th Rochester Trophoblast Conference and the European Placenta Group, October 9-12, 1988, Rochester, New York (In press).

Leung, F. C., L R. Bohn, and G. E. Dagle. Elevated epidermal growth factor (EGF) receptor binding in dog lung tumors. In: Proceedings, Eighth Intemational Congress of Endocrinology, July 17-23, 1988, Kyoto, Japan (in press).

Petersen, G. R., E. S. Gilbert, J. A. Buchanan, and R. G. Stevens. A case-cohort study of lung cancer, ionizing radiation, and tobacco smoking among males at the Hanford Site. Health Phys. (in press).

Ragan, H. A. Comparative hematology. In: Clinical Hematology, M. M. Wintrobe, G. R. Lee, and J. $K$ Athens, eds. Lea and Febiger, Philadelphia, Pennsylvania (in press).

Rithidech, K, J. A. Hotchkiss, W. C. Griffith, R. F. Henderson, and A. L. Brooks. Chromosome damage in rat pulmonary alveolar macrophages following ozone inhalation. Muttet. Res. (in press).
Sanders, C. L, and J. A Mahaffey. Inhalation carcinogenesis of repeated exposures to highfired ${ }^{244} \mathrm{CmO}_{2}$ in rats. Heelth Phys. (in press).

Sasser, L. B., D. L. Lundstrom, D. L Springer, and D. D. Mahlum. Cardiovascular effects following inhalation exposure of rats to a high-boiling coal liquid. J. Appl. Toxicol. (in press).

Stevens, R. G. Iron and the risk of cancer. Med. Oncol. Tumor Phermacother. (in press).

Stevens, R. G., and D. R. Kalkwarf. Iron, radiation, and cancer. Environ. Health Perspect.87 (in press).

Tenforde, T. S. Biological effects of static magnetic fields. int. J. Appl. Electromag. Mat. (in press).

Weller, R. E., G. E. Dagle, and J. F. Park. Primary pulmonary chondrosarcoma in a dog. Vet. Pethol. (in press).

Zangar, R., D. L. Springer, R. L Buschbom, and D. D. Mahium. Comparison of fetotoxic effect of dermally applied complex organic mixture in rats and mice. Fundem. Appl. Toxicol. (in press). 
$-$ 


\section{Presentations}

\section{8}

Bean, R. M., B. L Thomas, D. A. Dankovic, D. B. Mann, G. A Ross, and D. L Springer. 1988. Analysis of Classical and Nonclassical Adducts. Presented at the DOE Contractor's Meeting on Interactions of Chemicals with Living Systems, November 17-18, 1988, Albuquerque, New Mexico.

Bean, R. M., D. L Springer, B. L Thomas, D. A. Dankovic, D. B. Mann, G. A. Ross, C. G. Edmonds, and J. G. Pavlovich. 1988. Analysis of Classical and Nonclassical DNA Adducts. Presented at the 27th Hanford Symposium on Health and the Environmem, October 18-21, 1988, Richland, Washington.

Brooks, A. L, and W. C. Griffith. 1988. Binding and Clearance of Carcinogens from Chromosomes. Presented at the 27th Hanford Symposium on Health and the Environment, October 1821,1988 , Richland, Washington.

Cross, F. T. 1988. Health Effects of Radon Exposure. Presented at the 1988 Winter Meeting of the American Nuclear Society, October 30 Novernber 4, 1988, Washington, D.C.

Cross, F. T. 1988. Initiation-Promotion-Initiation Radon Mechanistic Studies. Presented at the PNL Life Sciences Center Scientific Advisory Committee Meeting, December 1-2, 1988, Richland, Washington.

Cross, F. T. 1988. PNL Radon Health-Effects Overview. Presented at the PNL Life Sciences Center Scientific Advisory Committee Meeting, December 1-2, 1988, Richland, Washington.

Cross, F. T. 1988. PNL Radon Toxicologic Studies. Presented at the PNL Life Sciences Center Scientific Advisory Committee Meeting, December 1-2, 1988, Richland, Washington.

Diamond, M. C., T. S. Tenforde, E. R. Greer, K. Hedges, B. Steinke, E. Davies, J. Yu, and D. Nguyen. 1988. The Influence of Ultrahigh Magnetic Fields on Cerebral Cortical Morphological Development: A Preliminary Study. Presented at the Annual Meeting of the Society for Neuro- science, November 13-18, 1988, Toronto, Ontario, Canada.

Frazler, M. E., T. M. Seed, L L. Scott, and G. L Stiegler. 1988. Evidence for Oncogene Activation in Radiation-Induced Carcinogenesis. Presented at the 27th Hanford Symposium on Heakth and the Environment, October 18-21, 1988, Richland, Washington.

Gilbert, E. S., and F. T. Cross. 1988. Radon Risk in Animals with Reference to Man. Presented at the 27th Hanford Symposium on Health and the Environment, October 18-21, 1988, Richland, Washington.

Gilbert, E. S., and F. T. Cross, 1988, Radon Risk in Animals with Reference to Man. Presented at the PNL Life Sciences Center Scientific Advisory Committee Meoting, December 1-2, 1988, Richland, Washington.

Jostes, R. F, and F. T, Cross. 1988, In Vitro Genotoxicity of Radon Gas and Its Daughters. Presented at the PNL Life Sciences Center Scientific Advisory Committee Meeting, December 1-2, 1988, Richland, Washington.

Leung, F. C., and G. Saccomanno. 1988. Growth Factors and Their Receptors in Uranium-Miner Lung Tumors. Presented at the 27th Hanford Symposium on Health and the Environment, October 18-21, 1988, Richland, Washington.

Loung, F. C., J. R. Coleman, G. E. Dagle, and F. T. Cross. 1988. Imvolvement of Growth Factors and Their Receptors in Radiation-Induced Carcinogenesis. Prasented at the 27th Hanford Symposium on Health and the Environment, October 1821, 1988, Richland, Washington.

Leung, F. C., J. R. Coleman, G. E. Dagle, and F. T. Cross. 1988. Imvolvement of Growth Factors and Their Receptors in Radiation-Induced Carcinogenesis. Presented at the PNL Life Sciences Center Scientific Advisory Committee Meeting, December 1-2, 1988, Richland, Washington. 
Mahlum, D. D., D. L. Springer, D. B. Mann, and D. A. Dankovic. 1988. Can Carcinogenicity of Benzo[a]pyreno in Mixtures be Predicted by Chemical Analysis and DNA Binding? Presented at the 27th Hanford Symposium on Health and the Environment, October 18-21, 1988, Richland, Washington.

Mann, D. B., G. L. Stiegler, and D. L. Springer. 1988. Mapping of Benzo[a]pyrene Adducts to the $5 S$ rRNA Gene Carried on a Plasmid Target. Presented at the 27th Hanford Symposium on Health and the Environment, October 18-21, 1988, Richland, Washington.

Mast, T. J., R. L. Rommereim, J. R. Coleman, and F. C. Leung. 1988. Fetal Pulmonary Development in the Rat: Effect of Chemical Mixtures on Cellular Morphology and Growth Factors. Presented at the 27th Hanford Symposium on Health and the Environment, October 18-21, 1988, Richland, Washington.

Morgan, T. L., E. W. Fleck, B. J. F. Rossiter, and J. H. Miller. 1988. Use of Mammalian Cells to Imvestigate the Genetic Consequences of DNA Damage induced by lonizing Radiation. Presented at the 27th Hanford Symposium on Health and the Environment, October 18-21, 1988, Richland, Washington.

Park, J. F., G. E. Dagle, R. E. Weller, and R. L. Buschbom. 1988, Lifespan Dose-Effect Relationship for Inhaled ${ }^{239} \mathrm{PuO}_{2}$ in Beagles. Presented at the Seventh International Congress of the International Radiation Protection Association, April 1017,1988 , Sydney, Australia.

Sanders, C. L., K. E. McDonald, and K E. Lauhala. 1988. Autoradiography of Sott Tissues for Case 246. Presented at the U.S. Transuranium and Uranium Registries Advisory Committee Meeting, November 3, 1988, Richland, Washington.

Sanders, C. L., K. E. McDonald, and K. E. Lauhala. 1988. Bronchiolar Dose and Lung Carcinoma Following Inhalation of ${ }^{239} \mathrm{PuO}_{2}$. Presented at the Radiobiology Meeting, DOE/OHER, November 1012, 1988, Salt Lake City, Utah.

Sanders, C. L., K. E. McDonald, K E. Lauhala, F. C. Leung, and M. E. Frazier. 1988, Use of Archived Tissues for Studies of Plutonium-Induced Lung Tumors. Presented at the 27th Hanford
Symposium on Health and the Environment, October 18-21, 1988, Richland, Washington.

Seed, T. M., L. V. Kasper, D. V. Tolle, T. E. Fritz, and M. E. Frazier. 1988. Analyses of Critical Target Cell Responses During Preclinical Phases of Evolving, Chronic, Radiation-Induced Myeloproliferative Disease: Exploitation of a Unique Canine Model. Presented at the 27th Hanford Symposium on Health and the Environment, October 18-21, 1988, Richland, Washington.

Sikov, M. R. 1988. Placental Transfer and Dosimetry of Actinides and Effects of Actinides on the Fetus. Invited presentation at the meeting of the EULEP Task Group on the Foetus, November 7, 1988, Oxtord, Chilton, United Kingdom.

Sikov, M. R. 1988. Perinatal Dosimetry and Tumorigenic Effects of Actinides. Presented at a seminar on November 11, 1988, Kemforschungszentrum, Karlsruhe, FRG.

Sikov, M. R. 1988. Placental Transfer and Embryonic Effects of Radionuclides. Preserted at a seminar on November 14, 1988, Institut für Medizinische Strahlenbiologie, Universitătsklinicum, Essen, FRG (invited presentation).

Sikov, M. R. 1988. Prenatal and Age-Related Distribution, Dosimetry, and Effects of Actinides. Presented at a seminar on November 18, 1988, Institut für Strahlenhygiene des Bundesgesundheitsamtes, Neuherberg, FRG.

Sikov, M. R., D. D. Mahlum, G. E. Dagle, J. L. Daniel, and M. Goldman. 1988. Mechanistic Explanations for the Elevated Susceptibility of the Perinatal Thyroid Gland to Radiogenic Cancer. Presented at the 27th Hanford Symposium on Health and the Environment, October 18-21, 1988, Richland, Washington.

Springer, D. L., and R. C. Zangar. 1988. Influence of Imprirting Agents on Cytochrome P450 Expression. Presented at the 27th Hantord Symposium on Health and the Environment, October 18-21, 1988, Richland, Washington.

Springer, D. L., and R. C. Zangar. 1988. Involvement of Cytochrome P-450 in Altered Imprinting. Presented at the DOE Contractor's Meeting on Interactions of Chemicals with Living Systems, November 17-18, 1988, Albuquerque, New Mexico. 
Springer, D. L, D. B. Mann, and G. L Stiegler. 1988. Characterization of BaP Adducts to the $5 S$ rFNA Gene. Presented at the DOE Contractor's Meeting on interactions of Chemicals with Lving Systems, November 17-18, 1988, Albuquerque, New Mexico.

Stevens, R. G. 1988. Iron and Cancer in the NHANES I. Presented at the Radiation Eflects Research Foundation Lecture, October 15, 1988, Hiroshima, Japan.

Stiegler, G. L., and M. E. Frazier. 1989. Molecular Analysis of Specific DNA Sequences Using the Polymerase-Chain-Reaction Method. Presented at the 27th Hanford Symposium on Health and the Environment, October 18-21, 1988, Richland, Washington.

Tenforde, T. S. 1988. Review of Research on Electromagnetic Fields and Carcinogenesis. Presented at the Electric Power Research institute Tutorial on Cancer Biology and Electromagnetic Fields Research, October 30, 1988, Phoenix, Arizona.

Tenforde, T. S. 1988. Biological Effects Associated with Magnetic Fields from a Superconducting Magnetic Energy Storage System. Presented at the Department of Energy/Bonneville Power Administration/Battelle, Pacific Northwest Laboratories Meeting on Superconducting Magnetic Energy Storage Systems, November 8, 1988, Richland, Washington.

Tenforde, T. S. 1988. The ELF Controversy: A Current View. Presented at a Tutorial on Heaith Physics of Nonionizing Radiation, Pacific Northwest Laboratory, October 26, 1988, Richland, Washington.

Tenforde, T. S. 1988. Structural Biology Research at the Pacific Northwest Laboratory. Presented at the U.S. Department of Energy Office of Health and Environmental Research Meeting on Structural Biology Research, December 13-14, 1988, Germantown, Maryland.

\section{9}

Afzal, S. M. J., T. S. Tenforde, K. S. Kavanau, and S. B. Curtis. 1989. Reoxygenation Kinetics in Rat Rhabdomyosarcoma Tumors Following
X-irradiation. Presented at the 37th Annual Meeting of the Radiation Research Society, March 19-23, 1989, Seattle, Washington.

Bair, W. J. 1989. Lffespan Studies on the Biological Effects of Inhaled Plutonium and Human Risk Estimation. Presented at the 21st Annual Symposium of the National Institute of Radiological Sciences, Inhalation of Airborne Particles and induction Mechanisms of ths Biological Effects, December 7-8, 1989, Chiba-shi, Japan, and on December 15, 1989, in Hiroshima, Japan.

Bair, W. J. 1989. Revision of the ICRP Dosimetric Model for the Human Respiratory Tract. Presented on December 8, 1989, in Chiba-shi, Japan (irvited lecture), and on December 15, 1989, in Hiroshima, Japan.

Bean, R. M. 1989. Characterization of Biologically Prepared PAH-DNA Adducts as Standards for Analyticai Methods Development. Presented at the Twelth Intemational Symposium on Polynuclear Hydrocarbons, September 19-21, 1989, Gaithersburg, Maryland.

Brooks, A. L, N. F. Johnson, and G. F. Finch. 1989. The Influence of Cell Cycle Changes on Radiation- and Beryllium-Induced Chromosome Aberrations. Presented at the 6th Annual Meeting of the Pacific Northwest Association of Toxicologists, September 15-16, 1989, Vancouver, B.C., Canada.

Brooks, A. L., B. S. Scott, and L J. Shyr. 1989. Repair of Alpha-Induced Chromosome Damage. Presented at the 5th International Conference on Environmental Mutagens, July 10-15, 1989, Case Western Reserve University, Cleveland, Ohio.

Brooks, A. L, F. A. Seiler, and B. R. Scott. 1989. The Combined Effect of Alpha Particles and $X$-Rays on the Induction of Micronuclei in Rat Lung Epithelial Cells. Presented at the 37th Annual Meeting of the Radiation Research Society, March 18-23, 1989, Seattle, Washington.

Brooks, A. L., N. F. Johnson, G. J. Newton, and D. G. Thomassen. 1989. Radon-Induced Chromosome Damage in Rat Tracheal Epitheliaj Cells. Presented at the 5th international Conference on Environmental Mutagens, July 10-15, 1989, Case Western Reserve University, Cleveland, Ohio. 
Brooks, A. L, K Rithidech, B. A. Muggenburg, D. Lozano, and D. L. Lundgren. 1989. In Vvo and In Vitro Interaction Between X Rays and Alpha Particles in the Production of Micronuclei. Presented at the 34th Annual Meeting of the Health Physics Society, June 25-29, 1989, Albuquerque, New Mexico.

Cross, F. T., G. E. Dagle, R. A. Gies, and R. L. Buschbom. 1989. Non-Pulmonary Neoplasms Following Radon Inhalation Exposure. Presented at the 34th Annual Meeting of the Health Physics Society, June 25-29, 1989, Albuquerque, New Mexico.

Dagle, G. E. 1989. Development of Beagle Pathology Atlas. Presented at the European Late Effects Project (EULEP) Pathology Working Group Meeting, October 27, 1989, Munich, FRG.

Dagle, G. E., and J. F. Park. 1989. Tracheobronchial Lymphadenopathy in Dogs Inhaling Plutonium. Presented at the 37th Annual Meeting of the Radiation Research Society, March 22, 1989, Seattle, Washington.

Dagle, G. E., J. F. Park, and R. E. Weller. 1989. Pathology in Dogs Inhaling Plutonium. Presented at Harwell Laboratories, Environmental and Medical Sciences Division, October 23, 1989, Oxfordshire, United Kingdom.

Dagle, G. E., J. F. Park, R. E. Weller, R. L Buschbom, and E. S. Gilbert. 1989. Health Effects of Inhaled Soluble Plutonium: Predicting from 11 Years After Exposure. Presented at the 34th Annual Meeting of the Health Physics Society, June 25-29, 1989, Albuquerque, New Mexico.

Diamond, M. C., T. S. Tenforde, E. R. Greer, K Hedges, B. Steinke, E. Davies, J, Yu, and D. Nguyen. 1989. Influence of Ultrahigh Magnetic Fields on Cerebral Cortical Morphological Development. Presented at the Eleventh Annual Meeting of the Bioelectromagnetics Society, June 18-22, 1989, Tucson, Arizona.

Douthart, R. J. 1989. Computers and Genome Mapping. Presented at the INEL Computer
Symposium, October 10-12, 1989, Idaho Falls, idaho (invited lecturer).

Douthart, A. J., D. A. Thurman, and V. A. Lortz. 1989. GnomeView: The Graphics Interface to the Human Genome. Presented at the Macromolecules, Genes, and Computers Symposium, July 13-16, 1989, Waterville Vallay, New Hampshire.

Dunker, A. K, G. Amold, and R. J. Douthart. 1989. The Sequence Attributes Method. Presented at the Macromolecules, Genes, and Computers Symposium, July 13-16, 1989, Waterville Valley, New Hampshire.

Fisher, D. R. 1989. Antibodies, Radionuclides, and Dosimetry for Cancer Treatment. Presented at the Health Physics Department Seminar, January 4, 1989, Richland, Washington.

Fisher, D. R. 1989. Alpha-Particle Emitters in Medicine. Presented at the Joint Symposium on Dosimetry of Administered Radionuclides, September 21-22, 1989, Washington, D.C.

Fisher, D. R., and D. A. Baker. 1989. Fundamentals of Data Communications for Health Physicists. Presented at the Westem Regional Symposium of the Health Physics Society, March 16-17, 1989, Richland, Washington.

Fisher, D. R., T. E. Hui, and J. W. Poston. 1989. The Microdosimetry of Radon Decay Products in the Respiratory Tract. Presented at the 10th Symposium on Microdosimetry, May 22-25, 1989, Rome, thaly.

Frazier, M. E. 1989. Oncogenes and TumorSuppressing Genes in Radiation Carcinogenesis. Presented at a Seminar at Washington State University, May 1, 1989, Pullman, Washington (invited presentation).

Frazier, M. E. 1989. Oncogenes and TumorSuppressing Genes: State of the Art Address. Presented at the Seventh Annual Veterinary Medical Forum of the American College of Veterinary Intemal Medicine, May 26, 1989, San Diego, California. 
Frazier, M. E., G. L Stiegler, F. T. Cross, and C. L Sanders. 1989. Use of Archived ParaffinEmbedded Tissues for Studying Oncogene Activation in Radiation-Induced Lung Tumors. Presented at the 37 th Annual Meeting of the Radiation Research Society, March 18-23, 1989, Seattle, Washington.

Frazier, M. E., B. J. Kelman, T. M. Seed, L L Whiting, and G. L Stiegler. 1989. Oncogene Activation in Experimentally Induced Lung Tumors. Presented at the Fifth International Congress of Toxicology, July 16-21, 1989, Brighton, England.

Fritz, L. K, P. H. Bhatavta, and A. A. Pelroy. 1989. A Study of Mutagenesis Using Synthetic DNA Targets. Presented at the 89th Annual Meeting of the American Society for Microbiology, May 15-19, 1989, New Orleans, Louisiana.

Gilbert, E. S. 1989. Assessing Risks trom Occupational Exposure to Low-level Radiation: The Statistician's Role. Presented at the Annual Meeting of the Western North American Region Conterence of the Biometrics Society, June 26-28, 1989, Davis, California (President's invited address).

Gilbert, E. S. 1989. The Hanford Mortality Study and Collaborative Combined Populations Studies. Presented at the NAS-NRC Advisory Committee on DOE's Comprehensive Epidemiologic Data Resource, Novernber 20, 1989, Oak Ridge, Tennessee.

Gilbert, E. S. 1989. The Hantord Mortality Study and Collaborative Combined Populations Studies. Presented at the SPEERA Committee Meeting, December 21, 1989, Richland, Washington.

Gillett, N. A., R. A. Guilmette, A. F. Eidson, W. C. Griffith, and A. L. Brooks. 1989. Comparison of Heterogeneous and Homogeneous Patterns of Alpha Irradiation in the Induction of Liver Cancer in the Chinese Hamster. Presented at the 37th Annual Meeting of the Radiation Research Society, March 18-23, 1989, Seattle, Washington.

James, A C. 1989. The Importance of Particle Sizo in Respiratory Deposition and Dose. Presented at the DOE Workshop on Unattached Fraction and Radon Decay Product Activity Size
Measurements, April 24-25, 1989, University of Illinols, Champaign-Urbana, Illinois.

James, A. C., R. C. Roth, R. W. Kuennen, and F. T. Cross. 1989. The Efficacy of a High-Efficiency Room Air Treatment System in Mitigating Dose from Radon Decay Products. Presented at the Annual Meeting of the American Association for Aerosol Research, October 9-13, 1989, Reno, Nevada.

Jostes, R. F., R. A Gies, W. F. Morgan, and F. T. Cross. 1989. Radon-Induced Mutagenesis. Presented at the American Society for Cell Biology and the American Society for Biochemistry and Molecular Blology Meeting, January 29-February 2, 1989, San Francisco, California.

Jostes, R.F., R.A Gies, W.F. Morgan, E.W. Fleck, and F. T. Cross. 1989. Radon-Induced DNA Damage in Mammalian Cell Systems. Presented at the 37th Annual Meeting of the Radiation Research Society, March 19-23, 1989, Seattle, Washington.

Kerkof, P, R., G. Kelly, and A L. Brooks. 1989. Oncogene Expression in Radiation-Induced Lung Tumors: A Rapid Screening Procedure. Presented at the 4th International Congress of Cell Biology, August 15-19, 1989, Ottawa, Ontario, Canada.

Mahaffey, J. A., A. C. James, J. R. Johnson, and C. L. Sanders. 1989. Robust Estimation of Lung Kinetics in Laboratory Animals Exposed to $\alpha$ Emitting Radionuclides. Presented at the Annual Meoting of the Society for Risk Analysis, October 29-November 1, 1989, San Francisco, Califomia.

Mahlum, D. D., and M. R. Sikov. 1989. Prenatal Irradiation and Adult Tumor Response. Presented at the 37th Annual Meeting of the Radiation Research Society and Ninth Annual Meeting of the North American Hyperthermia Group, March 19 23, 1989, Seattle, Washington.

Meznarich, H. K., and M. R. Sikov. 1989. Development of Mouse Limb Bud in Culture Following Radiation. Presented at the Annual Meeting of the Society for Experimental Biology and Medicine, Northwest Section, October 28, 1989, Richland, Washington. 
Meznarich, H. K., M. R. Sikov, and J. E. Ballou. 1989. Kinetics of Inhaled Krypton in the Blood of Pregnant Ewes and Their Fetuses. Presented at the Annual Meeting of the Federation of American Societies for Experimental Biology, March 19-23, 1989, New Orleans, Louisiana.

Meznarich, H. K. M. R. Sikov, and J. E. Ballou. 1989. Kinetics of Inhaled Krypton in the Blood of Pregnant Ewes and Their Fetuses. Presented at the Annual Meeting of the Society for Experimental Biology and Medicine, Northwest Section, October 28,1989 , Richland, Washington.

Park, J.F., G.E. Dagle, R.E. Weller, R.L Buschbom, and E.S. Gilbert. 1989. Health Effects of Inhaled ${ }^{239} \mathrm{PuO}_{2}$ in Beagle Dogs. Presented at the 34th Annual Meeting of the Health Physics Society, June 29, 1989, Albuquerque, New Mexico.

Rithidech, K, D. G. Thomassen, and A. L. Brooks. 1989. Chromosome Changes During Neoplastic Progression in Rat Tracheal Epithelial (RTE) Cells. Presented at the 5th International Conference on Environmental Mutagens, July 10-15, 1989, Case Western Reserve University, Cleveland, Ohio.

Rithidech, K, D. L Lundgren, B. A. Muggenberg, D. Lozano, and A. L. Brooks. 1989. The Influence of Plutonium Exposure and Lung Cancer on the Frequency of $X$-Ray-Induced Micronuclei in Dog Blood Lymphocytes. Presented at the 37th Annual Meeting of the Radiation Research Society, March 18-23, 1989, Seattle, Washington.

Sanders, C. L, K. E. McDonald, and K. E. Lauhala 1989. Relationship Between Bronchiolar Dose and Lung Tumor Induction Following Inhalation of Plutonium. Presented at the 37th Annual Meeting of the Radiation Research Society, March 19-23, 1989, Seattle, Washington.

Sanders, C. L, K. E. McDonald, and K. E. Lauhala 1989. Scanning Electron Microscopy of Lung Following Alpha Irradiation. Presented at the Annual Meeting of the Scanning Microscopy Society International Meeting, May 1-5, 1989, Salt Lake City, Utah.

Sanders, C. L, K. E. McDonald, and K. E. Lauhala. 1989. Threshold Model of Lung Tumor Induction
In Rats Following Inhalation of Plutonium. Presented at the 34th Annual Meeting of the Health Physics Society, June 25-29, Albuquerque, New Mexico.

Sanders, C. L., K. E. McDonald, and K. E. Lauhala. 1989. Phagocytosis of Pulmonary Deposited Particles by Type I Alveolar Epithelium. Presented at the Electron Microscopy Society of America Annual Meeting, August 6-11, 1989, San Antonio, Texas.

Scott, B. R., A. L. Brooks, and K. Rithidech. 1989. Distribution of Micronuclei Among Cells Exposed to lonizing Radiation. Presented at the 34th Annual Meeting of the Health Physics Society, June 25-29, 1989, Albuquerque, New Mexico.

Selier, F. A., B. R. Scott, and A. L. Brooks. 1989. Dose-Response Model for Combined Effects of Alpha Particles and X-Rays on Lung Epithelial Cells. Presented at the 37th Annual Meeting of the Radiation Research Society, March 18-23, 1989, Seattle, Washington.

Sikov, M. R., R. J. Traub, and H. K. Meznarich. 1989. Expression of Radiation Doses to the Embryo or Fetus from incorporated Radionuclides. Presented at the 34th Annual Meeting of the Health Physics Society, June 25-29, 1989, Albuquerque, New Mexico.

Sikov, M. R., D. D. Mahlum, G. E. Dagle, and J. L. Daniel. 1989. Possible Mechanisms for Increased Perinatal Sensitivity to Thyroid Carcinogenesis by I-131. Presented at the 37th Annual Meeting of the Radiation Research Society and Ninth Annual Meeting of the North American Hyperthermia Group, p. 198, March 19-23, 1989, Seattle, Washington.

Sikov, M. R., H. K. Meznarich, R. J. Traub, and B. J. Kelman. 1989. Determining Embryo-Fetal Doses from Matemal Exposure. Presented at the Annual Meeting of the Society for Experimental Biology and Medicine, Northwest Section, October 28, 1989, Richland, Washington.

Stevens, R. G. 1989. Iron and the Risk of Cancer. Presented at the American Cancer Society: 31st Annual Science Writers Conference, April 2-5, 1989, Irvine, Califomia (imvited participant). 
Stevens, R. G. 1989. Iron and the Risk of Cancer. Presented at the Fourth international Symposium on Hematology and Oncology: Nutrition and Cancer, Karolinska Hospital, September 20-21, 1989, Stockholm, Sweden (irvited Symposium speaker).

Tenforde, T. S. 1989. Ervironmental and Health Effects of Magnetic Fields. Presented at the Site Review of the Hanford Superconducting Magnetic Energy Storage System Proposal, February 9, 1989, Richland, Washington.

Tenforde, T. S. 1989. Applications of Flow Cytometry to Tumor Cell Kinetics and Tumor-Host Interactions Following Irradiation. Presented at the University of Washington Program in Radiological Sciences Lecture, March 7, 1989, Seattle, Washington,

Tenforde, T. S. 1989. Interaction of Extremely Low-Frequency Electromagnetic Fields with Humans. Presented at the National Research Council Workshop on Biological Effects of ELF Fields, March 13, 1989, Washington, D.C.

Tentorde, T. S. 1989. Biological Interactions of Extremely Low Frequency Electromagnetic Fields. Presented at the U.S. Department of Energy Office of Health and Ervironmental Research, March 21, 1989, Germantown, Maryland.

Tenforde, T. S. 1989. Research on the Chemistry of Biological Macromolecules. Presented at the U.S. Department of Energy Office of Basic Energy Sciences Review of the Ervironmental Molecular Sciences Laboratory Proposal, March 21, 1989, Germantown, Maryland.

Tenforde, T. S. 1989. The Basics of EMF. Presented at the Northwest Electric Light and Power Association EMF Seminar for Top Management, June 14, 1989, Portland, Oregon.

Tenforde, T. S. 1989. Health and Ervironmental Effects of SMES Magnetic Fields. Presented at the Electric Power Research Institute Superconducting Magnetic Energy Storage System Interest Group Meeting, June 23, 1989, Portland, Oregon.

Tenforde, T. S. 1989. Introduction to Electric and Magnetic Fields. Presented at the American Statistical Association 8th Conference on Radiation and Health, July 9-13, 1989, Copper Mourtain, Colorado.

Tenforde, T. S. 1989. Mechanisms of Imteraction of Extremely Low-Frequency Electromagnetic Fields with Living Systems. Presented at the 10th international Conference of the Bioelectrochemical Society, September 25-29, 1989, Pont-a-Mousson, France.

Tenforde, T. S. 1989. Biological Effects of Magnetic Fields from Superconducting Magnet Systems. Presented at the American Society of Mechanical Engineers Annual Winter Meeting, December 10-15, 1989, San Francisco, Calitomia.

Tenforde, T. S., K Kavanau, S. M. J. Afzal, and S. B. Curtis. 1989. Phase-Specific Cell Survival and Host Cell Toxicity in Rat Rhabdomyosarcoma Tumors Irradiated with Peak Neon lons. Presented at the Radiation Research Society 37th Annual Meeting, March 19-23, 1989, Seattle, Washington.

Tenforde, T. S., M. F. Maestre, R. P. Liburdy, and E. J. Gibbs. 1989. Magnetic Circular Dichroism Studies on the Conformation of Native and $X$ Irradiated DNA-Protein Condensates. Presented at the Bioelectromagnetics Soclety 11th Annual Mecting, June 18-22, 1989, Tucson, Arizona.

Watson, C. R. 1989. Overview of the National Radiobiology Archives Project--Definitions, Personnel, and Progress to Date. Presented at the National Radiobiology Archives Site Review Meeting, March 28-29, 1989, Richland, Washington.

Watson, C. R. 1989. Review of Project PlanSummary of Technical Aspects. Presented at the National Radiobiology Archives Site Review Meeting, March 28-29, 1989, Richland, Washington.

Watson, C.R. 1989. Selection of Materials--The Evaluation Process at LEHR. Presented at the National Radiobiology Archives Site Review Meeting, March 28-29, 1989, Richland, Washington.

Weller, R. E. 1989. Diagnosis and Management of Endocrine Gland Neoplasms. Presented at the Seventh Annual Veteninary Medical Forum of the American College of Veterinary Internal Medicine, May 26, 1989, San Diego, California. 
Weller, R. E. 1989. Hepatic Effects of Inhaled Plutonium in Beagle Dogs. Presented at the 34th Annual Meeting of the Health Physics Society, June 25-29, 1989, Albuquerque, New Mexico.

Weller, R. E. 1989. Radiographically Determined Growth Kinetics of Primary Lung Tumors in the Dog. Presented at the Veterinary Cancer Society Annual Conterence, October 16, 1989, Raleigh, North Carolina.

Weller, R. E., J. F. Park, G. E. Dagle, H. A. Ragan, and R. Buschbom. 1989. Hepatic Effects of
Inhaled Plutonium in Beagle Dogs. Presented at the 34th Annual Meeting of the Health Physics Society, June 25-29, 1989, Albuquerque, New Mexico.

\section{0}

Kelman, B. J., and M. R. Sikov. 1990. Estimating Fetal Exposure to Toxic Materials. Presented at the Annual Meeting of the Society of Toxicology, February 12-16, 1990, Miami Beach, Florida. 


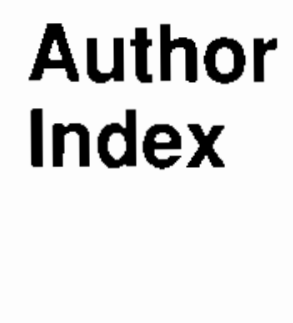




\section{Author Index}

Adee, R. R., 29

Akiba, S. (Radiation Effects

Research Foundation,

Japan), 5

Blot, W. (National Cancer Institute), 5

Boyd, P. J., 87

Briant, J. K, 87

Buchanan, J. A., 1

Buschbom, R. L., 11, 29, 47, 53,81

Coleman, J. R., 61

Cross, F. T., 47, 53, 57, 61

Dagle, G. E., 11, 29, 47, 53, 61,81

Decker, J. R., 87

Douthart, R. J., 95

Driver, C. J., 87

Eyler, L. L., 87

Fisher, D. R., 57

Fix, J. J., 1

Fleck, E. W. Whitman College), 53

Frank, D. D. (NORCUS), 87

Frazier, M. E., 53, 67

Fritz, L. K., 77

Gideon, K. M., 11, 29, 47

Gies, R. A, 47, 53

Gilbert, E. S., 1, 11, 29, 47
Greenspan, B. J., 87

Holter, N. A., 1

Hui, T. E., 57

Hulla, J. E., 73

James, A. C., 53, 57, 87

Jostes, R. F., 53, 57

Kabuto, M. (Radiation Effects

Research Foundation,

Japan), 5

Kalkwarf, D. R., 81

Karagianes, M. T., 37

Land, C. (National Cancer

Institute), 5

Lauhala, K E., 41

Leach, C. L., 87

Leung, F. C., 53, 61

Mahlum, D. D., 81

Mann, D. B., 73

McDonald, K. E., 41

Meznarich, H. K., 81.

Moolgavkar, S. H. (Fred

Hutchinson Cancer Research

Center), 53

Morgan, T. L., 53

Morris, J. E., 67

Neriishi, K. (Radiation Effects

Research Foundation,

Japan), 5
Park, J. F., 11

Peloquin, R. A., 99

Pelroy, R. A., 77

Poston, J. W. (Texas A\&M

University), 57

Powers, G. J., 11, 29

Ragan, H. A., 11, 29

Rommereim, D. N., 81

Romsos, C. O., 11, 29

Sanders, C. L., 41

Schmaltz, J. E., 91

Schneider, R. P., 67, 77

Sikov, M. R., 81

Smith, L. G., 53, 87

Springer, D. L., 73

Stevens, R. G., 5

Stiegler, G. L., 53, 67

Stram, D. (Radiation Effects

Research Foundation,

Japan), 5

Thompson, R. C., 37

Thurman, D. A., 95

Van Houten, N. C., 99

Watson, C. R., 11, 29, 37

Weller, R. E., 11, 29

Wierman, E. L., 11, 29

Williams, J. R., 11 


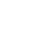


Distribution 
PNL-7200, Pt. 1

UC-408

\section{Distribution}

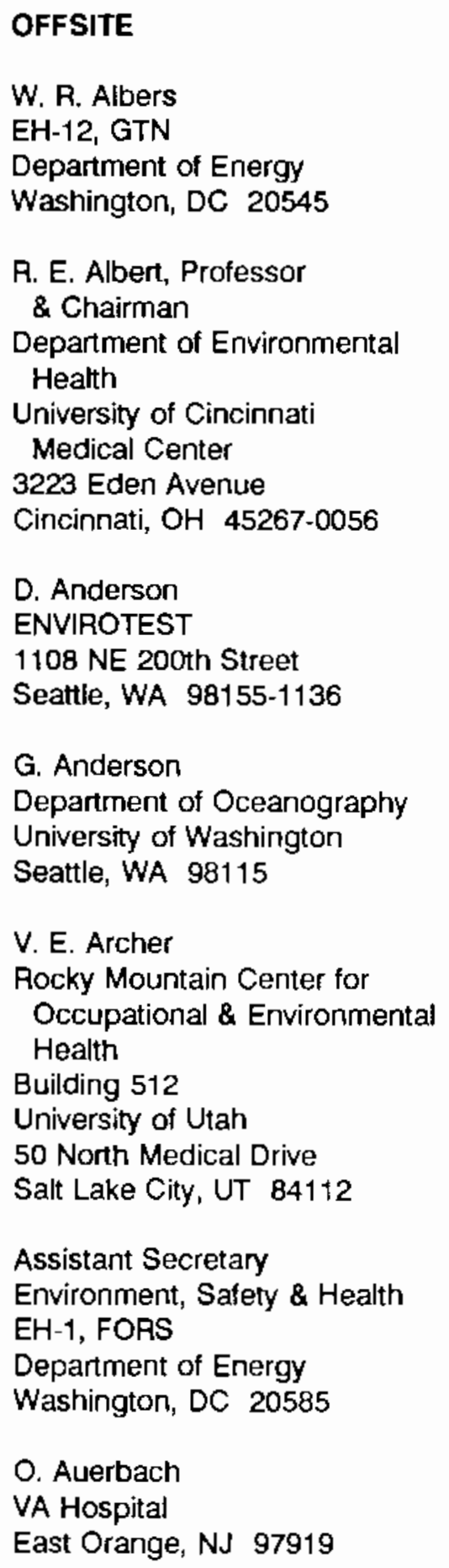

\author{
J. A. Auxier \\ $\Pi$ Corporation \\ 312 Directors Drive \\ Knoxville, TN 37701 \\ F. Badgley \\ 13749 NE 41st Street \\ Seattle, WA 98125 \\ R. E. Baker \\ 8904 Roundleaf Way \\ Gaithersburg, MD 20879-1630 \\ R. M. Baltzo \\ Radiological Safety Division \\ University of Washington \\ Seattle, WA 98105 \\ R. W. Barber \\ EH-131, GTN \\ Department of Energy \\ Washington, DC 20545
}

A. D. Barker

Battelle Columbus

Laboratories

505 King Avenue

Columbus, $\mathrm{OH} 43201$

J. R. Barker

Office of Environmental Audit

and Compliance

Department of Energy

Washington, DC 20545

W. W. Barker, Chairman

Department of Biology

Central Washington University

Ellensburg, WA 98926

N. F. Barr

ER-72, GTN

Department of Energy

Washington, DC 20545
J. W. Baum

Brookhaven National

Laboratory

Bldg. 703-M

Upton,

Long Island, NY 11973

J. R. Beall

ER-72, GTN

Department of Energy

Washington, DC 20545

G. L Bennett

Code RP

National Aeronautics \& Space

Administration

Washington, DC 20545

R. P. Berube

EH-151, GTN

Department of Energy

Germantown, MD 20545

M. H. Bhattacharyya

BIM Div., Bldg. 202

Argonne National Laboratory

9700 South Cass Avenue

Argonne, IL 60439

R. W. Bistline

Rockwell International

Rocky Flats Plant

P. O. Box 464

Golden, CO 80401

B. B. Boecker

Inhalation Toxicology Research

institute

The Lovelace Foundation for

Medical Education \&

Research

P. O. Box 5890

Albuquerque, NM 87185 
PNL-7200, Pt. 1

UC-408

\author{
V. P. Bond \\ Life Sciences, Chemistry and \\ Safety \\ Brookhaven National \\ Laboratory \\ Bldg. 460 \\ Upton, Long Island, NY 11973 \\ C. M. Borgstrom \\ Acting Director, NEPA \\ EH-25, Room 3E080 \\ Department of Energy \\ 1000 Independence Ave. SW \\ Washington, DC 20585

\section{J. D. Brain \\ Director, Harvard Pulmonary \\ Specialized Center of \\ Research \\ Harvard University School of \\ Public Health \\ 665 Huntington Avenue \\ Boston, MA 02115 \\ L. C. Brazley, Jr. \\ NE-22, GTN \\ Department of Energy \\ Washington, DC 20545} \\ Professor of Physiology
}

\section{A. Brodsky \\ 16412 Kipling Road \\ Derwood, MD 20855}

F. W. Bruenger

Division of Radiobiology

Bldg. 586

University of Utah

Salt Lake City, UT 84112

D. R. Buhler, Chairman

Toxicology Program

Oregon State University

Corvallis, OR 97331
R. J. Buil

Associate Professor of

Pharmacology/Toxicology

College of Pharmacy

Pullman, WA 99164-6510

G. Burley

Office of Radiation Programs,

ANR-458

Environmental Protection

Agency

Washington, DC 20460

W. W. Burr, Chairman

Medical \& Health Sciences

Division

Oak Ridge Associated

Universities

P. O. Box 117

Oak Ridge, TN 37830

L. K. Bustad

College of Veterinary Medicine

Washington State University

Pullman, WA 99164-7010

C. E. Carter

National Institute of

Environmental

Health Sciences

P. O. Box 12233

Research Triangle Park, NC 27709

G. W. Casaretı

Biophysics Department

University of Rochester Medical Center

Rochester, NY 14642

H. W. Casey, Chairman

Department of Veterinary Pathology

School of Veterinary Medicine Louisiana State University

Baton Rouge, LA 70803
R. J. Catlin, President

Robert J. Catlin Corporation

701 Welch Road, Suite 1119

Palo Alto, CA 94304

N. Cohen

New York University Medical

Center

P. O. Box 817

Tuxedo, NY 10987

D. W. Cole, Jr.

ER-73, GTN

Department of Energy

Washington, DC 20545

W. Cool

Nuclear Regulatory

Commission

Washington, DC 20545

Council on Environmental

Quality

722 Jackson Place, NW

Washington, DC 20503

D. K Craig

Battelle Columbus Laboratory

505 King Avenue

Columbus, Ohio 43201-2693

E. P. Cronkite

Medical Department

Brookhaven National

Laboratory

Upton, Long Island, NY 11973

J. Crowell

The Maxima Corporation

107 Union Valley Road

Oak Ridge, TN 37830 
PNL-7200, Pt. 1

UC-408

F. G. Dawson

Battelle Memorial Institute

505 King Avenue

Columbus, $\mathrm{OH} 43201$

Department of Energy

Environment \& Health Division

P. O. Box 5400

Albuquerque, NM 87115

G. DePlanque, Director Department of Energy-EMEL. 375 Hudson Street New York, NY 10014

G. P. Dix

26619 Haney Avenue

Damascus, MD 20750

T. J. Dobry, Jr.

DP-221, GTN

Department of Energy

Washington, DC 20545

DOE/Office of Scientific \&

Technical Information (12)

DOE - Savannah River

Operations Office

Environmental Division

P. O. Box A

Aiken, SC 29801

H. Drucker

Argonne National Laboratory

9700 South Cass Avenue

Argonne, IL 60439

G. D. Duda

ER-72, GTN

Department of Energy

Washington, DC 20545

A. P. Duhamel

ER-74, GTN

Department of Energy

Washington, DC 20545
D. Dungworth

Associate Dean of Research

and Professor \& Chairman

Department of Veterinary

Pathology

School of Veterinary Medicine

University of California

Davis, CA 95616

K. F. Eckerman

Health Studies Section

Health and Safety Research

Division

Oak Ridge National Laboratory

P. O. Box 2008

Oak Ridge, TN 37831-6383

C. W. Edington, Director

National Research Council

2101 Constitution Avenue, NW

Washington, DC 20418

G. R. Eisele

Medical Division

Oak Ridge Associated

Universities

P. O. Box 117

Oak Ridge, TN $\mathbf{3 7 8 3 0}$

$M$. Eisenbud

711 Bayberry Drive

Chapel Hill, NC 27514

W. H. Ellett

BRER-National Research

Council,

$\mathrm{MH}-370$

2101 Constitution Avenue, NW

Washington, DC 20418

R. J. Engelmann

11701 Karen

Potomac, MD 20854
B. M. Erickson

DOE - Schenectady Naval

Reactors Office

P. O. Box 1069

Schenectady, NY 12301

N. B. Everett

Department of Biological

Structure

University of Washington

School of Medicine

Seattle, WA 98105

B. H. Fimiani

Battelle, Pacitic Northwest

Laboratories

Washington Operations

370 L'Enfant Promenade. Suite 900

901 D Street, SW

Washington, DC 20024

H. L. Friedell

School of Medicine, WA77

Case-Western Reserve

University

2109 Abington Road

Cleveland, $\mathrm{OH} 44106$

D. E. Gardner

Northrop Services, Inc.

P. O. Box 12313

Research Triangle Park,

NC 27709

T. F. Gesell

Idaho Operations Office

Department of Energy

785 DOE Place

Idaho Falls, ID $83402-4149$

R. D. Gilmore, President

Environmental Health

Sciences, Inc.

Nine Lake Bellevue Building

Suite 104

Bellevue, WA 98005 
PNL-7200, Pt. 1

UC-408

\section{Goldman \\ Department of Radiological Sciences (VM) \\ University of California \\ Davis, CA 95616 \\ R. Goldsmith \\ ER-73, GTN \\ Department of Energy \\ Washington, DC 20545 \\ G. Goldstein \\ ER-74, GTN \\ Department of Energy \\ Washington, DC 20545 \\ J. A. Graham \\ ECAO, Mail Drop 52 \\ Environmental Protection Agency \\ Research Triangle Park, NC 27711}

R. A. Griesemer, Director

National Toxicology Program

National institutes of Health

P. O. Box 12233

Research Triangle Park,

NC 27709

\section{G. H. Groenewold \\ Energy and Mineral Research Center \\ University of North Dakota \\ Box 8123, University Station \\ Grand Forks, ND 58202}

J. G. Hadley

Owens Corning Fiberglas

Corporation

Technical Center

P. O. Box 415

Granville, OH 42023

F. F. Hahn

Lovelace Inhalation Toxicology

Research Institute

P. O. Box 5890

Albuquerque, NM 87115
E. J. Hall

Radiological Research

Laboratory

Columbia University

630 West 168th Street

New York, NY 10032

R. Hamlin

Dept. of Veterinary Physiology

The Ohio State University

1900 Coffey Road

Columbus, $\mathrm{OH} 43201$

J. W. Healy

51 Grand Canyon Drive

White Rock, NM 87544

C. H. Hobbs

Inhalation Toxicology Research Institute

The Lovelace Foundation for Medical Education \&

Research

P. O. Box 5890

Albuquerque, NM 87185

L. M. Holland

Los Alamos National Laboratory

P. O. Box 1663

Los Alamos, NM 87545

R. O. Hunter, Jr.

ER-1, FORS

Department of Energy 1000 Independence Ave. SW

Washington, DC 20585

F. Hutchinson

Department of Molecular

Biophysics \& Biochemistry

Yale University

260 Whitney Avenue

P. O. Box 6666

New Haven, CT 06511
D. S. Ingle

Dayton Area Otfice

DOE - Albuquerque Operations Otfice

P. O. Box 66

Miamisburg, $\mathrm{OH} 45342$

H. Ishikawa, General Manager

Nuclear Safety Research

Association

P. O. Box 1307

Falls Church, VA 22041

K. L. Jackson, Chairman

Radiological Sciences Group

SB-75

University of Washington

Seattle, WA 98195

E. D. Jacobson

Center for Devices \&

Radiological Health

Food \& Drug Administration

5600 Fishers Lane, HFZ-100

Rockville, MD 20857

A. W. Johnson

Vice President for Academic

Affairs

San Diego State University

San Diego, CA 92182

R. K Jones

The Lovelace Foundation for Medical Education \& Research

Building 9200, Area $Y$

Sandia Base

Albuquerque, NM 87108

G. Y. Jordy, Director

ER-30, GTN

Department of Energy

Washington, DC 20545 
C. M. Kelly

Air Products and Chemicals,

Inc.

Corporate Research and

Development

P. O. Box 538

Allentown, PA 18105

\section{A. R. Kennedy \\ Department of Physiology \\ Harvard School of Public \\ Health}

665 Huntington Avenue

Boston, MA 02115

\section{R. T. Kratzke}

NP-40

Department of Energy

Germantown, MD 20585

H. Kraybill

National Cancer Institute

Landau Building, Room C-337

Bethesda, MD 20014

W. Lauder

Office of Health and

Environmertial Research

Otfice of Energy Research

Department of Energy

Germantown, MD 20545

W. M. Leach

Food \& Drug Administration

5600 Fishers Lane, HFZ-100

Rockville, MD 20857

Librarian

Brookhaven National

Laboratory

Research Library, Reference

Upton, Long Island, NY 11973

Librarian

Colorado State Universily

Documents Department--

The Libraries

Ft. Collins, CO 80523
Librarian

Electric Power Research

Institute

3412 Hillview Avenue

P. O. Box 10412

Palo Alto, CA 94303

\section{Librarian}

Health Sciences Library, SB-55

University of Washington

Seattle, WA 98195

Librarian

Lawrence Livermore National Laboratory

University of California

Technical Information Dept., L-3

P. O. Box 808

Livermore, CA 94550

Librarian

Los Alamos National Laboratory

Report Library, MS P364

P. O. Box 1663

Los Alamos, NM 87545

Librarian

Oregon Regional Primate

Research Center

505 NW 185th Avenue

Beaverton, OR 97006

Librarian

Washington State University

Pullman, WA 99164-6510

Library

Serials Department

(\#80-170187)

University of Chicago

1100 East 57 th Street

Chicago, IL 60637

\author{
J. B. Little \\ Department of Physiology \\ Harvard School of Public \\ Health \\ 665 Humtington Avenue \\ Boston, MA 02115
}

A. B. Lovins
Rocky Moumtain Institute
1739 Snowmass Creek Road
Snowmass, CO $81654-9199$
O. R. Lumt
Laboratory of Biomedical \&
Environmental Sciences
University of California
900 Veteran Avenue
Los Angeles, CA 90024-1786

J. N. Maddox

ER-73, GTN

Department of Energy

Washington, DC 20545

J. R. Maher

ER-65, GTN

Departmert of Energy

Washington, DC 20545

T. D. Mahony

750 Swift Boulevard

Richland, WA 99352

S. Marks

$\%$ U.S. Marine Corps. Air

Station

ABCC/RERF

FPO

Seattle, WA $98764-5000$

D. R. Mason

Nuclear Safely Branch

Department of Energy

P. O. Box A

Aiken, SC 29801 
PNL-7200, Pt. 1

UC-408

W. H. Matchett

Graduate School

New Mexico State University

Box 3G

Las Cruces, NM 88003-0001

H. M. McCammon

ER-75, GTN

Department of Energy

Washington, DC 20545

R. O. McClelian, President

Chemical Industry Institute of Toxicology

P. O. Box 12137

Research Triangle Park,

NC 27709

J. F. Mclnroy

Los Alamos National

Laboratory

Mail Stop K484

P. O. Box 1663

Los Alamos, NM 87545

Medical Officer

Monsanto Research Corp.

Mound Laboratory

P. O. Box 32

Miamisburg, $\mathrm{OH} 45342$

C. B. Meinhold

Radiological Sciences Division

Bldg. 703M

Brookhaven National

Laboratory

Upton, Long Island, NY 11973

M. L. Mendelsohn

Biomedical and Environmental

Research Program

Lawrence Livermore National

Laboratory, L-452

University of Califomia

P. O. Box 5507

Livermore, CA 94550
H. Menkes

Assistant Professor of

Medicine \& Environmental

Medicine

The John Hopkins University

Baltimore, MD 21205

D. B. Menzel

Southern Occupational Health

Center

University of California, Irvine

Irvine, CA 92717

S. Michaelson

University of Rochester

Medical Center

Rochester, NY 14642

C. Miller

P.O. Box 180

Watermill, NY 11976

W. A. Mills

Committee on Interagency

Radiation

Research \& Policy

Coordination (CIRRPC)

Oak Ridge Associated

Universities

1019 19th Street, NW

Suite 700

Washington, DC 20036

K. Z. Morgan

1984 Castleway Drive

Atlanta, GA 30345

P. E. Morrow

Department of Biophysics

Medical Center

University of Rochester

Rochester, NY 14642

O. R. Moss

Chemical Industry Institute of Toxicology

P. O. Box 12137

Research Triangle Park,

NC 27709
W. F. Mueller

New Mexico State University

Box 4500

Las Cruces, NM 88003-4500

D. S. Nachtwey

NASA_Johnson Space Center

Mail Code SD-5

Houston, TX 77058

D. B. Nash, Editorial Assistant

Department of Radiation

Biology and Biophysics

University of Rochester

School of Medicine and

Dentistry

260 Crittenden Boulevard

Rochester, NY 14620

R. Nathan

Battelle Project Management

Division

505 King Avenue

Columbus, Ohio 43201

National Library of Medicine

TSD-Serials

8600 Rockville Pike

Bethesda, MD 20014

S. M. Nealey

Battelle - Seattle

4000 NE 41st Street

Seattle, WA 98105

N. S. Nelson

Office of Radiation Programs

(ANR-461)

Environmental Protection

Agency

401 M Street, SW

Washington, DC 20460 


\author{
P. Nettesheim \\ National Institutes of \\ Environmental \\ Health Sciences \\ Research Triangle Park, \\ NC 27711
}

W. R. Ney, Executive Director

National Council on Radiation

Protection and Measurements

7910 Woodmont Avenue

Suite 1016

Washington, DC 20014

S. W. Nielsen

Department of Pathology

New York State Veterinary

College

Comell University

Ithaca, NY 14850

\section{R. A. Nilan \\ Division of Sciences \\ Washington State University \\ Pullman, WA 99164}

M. Nolan

10958 Rum Cay Court

Columbia, MD 21044

Nuclear Regulatory

Commission

Advisory Committee on

Reactor Safeguards

Washington, DC 20555

D. E. Olesen

Battelle Memorial Institute

505 King Avenue

Columbus, $\mathrm{OH} 43201$

T. B. Owen, Project Officer

Smoking and Health Program

National Cancer Institute

Bethesda, MD 20014
A. F. Perge

RW-43, FORS

Department of Energy

Washington, DC 20545

D. F. Petersen

Los Alamos National

Laboratory

P. O. Box 1663

Los Alamos, NM 87545

L. E. Peterson

NASAJJSC SD23

Houston, TX 77058

H. Pfuderer

Oak Ridge National Laboratory

P. O. Box X

Oak Ridge, TN 37830

O. G. Raabe

Laboratory for Energy-Related

Health Research

University of California

Davis, CA 95616

R. Rabson

Division of Biological Energy

Research

ER-17, GTN

Department of Energy

Washington, DC 20545

D. P. Rall, Director

National Institutes of

Environmental Health

Sciences

P. O. Box 12233

Research Triangle Park, NC 27709

R. D. Reed, Chief

Rocky Flats Area Office

Albuquerque Operations Office

Department of Energy

P. O. Box 928

Golden, CO 80402-0928
C. A. Reilly, Jr.

Argonne National Laboratory

Bidg. 203

9700 South Cass Avenue

Argonne, IL 60439

C. R. Richmond

Oak Ridge National Laboratory

$4500 \mathrm{~N}, \mathrm{MS}-62523$

P. O. Box 2008

Oak Ridge, TN 37831-6253

J. S. Robertson

ER-73, GTN

Department of Energy

Washington, DC 20545

B. Robinson

Monsanto Research Corp.

Mound Laboratory

P. O. Box 32

Miamisburg, $\mathrm{OH} 45342$

S. L. Rose

ER-73, GTN

Department of Energy

Washington, DC 20545

G. Runkle, Chief

Department of Energy, AL

HPB/EHD

P. O. Box 5400

Albuquerque, NM 87115

G. Saccomanno

Pathologist and Director of

Laboratories

St. Marys and V. A. Hospitals

Grand Junction, CO 81501

U. Saffiotti

Laboratory of Experimental

Pathology, DCCP

National Cancer Institute

Bldg. 560, Rm. 32-60

Frederick, MD 21701 
PNL-7200, PT. 1

UC-408

\section{Sagan \\ Electric Power Research Institute \\ 3412 Hillview Avenue \\ P. O. Box 10412 \\ Palo Alto, CA 94304 \\ R. A. Scarano \\ Mill Licensing Section \\ Nuclear Regulatory \\ Commission \\ Washington, DC 20545}

R. A. Schlenker

Center for Human Radiobiology

Argonne National Laboratory

9700 South Cass Avenue

Argonne, IL 60439

E. Schreiber

Department of Geology

Queens College

Flushing, NY 11367

C. R. Schuller

Battelle - Seattle

4000 NE 41st Street

Seattle, WA 98105

M. Schulman

ER-70, GTN

Department of Energy

Washington, DC 20545

T. M. Seed

BIM 202

Argonne National Laboratory

9700 South Cass Avenue

Argonne, IL 60439

R. B. Setlow

Brookhaven National

Laboratory

Upton, Long Island, NY 11973

R. Shikiar

Battelle - Seattle

4000 NE 41st Street

Seattle, WA 98105

\section{T. Sibley \\ Department of Fisheries, WH-10 \\ University of Washington \\ Seattle, WA 98195}

P. H. Silverman

Lawrence Berkeley Laboratory

Bldg. 50A/5104

Berkeley, CA 94720

W. K. Sinclair, President

National Council on Radiation

Protection

7910 Woodmont Avenue

Suite 1016

Bethesda, MD 20814

D. H. Slade

ER-74, GTN

Department of Energy

Washington, DC 20545

D. A. Smith

ER-72, GTN

Department of Energy

Washington, DC 20545

G. S. Smith

New Mexico State University

Box 3-1

Las Cruces, NM 88003-0001

J. M. Smith

$\mathrm{NIOSH}$

4676 Columbia Parkway

Cincinnati, $\mathrm{OH} 45226$

J. N. Stannard

University of California

17441 Plaza Animado $\$ 132$

San Diego, CA 92128

G. E. Stapleton

ER-72, GTN

Department of Energy

Washington, DC 20545
R. W. Starostecki

Department of Energy

1000 independence Ave. SW

Washington, DC 20585

R. J. Stern

EH-10, FORS

Department of Energy

Washington, DC 20585

K G. Steyer

Nuclear Regulatory

Commission

Washington, DC 20555

E. T. Still

Kerr-McGee Corporation

P. O. Box 25861

Oklahoma City, OK 73125

Dr. Betsy Jones Stover

V-243 Carolina Meadows

Chapel Hill, NC 27514

D. Swanger

Biology Department

Eastern Oregon State College

La Grande, OR 97850

J. Swinebroad

PE-24, GTN

Department of Energy

Washington, DC 20545

G. N. Taylor

Division of Radiobiology

Bldg. 351

University of Utah

Salt Lake City, UT 84112

Technical Information Service

Savannah River Laboratory

Room 773A

E. I. duPont de Nemours \&

Company

Aiken, SC 29801 
PNL-7200, Pt. 1

UC-408

A. G. Thomas

ER-72, GTN

Department of Energy

Washington, DC 20545

P. W. Todd

Center for Chemical

Engineering

National Bureau of Standards

(773.10)

325 Broadway

Boulder, CO 80303

P. T'so

Division of Biophysics,

Room 3102

School of Hygiene \& Public Health

The Johns Hopkins University

615 North Wolfe Street

Baltimore, MD 21205

\section{A. C. Upton \\ New York University Medical \\ Center \\ Institute of Environmental \\ Medicine}

A. J. Lanza Laboratory

Long Meadow Road

Tuxedo, NY 10987

E. J. Vallario

15228 Red Clover Drive

Rockville, MD 20853

B. Valett

NORCUS

390 Hanford Street

Richland, WA 99352

R. L Van Citters, Dean

Research and Graduate

Programs

University of Washington

Seattle, WA 98105
C. R. Vest

Battelle, Pacific Northwest Laboratories

Washington Operations

370 L'Enfant Promenade,

Suite 900

901 D Street, SW

Washington, DC 20024

G. J. Vodapivc

DOE - Schenectady Naval

Reactors Office

P. O. Box 1069

Schenectady, NY 12301

G. L Voelz

Los Alamos National

Laboratory

MS-K404

P. O. Box 1663

Los Alamos, NM 87545

B. W. Wachholz

Radiation Effects Branch

National Cancer Institute

EPN, Room 530

8000 Rockville Pike

Bethesda, MD 20892

N. Wald

School of Public Health

University of Pittsburgh

Pittsburgh, PA 15213

A. Waldo

Department of Energy

(EH-231)

1000 Independence Ave. SW

Washington, DC 20585

R. A. Wahters

Assistant to the Associate

Director

Los Alamos National Laboratory

MS-A114

P. O. Box 1663

Los Alamos, NM 87545
M. E. Weaver

Professor of Anatomy

University of Oregon Health

Science Center

School of Dentistry

Portland, OR 97201

M. H. Weeks

U.S. AEHA, BIdg. 2100

Edgewood Arsenal

Aberdeen Proving Ground,

MD 21014

C. G. Welty, Jr.

EH-123, GTN

Department of Energy

Washington, DC 20585

I. Wender

Department of Chemical

Engineering

1249 Benedum Hall

University of Pittsburgh

Pittsburgh, PA 15261

W. W. Woyzen

Electric Power Research

Institute

3412 Hillview Avenue

P. O. Box 10412

Palo Alto, CA 94303

$K$ Wilzbach

Argonne National Laboratory 9700 South Cass Avenue

Argonne, IL 60439

F. J. Wobber

Department of Energy

14 Goshen Court

Gaithersburg, MD 20879-4403

R. W. Wood

PTRD, OHER

ER-74, GTN

Department of Energy

Washington, DC 20545 
PNL-7200, Pt. 1

UC 408

M. E. Wrenn

Ervironmental Radiation \&

Toxicology Laboratory

956 West Levoy, Suite 100

Salt Lake City, UT 84123

R. E. Yoder

Rockwell International

P. O. Box 464

Golden, CO 80401

Zhu Zhixian

Laboratory for Energy-Related

Health Research

University of California

Davis, CA 95616

FOREIGN

G. E. Adams, Director Medical Research Council

Radiobiology Unit

Harwell, Didcot

OxOn OX11 ORD

ENGLAND

\section{E. L. Alpen \\ University of California \\ Study Center \\ 21 Stratton Ground \\ London SW1 P2HY \\ ENGLAND}

\section{Anderson}

Library

Department of National Health

\& Welfare

Ottawa, Ontario

CANADA
R. K Appleyard
Director, Biology
European Atomic Energy
Community, EURATOM
Brussels
BELGIUM

Atomic Energy of Canada, Ltd.

Scientific Document

Distribution Office

Station 14

Chalk River Nuclear

Laboratories

Chalk River, Ontario KOJ IJO

CANADA

D. C. Aumann

Institut für Physikalische Chemie

Universităt Bonn

Abt. Nuklearchemie

Wegelerstraße 12

5300 Bonn 1

FEDERAL REPUBLIC OF

GERMANY

M. R. Balakrishnan, Head

Library \& Information

Services

Bhabha Atomic Research

Centre

Bombay 400085

INDIA

G. W. Barendsen

Laboratory for Radiobiology

AMC, FO 212

Meibergdreef 9

1105 AZ Amsterdam

THE NETHERLANDS

J. K. Basson, Vice-President

Raad Op Atomic

Atoomkrag Energy Board

Privaatsk $\times 256$

Pretoria 0001

REPUBLIC OF SOUTH AFRICA

A. M. Beau, Librarian

Département de Protection

Sanitaire

Commissariat à l'Énergie

Atomique

BP 6

F-92265 Fontenay-aux-Roses

FRANCE
G. Bengtsson

Director-General

Statens Stralskyddsinstitut

Box 60204

S-104 01 Stockholm

SWEDEN

D. J. Beninson

Gerencia de Protección

Radiológica y Seguridad

Comisión Nacional de

Energía Atómica

Avenida del Libertador 8250

2 Piso Of. 2330

1429 Buenos Aires

ARGENTINA

A. Bianco

ENEA, Dipart. Protezione

Via le Regina Margherita 125

1-00198 Roma

ITALY

J. Booz

KFA Jülich Institut für Medezin

Kernsforschungsanlage Jūlich

Postfach 1913

D-5170 Jülich

FEDERAL REPUBLIC OF

GERMANY

M. J. Bulman, Librarian

Medical Research Council

Radiobiology Unit

Harwell, Didcot

OXOn OX11 ORD

ENGLAND

M. Calamosia

ENEA-LAB Fisica E

Tossicologia Aerosol

Via Mazzini 2

1.40138 Bologna

ITALY 
Cao Shu-Yuan, Deputy Head Laboratory of Radiation Medicine North China Institute of Radiation Protection P. O. Box 120

Tai-yuan, Shan-Xi

THE PEOPLE'S REPUBLIC OF CHINA

M. Carpentier Commission of the European Communities 200 rue de la Loi J-70 6/16

B-1049 Brussels BELGIUM

M. W. Charles

National Power Nuclear

Berkeley Nuclear Laboratories

Berkeley

Gloucestershire GL 13 9PB

ENGLAND

Chen Xing-An

Laboratory of industrial Hygiene

Ministry of Public Health

2 Xinkang Street

Deshengmenwai, Beijing

THE PEOPLE'S REPUBLIC OF CHINA

R. Clarke

National Radiological

Protection Board

Harwell, Didcot

Oxon OX11 ORO

ENGLAND
G. F. Clemente, Director

Radiation Toxicology

Laboratory

National Committee of Nuclear

Energy (CNEN)

Casaccia Centre for Nuclear

Studies (CSN)

Casella Postale 2400

1-00100 Roma

ITALY

H. Cotfigny

Institut de Protection et de

Sûreté Nucléaire

Département de Protection

Sanitaire

Service de Pathologie

Expérimentale

BP 6

F-92265 Fontenay-aux-Roses

FRANCE

Commission of the European

Communities

DG XII - Library SDM8 R1

200 rue de la Loi

B-1049 Brussels

BELGIUM

B. de la Cruz, Head

Biomedical Department

Republic of the Philippines

National Science Development Board

Philippine Atomic Energy

Commission

P.O. Box 932

Manila

THE PHILIPPINES
Deng Zhicheng

North China Institute of

Radiation Protection

Tai-yuan, Shan-Xi

THE PEOPLE'S REPUBLIC OF

CHINA

M. Di Paola

ENEA, PASNALEPID

C.R.E. Casaccia

Casella Postale 2400

I-00100 Roma

TALY

Director

Commissariat à l'Énergie

Atomique

Centre d'Etudes Nucléaires

Fontenay-aux-Roses (Seine)

FRANCE

Director

Commonwealth Scientitic and Industrial Research

Organization

Aspendal, Victoria

AUSTRALIA

Director

Laboratorio di Radiobiologia

Animale

Centro di Studi Nucleari Della

Casaccia

Comitate Nazionale per

l'Energia Nucleare

Casella Postale $\mathbf{2 4 0 0}$

I-00100 Roma

ITALY 
PNL-7200, Pt. 1

UC-408

D. Djuric

Institute of Occupational and

Radiological Health

11000 Beograd

Deligradoka 29

YUGOSLAV!A

M. Dousset

Health Ministry

Frue de la Gruerie

F-91190 Gifsur Yvette

FRANCE

R. Ducousso

Section de Pathologie et de

Toxicologie Expérimentale

Département de la Protection

Sanitaire

Commissariat à l'Énergie

Atomique

BP 6

F-92260 Fontenay-aux-Roses

FRANCE

H. J. Dunster

National Radiological Protection

Board

Chilton, Didcot

Oxon OX11 ORO

ENGLAND

J. Eapen

Biochemistry Division

Bhabha Atomic Research

Centre

Bombay-400 085

INDIA

Estac̄ao Agronómica Nacional

Biblioteca

2780 Oeiras

PORTUGAL

L. Feinendegen, Director

Institut für Medezin

Kernsforschungsanlage Jülich

Postfach 1913

D-5170 Jülich

FEDERAL REPUBLIC OF

GERMANY

T. M. Fliedner

Institut für Arbeits-

u. Sozialmedizin

Universitat UIm

Oberer Eselsberg M 24, 309

D-7900 UIm

FEDERAL REPUBLIC OF

GERMANY

L. Friberg

The Karolinska institute

Stockholm

SWEDEN

R. M. Fry, Head

Office of the Supervising

Scientist for the Alligator

Rivers Region

P. O. Box 387

Bondi Junction NSW 2022

AUSTRALIA

A. Geertserna

Sasol Technology (Pty), Ltd.

P. Q. Box 1

Sasolburg 9570

REPUBLIC OF SOUTH AFRICA

G. B. Gerber

Radiobiology Department

Commission of the European

Communities

200 rue de la Loi

B-1049 Brussels

BELGIUM
T. Giuseppe

ENEA-PAS-FIBI-AEROSOL

Via Mazzini 2

l-40138 Bologna

ITALY

H. L. Gjorup, Head

Health Physics Department

Atomic Energy Commission

Research Establishment

Risø, Roskilde

DENMARK

A. R. Gopal-Ayengar

73-Mysore Colony

Mahul Road, Chembur

Bombay-400 074

INDIA

R. V. Griffith

International Atomic Energy Agency

Wagramerstraße 5

P. O. Box 200

A.1400 Vienna

AUSTRIA

Y. Hamnerius

Applied Electron Physics

Chalmers University of

Technology

S-412 96 Goteborg

SWEDEN

J. L. Head

Department of Nuclear Science

\& Technology

Royal Naval College,

Greenwich

London SE10 9NN

ENGLAND 
PNL-7200, Pt. 1

UC-408

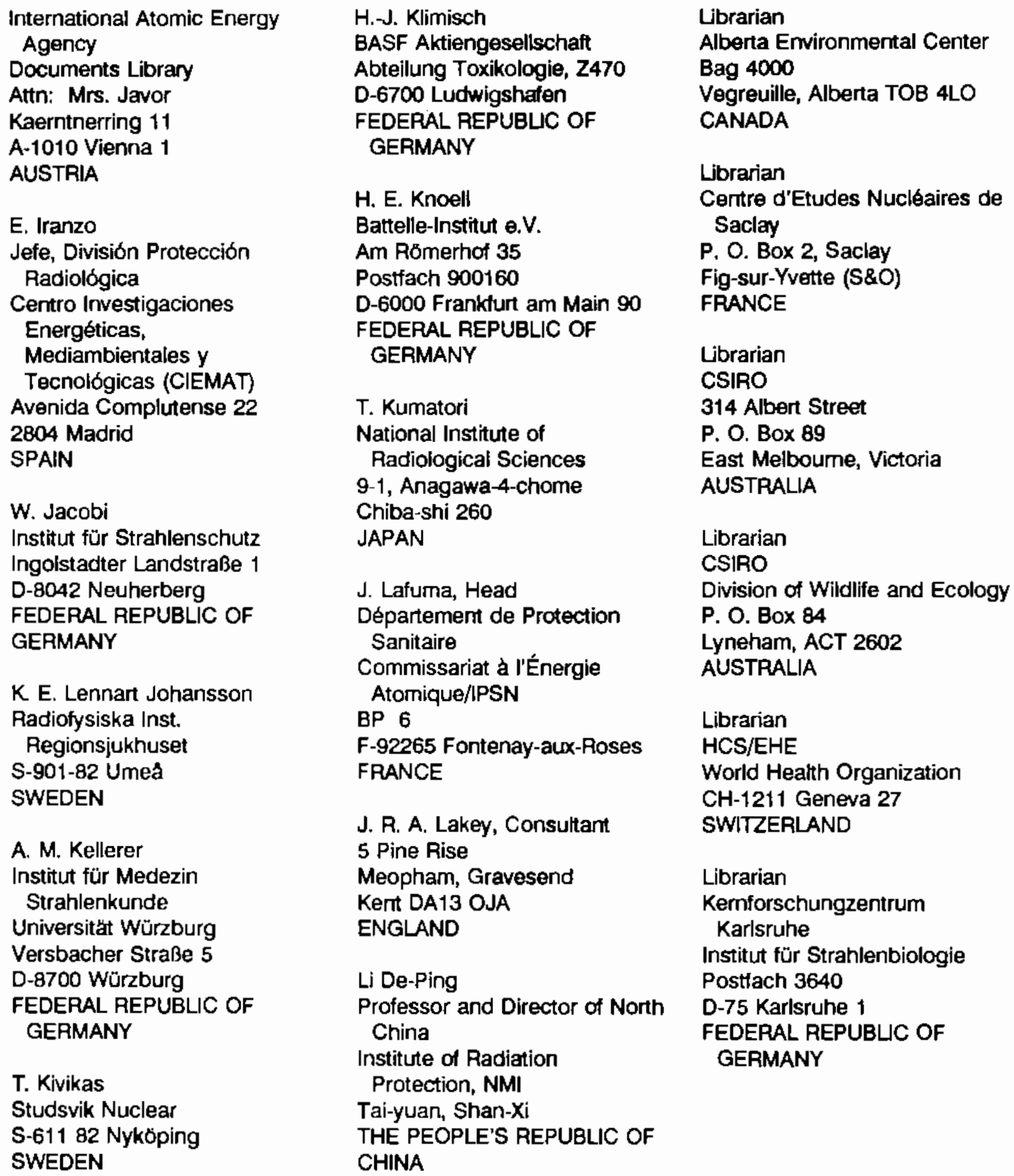


PNL-7200, Pt. 1

UC-408

Librarian

Max-Planck-Institut für

Biophysics

Forstkasstraße

D-6000 Franklurt/Main

FEDERAL REPUBLIC OF GERMANY

Librarian

Medical Research Council

Radiobiology Unit

Chilton

OXOn OX11 ORD

ENGLAND

Librarian

Ministry of Agriculture,

Fisheries \& Food

Fisheries Laboratory

Lowestoft, Sutlolk NR33 OHT

ENGLAND

Librarian

National Institute of

Radiological Sciences

9-1, Anagawa-4-chome

Chiba-shi 260

JAPAN

Librarian

Supervising Scientist for the Alligator Rivers Region

Level 23, Bondi Junction Plaza

P. O. Box 387

Bondi Junction NSW 2022

AUSTRALIA

Library

Atomic Energy Commission of

Canada, Ltd.

Whiteshell Nuclear Research

Establishment

Pinawa, Manitoba ROE ILO

CANADA

\author{
Library \\ Department of Meteorology \\ University of Stockholm \\ Arrhenius Laboratory \\ S.106 91 Stockholm \\ SWEDEN
}

Library

Rise National Laboratory

DK-4000 Roskilde

DENMARK

B. Lindell

National institute of Radiation

Protection

Fack S-104 01

Stockholm 60

SWEDEN

\section{J. R. Maisin \\ Radiobiology Department \\ C.E.N. - S.C.K. \\ Mol \\ BELGIUM}
A. M. Marko
9 Huron Street
Deep River, Ontario KOJ 1 PO
CANADA

\section{R. Masse}

Institut de Protection et de

Sûreté Nucléaire

Département de Protection

Sanitaire

Service d'Etudes Appliquées de

Protection Sanitaire

BP 6

F-92260 Fontenay-aux-Roses

FRANCE
H. Matsudaira,
Director General
National Institute of
Radiological Sciences
$9-1$, Anagawa-4-chome
Chiba-shi 260
JAPAN

O. Matsuoka, Deputy DirectorGeneral

Division of Comparative Radiotoxicology

National Institute of Radiological Sciences

9-1, Anagawa-4-chome

Chiba-shi 260

JAPAN

N. Matsusaka

Department of Veterinary

Medicine

Faculty of Agriculture

Iwate University

Ueda, Morioka

Iwate 020

JAPAN

A. G. C. McElroy

Atomic Energy Commission of

Canada, Ltd.

Dosimetric Research Branch

Chalk River, Ontario KOJ $1 \mathrm{JO}$

CANADA

F.-I. S. Medina

Cytogenetics Laboratory

Biomedical Research Division

A.R.C.

Philippine Atomic Energy

Commission

P. O. Box 932

Manila

THE PHILIPPINES 
PNL-7200, Pt. 1

UC-408

\author{
P. Metalli \\ ENEA-PAS \\ CRE Casaccia \\ Casella Postale 2400 \\ 1-00100 Roma \\ ITALY
}
H. J. Metivier
Institut de Protection et de
Sûreté Nucléaire
Centre d'Études de Service de
Fontenay-aux-Roses
BP 6
F-92265 Fontenay-aux-Roses
FRANCE

\section{A. Morgan \\ Inhalation Toxicology Group \\ Environmental and Medical \\ Sciences Division \\ Atomic Energy Research \\ Establishment, Bldg. 551 \\ Harwell, Didcot \\ Oxon OX11 ORA \\ ENGLAND}

Y. I. Moskaley
Institute of Biophysics
Ministry of Public Health
Givopisnaya 46
Moscow
USSR
J. Muller
7 Miligate Crescent
Willowdale, Ontario M2K 1 L5
CANADA
D. K Myers, Head
Radiation Biology Branch
Atomic Energy Commission of
Canada, Ltd.
Chalk River, Ontario
CANADA

J. C. Nénot, Deputy Director

Département de Protection

Centre d' Etudes Nucléaires

BP 6

F-92260 Fontenay-aux-Roses

FRANCE

R. Osborne

Atomic Energy Commission of Canada, Ltd.

Biology and Health Physics

Division

Chalk River Nuclear

Laboratories

P. O. Box 62

Chalk River, Ontario KOJ 1JO

- CANADA

J. Pacha

Silesian University

Department of Microbiology

UI. Jagiellonska 28

40-032 Katowice

POLAND

H. G. Paretzke

GSF Institut für Strahienschutz

Ingolstadter Landstraße 1

D-8042 Neuherberg

FEDERAL REPUBLIC OF GERMANY

N. Parmentier

Département de Protection Sanitaire

Centre d'Etudes Nucléaires

BP 6

F-92260 Fontenay-aux-Roses

FRANCE

G. Patrick

Medical Research Council

Radiobiology Unit

Harweil, Didcot

Oxon OX11 ORD

ENGLAND
O. Pavlorski

Institute of Biophysics

Ministry of Public Health

Givopisnaya 46

Moscow D-182

USSA

R. Perraud

Commissariat à l'Énergie

Atomique

BP 1

87640 Razes

FRANCE

E. Pochin

National Radiological

Protection Board

Chilton, Didcot

Oxon OX11 ORQ

ENGLAND

G. Premazzi

Commission of the European

Communities

Joint Research Centre

Ispra Establishment

I-21020 Ispra

ITALY

V. Prodi

Department of Physics

University of Bologna

Via Irnerio 46

I-40126 Bologna

ITALY

O. Ravera

Commission of the European

Communities, C.C.R.

I-21020 Ispra (Varese)

ITALY

D. V. Rebollo

Junta de Energia Nuclear

Sección de Isotopos

Calle de Serrano, 121

6 Madrid

SPAIN 
PNL-7200, Pt. 1

UC-408

REP Institutes TNO

TNO Division of Health

Research Library

P. O. Box 5815

151 Lange Kleiweg

2280 HV Rijswijk

THE NETHERLANDS

Reports Librarian

Harwell Laboratory, Bldg. 465

UKAEA

Harwell, Didcot

OxOn OX11 ORB

ENGLAND

\section{P. J. A. Rombout \\ Inhalation Toxicology \\ Department \\ National Institute of Public \\ Health and Environmental \\ Protection}

P. O. Box 1

NL-3720 BA Bilthoven

THE NETHERLANDS

M. Roy
Institut de Protection et de
Süreté Nucléaire
Département de Protection
Sanitaire
Service d'Etudes Appliquées
de Protection Sanitaire
BP 6
F-92260 Fontenay-aux-Roses
FRANCE
M. Rzekiecki
Commissariat à l'Énergie
Atomique
Centre d'Etudes Nucleaires de
Cadarache
BP 13-St. Paul
Les Durance
FRANCE

\author{
F. A. Sacherer \\ Battelle-Institut e.V. \\ Am Romerhof 35 \\ Postfach 900160 \\ D-6000 Frankfurt am Main 90 \\ FEDERAL REPUBLIC OF \\ GERMANY
}

W. Seelentag, Chief Medical

Officer

Radiation Health Unit

World Health Organization

$\mathrm{CH}-1211$ Geneva 27

SWITZERLAND

H. Smith

International Commission on

Radiological Protection

P. O. Box 35

Didcot

Oxon OX11 ORJ

ENGLAND

J. W. Stather

National Radiological

Protection Board

Building 383

Chilton, Didcot

Oxon OX11 ORQ

ENGLAND

A. M. Stewart

Cancer Epidemiology

Research Unit

University of Birmingham

Edgbaston

Birmingham B15 2Tा

ENGLAND
M. J. Suess
Regional Officer for
Environmental Hazards
World Health Organization
8 , Scherfigsvej
DK-2100 Copenhagen
DENMARK

Sun Shi-quan, Head

Radiation-Medicine Department

North China Institute of

Radiation Protection, MNI

P. O. Box 120

Tai-yuan, Shan-Xi

THE PEOPLE'S REPUBLIC OF CHINA

G. Tarroni

ENEA-PAS-FIBI-AEROSOL Laboratorio Fisica Sanitaria

Via Ercolani 8

1-40138 Bologna

ITALY

D. M. Taylor

Kernforschungzentrum Karlsruhe

Institut für Strahlenbiologie

Postfach 3640

D.75 Karlsruhe 1

FEDERAL REPUBLIC OF

GERMANY

K. H. Tempel

Institut für Pharmakologie,

Toxikologie und Pharmazie

Fachbereich Tiermedizin der

Universităt München

Veterinarstraße 13

D-8000 München 22

FEDERAL REPUBLIC OF

GERMANY

J. W. Thiessen

Radiation Effects Research

Foundation

5-2 Hijiyama Park

Minami-Ku

Hiroshima 732

JAPAN 
PNL-7200, Pt. 1

UC -408

United Nations Scientific Committee on the Effects of Atomic Radiation

Vienna International Center P. O. Box 500

A-1400 Vienna

AUSTRIA

D. Van As

Atomic Energy Corporation

P. O. Box 582

Pretoria 0001

REPUBLIC OF SOUTH AFRICA

J. Vaughan

1 Fairlawn End

First Turn

Wolvercote

OxOn OX2 BAP

ENGLAND

J. Vennart

Bardon, Ickleton Road,

Wantage

Oxon OX12 90A

ENGLAND

Vienna International Centre

Library

Gifts and Exchange

P. O. Box 100

A-1400 Vienna

AUSTRIA

V. Volf

Kernforschungzentrum

Karisruhe

Institut für Genetik und

Toxikologie von Spaltstoffen

Postfach 3640

D-7500 Karlsruhe 1

FEDERAL REPUBLIC OF

GERMANY
G. Walinder

Unit of Radiological Oncology

University of Agricultural

Sciences

P. O. Box 7031

S-750 07 Uppsala

SWEDEN

Wang Hengde

North China Institute of

Radiation Protection

P. O. Box 120

Tai-yuan, Shan-Xi

THE PEOPLE'S REPUBLIC OF

CHINA

Wang Renzhi

Institute of Radiation Medicine

11\# Tai Ping Road

Beijing

THE PEOPLE'S REPUBLIC OF

CHINA

Wang Ruifa, Associate Director

Laboratory of Industrial Hygiene

Ministry of Public Health

2 Xinkang Street

P. O. Box 8018

Deshengmenwai, Beijing

100088

THE PEOPLE'S REPUBLIC OF

CHINA

Wang Yibing

North China institute of Radiation Protection

P. O. Box 120

Tai-yuan, Shan-Xi

THE PEOPLE'S REPUBLIC OF CHINA
Wei LÜ-Xin

Laboratory of Industrial

Hygiene

Ministry of Public Health

2 Xinkang Street

Deshengmenwai, Beijing 100088

THE PEOPLE'S REPUBUC OF

CHINA

J. Wells

Radiobiology Laboratory

Health Physics Research

Central Electricity Generating Board

Berkeley Nuclear Laboratories

Berkeley, Gloucestershire

GL 13 9PB

ENGLAND

B. C. Winkler, Director

Licensing

Raad Op Atomic

Atoomkrag Energy Board

Privaatsk X 256

Pretoria 0001

REPUBLIC OF SOUTH AFRICA

Wu De-Chang

Institute of Radiation Medicine

27\# Tai Ping Road

Beijing

THE PEOPLE'S REPUBLIC OF

CHINA

Yao Jiaxiang

Laboratory of Industrial Hygiene

2 Xinkang Street

Deshengmenwai, Beijing

100088

THE PEOPLE'S REPUBLIC OF

CHINA 
PNL-7200, Pt. 1

UC-408

$K$ Yokoro, Director

Research Institute for Nuclear

Medicine \& Biology

Hiroshima University

Kasumi 1-2-3, Minami-ku

Hiroshima 734

JAPAN

\section{ONSITE}

\section{DOE RIchlend Operatlons Office (3)}

P. W. Kruger A5-90

E. C. Norman A5-51

Public Reading Room A1-65

\section{Trl-Clties Unlverslty Center}

J. Cooper, Librarian H2-52

Henford Emvironmentel Health Foundation (4)

S. E. Dietert H1-03

R. L. Kathren H1-01

W. C. Milroy H1-02

M. J. Swint H1-02

U. S. Testing

V. H. Pettey H2-51

Westinghouse Hanford Co.

D. E. Simpson B3-51

\section{Paciflc Northwest Laboratory} (219)

R. R. Adee PB-13

R. C. Adams K6-52

L E. Anderson K4-28

R. W. Baalman (5) K1-50

J. F. Bagley K1-45

W. J. Bair (15) K1-50

L. A. Braby P8-47

M. G. Brown K4-04

J. A. Buchanan P7-82

R. L Buschbom P7-82

T. D. Chikalla P7-75

B. J. Chou K4-10
M. L. Clark K4-16

T. T. Claudson K1-66

J. A. Creim K4-28

F. T. Cross K4-16

G. E. Dagle K4-10

J. R. Decker K4-16

H. S. DeFord K4-16

J. A. Dill K4-16

R. J. Douthart K4-14

R. D. DuBois $\mathrm{PB}-47$

F. N. Eichner P7-03

C. E. Elderkin K6-03

J. J. Evanoff K4-10

J. W. Falco K6-78

D. Felton P7-50

D. R. Fisher K3-53

R. M. Fleischman K1-43

L. G. Florek K4-16

W. C. Forsythe K4-16

M. E. Frazier P7-50

R. A. Gelman K4-10

K. M. Gideon K4-10

R. A. Gies K4-16

A. W. Gjeschen K4-16

E. S. Gilbert P7-82

M. F. Gillis K1-50

W. A. Glass K4-13

L. S. Gorham K4-04

B. J. Greenspan K4-16

D. K. Hammerberg K4-16

M. S. Hanson K1-51

B. K. Hayden K4-16

L. A. Holmes K1-79

M. G. Horstman K4-10

V. G. Horstman P7-50

J. R. Houston A3-60

A. C. James K3-53

A. E. Jarrell K4-10

J. R. Johnson K3-53

R. F. Jostes P7-50

D. R. Kalkwarf P7-50

M. T. Karagianes P7-50

M. Knotek K1-48

S. A. Kreml (2) P7-50

E. G. Kuffel K4-16

W. W. Laity K2-15

K E. Lauhala P7-50

C. L. Leach K4-10
F. C. Loung K4-16

M. K LJen P8-47

J. A. Mahaffey P7-82

D. D. Mahlum P7-50

E. M. Maloney K4-13

T. J. Mast K4-10

K. E. McDonald P7-50

P. W. Mellick K4-10

M. E. Mericka P7-50

H. K Meznarich P7-50

D. L Miller P7-50

J. H. Miller P8-47

M. C. Miller P7-44

R. A. Miller K4-10

J. E. Morris P7-50

D. A. Mueller P7-50

D. A. Nelson K2-44

J. M. Nelson P8-47

J. F. Park (50) P7-50

R. W. Perkins P7-35

J. T. Pierce K4-10

C. A. Poindexter K4-16

G. J. Powers P7-50

H. A. Ragan K4-13

R. A. Renne K4-10

J. T. A. Roberts K1-40

D. N. Rommereim K4-28

R. L Rommereim K4-10

C. O. Romsos K4-10

E. J. Rossignol K4-16

S. E. Rowe K4-10

P. S. Ruemmler K4-10

J. L Ryan P7-63

C. L. Sanders P7-50

L 8. Sasser P7-50

G. F. Schiefelbein K2-03

L. C. Schmid K1-34

R. P. Schneider P7-50

8. D. Shipp K1-73

M. R. Sikov P7-50

J. C. Simpson K1-86

L G. Smith K4-16

D. L Springer P7-50

J. G. Stephan K3-54

R. G. Stevens P7-82

D. L Stewart K6-91

G. L. Stiegler P7-50

G. M. Stokes K1-08 
PNL-7200, Pt. 1

UC-408

K. H. Stoney K4-16

K. L. Swinth K3-55

W. L Templeton $\mathrm{K} 1-30$

T. S. Tenforde (2) K1-50

R. M. Thomas P7-50

R. C. Thompson P7-50

L. H. Toburen P8-47

R. J. Traub K3-57

V. D. Tyler K4-04

H. R. Udseth P8-19
B. E. Vaughan K1-70

M. B. Walter K6-96

C. R. Watson P7-82

A. P. Wehner K4-13

R. J. Weigel K4-16

R. E. Weller P7-50

R. B. Westerberg K4-16

T. J. Whitaker K2-21

E. L. Wierman (2) P7-50

R. E. Wildung P7-50
L D. Williams $\quad \mathrm{K} 1-41$

W. E. Wilson P8-47

J. D. Zimbrick (10) P7-50

Health Physics Department Library

Life Sciences Library (2)

Publishing Coordination

Technical Report Files (5) 


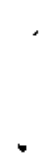

